\title{
Redefinition and partial revision of the genus Stenaelurillus Simon, 1886 (Arachnida, Araneae, Salticidae)
}

\author{
Dmitri V. LOGUNOV ${ }^{1, *}$ \& Galina N. AZARKINA ${ }^{2}$ \\ ${ }^{1}$ The Manchester Museum, University of Manchester, Oxford Road, Manchester M13 9PL, UK. \\ ${ }^{2}$ Laboratory of Systematics of Invertebrate Animals, Institute of Systematics and Ecology of Animals \\ SB RAS, Frunze Street 11, Novosibirsk 630091, Russia. \\ *Corresponding author: dmitri.v.logunov@manchester.ac.uk \\ ${ }^{2}$ Email: urmakuz@gmail.com \\ ${ }^{1}$ urn:1sid:zoobank.org:author:0692E80C-BF14-471A-8692-E6B37FC8C75D \\ ${ }^{2}$ urn:1sid:zoobank.org:author:BE783F8E-0803-48B2-80A4-9D246C0F2370
}

\begin{abstract}
This paper presents an improved diagnosis and definition of the genus Stenaelurillus Simon, 1886, with new taxonomic and faunistic data for 23 species. The genera Microheros Wesołowska \& Cumming, 1999 and Mashonarus Wesołowska \& Cumming, 2002 are synonymized with Stenaelurillus. Six new species are described: Stenaelurillus bandama sp. nov. (đ’+ from Côte d'Ivoire), S. belihuloya

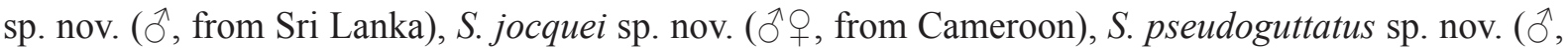
from Namibia), S. senegalensis sp. nov. (ð우, from Senegal), and Stenaelurillus siyamae sp. nov. (ㅇ, from Sudan). Lectotypes are designated for two species: S. albopunctatus Caporiacco, 1949 (ठ) from Kenya and S. werneri Simon, 1906 (†) from South Sudan. Six new combinations are proposed: Aelurillus ambiguus (Denis, 1966), comb. nov. (ex Stenaelurillus); Evarcha werneri (Simon, 1906), comb. nov. (ex Stenaelurillus); Phlegra davidi (Caleb, Mungkung \& Mathai, 2015), comb. nov. (ex Mashonarus); Stenaelurillus brandbergensis (Wesołowska, 2006), comb. nov. (ex Mashonarus); Stenaelurillus guttatus (Wesołowska \& Cumming, 2002), comb. nov. (ex Mashonarus); and S. termitophagus (Wesołowska \& Cumming, 1999), comb. nov. (ex Microheros). Two species names are synonymized: Evarcha elegans Wesołowska \& Russell-Smith, 2000 with E. werneri comb. nov.; and Aelurillus sahariensis Berland \& Millot, 1941 with Stenaelurillus nigricaudus Simon, 1886. The female of S. fuscatus Wesołowska \& Russell-Smith, 2000 is described for the first time.
\end{abstract}

Keywords. Spiders, new species, descriptions, synonymy, distribution.

Logunov D.V. \& Azarkina G.N. 2018. Redefinition and partial revision of the genus Stenaelurillus Simon, 1886 (Arachnida, Araneae, Salticidae). European Journal of Taxonomy 430: 1-126. https://doi.org/10.5852/ejt.2018.430

\section{Introduction}

Stenaelurillus Simon, 1886 is a diverse genus of jumping spiders, currently consisting of 39 valid species (WSC 2017). The genus was recently reviewed in both the Afrotropical and Oriental Regions (Wesołowska 2014a, 2014b). Since then, a number of new species have been described, particularly 
from India (Sebastian et al. 2015; Caleb \& Sanap 2016; Prajapati et al. 2016; Caleb et al. 2017; etc.) and China (Cao et al. 2016). Despite the availability of two relatively recent taxonomic surveys of the genus (Wesołowska 2014a, 2014b), many species still remain poorly diagnosed: e.g., S. hirsutus Lessert, 1927, S. glaber Wesołowska \& Russell-Smith, 2011, S. kronestedti Próchniewicz \& Heçiak, 1994 and S. pilosus Wesołowska \& Russell-Smith, 2011. Recently, one of us (GA) had an opportunity to examine diverse collections of Salticidae at several natural history museums in South Africa and the Royal Museum for Central Africa in Tervuren (Belgium). These collections contain large undetermined material on Stenaelurillus which have allowed us to reconsider the scope of the genus, to revise the status and validity of many poorly-distinguishable African species, and to clarify the distribution of many insufficiently known species. This work necessitated a re-examination of many types, including those of the species that still remain known from the original descriptions only (e.g., S. strandi Caporiacco, 1939). The results of this revisionary study are summarized in the present paper. A total of 29 species of Stenaelurillus is considered herein.

The aims of this paper are as follows: (1) to provide a new definition and diagnosis of the genus Stenaelurillus and to briefly discuss its diversity and distribution; (2) to map distribution of all the species currently included in Stenaelurillus; (3) to describe six new species from Africa and Sri Lanka; (4) to redescribe and/or provide taxonomic remarks on 23 species; and (5) to justify six new taxonomic combinations and four synonyms.

\section{Material and methods}

This paper is based on both newly collected and old museum Stenaelurillus specimens; in total, 1233 specimens have been examined. The studied material has been deposited in or borrowed from the following museums (curator mentioned in parentheses):

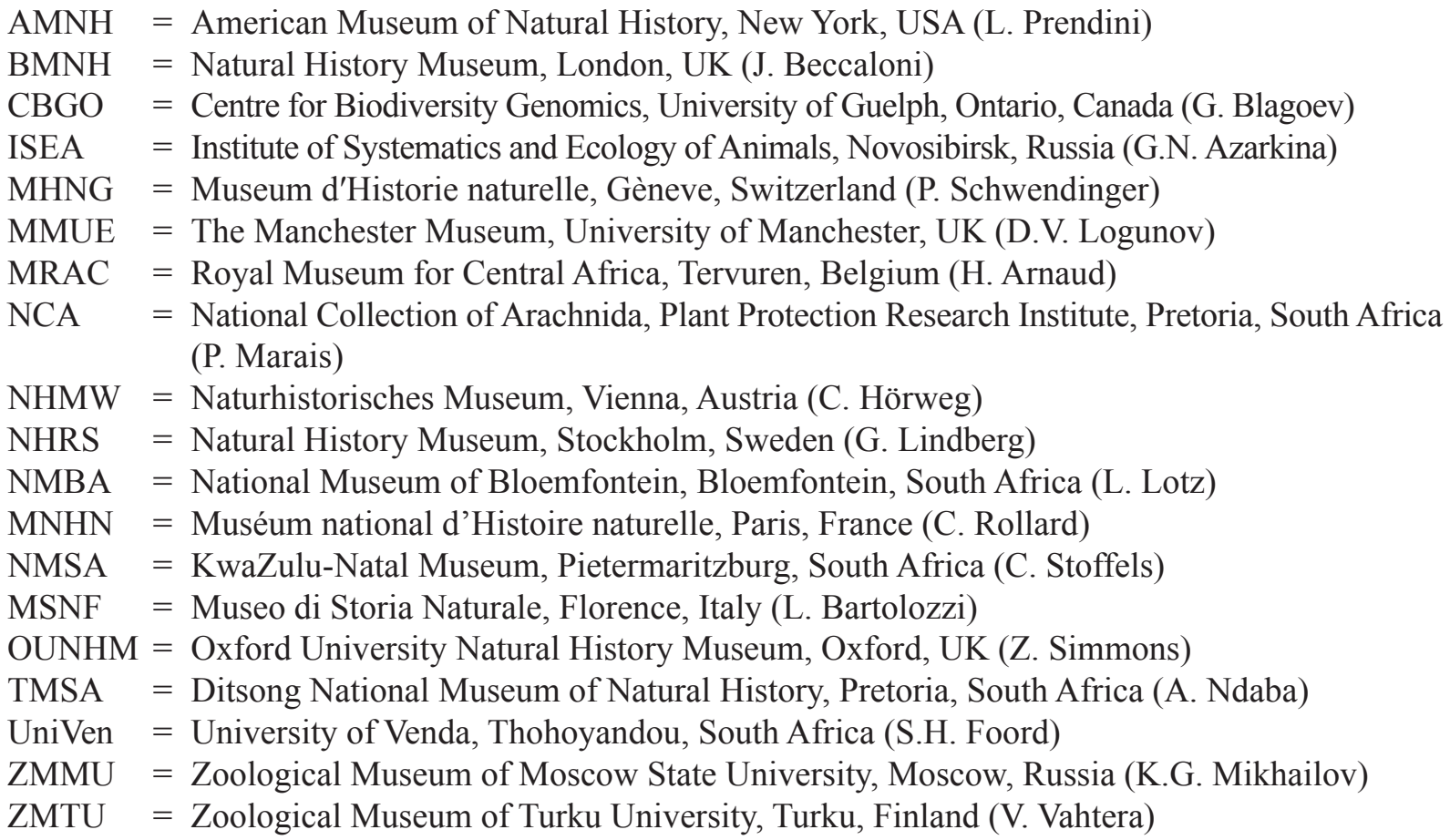

\section{Comparative material}

SEM images of the tarsal claws have been produced for the three following comparative aelurilline species:

- Aelurillus v-insignitus (Clerck, 1757) (Figs 24-25): 2 §ึ, 2 우우, Finland, Parainen [= Pargas], Mustfinnö, ca $60^{\circ} 19^{\prime}$ N, $22^{\circ} 08^{\prime}$ E, 30 May 1967, M. Saaristo leg. (ZMTU). 
- Langona bristowei Berland \& Millot, 1941 (Figs 28-29): 1 Õ, Senegal, ca 20 km S of Richard Toll $\left(16^{\circ} 20^{\prime} \mathrm{N}, 15^{\circ} 30^{\prime} \mathrm{W}\right)$, savanna, pitfall traps, 23 Sep. 1991, H. van der Valk leg. (MRAC 201.167).

- Phlegra fasciata (Hahn, 1826) (Figs 26-27): 1 ○’, Finland, Nauvo [= Navu], Lökholm, ca 5954' N, $21^{\circ} 52^{\prime}$ E, pitfall traps, 1970, P. Lehtinen leg. (ZMTU).

Position of leg spines: $\mathrm{d}=$ dorsal, $\mathrm{pr}=$ prolateral, $\mathrm{rt}=$ retrolateral, $\mathrm{v}=$ ventral. While presenting leg spination and formulas, the sign ' $/$ means 'or' and is used to show a variation in spine numbers or leg lengths. For the leg spination the system adopted is that used by Ono (1988); the term 'spine' (sensu Jocque \& Dippenaar-Schoeman 2006: 25) is used to describe pointed, rigid and usually articulating macrosetae on legs. The terminology used for describing trichobothrial bases and tarsal organs follows Ramírez (2014). In the following descriptions, the term 'cheeks' is used to describe the areas of the carapace situated below the ALE-PLE line, on both sides of the clypeus. The sequence of leg segments in measurement data is as follows: femur + patella + tibia + metatarsus + tarsus (total). All measurements are in $\mathrm{mm}$. If a range for measurements is given, it contains only the smallest and the largest values taken from the studied specimens. For known species, only references to their original descriptions are included; full reference lists can be found in WSC (2017). Distributional maps were produced by using the online mapping software SimpleMappr (Shorthouse 2010).

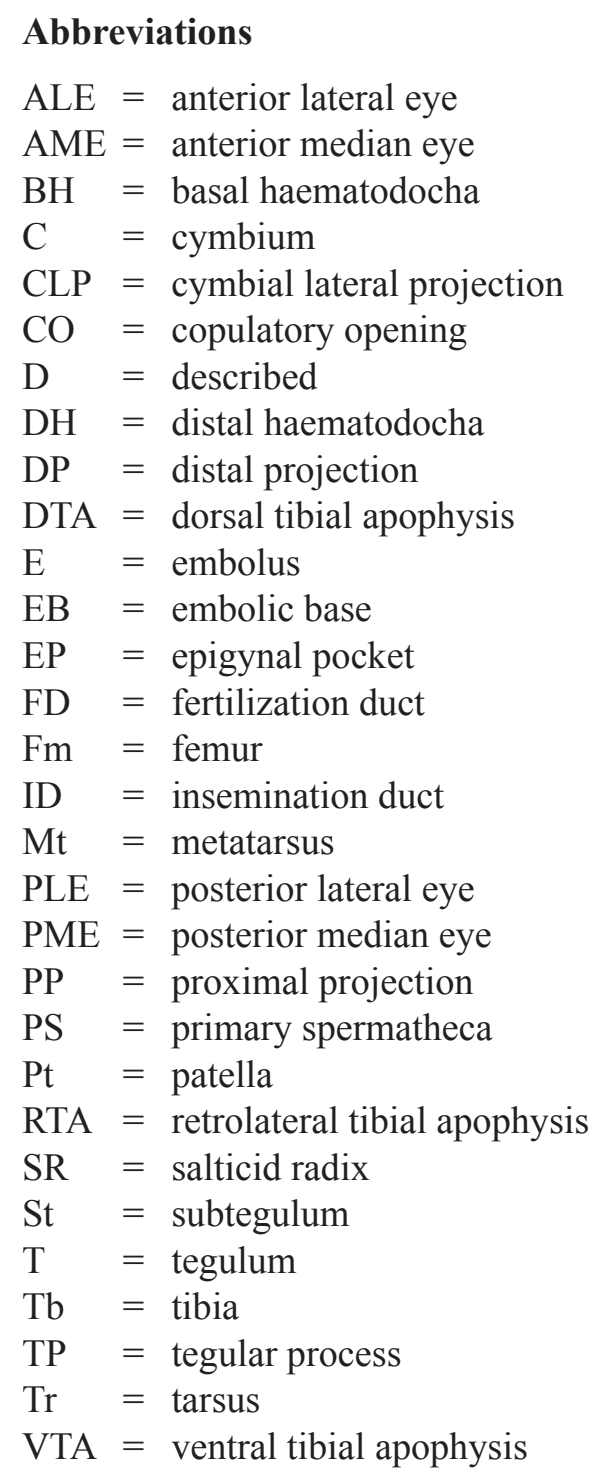




\title{
Results
}

\author{
Class Arachnida Cuvier, 1812 \\ Order Araneae Clerck, 1757 \\ Family Salticidae Blackwall, 1841 \\ Genus Stenaelurillus Simon, 1886
}

Stenaelurillus Simon, 1886: 351. Type species: Stenaelurillus nigricaudus Simon, 1886; by subsequent designation by Simon (1903: 669).

Mashonarus Wesołowska \& Cumming, 2002: 165. Type species: Mashonarus guttatus Wesołowska \& Cumming, 2002; by original designation. Syn. nov.

Microheros Wesołowska \& Cumming, 1999: 204. Type species: Microheros termitophagus Wesołowska \& Cumming, 1999; by monotypy. Syn. nov.

\section{Definition}

Small to medium spiders, ranging in body length from 3.30 to $6.40 \mathrm{~mm}$ in males $(4.69 \pm 0.72, \mathrm{n}=23)$ and 4.00 to $8.20 \mathrm{~mm}$ in females $(5.74 \pm 1.16, \mathrm{n}=19)$. Sexes similar in general body shape. Sexual dimorphism is poorly marked and can be seen in the following characters: males are usually smaller (on average, by some $20 \%$ of their body length) and brighter coloured; their $\mathrm{Tb}$, Mt and $\mathrm{Tr}$ of legs I can be entirely dark brown or black in some species (e.g., S. jocquei sp. nov., S. fuscatus; Figs 150, 300) or with dark brown ventral sides (e.g., S. nigricaudus; Figs 391, 393), or all their legs are darker (dark brown to black; e.g., S. modestus Wesołowska, 2014; Figs 361-363); males of some species have their carapaces covered with dense bunches of long (black, white and iridescent) hairs (e.g., S. hirsutus, S. jocquei sp. nov.; Figs 252, 299); in other species (e.g., S. albopunctatus) the male endites differ in having visible distal ectal projections (sensu Ramírez 2014; Fig. 46) which are absent in females.

CARAPACE. Rather high, with the posterior half of the thorax abruptly declining, almost vertical (Figs 61, 118,133 , etc.); densely covered with elongated recumbent scales making its colour pattern of two wide, white longitudinal stripes running along the ALE-PLE lines and two white marginal stripes (Figs 55, 102,115 , etc.); fovea present and situated between PLEs, but sometimes poorly seen because of the dense scale cover; in many species (e.g., in S. bandama sp. nov.) the anterior part of the eye field is covered with short erect bristles, similar to what was described in the aelurilline genus Asianellus Logunov \& Heçiak, 1996 as 'rod-hairs' (see Logunov \& Heçiak 1996: 105, figs 14-16), or in some species (especially in the males) carapace bears dense, mane-like bunches of hairs, sometimes also occupying cheeks (Figs 164, 252-255, 298-300).

EYES. In three rows, with large black areas surrounding eyes (Figs 85, 87, 118, etc.); in most species, the anterior eye row is slightly wider in both sexes (by 3-9\% in males and $2-4 \%$ in females), but females of at least five species (viz., S. albopunctatus, S. jocquei sp. nov., S. darwini Wesołowska \& Russell-Smith, 2000, S. kronestedti and $S$. modestus) have the anterior and posterior eye rows equally wide, and yet the anterior eye row is narrower by 3-5\% than the posterior one in $S$. guttiger (in both sexes); the second row midway between ALEs and PLEs; quadrangle length 32-50\% of carapace length.

Clypeus (Figs 53, 89, 117, etc.). Vertical, medium to high, ranging between $45-79 \%$ of the AME diameter in males and $42-60 \%$ in females; clypeal colourful coloration in many species of Stenaelurillus is diagnostic at the species level (e.g., in S. hirsutus, S. lesserti Reimoser, 1934, S. pilosus, S. striolatus Wesołowska \& Russell-Smith, 2011, etc.; Figs 255, 413, 468). 
Chelicerae. Medium, vertical and of usual shape, with no projections or other modifications (Figs 1013); promargin with two small teeth, usually fused together and sometimes forming a low blade-shaped ridge (e.g., in S. nigricaudus; Fig. 10), retromargin with a small tooth (Figs 10-12).

ENDITES. Subparallel, of usual shape, but in the males of some species (e.g., S. albopunctatus) with poorly marked but visible distal ectal projections (arrowed in Fig. 13); in all species of Stenaelurillus endites with pale yellow to white apices.

LABIUM. Wide-triangular, with the obtuse tip directed forward.

Sternum. Ovoid, longer than wide (Figs 56, 78, 131, etc.).

Pedicel. Short, in live specimens not visible in dorsal view.

ABDOMEN. Elongate (Figs 55, 130, etc.); males with the large dorsal scutum occupying the proximal half/two-thirds of the dorsum (Figs 45, 62, 112, etc.), the scutum may be invisible under the dense scale cover; colour markings on dorsum simple, either consisting of paired and/or singular white spots (Figs 176, 215, 254) or white longitudinal stripes (Figs 102, 130, 350, 482), sometimes with no white colour pattern at all (Figs 147, 462).

BOOK-LUNG COVERs. Not sclerotized.

SPINNERETS. Medium, $21-36 \%$ of the abdominal length; the posterior pair slightly longer than the anterior one (Figs 134-135, 462, 484), in some species (e.g., S. albopunctatus, S. furcatus, S. mirabilis, S. strandi; Figs $45,347,385$ ) the tips of posterior spinnerets or entire posterior spinnerets are contrastingly dark brown, especially in males.

LEGs. Subequally developed (Figs 49-56, 111-118); male legs I are usually darker than those of females, being entirely dark brown/black or with dark brown/black Tb, Mt and Tr (Figs 204, 210, 298-303); tarsal claws narrow, with well-developed and numerous teeth (Figs 14-23): 7-20 teeth prolaterally and 5-19 retrolaterally. Leg formula: IV/III,II/I in both sexes, the third and fourth pairs of legs are always longer than the first and second pairs.

TRichoвothria. Tr with 2-3 trichobothria in a single row, Mt with 2-4 trichobothria in a single row, Tb with a group of 5-6 trichobothria on its dorso-proximal end (other leg segments were not examined in this regard); trichobothrial proximal and distal plates present (Figs 1-3, 5-8); the proximal plate (= trichobothrial 'hood') is finely striated (= fingerprint-like cuticular sculpture), with a medial differentiation and with one-two clearly marked transverse ridges on its distal margin; the margin of the alveolus smooth; the distal plate smooth, with or without a pair of transverse ridges in front of it; bothrial base thin.

TARSAL ORGAN. Of the capsulate type, with an ovoid pore being situated at the top of a low, round, domeshaped elevation and slightly disposed to one end, distally (Figs 4, 9).

Leg SPINATION. All legs with numerous spines, especially on Tb and Mt of legs III-IV; the spine patterns of legs I-II are similar/identical, as are those of legs III-IV; the common spine patterns for most species are as follows: Fm I-II d 0-1-1/2-3/5; Fm III-IV d 0-1-1/2-4/5; Pt I-II pr 0-1-0; Pt III-IV pr and rt 0-1-0; Tb I-II pr 1-1, v 0/1-0/1-2ap; Tb III-IV d 1-0-0, pr and rt 1-1-1-1 or 1-1-1/2, v 1-0-2ap; Mt I-II pr 0/1-1ap, v 2-2ap; Mt III-IV pr and rt 1-0/1-1/2ap; some species have spineless Pt I-II, for instance, S. belihuloya sp. nov., S. brandbergensis comb. nov., S. guttatus comb. nov., and S. pseudoguttatus 
sp. nov., of which two (S. brandbergensis comb. nov. and S. guttatus comb. nov.) were earlier considered in the separate genus Mashonarus.

Female Palp. General form; without an apical claw (Figs 89, 128, 233).

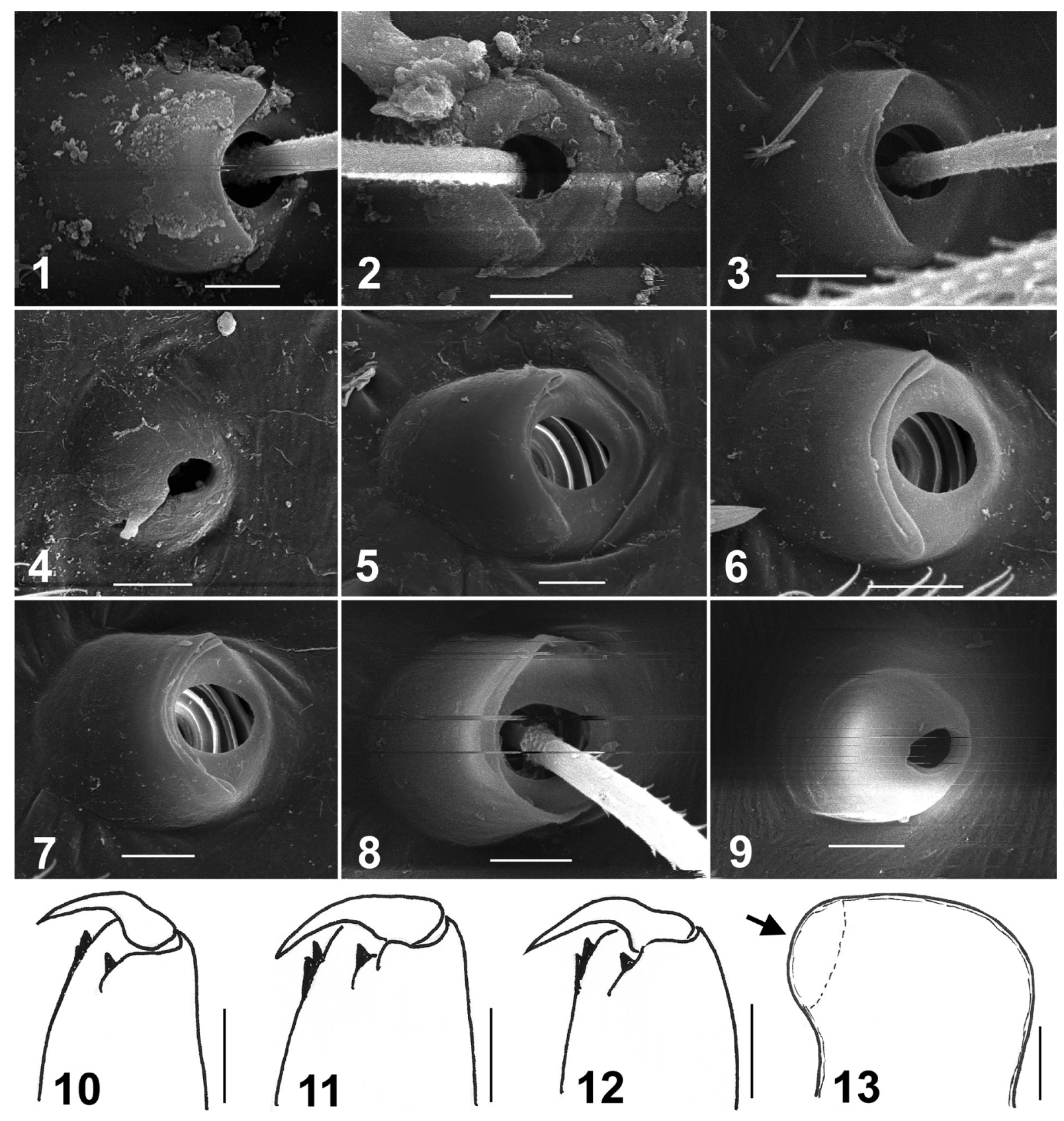

Figs 1-13. Trichobothrial bases (1-3, 5-8), tarsal organs (4, 9), left chelicerae (10-12) and right endite (13) of Stenaelurillus Simon, 1885. 1-2. S. nigricaudus Simon, 1886, ․ 1. Tb 1. 2. Tr 1. 3. S. hirsutus Lessert, 1927, ․ Tr 2. 4-7. S. termitophagus (Wesołowska \& Cumming, 1999) comb. nov., ․ 4. $\operatorname{Tr} 1$. 5. Mt 1. 6. $\operatorname{Tr}$ 2. 7. $\operatorname{Tr} 1$. 8-9. S. guttatus (Wesołowska \& Cumming, 2002) comb. nov., ․ . 8. $\operatorname{Tr} 1$. 9. $\operatorname{Tr} 1$. 10. S. nigricaudus Simon, 1886, ․ 11. S. termitophagus comb. nov., ․ 12. S. darwini Wesołowska \& Russell-Smith, 2000, ‥ 13. S. albopunctatus Caporiacco, 1949, Ô, right endite. Abbreviations: see Material and methods. Scale bars: $1-9=5 \mu \mathrm{m} ; 10-12=0.25 \mathrm{~mm} ; 13=0.1 \mathrm{~mm}$. 
Male palp. Femora of usual shape but in some species can be densely covered with long hairs and bristles (e.g., in S. lesserti; see Sebastian et al., 2015: fig. 5A-C) or bears a low but clearly developed laminar crest (e.g., in S. darwini; see Wesołowska \& Russell-Smith, 2000: fig. 273); tibia short and wide, with two/three processes, ventral (VTA), retrolateral (RTA) and dorsal (DTA; e.g., in S. albopunctatus, S. kronestedti); VTA usually looks like a ventral bulge of the tibia (Figs 90,156, 165) or like the short process (e.g., in S. abramovi Logunov, 2008 or S. fuscus Cao \& Li, 2016; see Logunov 2008: fig. 11; Cao et al. 2016: fig. 40A-B), whereas the well-developed DTA can bear a sharp apical spur or bunches/ rows of thick bristles (iridescent, dark brown or black; Figs 41, 106, 137, 318: DTA); the retrolateral and
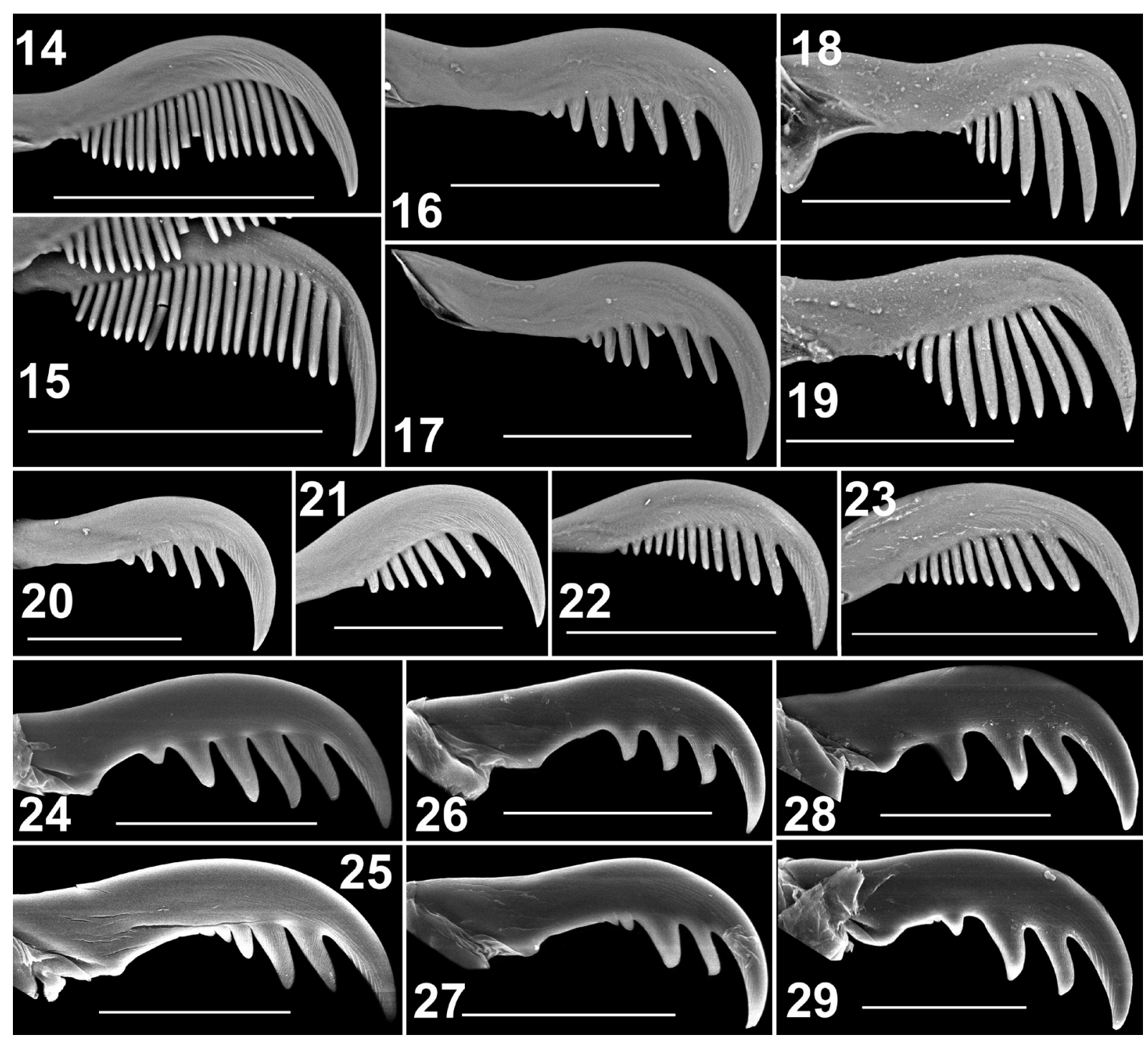

Figs 14-29. Tarsal claws of legs 1 in females of Stenaelurillus Simon, 1886, scanning electron micrographs. 14-15. S. nigricaudus Simon, 1886. 14. Retrolateral. 15. Prolateral. 16-17. S. guttatus (Wesołowska \& Cumming, 2002) comb. nov. 16. Retrolateral. 17. Prolateral. 18-19. S. termitophagus (Wesołowska \& Cumming, 1999) comb. nov. 18. Retrolateral. 19. Prolateral. 20-21. S. fuscatus Wesołowska \& Russell-Smith, 2000. 20. Retrolateral. 21. Prolateral. 22-23. S. guttiger (Simon, 1901). 22. Retrolateral. 23. Prolateral. 24-25. Aelurillus v-insignitus (Clerck, 1757). 24. Retrolateral. 25. Prolateral. 26-27. Phlegra fasciata (Hahn, 1826). 26. Retrolateral. 27. Prolateral. 28-29. Langona bristowei Berland \& Millot, 1941. 28. Retrolateral. 29. Prolateral. Scale bars: $0.1 \mathrm{~mm}$. 
dorsal sides of the tibia can be densely covered with thick and long hairs and bristles (Figs 282, 293); the cymbium is oval, with no apical spines and usually with no processes or projections, except for a few species having the proximo-lateral corner of the cymbium developed into a marked cymbial lateral projection (e.g., S. guttatus comb. nov., S. strandi, S. termitophagus comb. nov.; Figs 166, 455, 474: CLP); the cymbial apex is slightly extended beyond the alveolus and in many species can bear a poorlymarked ventral groove (sensu Ramírez, 2014; arrowed in Figs 193, 246); the basal haematodocha is welldeveloped (Figs 30, 32-33: BH); the subtegulum is simple, bean-shaped and visible in an expanded palp only (Fig. 30: ST); the tegulum is narrow and elongated, with an obtuse shoulder (Figs 31, 39, 58, 91, 377: T), which can bear a finger-shaped tegular process directed distad (e.g., in S. guttiger, S. nigricaudus, S. strandi, etc.; Figs 64, 192, 455: TP); the distal haematodocha is well-developed (Figs 30, 32-33: $\mathrm{DH}$ ), clearly separating the true tegulum from the salticid radix; the functional tegulum consists of the salticid radix (sensu Logunov 1999; Logunov \& Cutler 1999; Logunov \& Marusik 2003; Figs 31-32, 37: SR), which seems to be fused with a large distal sclerite on unknown origin that in some species (e.g., S. termitophagus comb. nov.) is visible and delimited from the salticid radix by a membranous area (arrowed in Figs 472); the salticid radix usually has a pointed or obtuse proximal projection (Figs 31, 58, 166: PP) and also bears a finger-shaped, bifurcated or pointed distal projection (Figs 40, 105, 120, 246: DP), which in some species can be decorated with crest-forming stiff bristles (e.g., in S. lesserti; Wesołowska 2014a: fig. 2A-D), in other species (e.g., S. abramovi, S. fuscus; Figs 36-39, see also Logunov 2008: figs 1-3; Cao et al. 2016: fig. 41B-C) the DP is strong, distinct and movable (see below for further discussion); the embolic division consists of the embolus (E) with the heavy embolic base (EB), which is either fused by its median edge with the distal edge of the salticid radix (Figs 31, 376) or connected to it by a visible membrane (arrowed in Fig. 40); the embolic conformation varies from whipshaped, with the poorly-developed embolic base (Fig. 457, 475), to needle-, hook- or ribbon-shaped, with a well-developed base (Figs 33, 93, 160, 378).

Female COPULATORY ORGans. The epigyne is usually flat, without epyginal depression or fossae, with openly displayed copulatory openings (Figs 47, 99, 126: CO), but in a few species (S. darwini and S. termitophagus comb. nov.; Figs 109, 476) they are hidden under a pair of bulge-shaped, chitinous flaps; the copulatory openings are either as rounded pores (Figs 126, 262), which sometimes are poorly seen on the epigynal plate (Figs 99, 171), or as deep furrows that could be subparallel (e.g., S. jocquei sp. nov., S. pilosus; Figs 296, 412; Wesołowska \& Russell-Smith 2011: figs 165-166) or positioned transversely, forming a single transverse line (S. bandama sp. nov., S. iubatus Wesołowska \& RussellSmith, 2011, S. sudanicus Wesołowska, 2014; Figs 70, 278, 452; Wesołowska 2014b: fig. 12B-C; Wesołowska \& Russell-Smith, 2011: figs 159-160); in most species, the copulatory openings are widely separated, but in some (e.g., S. lesserti, S. abramovi, S. pecten Wesołowska, 2014; Logunov 2008: fig. 4; Wesołowska 2014b: fig. $10 \mathrm{~F}-\mathrm{G}$ ) they are close to each other, being separated by a space that is equal to or smaller than the diameter of each; epigynal pocket present, usually narrow and deep, situated at the edge of the epigastric furrow (Figs 262, 278: EP) or in between the copulatory openings (Figs 126227, 288: EP), but in some species it can be absent or poorly-marked (e.g., in S. guttatus comb. nov., S. latibulbus Wesołowska, 2014; Figs 171, 334) or in some species (viz., S. abramovi; see Logunov 2008: fig. 4) be displaced forward and look like a round depression; the insemination ducts usually short and wide (Figs 335, 399: ID), except for S. termitophagus comb. nov. (Figs 477-478), and lead to the bean-shaped, round or ovoid, medium/large primary spermathecae (sensu Ramírez 2014; Figs 71, 127, 172: PS); the fertilization ducts are pronounced and well-visible (Figs 127, 145, 228: FD).

\section{Morphological notes}

The terms 'functional tegulum' and 'salticid radix' are used here in the same sense as in Logunov (1998, 1999), Logunov \& Cutler (1999) and Logunov \& Marusik (2003) to emphasise the composite nature of what is usually described in the advanced salticids as the tegulum; the cited works can be consulted for more details and evidence for this terminology. 
The present analysis has shown that the sclerite composition of the male palp in Stenaelurillus is similar to that of Habrocestoides Prószyński, 1992 (see Logunov 1999): viz., in both genera the true tegulum is small and hidden behind the large salticid radix forming the main part of the functional tegulum (Figs 31-33, 39, 64, 90). Compared to Habrocestoides, the functional tegulum of Stenaelurillus also includes the second large sclerite, which in the majority of species is firmly fused with the salticid radix but in some is visible, being delimited from the latter sclerite by a membranous area, for instance, in S. albus Sebastian, Sankaran, Malamel \& Joseph, 2015 (Sebastian et al. 2015: fig. 2E), S. arambagensis (Biswas \& Biswas, 1992) (see Prajapati et al. 2016: fig. 6B, sub. S. digitus Prajapati, Murthappa, Sankaran \& Sebastian, 2016; Caleb et al. 2017), or S. termitophagus comb. nov. (arrowed in Fig. 472). It is difficult to homologise this sclerite, as the detailed structure of male copulatory organs yet remains poorly studied in the majority of salticid genera. Based on its position between the salticid radix and the

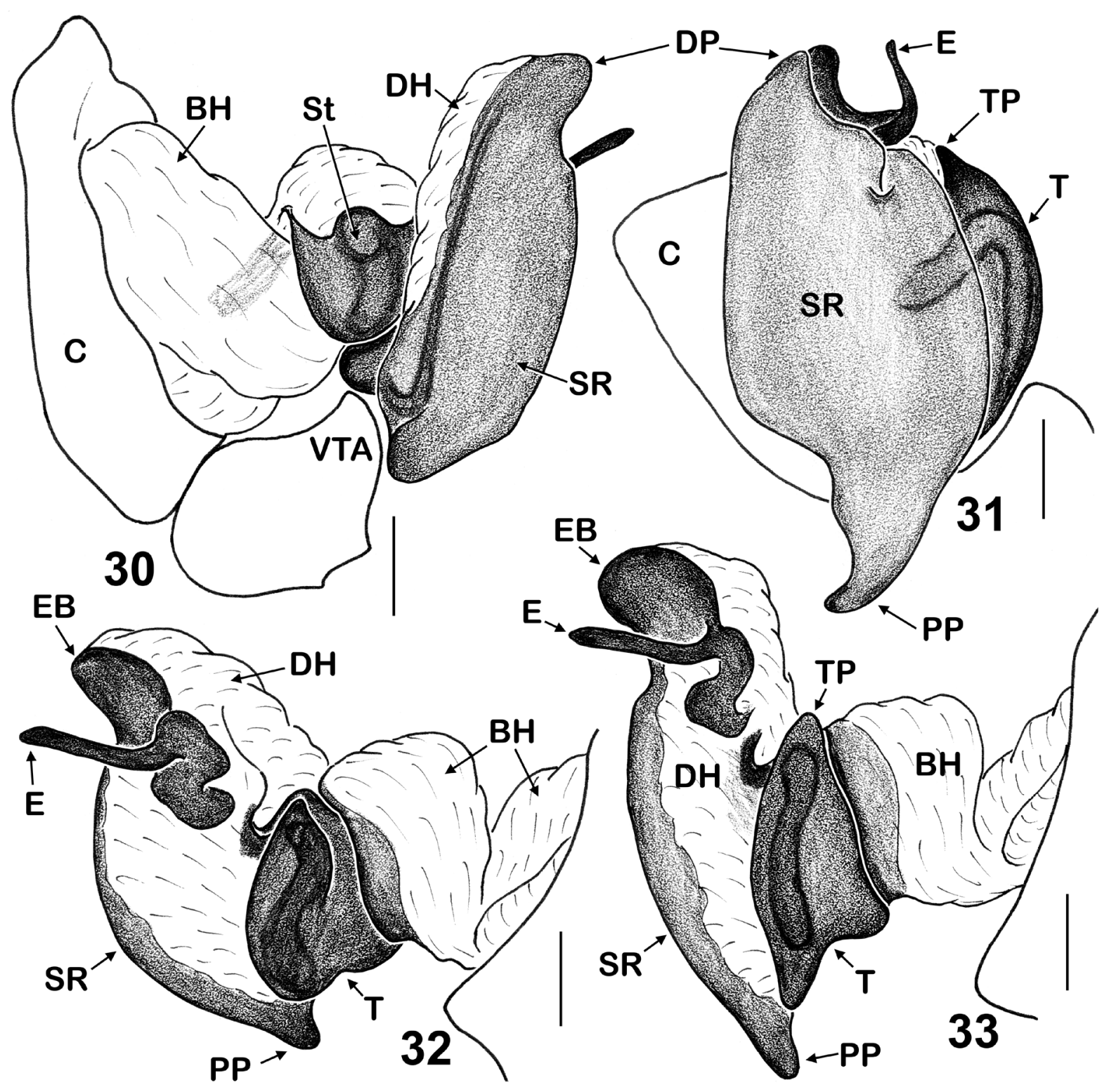

Figs 30-33. Expanded female palp of Stenaelurillus nigricaudus Simon, 1886 from Burkina Faso (Sissamba). 30. Median view. 31. Ventral view. 32. Retrolateral-dorsal view. 33. Retrolateral view. Abbreviations: see Material and methods. Scale bars: $0.1 \mathrm{~mm}$. 
embolic division, it is possible to conclude that this sclerite seems to be the same one as the 'sclerite-1' described in the genus Pseudeuophrys Dahl, 1912 (see Logunov 1998 for further discussion). The present finding also allows us to argue that the composite nature of the functional tegulum in Salticidae seems to be the rule rather than an exception. In many salticid genera, particularly in the Dendryphantinae and the Chrysillini (sensu Maddison 2015), the true tegulum is seen as a sclerotized, prolateral outgrowth (= shoulder of tegulum, sensu Maddison 1996) separated from the functional tegulum (= the salticid radix) by a visible tegular ledge (e.g., Maddison 1996: fig. 3). Nevertheless, in the alpha-taxonomic literature, both structures (the true tegulum and the salticid radix) are usually described together as 'the tegulum', though the latter is better called 'the functional tegulum' or 'the salticid tegulum'.

This clarification of what is the true tegulum in Stenaelurillus has allowed us to correctly code its proximal finger-shaped process, which is well-developed in many species (e.g., in S. nigricaudus, S. strandi, etc.). This structure is coded here as 'the tegular process' (Figs 33, 64, 192, 241: TP), because it clearly represents a distal prolongation of the true tegulum. It seems to be homologous to the distal tegular projection of Pisauridae (sensu Sierwald 1990) or the suprategulum of Linyphiidae (sensu Saaristo 1977; = the median apophysis in Merret 1963). By mistake, the TP in Stenaelurillus was coded by some earlier authors as the 'terminal apophysis' (e.g., Logunov 2008; Prajapati et al. 2016; Sebastian et al. 2015), although the true terminal apophysis is known to be part of the embolic division (see Merrett 1963: figs 1-3; Saaristo 1977).

In a few species (e.g., S. abramovi, S. fuscus), the distal projection (DP) of the functional tegulum is strong, distinct and even movable, being separated from the functional tegulum by a visible membrane (Figs 36, 39; see also Logunov 2008: figs 1-3; Cao et al. 2016: fig. 41B-C). The latter authors coded this sclerite as the 'sclerotized apophysis'. Based on its position at the top of the salticid radix and the fact that it is separated from it by a membrane, it is possible to hypothesize that this sclerite could be either the terminal apophysis or the lamella described, for instance, in the Linyphiidae (Merrett 1963: fig. 3). This assumption needs verification when more salticid taxa have been studied with regards to the detailed structure of their male copulatory organs.

It is worth noticing that in some Asian species (e.g., S. abramovi, S. albus, S. fuscus) the proximal projection of the bulbus seems to have been formed by the proximal extention of the true tegulum (Figs 38-39; see also Sebastian et al. 2015: fig. 2E) rather than the saltcid radix, as in most other species. In these species the functional tegulum has a narrow membranous area running across it, likely marking the border between the true tegulum and the salticid radix. Due to the limited/no material of these species available for the present study, we have been unable to expand their male palps and to verify this observation. The matter needs further attention when more fresh material of Asian species of Stenaelurillus have been made available.

\section{Diagnosis and affinities}

According to Maddison (2015) and his molecular data, Stenaelurillus belongs to the subtribe Aelurillina Simon, 1901 of the tribe Aelurillini Simon, 1901 in the subfamily Salticinae Blackwall, 1841. It is a compact group of ground-dwelling jumping spiders containing some 281 species in nine genera (Table 2; p. 119), which was formely known as the subfamily Aelurillinae Prószyński, 1976 (e.g., Metzner 1999). From all other aelurillines Stenaelurillus can be distinguished by the following characters: (1) the longest, conspicuous spinnerets (Figs 45, 134, 205, 462; 21-36\% of the abdominal length), in other genera spinnerets are usually small, inconspicuous and poorly visible in dorsal view; (2) well-developed and numerous teeth of tarsal claws (Figs 14-23; 7-20 teeth prolaterally and 5-19 retrolaterally), in other genera 3-5 teeth (Figs 24-29) (this character is diagnostic even in immature specimens); (3) the least developed cymbial pocket (sensu Logunov 1996) as compared to other aelurillines, usually the embolic division is situated openly, in a shallow cavity at the top of the bulbus (Figs 34, 40, 64, etc.); (4) the 
true tegulum is marked and visible as a heavily sclerotized sclerite hidden behind (retro-laterad of) the salticid radix (Figs 39, 377; see above for further details); and (5) the bright body coloration consisting of numerous stripes and paired/singular spots (Figs 102, 130, 178, 215, etc.), in other genera the body colour pattern is usually limited to longitudinal stripes (e.g., in Phlegra Simon, 1876 or Aelurillus Simon, 1884).

Based on the refined generic diagnosis, it is safe to conclude that the monotypic genus Microheros and the small genus Mashonarus with three species (WSC 2017), both from Africa, are to be synonymized with Stenaelurillus. Both the conformation of the copulatory organs (Figs 90-94, 165-172, 472-478) and the somatic morphology (long spinnerets, trichobothria and dentation of tarsal claws; Figs 5-9, 16-19, $176,484)$ of their generotypes are identical or in full agreement with those of Stenaelurillus nigricaudus (Figs 1-2, 14-15, 369-381, 395-399), the generotype of Stenaelurillus, and of other species included in the latter genus. All the species of Microheros and Mashonarus, except for the Indian Mashonarus davidi Caleb, Mungkung \& Mathai, 2015 (Figs 504-506), the holotype of which we have been unable to borrow, are redescribed and illustrated in detail below.

\section{Composition}

At present, Stenaelurillus consists of 45 valid species (Table 1), of which 33 are known from both sexes, eight species from the males and four species from the females (Table 2; p. 119). Details on the distribution of and references to all these species are provided in Table 1.

\section{Distribution}

The geographical distribution of Stenaelurillus is clearly palaeotropical (Fig. 507), covering almost the entire African continent, except for the western half of the equatorial zone, and then extending to southern Iran, south and SE Asia, including the southern and south-eastern territories of China. There are no common species between the Afrotropical and Oriental regions. As evidenced from the data at hand, there are three main centres of the present day species diversity (= chorological centres): western Africa ( 7 species), the south-eastern part of central Africa ( 21 species) and South Asia ( 5 species). The revealed distributional disjunction between the African and Asian parts of the generic range and the absence of species in Indonesia and Polynesia-Micronesia seem to be due to the incompleteness of our knowledge.

The outlined distribution of Stenaelurillus is virtually restricted to the Palaeotropical Zoogeographic Kingdom (sensu Kryzhanovsky 2002: inset 1), with a few records originating from the neighbouring regions of the Ancient Mediterranean (e.g., S. nigricaudus from N Algeria, S. marusiki Logunov, 2001 from SW Iran and S. triguttatus Simon, 1886 from Nepal and Tibet; Figs 509-510). Genera with such distributional patterns are classified as either "palaeotropical" (sensu Kryzhanovsky 2002: 58) or "multiregional of the eastern hemisphere" (sensu Pravdin \& Mishchenko 1980: 28) and are commonly considered to be of Neogene origin (i.e., 23 Ma or later; sensu Hilgen et al. 2012). Numerous examples of the palaeotropical distribution in tribes and genera are known from Coleoptera, Orthoptera, Diptera, Mantodea and other orders (Pravdin \& Mishchenko 1980; Nartschuk 1994; Kryzhanovsky 2002; Davies et al. 2002; etc.).

It is worth noticing that so far no species of Stenaelurillus have been recorded or described from Madagascar. This fact could be explained either by the current incompleteness of our knowledge of Stenaelurillus, or, more likely, by the later origin of the genus, after Madagascar had already separated from Africa (183-158 Ma) and India (96-65 Ma) during the late Jurassic to late Cretaceous fragmentation of Gondwana (see Vences et al. 2009); the latter assumption seems to be in agreement with a possible Neogene origin of Stenaelurillus (see above). To date, the only described Malagasy aelurilline species is 


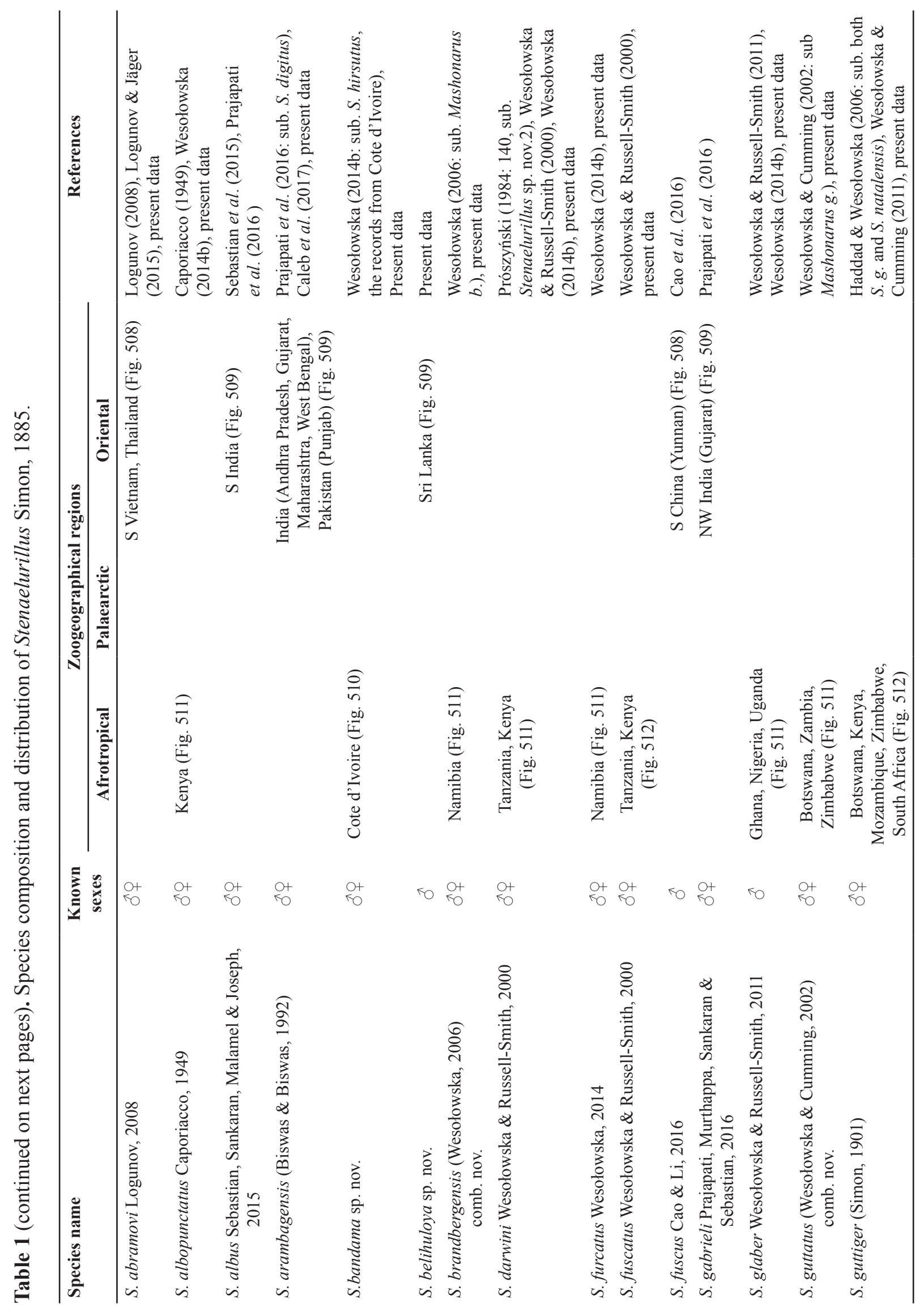




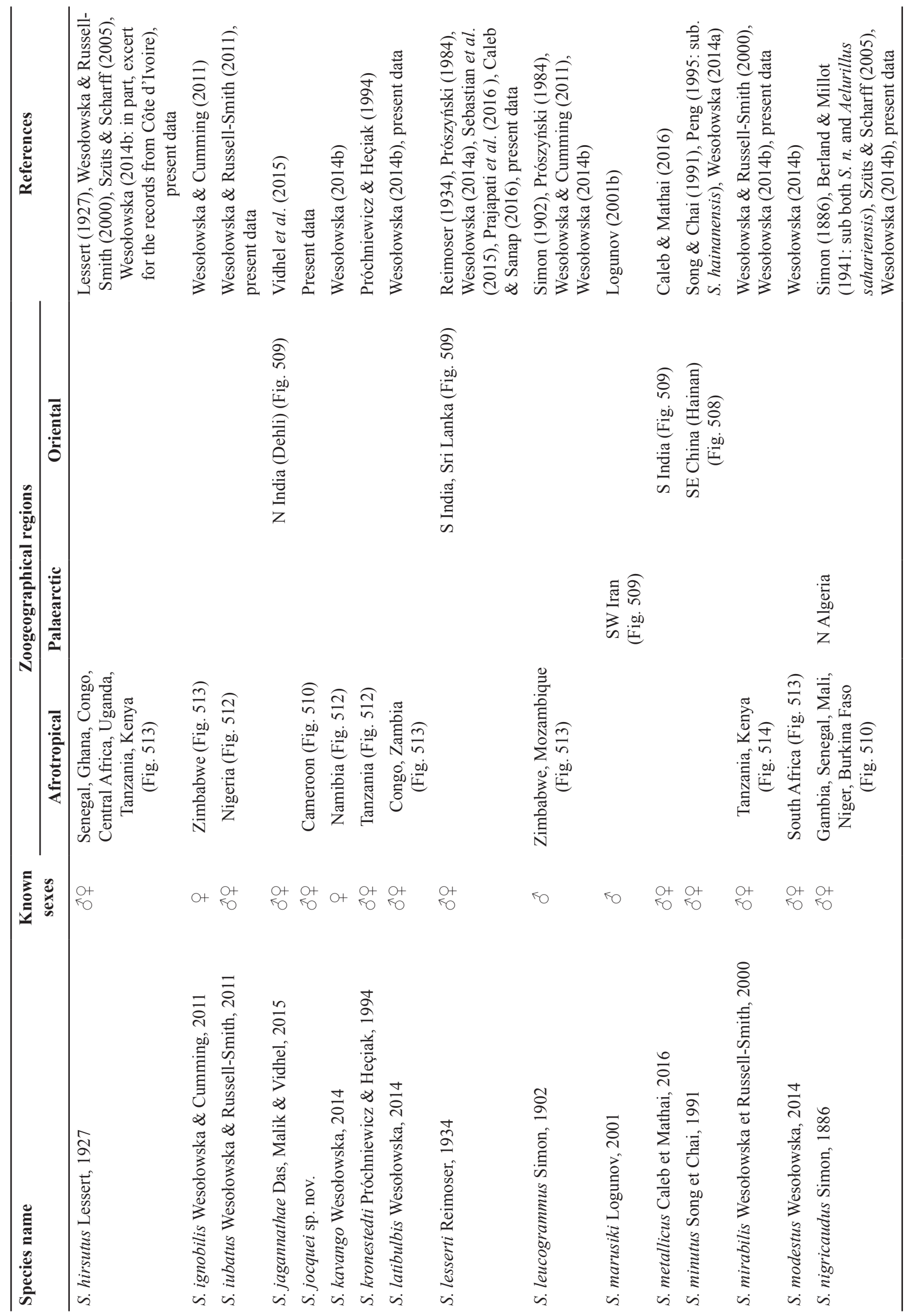




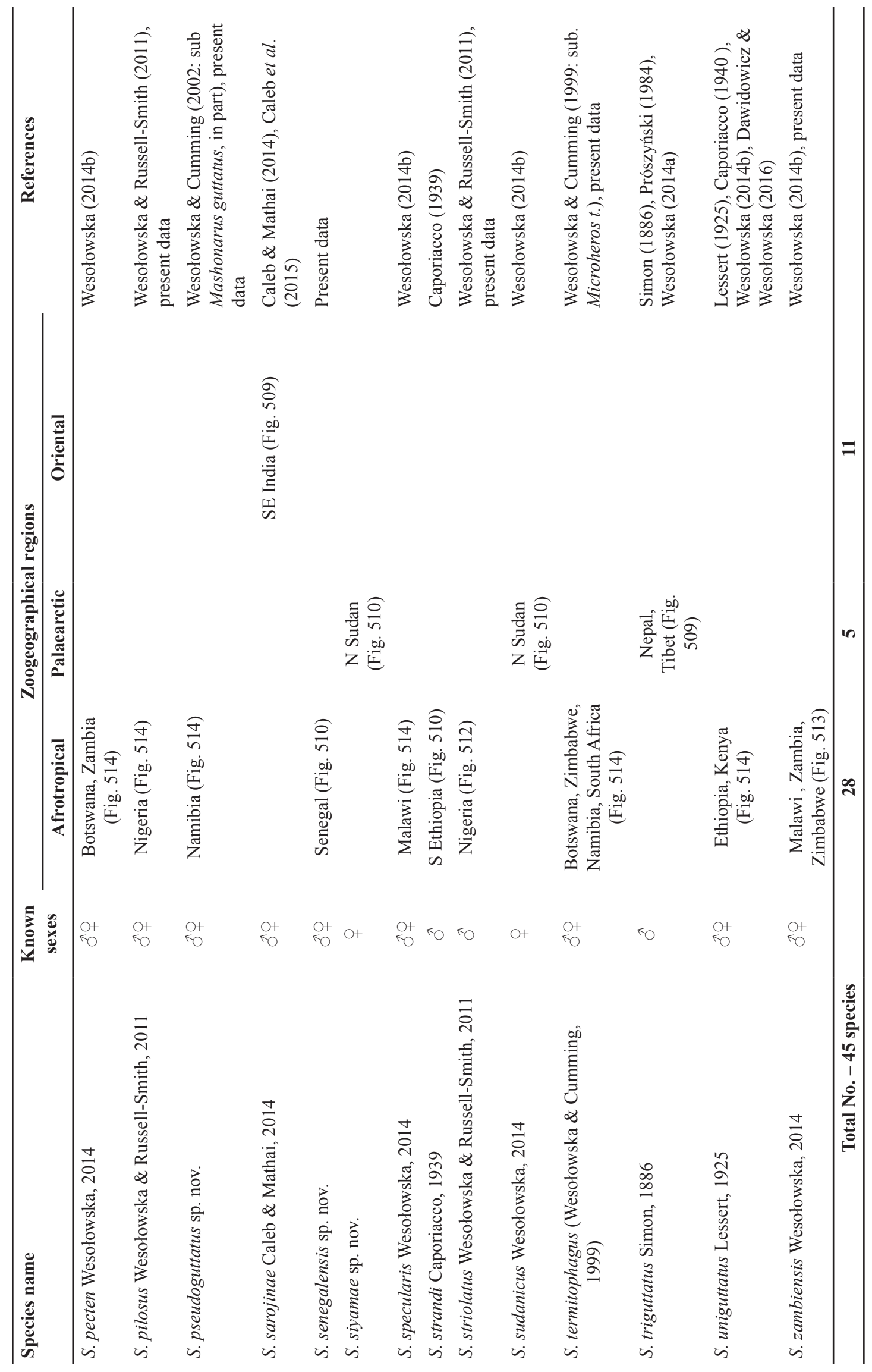


Aelurillus madagascariensis Azarkina, 2009 (see Table 3, p. 120), a true member of the genus Aelurillus Simon, 1885 that is related to some species from the Levant (Azarkina 2009).

The genus Stenaelurillus is not unique in the order Araneae, as far as its distributional pattern is concerned. A similar palaeotropical distribution is also known in a number of better studied spider genera, for instance: Borboropactus Simon, 1884 (Thomisidae) recorded from tropical Africa, S and SE Asia, but compared to Stenaelurillus also including Malaysia, Indonesia, the Phillipines and Papua New Guinea (Benjamin 2011; WSC 2017); Calommata Lucas, 1837 (Atypidae) recorded from Africa, the Near East and SE Asia (Fourie et al. 2011); Mallinella Strand, 1906 (Zodariidae), a recently revised genus occurring in central and west Africa, S and SE Asia, southeastward to the northern tip of Australia (Dankittipakul et al. 2012a: fig. 1415; 2012b); Sarascelis Simon, 1887 and the entire subfamily Chediminae (Palpimanidae) known from tropical Africa, India and Indonesia, but compared to Stenaelurillus with a lesser number of records (Zonstein \& Marusik 2013: fig. 51); Synaphosus Platnick \& Shadab, 1980 (Gnaphosidae) known from central Africa, the Near East, Central Asia and SE Asia (yet two species were also introduced to the USA; see Ovtsharenko et al. 1994; WSC 2017); and other spider genera. Two spider genera display an almost identical distributional pattern as that of Stenaelurillus, except for some singular records from the Neotropics, namely: Nesticella Lehtinen \& Saaristo, 1980 (Nesticidae) is known from tropical Africa, but not as widespread as Stenaelurillus, S and SE Asia, including the south-easternmost areas of the Palearcrtic Region and Papua New Guinea (Lin et al. 2016; WSC 2017), plus a single record from Brazil (Rodrigues \& Buckup 2007); Bianor Peckham \& Peckham, 1885 (Salticidae) is known from the Afrotropical, Oriental and Palaearctic (southern parts) Regions, with a single species - B. biocellosus Simon, 1902 - with its type locality in Brazil (Logunov 2001a). Of other jumping spider genera (Salticidae), most of which still remain rather poorly studied with regards to their composition and general distribution, the following genera seem to also demonstrate a palaeotropical distribution: Hyllus C.L. Koch, 1846 is widespread in tropical Africa and SE Asia (including the generotype; WSC 2017), but the congenerity of many species included in this genus requires revision; Harmochirus Simon, 1885, a revised genus the distribution of which is almost identical to that of Stenaelurillus but with a lesser number of species and records (Logunov 2001a; WSC 2017); and other salticid genera. A further comparative analysis of the distributional pattern of Stenaelurillus with that of other spider genera, including the Salticidae, lies outside the goals of the present study and seems to be premature at the currently incomplete state of knowledge.

Stenaelurillus abramovi Logunov, 2008

Figs $34-39,508$

Stenaelurillus abramovi Logunov, 2008: 43, figs 1-7 (D $\overbrace{}^{\wedge}$ ) $)$; holotype $\widehat{o}$ in ZMMU, examined.

\section{Diagnosis}

By the presence and shape of the movable distal projection (DP) of the functional tegulum (Figs 36-39), S. abramovi is closest to $S$. fuscus (see Cao et al. 2016: figs 40B, 41), from which the male can be distinguished by the longer, finger-shaped embolus (short and inconspicuous in S. fuscus) and by the absence of dense lateral pubescence on the carapace (present in S. fuscus; compare Logunov 2008: fig. 6 with Cao et al. 2016: fig. 41D). The female of S. fuscus remains unknown.

\section{Material examined}

THAILAND: 1 $\delta$, Trat Prov., Kho Chang Island, Chai Chet Cape, $12^{\circ} 04^{\prime} \mathrm{N}, 102^{\circ} 16^{\prime} \mathrm{E}, 20-60 \mathrm{~m}$ a.s.l., 28 Nov. 2016, V.K. Zinchenko leg. (ISEA 001.7320); 1 đૈ, same prov., Kho Chang Island, nr Coconut Beach Resort, $12^{\circ} 04^{\prime}$ N, $102^{\circ} 16^{\prime}$ E, 6 m a.s.1., 19-22 Nov. 2016, V.K. Zinchenko leg. (ISEA 001.7323). 


\section{Distribution}

To date, this species has been described and is known from the type locality in southern Vietnam (Binh Chau - Phuoc Buu Nat. Reserve) only (Logunov 2008; Logunov \& Jäger 2015). New to Thailand and the first record from outside the type locality. A detailed description of this species was provided by Logunov (2008).
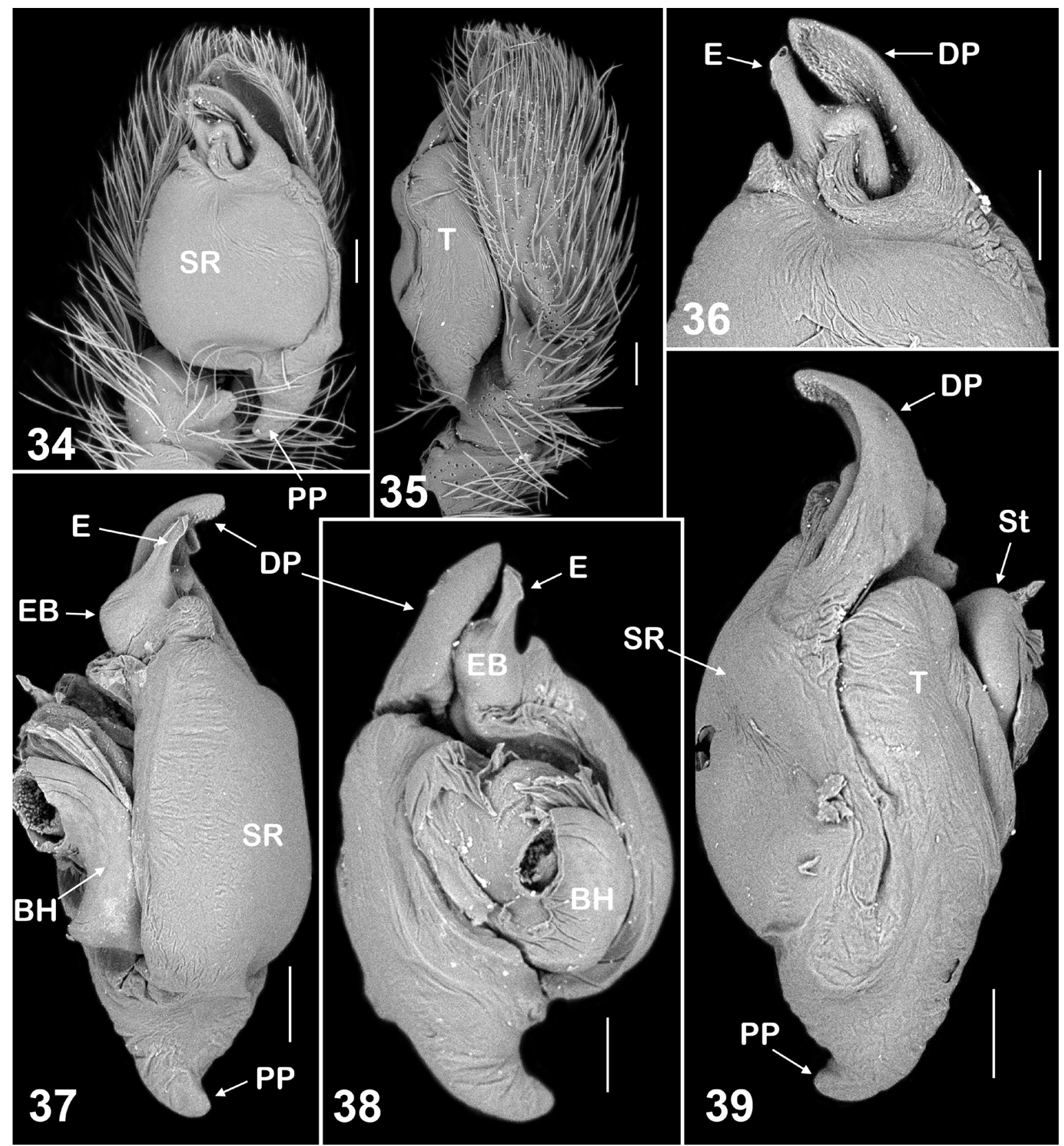

Figs 34-39. Male palp of Stenaelurillus abramovi Logunov, 2008 from Thailand (Chai Chet Cape), scanning electron micrographs. 34. Ventral view. 35, 39. Retrolateral view. 36. Embolic division, ventral view. 37. Median view. 38. Dorsal view. Abbreviations: see Material and methods. Scale bars: $0.1 \mathrm{~mm}$. 
Stenaelurillus albopunctatus Caporiacco, 1949

Figs 13, 40-56, 511

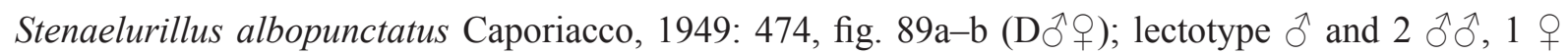
paralectotypes (designated here) in MSNF, examined.

Stenaelurillus albopunctatus - Wesołowska 2014b: 597, fig. 1A-F (ぷ+o).

\section{Diagnosis}

This species is most similar to S. kronestedti from Tanzania (Figs 317-329), with both species having very similar coloration and an almost identical conformation of the embolic division: viz., a hookshaped embolus with an anvil-shaped basis in the males. S. albopunctatus can be readily distinguished from $S$. kronestedti by the spatula-shaped RTA, the obtuse, wider and longer DTA, and the position of the row of long, transparent and black bristles on the DTA (Fig. 41) in the males, and by the closely situated copulatory openings (less than one diameter) and the markedly shorter insemination ducts in the females (Figs 47-48).

\section{Material examined}

Lectotype (designated here)

KENYA: ${ }^{\lambda}$, Nairobi, $1^{\circ} 16^{\prime} 59^{\prime \prime}$ S, 36 $36^{\circ} 00^{\prime \prime}$ E, 1944, Meneghetti leg.; according to Caporiacco (1949: 475), he also studied a single 9 from the locality Elmenteita, ca $0^{\circ} 29^{\prime} 08.2^{\prime \prime} \mathrm{S}, 36^{\circ} 09^{\prime} 15.2^{\prime \prime} \mathrm{E}$ in Kenya, collected in December 1945 (MSNF 645).

\section{Paralectotypes}

KENYA: $2 \hat{\jmath} \hat{\jmath}, 1$, same collecting data as for lectotype.

\section{Other material}

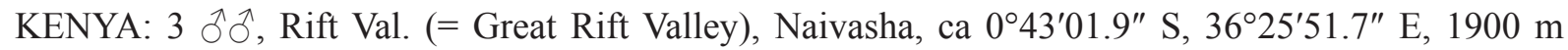
a.s.l., hillside scrub, 27 Jul. 1972, J. Murphy leg. (MMUE G7572.9); 1 §, same locality, shrubs, etc., 3 Aug. 1974, J. Murphy leg. (MMUE G7572.10); 1 `’, Nairobi, Langata, ca $1^{\circ} 21^{\prime} \mathrm{S}, 36^{\circ} 42^{\prime} \mathrm{E}$, swampy area with Sesbania, 29 Dec. 1985, A. Russell-Smith leg. (MMUE G7583.1); 2 우, Nairobi, grounds of National Museum, ca $1^{\circ} 16^{\prime} \mathrm{S}, 36^{\circ} 48^{\prime} \mathrm{E}$, in long grass, 12 Nov. 1982, A. Russell-Smith leg. (MMUE G7583.2).

\section{Description}

Male (lectotype, Figs 40-46)

Measurements: carapace: 2.65 long, 1.85 wide, 1.40 high. Abdomen: 2.70 long, 2.00 wide. Ocular area: 1.00 long, 1.43 wide anteriorly, 1.36 wide posteriorly. Cheliceral length 0.55 . Clypeal height 0.13 . Diameter of AME 0.40. Length of leg segments: I $1.28+0.70+0.75+0.60+0.50$ (3.83); II $1.30+0.75$ $+0.68+0.60+0.45(3.78) ;$ III $1.80+0.90+1.15+1.45+0.60(5.90) ;$ IV $1.75+0.85+1.25+1.65+$ 0.70 (6.20). Leg formula IV,III,I,II. Leg spination: I: Fm d 0-1-5; Pt pr 0-1-0; Tb pr 1-1, v 1-1-2ap; Mt pr 1-1ap, v 2-2ap. II: Fm d 0-1-2-4; Pt pr 0-1-0; Tb pr 1-1, v 1-1-2ap; Mt pr 1-1ap, v 2-2ap. III: Fm d 0-1-2-5; Pt pr and rt 0-1-0; Tb d 1-0-0, pr and rt 1-1-1-1, v 1-0-2ap; Mt d 2-2, pr and rt 1-1-2ap, v 0-12ap. IV: Fm d 0-1-1-5; Pt pr and rt 0-1-0; Tb d 1-0-0, pr and rt 1-1-1-1, v 1-0-1ap; Mt d 2-0-0, pr and rt 1-1-2ap, v 1-1-2-2ap. Coloration (in alcohol; Figs 45-46). Carapace light red-brown, with dark brown eye field. Clypeus brownish yellow, sparsely covered with long white hairs. Sternum yellow, covered with long white hairs. Endites (Fig. 13), labium and chelicerae yellow. Abdomen: dorsum brown, with large, brown-shining scutum covering its anterior half; sides and venter bright yellow, with sparse brown speckles. Book-lung covers bright yellow. Spinnerets yellow, but the distal pair with dark brown tips. All legs orange yellow, except for darker legs I, with Tb ventrally and Mt and Tr entirely dark brown. Palps 

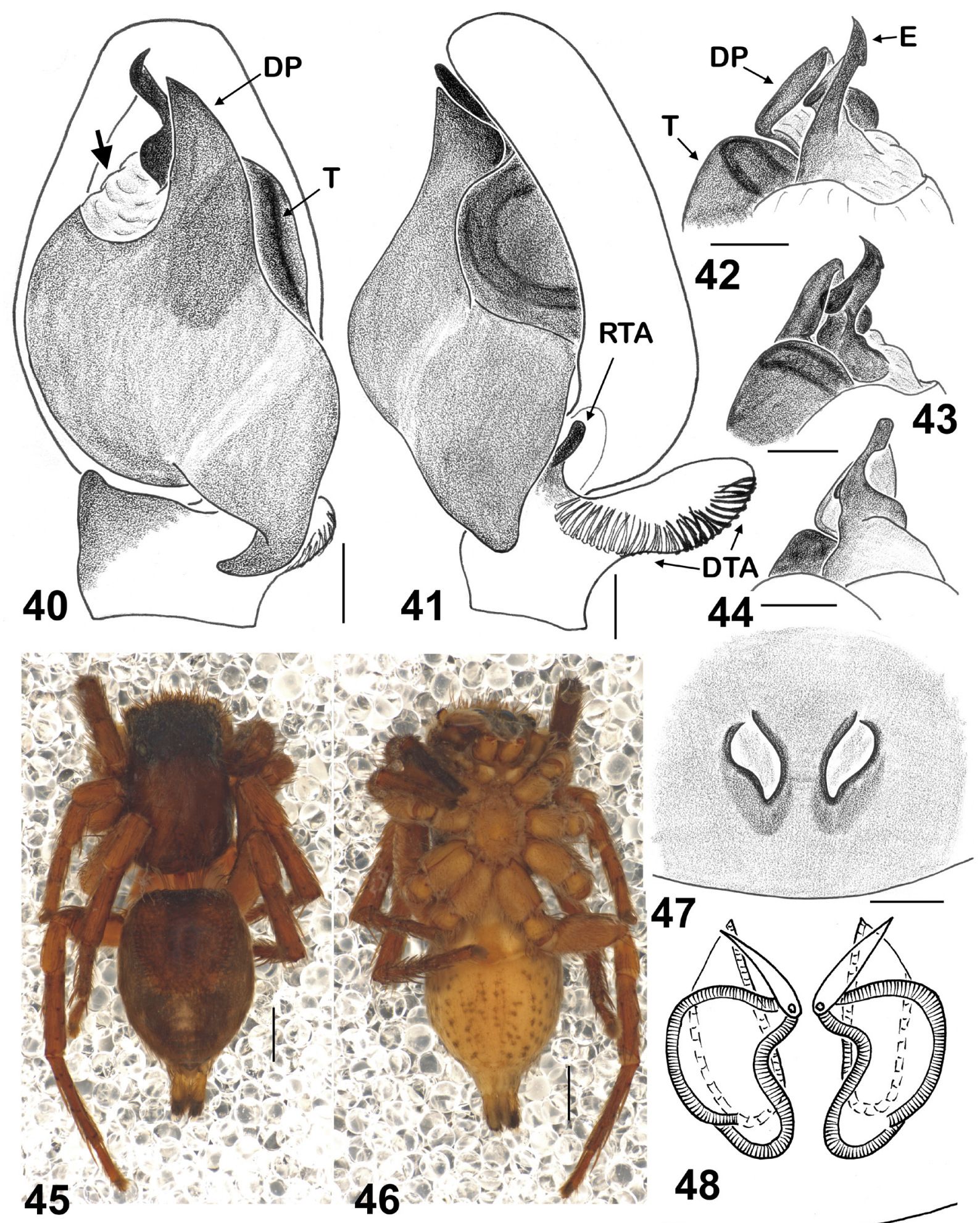

Figs 40-48. Stenaelurillus albopunctatus Caporiacco, 1949, lectotype, $ð$ and paralectotype,, . 40. Male palp, ventral view. 41. Male palp, retrolateral view. 42. Embolic division, dorsal view. 43. Embolic division, retrolateral view. 44. Embolic division, median view. 45. $\partial^{\lambda}$, dorsal view. 46. $\widehat{\partial}$, ventral view. 47. Epigyne, ventral view. 48. Spermathecae, dorsal view. Abbreviations: see Material and methods. Scale bars: $40-44,47-48=0.1 \mathrm{~mm} ; 45-46=1 \mathrm{~mm}$. 
yellowish, cymbium dorsally covered with white hairs. Palpal structure as in Figs 40-44: VTA bulgeshaped; RTA spatula-shaped, directed anteriad; DTA massive and obtuse, bearing a row of thick bristles along its entire length, also with bristles situated in its proximal half that are transparent (whitish) and sometimes poorly visible, which is why they were not illustrated by some earlier authors (e.g., Wesołowska, 2014b: fig. 1B); the tegulum small and poorly seen; the functional tegulum wide and elongated, with well-developed proximal (PP) and distal (DP, as triangular concave plate) projections; the embolus relatively short and thick, with an anvil-shaped base.

Female (paralectotype)

The specimen is badly damaged, with the carapace and abdomen being detached from each other and with almost all legs and both palps being detached from the carapace. Measurements: carapace: 3.10 long, 2.30 wide, 1.65 high. Abdomen: 4.20 long, 3.20 wide. Ocular area: 1.28 long, 1.63 wide anteriorly, 1.63 wide posteriorly. Cheliceral length 0.68 . Clypeal height 0.35 . Diameter of AME 0.43 . Length of leg segments: I $1.50+0.80+0.75+0.70+0.45(4.20)$; II $1.53+0.75+0.83+0.75+$ 0.55 (4.41); III $2.40+1.18+1.40+1.80+0.90$ (7.68); IV $2.30+1.00+1.50+2.05+0.75(7.60)$.

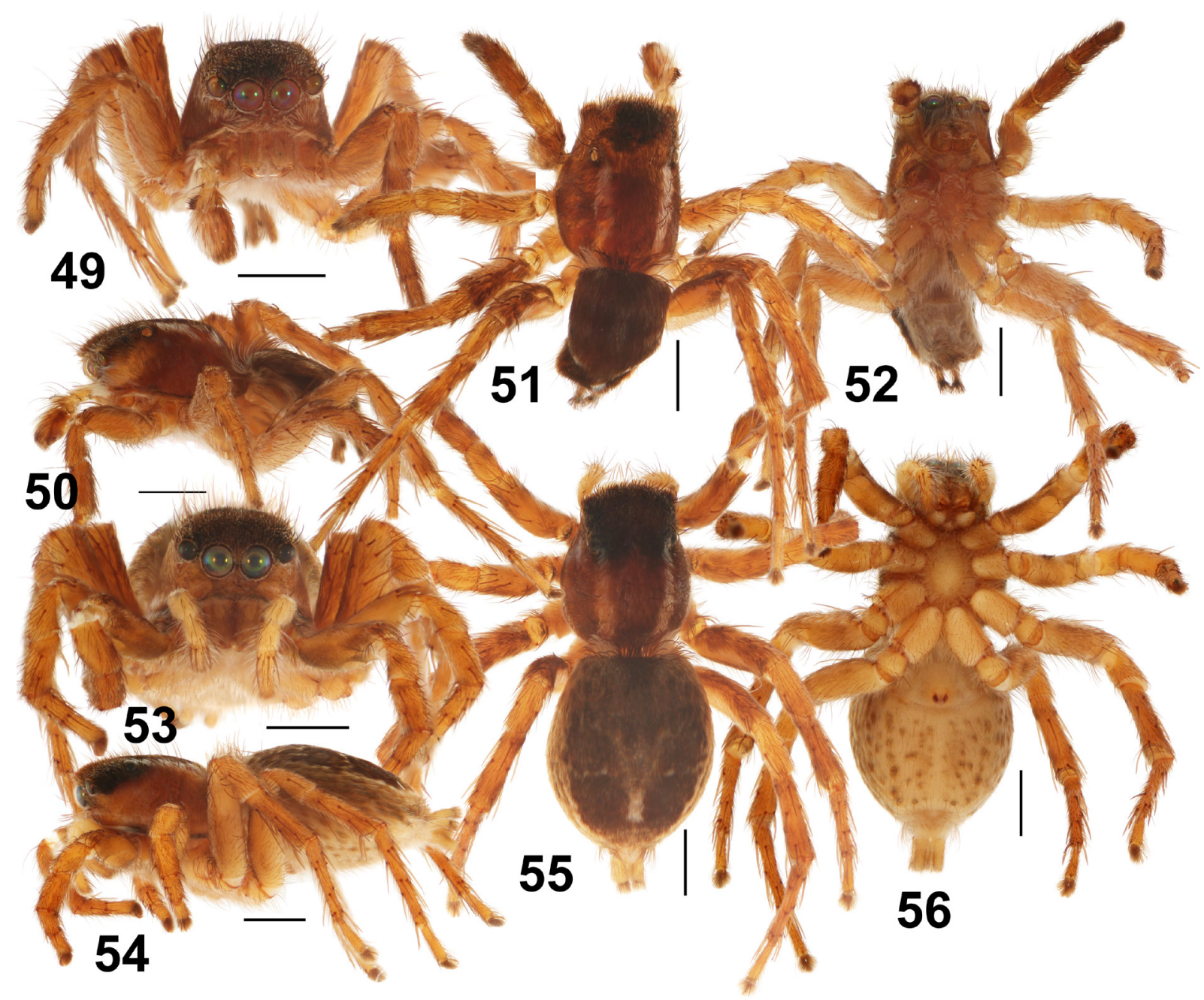

Figs 49-56. Stenaelurillus albopunctatus Caporiacco, 1949 from Kenya (Nairobi), general appearance. 49-52. §̊ (Langata, MMUE G7583.1). 53-56. ๆ (grounds of National Museum, MMUE G7583.2). Scale bars: $1 \mathrm{~mm}$. 
Leg formula III,IV,II,I. Leg spination: I: Fm d 0-1-1-5; Pt pr 0-1-0; Tb pr 1-1ap, v 2ap; Mt pr and rt 1-1ap, v 2-2ap. II: Fm d 0-1-2-5; Pt pr 0-1-0; Tb pr 1-1ap; Mt d, pr and rt 1-1ap, v 2-2ap. III: Fm d 0-1-2-5; Pt pr and rt 0-1-0; Tb pr and rt 1-1-1-1, v 1-0-2ap; Mt d 2-2, pr and rt 1-0-2ap, v 0-1-0. IV: Fm d 0-1-1-5; Pt pr and rt 0-1-0; Tb pr and rt 1-1-1-1, v 1-1-2ap; Mt d 1-1, pr and rt 1-1-2ap, v 1-22ap. Coloration (in alcohol; Figs 53-56). Yellow, tinged with brown, eye field dark brown. Clypeus yellowish, tinged with brown. Sternum, endites and labium bright yellow. Chelicerae yellow, anteriorly tinged with brown. Abdomen: dorsum yellow, densely covered with brown recumbent scales, with a poorly marked longitudinal yellow stripe; sides and venter bright yellow, with sparse brown speckles. Book-lung covers bright yellow. Spinnerets light brown, but the dorsal pair with dark brown tips. All legs yellow, but legs I and II visibly tinged with brown. Palps yellow. Epigyne and spermathecae as in Figs 47-48: epigynal plate flat, round, with a pair of ovoid copulatory openings situated rather close to each other (by less than their diameter); epigynal pocket absent; insemination ducts short, tube-shaped; primary spermathecae large, bean-shaped.

\section{Distribution}

Several localities in Kenya (Fig. 511) (Caporiacco 1949; Wesołowska 2014b; present data).

Stenaelurillus arambagensis (Biswas \& Biswas, 1992)

Figs 57-62, 509

Marpissa arambagensis Biswas \& Biswas, 1992: 390, figs 20-22 (Do+). Holotype in the National Zoological Collection, Zoological Survey of India, Kolkata, India; not examined.

Stenaelurillus digitus Prajapati, Murthappa, Sankaran \& Sebastian, 2016: 327, figs 1C-D, 6A-D, 7A-E, 8A-C, 9A-D (D̊̄o $)$. Synonymized by Caleb et al. (2017).

\section{Diagnosis}

This species can easily be separated from all other species of Stenaelurillus, except for S. albus Sebastian, Sankaran, Malamel \& Joseph, 2015, by the presence of the long, finger-shaped distal projection of the functional tegulum (Fig. 57: DP), the unique feature of S. arambagensis and S. albus. The only difference between the two related species is the presence of a more prominent, stout embolus in $S$. arambagensis (Fig. 57; Caleb et al. 2017: fig. 14), which is not visible in ventral view in S. albus (see Sebastian et al. 2015: fig. 2E, G), provided the latter authors correctly illustrated the embolic division. Females of both species differ in the shape of the primary spermathecae: round in S. arambagensis (see Caleb et al. 2017: fig. 17) and C-shaped in S. albus (see Sebastian et al. 2015: fig. 3B-C).

\section{Material examined}

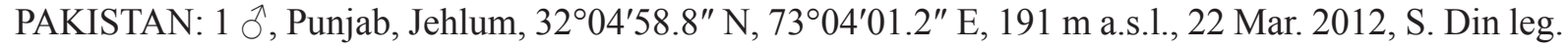
(CBGO).

\section{Remarks}

This species has been (re)described and illustrated in detail by Prajapati et al. (2016: sub. S. digitus) and Caleb et al. (2017). It is worth mentioning that both Sebastian et al. (2015) and Prajapati et al. (2016) mis-coded sclerites of the embolic division in $S$. albus and $S$. arambagensis respectively. What they coded as the 'embolus' is actually the distal projection of the functional tegulum; see above under 'Morphological notes' for further details. The true embolus is seen in S. arambagensis as the stout, pointed sclerite partly hidden behind the tegular tip (E on Fig. 57). 


\section{Distribution}

India (Andhra Pradesh, Gujarat, Maharashtra, West Bengal) and Pakistan (Punjab) (Fig. 509) (Caleb et al. 2017; present data).

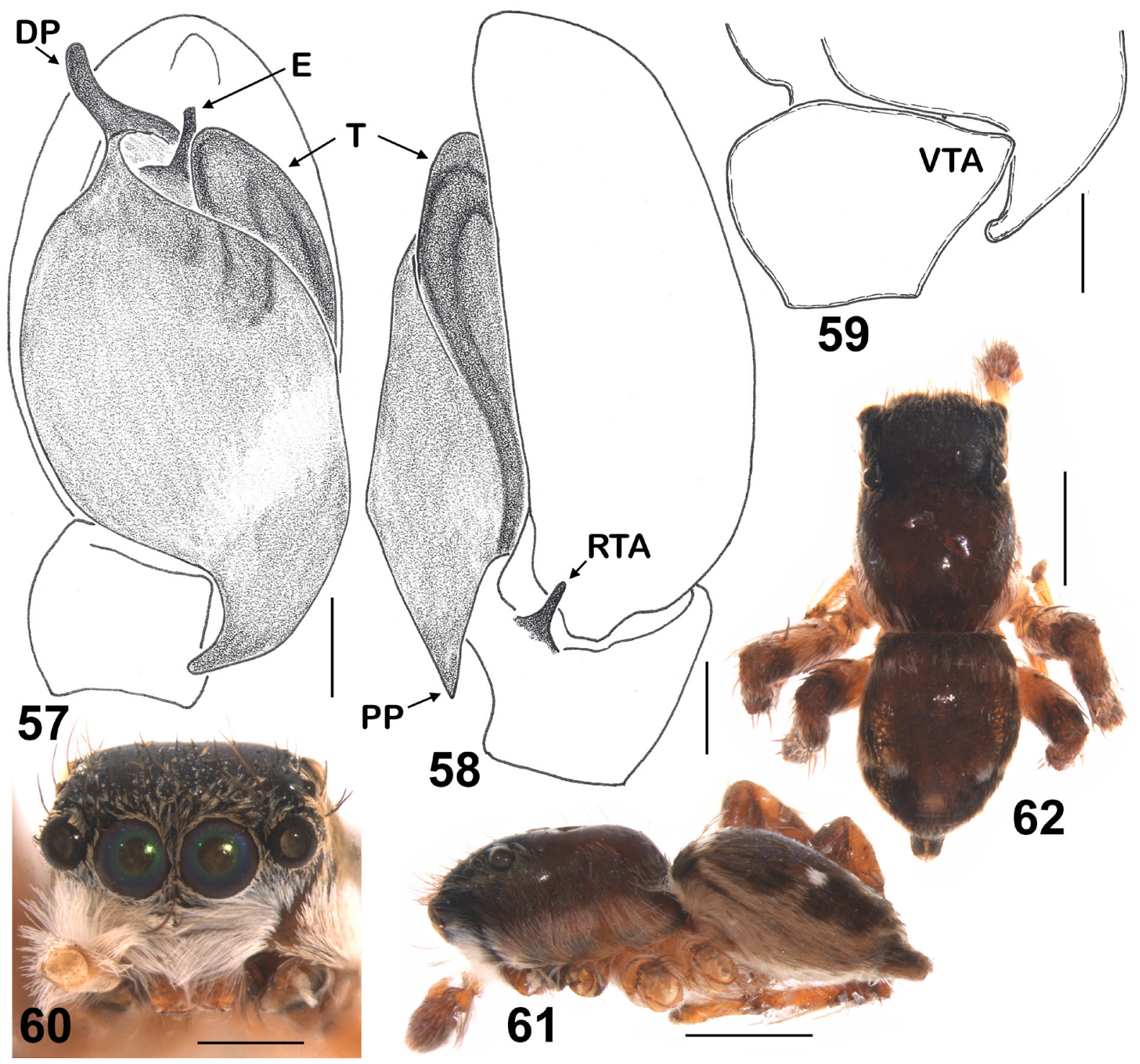

Figs 57-62. Stenaelurillus arambagensis (Biswas \& Biswas, 1992), ठ̊ from Pakistan (Jehlum). 57. Male palp, ventral view. 58. Male palp, retrolateral view. 59. VTA, median view. 60. Clypeus, front view. 61. Body, lateral view. 62. Body, dorsal view. Abbreviations: see Material and methods. Scale bars: $57-59=0.1 \mathrm{~mm} ; 60=0.5 \mathrm{~mm} ; 61-62=1 \mathrm{~mm}$. 


\section{Stenaelurillus bandama sp. nov. urn:1sid:zoobank.org:act:1EADE375-7C70-4DF0-9C6D-4DB7A9451C4E}

Figs $63-78,510$

Stenaelurillus hirsutus - Wesołowska 2014b: 603-604; in part, the specimens from Côte d'Ivoire only.

\section{Diagnosis}

The males of the new species are most similar to those of S. hirsutus (Figs 239-242, 246-251), from which they can easily be distinguished by the narrower, nail-shaped embolus (ribbon-shaped in S. hirsutus) and the wider vertical white stripes on the clypeus (cf. Figs 74, 76, 253, 255). The females of S. bandama sp. nov. are most similar to those of S. iubatus (Figs 278-279), but can be distinguished from them by the longer epigynal pocket and the shorter insemination ducts. See also remarks below under Diagnosis of $S$. striolatus.

\section{Etymology}

The specific epithet refers to the Bandama River, the longest river in Côte d'Ivoire, on which the type locality is situated.

\section{Material examined}

\section{Holotype}

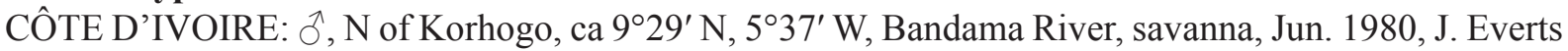
leg. (MRAC 172.449).

\section{Paratypes}

CÔTE D'IVOIRE: 1 q, Bandama River, $9^{\circ} 27^{\prime} \mathrm{N}, 5^{\circ} 38^{\prime} \mathrm{W}$, edge of riverine forest, May 1980, J. Everts leg.; (MRAC 172.481); 1 O’, R.C.I. Kossou, ca $7^{\circ} 01^{\prime}$ N, $5^{\circ} 29^{\prime}$ W, humid savanna, 22-30 Jul. 1974, R. Jocqué leg. (MRAC 151.716).

\section{Description}

\section{Male (holotype)}

Measurements: carapace: 2.45 long, 1.80 wide, 1.30 high. Abdomen: 2.40 long, 1.50 wide. Ocular area: 1.00 long, 1.50 wide anteriorly, 1.40 wide posteriorly. Cheliceral length 0.65 . Clypeal height 0.35 . Diameter of AME 0.45. Length of leg segments: I $1.20+0.70+0.75+0.55+0.45$ (3.65); II $1.30+0.70$ $+0.80+0.60+0.50(3.90) ;$ III $1.90+0.80+1.35+1.40+0.60(6.05) ;$ IV $1.60+0.80+1.10+1.45+$ 0.65 (5.60). Leg formula III,IV,II,I. Leg spination: I: Fm d 0-1-1-5; Pt pr 1; Tb pr 1-1, v 1-2-2ap; Mt pr and rt 0-1ap, v 2-2ap. II: Fm d 0-1-2-5; Pt pr and rt 1; Tb pr 1-1-1, rt 1-0, v 1-1-2ap; Mt pr and rt 1-1 ap, v 2-2ap. III: Fm d 1-0-2-5; Pt pr and rt 1; Tb d 1-0-0, pr and rt 1-1-1-1, v 1-0-2ap; Mt d 1-1-0, pr and rt 1-0-2ap, v 0-2-2ap. IV: Fm d 1-0-1-5; Pt pr and rt 1; Tb d 1-0-0, pr and rt 1-1-1-1, v 1-0-2ap; Mt d 1-1-0, pr 1-1-2ap, rt 1-0-2ap, v 0-2-2ap. Coloration (in alcohol; Figs 73-78). Carapace brown, covered with dark brown recumbent scales, dorsally with two longitudinal white stripes of scales running from PLEs to the rear margin of the carapace; sides densely covered with long brownish transparent hairs. Eye field densely covered with short, protruding hairs. Clypeus brownish yellow, with vertical stripes of short and dense black hairs; central area of the clypeus and cheeks densely covered with long, whitetransparent iridescent hairs; such hairs (but shorter) also occur on the eye field. Sternum brown. Endites and labium brownish yellow. Chelicerae brown-yellow, their central parts anteriorly covered with whitetransparent iridescent hairs. Abdomen: dorsum dark brown, with two irregular transverse stripes on its anterior end and three white spots on its posterior half; venter yellow, with four longitudinal stripes of brownish hairs. Book-lung covers yellow. Spinnerets: ventral pair brown, dorsal pair dark brown. All legs brownish yellow, covered with yellow and dark brown hairs. Palps: Fm brownish yellow, dorsally 
dark brown, covered with long white hairs, apically with dark brown short hairs; Pt, Tb and cymbium brownish yellow, dorsally dark brown, retrolaterally covered with short dark brown hairs, prolaterally with long and dense white recumbent hairs. Palpal structure as in Figs 63-69: VTA looks like two low
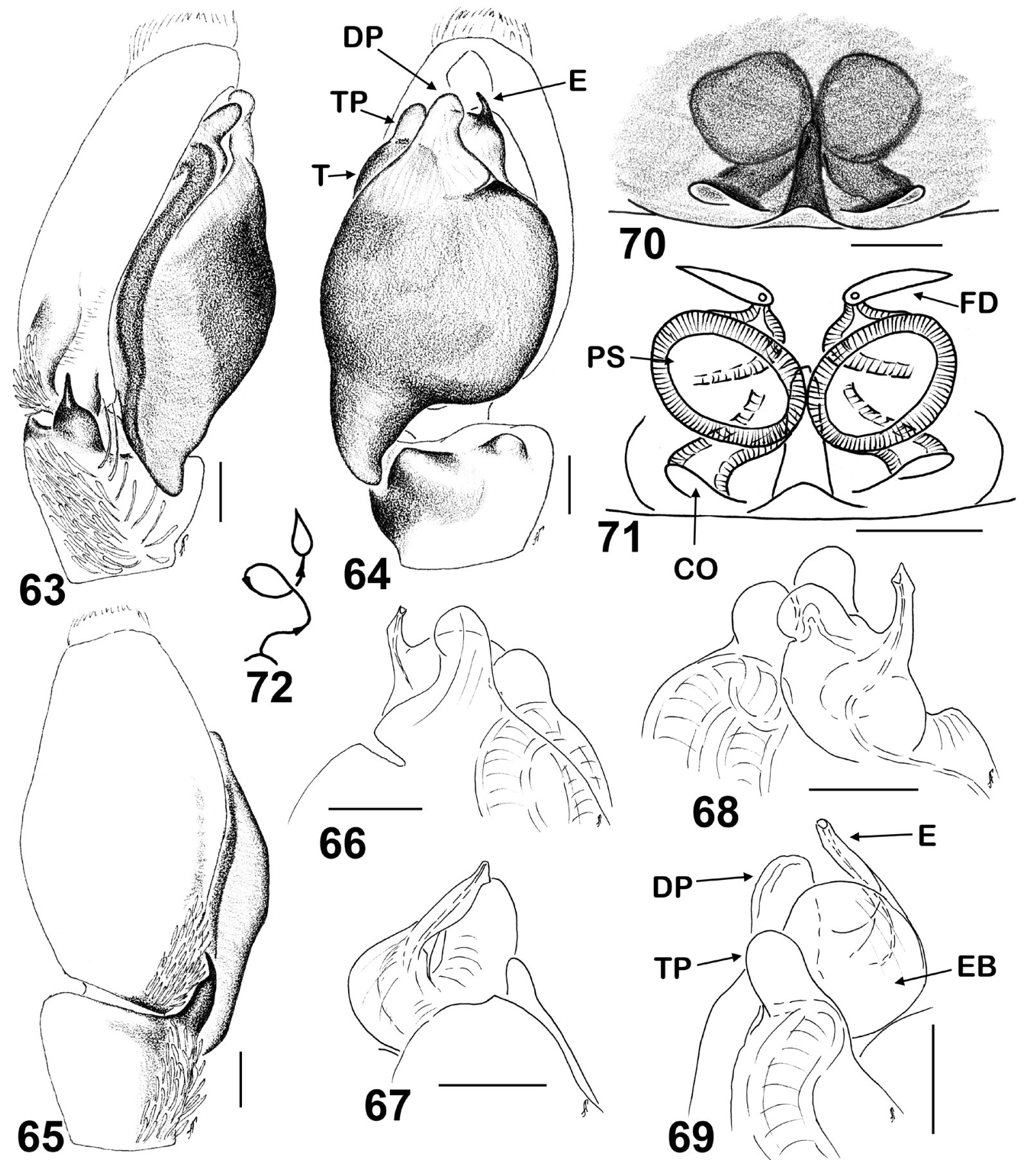

Figs 63-72. Stenaelurillus bandama sp. nov., holotype, $ð$ (63-65), paratype, $\widehat{O}(66-69)$ and paratype,, . 63. Male palp, retrolateral view. 64. Male palp, ventral view. 65. Male palp, dorsal view. 66-69. Embolic division. 66. Ventral view. 67. Median view. 68. Dorsal view. 69. Retrolateral view. 70. Epigyne, ventral view. 71. Spermathecae, dorsal view. 72. Diagrammatic course of the insemination ducts. Abbreviations: see Material and methods. Scale bars: $0.1 \mathrm{~mm}$. 
bulges; RTA short, with a wide base, sharpened apically and directed anteriad; the cymbium with a visible cymbial ventral process (CLP); the tegulum small and elongated, with a short obtuse tegular process (TP); the functional tegulum wide and elongated, with well-developed proximal (PP) and obtuse distal (DP) projections; the embolus nail-shaped, with a wide, round base.

Female (paratype MRAC 172.481)

Measurements: carapace: 2.55 long, 1.90 wide, 1.25 high. Abdomen: 3.10 long, 2.45 wide. Ocular area: 1.13 long, 1.50 wide anteriorly, 1.45 wide posteriorly. Cheliceral length 0.73 . Clypeal height 0.25 . Diameter of AME 0.43. Length of leg segments: I $1.33+0.63+0.70+0.58+0.40$ (3.64); II $1.38+0.65$ $+0.65+0.63+0.40(3.71) ;$ III $2.03+0.95+1.30+1.50+0.60(5.38) ;$ IV $1.48+0.65+1.00+1.18+$ 0.60 (4.91). Leg formula III,IV,II,I. Leg spination: I: Fm d 0-1-1-4; Pt pr 1; Tb pr 1-1, v 1-1-2ap; Mt pr

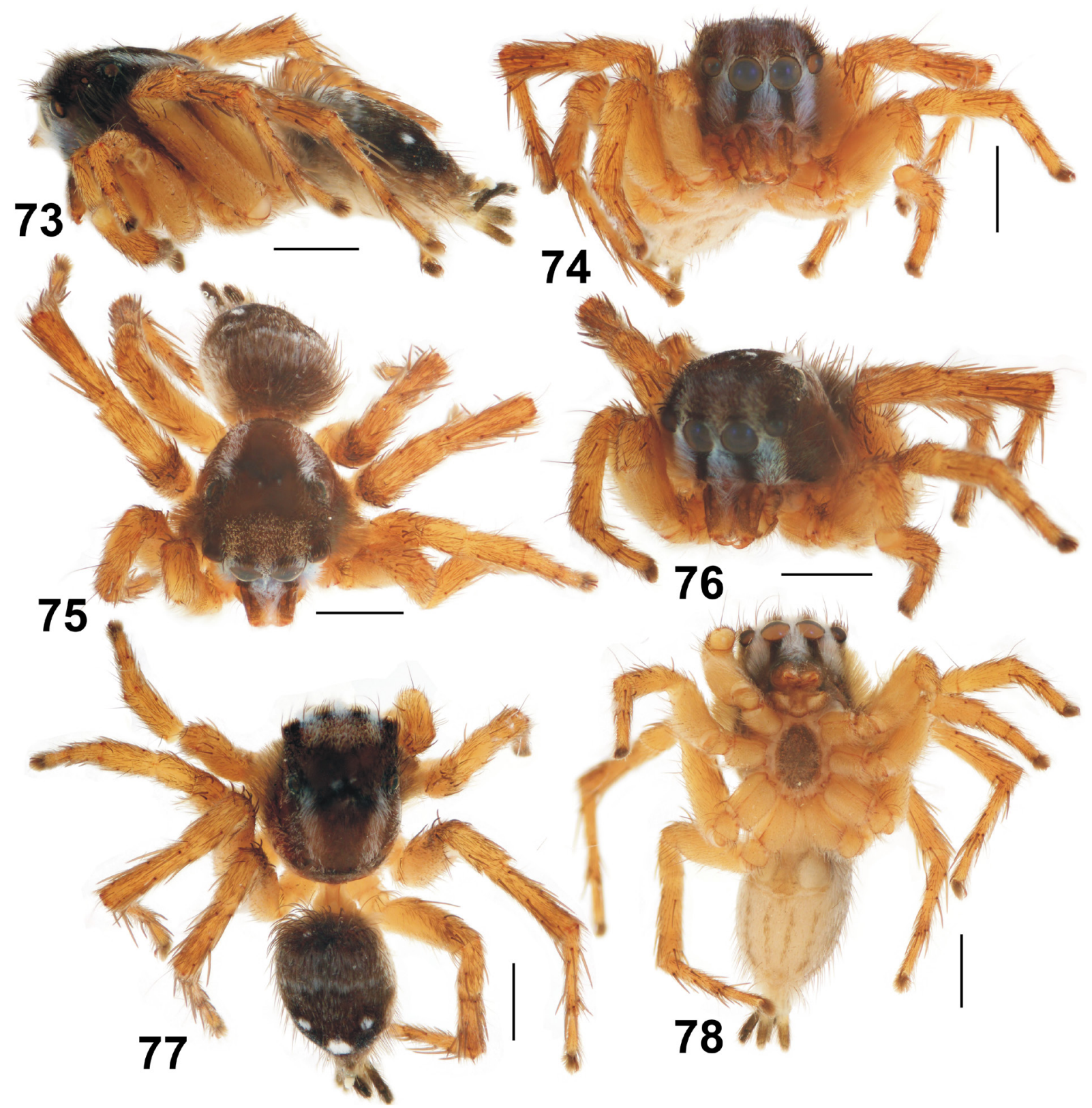

Figs 73-78. Stenaelurillus bandama sp. nov., holotype, đ̊, general appearance. Scale bars: $1 \mathrm{~mm}$. 
and rt 1ap, v 2-2ap. II: Fm d 0-1-1-5; Pt pr 1; Tb pr 1-1, v 1-1-2ap; Mt pr 1-1ap, rt 1ap, v 2-2ap. III: Fm d 0-1-2-5; Pt pr and rt 0-1-0; Tb d 1-0-0, pr and rt 1-1-1-1, v 1-0-2ap; Mt d 1-1-0, pr and rt 1-0-2ap, v 0-2-2ap. IV: Fm d 0-1-1-4; Pt pr and rt 0-1-0; Tb d 1-0-0, pr 0-1-1-1, rt 1-1-1-1, v 1-0-1ap; Mt d 1-0-0, pr 2-1-2ap, rt 1-0-2ap, v 0-2-2ap. Coloration (in alcohol, the specimen is damaged and shabby). Carapace yellow, slightly brownish tinged, covered with brown recumbent scales; eye field densely covered with short erect brown bristles; clypeus light yellow, sparsely covered with white hairs. Sternum light yellow, densely covered with white hairs. Endites, labium and chelicerae light yellow. Abdomen: dorsum brown, with an elongated ventral white spot on its posterior half; sides light yellow, with numerous brownish elongated speckles; venter light yellow. Book-lung covers yellow. Spinnerets yellow, tinged with grey. Legs I yellow, but their Fm with two brown spots at both ends of the segment. Legs II-IV and palps light yellow. Epigyne and spermathecae as in Figs 70-71: the epigynal plate flat, with a pair of transversely oriented copulatory openings situated close to the epigastric furrow; deep epigynal pocket present; the insemination ducts short, tube-shaped; the primary spermathecae large, round, with extended distal ends bearing the festilization ducts.

\section{Distribution}

Few localities in Côte d'Ivoire (Fig. 510) (Wesołowska 2014b: sub. S. hirsutus; present data).

Stenaelurillus belihuloya sp. nov. urn:lsid:zoobank.org:act:6D137A2F-C833-4DFE-BFC7-0ECB2A7E3F02

Figs 79-86, 509

\section{Diagnosis}

The male of the new species is most similar with that of $S$. albus described recently from Western Ghats in India (cf. Sebastian et al. 2015: Figs 2A-G, 8A-I), but can be readily distinguished from it by the different shape of the embolus and retrolateral tibial apophsyis, as well as by the body coloration: viz., the absence of a wide white transverse band at the anterior end of the dorsum, the less-pronounced white marginal band on the carapace, and the monochrome palp colour.

\section{Etymology}

The specific epithet is a noun in apposition taken from the type locality, the village Belihuloya in the Sabaragamuwa Province of Sri Lanka.

\section{Material examined}

Holotype

SRI LANKA: $\widehat{\partial}$, Sabaragamuwa Prov., Ratnapura Distr., Belihuloya, 643'06.2" N, 8046'26.7" E, 10-14 Feb. 1969, F. Hill leg. (ZMTU).

\section{Description}

\section{Male}

Measurements: carapace 2.50 long, 1.75 wide and 1.13 high at PLE. Ocular area: 1.05 long, 1.50 wide anteriorly and 1.45 wide posteriorly. Diameter of AME 0.46. Clypeal height 0.19 , chelicera length 0.57 . Abdomen 2.25 long, 1.63 wide. Length of leg segments: I $1.20+0.60+0.73+0.50+0.50$ (3.53); II $1.20+0.63+0.65+0.61+0.40(3.49) ;$ III $1.75+0.95+1.08+1.30+0.55(5.63) ;$ IV $1.58+0.65+$ $1.04+1.35+0.55$ (5.17). Leg formula III,IV,I,II. Leg spination: I: Fm d 0-1-1-3; Tb pr 1-2, v 1-1-2ap; Mt pr 1-1ap, rt 1 ap, v 2-2ap. II: Fm d 0-1-0-4; Pt pr 0-1-0; Tb pr 1-1, v 1-1-2ap; Mt pr 1-1ap, rt 1ap, v 2-2ap. III: Fm d 0-1-1-3; Pt pr and rt 0-1-0; Tb pr and rt 1-1-1, v 1-0-2; Mt d 1-1, pr and rt 1-0-2ap, v 0-1-2ap. IV: Fm d 0-1-1-4; Pt pr and rt 0-1-0; Tb d 1-0, pr and rt 1-1, v 1-0-2ap; Mt d and pr 1-1- 
2ap, rt 0-1-2ap. Coloration (in alcohol; Figs 84-86). Carapace brown, eye field dark brown, almost black; thorax with black radial patches and a wide white marginal band; clypeus densely covered with white hairs. Sternum, endites and labium yellow, tinged with brownish. Chelicerae brownish yellow. Abdomen: dorsum brown, with a large shiny scutum occupying the anterior half and with a pair of white round spots on its rear third; sides brownish yellow, covered with white scales; venter yellow. Book-lung covers and spinnerets yellow, gently brownish tinged. Legs I and II brown, legs III and IV brown with yellow (semi-rings), coxae III and IV completely yellow. Palps yellow, tinged with brown. Palpal structure as in Figs 79-83: VTA bulge-shaped; RTA short, hook-shaped, sharpened apically and directed anteriad; the cymbium with a visible cymbial ventral process (CLP); the tegulum small and elongated, with a finger-shaped tegular process (TP); the functional tegulum wide and elongated, with

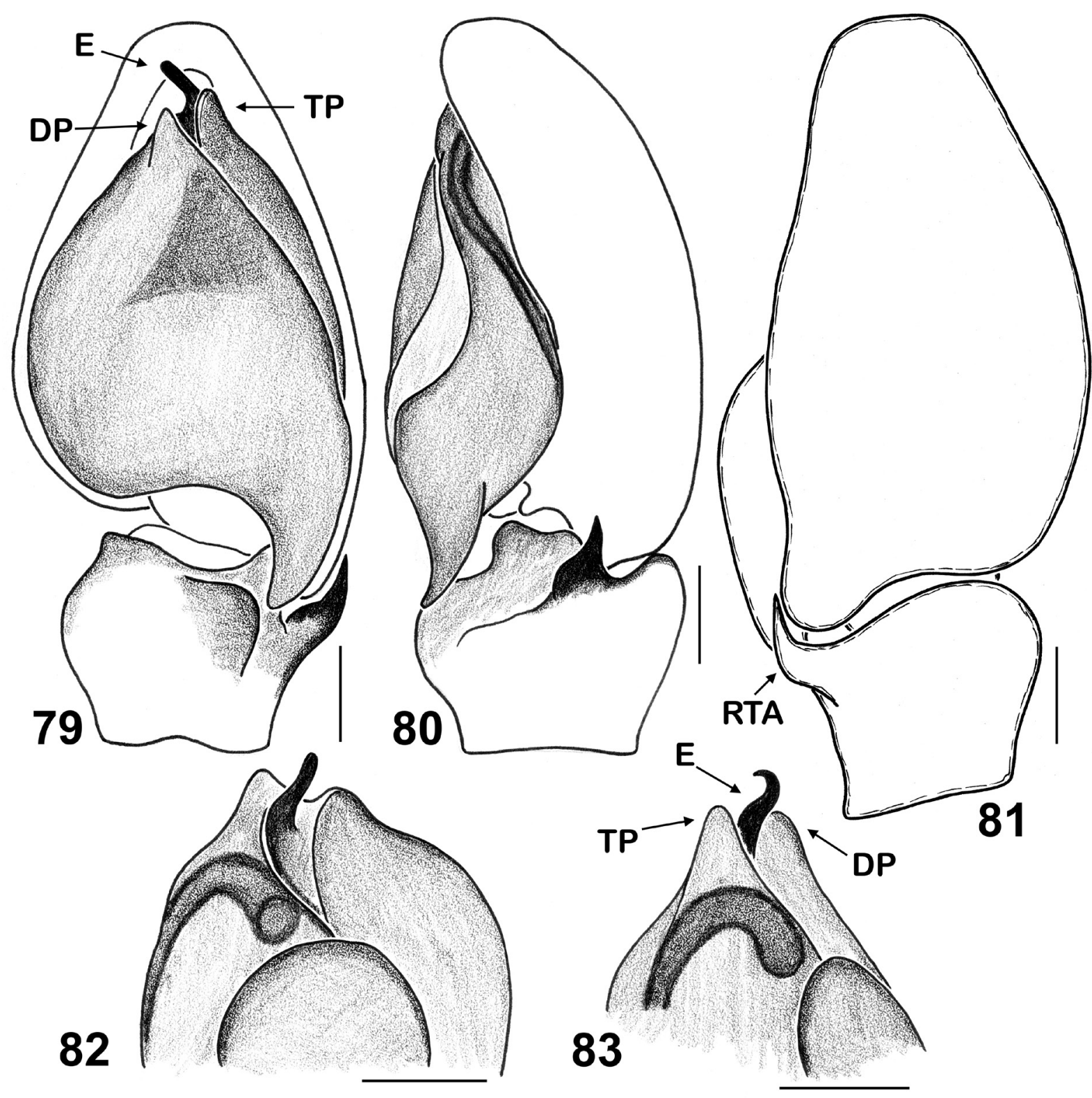

Figs 79-83. Male palp of Stenaelurillus belihuloya sp. nov., holotype. 79. Ventral view. 80. Retrolateral view. 81. Dorsal view. 82. Embolic division, dorsal view. 83. Embolic division, retrolateral view. Abbreviations: see Material and methods. Scale bars: $0.1 \mathrm{~mm}$. 
well-developed proximal (PP) and poorly-developed, obtuse distal (DP) projections; the embolus fingershaped, with a wide base that is fused with the apical edge of the functional tegulum.

\section{Female}

Unknown.

\section{Distribution}

The type locality only (Fig. 509).

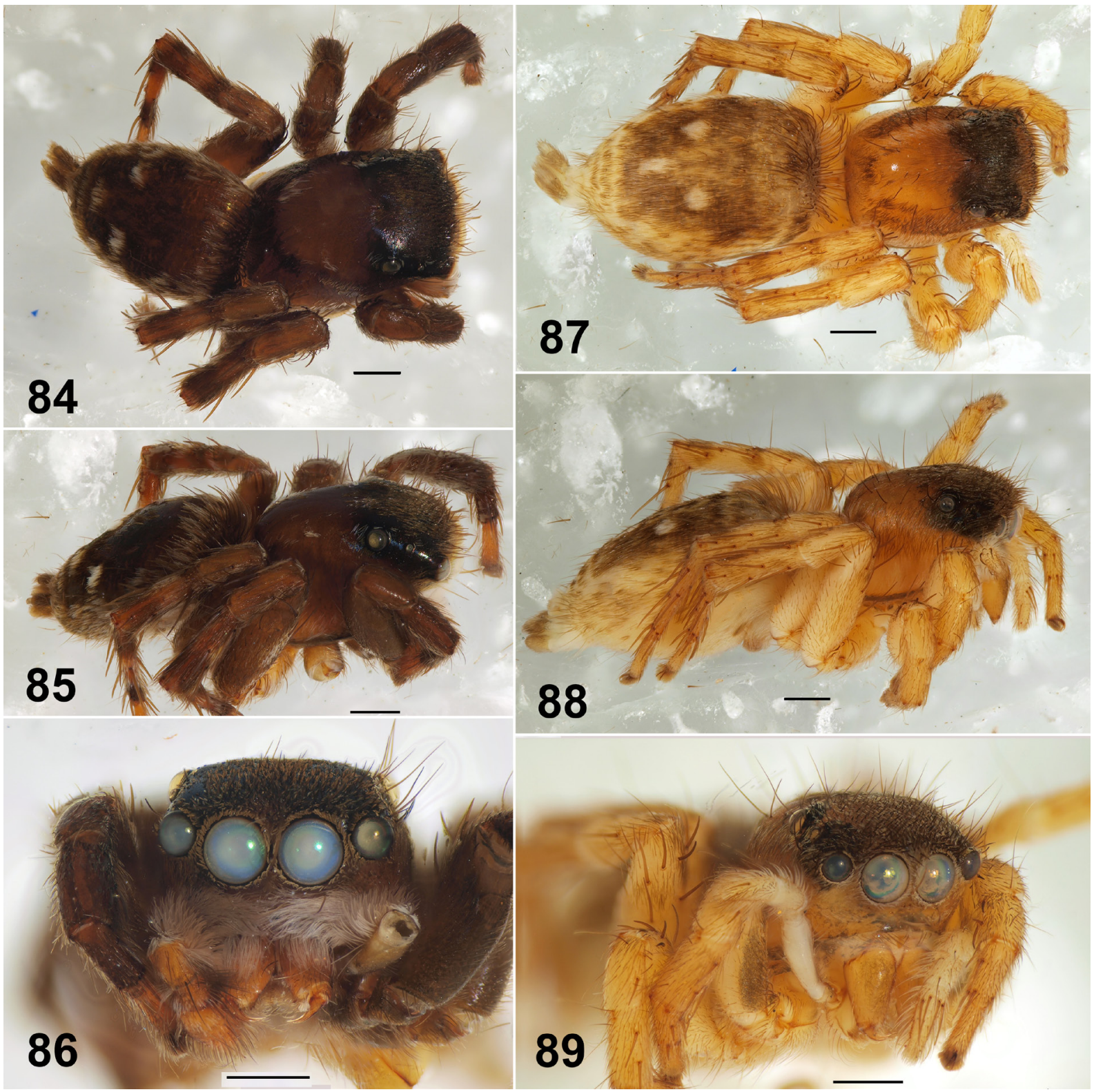

Figs 84-89. General appearance of the holotype of Stenaelurillus belihuloya sp. nov. (84-86) and a female of $S$. lesserti Reimoser, 1934 from Sri Lanka (Pollonaruwa) (87-89). Scale bars: $1 \mathrm{~mm}$. 
Stenaelurillus brandbergensis (Wesołowska, 2006) comb. nov.

Figs 90-104, 511

Mashonarus brandbergensis Wesołowska, 2006: 239, figs 63-77 (D ${ }^{\lambda}$ ) $)$; the ${ }^{1}$ holotype in the State Museum of Namibia (Windhoek), not examined; the paratypes in MRAC, examined.

\section{Diagnosis}

By the conformation of the copulatory organs (the well-marked proximal projection of the functional tegulum, the stiletto-shaped embolus and the developed cymbial lateral projection, etc.), S. brandbergensis comb. nov. is most similar to $S$. guttatus comb. nov. and S. pseudoguttatus sp. nov. (cf. Figs 90-94 and 416-420). The males of $S$. brandbergensis comb. nov. differ in having the RTA visibly directed ventrad (distad in the related species) and the distal projection wide and obtuse (pointed in S. guttatus comb. nov., absent in S. pseudoguttatus sp. nov.). The females differ in having very short insemination ducts (long in S. guttatus comb. nov., not yet known in S. pseudoguttatus sp. nov.; Fig. 100). Besides, both sexes of S. brandbergensis comb. nov. can easily be distinguished from all species of Stenaelurillus, except for S. marusiki from Iran (see Logunov 2001b: fig. 30), by the presence of a pair of wide, longitudinal white stripes on the dorsum (Figs 96, 102).

\section{Material examined}

\section{Paratypes}

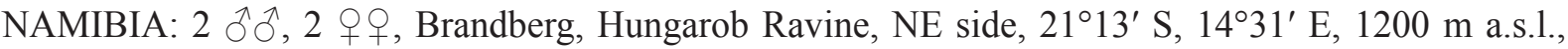
3-13 Nov. 1998, A. Kirk-Spriggs leg. (MRAC 216.021).

\section{Other material}

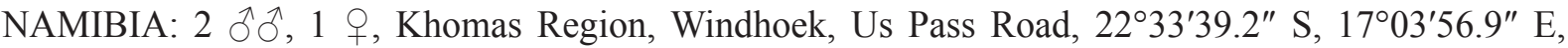
13 Nov. 1974, S. Endrödy-Younga leg. (TMSA 21541).

\section{Remarks}

We have been unable to borrow the holotype of this species, because it was impossible to post them to us from Namibia. Therefore, the present diagnosis and redescription are based on the paratypes of Mashonarus brandbergensis retained at the MRAC (216.021).

\section{Description}

\section{Male (paratype)}

Measurements: carapace: 2.15 long, 1.55 wide, 1.05 high. Abdomen: 2.15 long, 1.35 wide. Ocular area: 1.08 long, 1.28 wide anteriorly, 1.20 wide posteriorly. Cheliceral length 0.68 . Clypeal height 0.13 . Diameter of AME 0.38. Length of leg segments: I $1.30+0.65+0.88+0.73+0.48$ (4.04); II $1.25+0.65$ $+0.73+0.65+0.38(3.66)$; III $1.53+0.78+0.93+1.15+0.45(4.84) ;$ IV $1.35+0.63+0.95+1.25+$ 0.50 (4.68). Leg formula III,IV,I,II. Leg spination: I: Fm d 0-1-1-4; Tb pr 1-1, v 1-1-2ap; Mt pr 1ap, v 2-2ap. II: Fm d 0-1-1-5; Tb pr 1-1, v 1-1-2ap; Mt pr 1-1ap, rt 1ap, v 2-2ap. III: Fm d 0-1-2-4; Pt pr and rt 0-1-0; Tb d 1-0-0, pr and rt 1-1-1, v 1-0-2ap; Mt d 0-1-0, pr and rt 1-0-2ap, v 0-2-2ap. IV: Fm d 0-11-3; Pt pr and rt 0-1-0; Tb d 1-1-0, pr and rt 1-1-1, v 1-0-2ap; Mt pr 1-1-2ap, rt 2-1-2ap, v 0-1-1-2ap. Coloration (in alcohol; Figs 95-98). Carapace brown, with black eye field, densely covered with long brown recumbent scales; there are two white longitudinal stripes of scales; clypeus light brown, sparsely covered with long white hairs. Sternum yellowish brown, densely covered with white hairs. Labium and endites yellow, tinged with brown. Chelicerae yellow, tinged with brown. Abdomen: dorsum dark brown, with a pair of white spots at its anterior margin and a large V-shaped white figure on its rear half; sides and venter yellow. Book-lung covers yellow. Spinnerets brownish. Legs: coxae and trochanters I yellow, with brown anterior sides; coxae and trochanters II-IV yellow; Fm I dark brown anteriorly and 


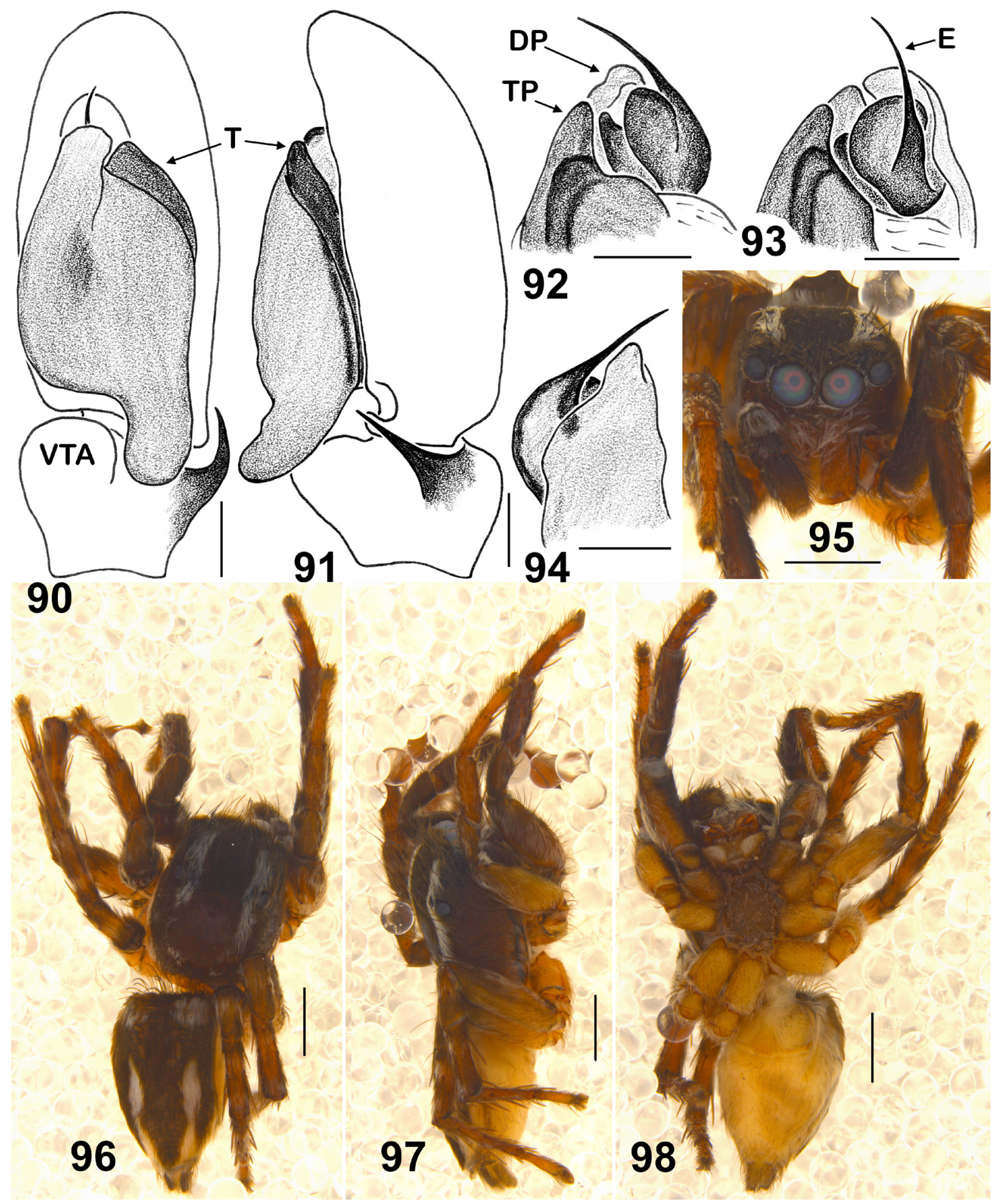

Figs 90-98. Stenaelurillus brandbergensis (Wesołowska, 2006), paratype, $\widehat{\jmath}$ from Namibia (MRAC 216.021). 90. Palp, ventral view. 91. Palp, retrolateral view. 92. Embolic division, retrolateral view. 93. Embolic division, dorsal view. 94. Embolic division, median view. 95-98. General appearance. Abbreviations: see Material and methods. Scale bars: 90-94 $=0.1 \mathrm{~mm}$; 95-98 $=1 \mathrm{~mm}$. 
yellow posteriorly, Pt and Tb I dark brown, Mt and Tr I brownish yellow; Fm II-IV yellow, with brown tips, the remaining segments of legs II-IV yellow, with brownish (semi)rings and patches. Palps brown, but its Pt and the tips of Tb dorsally densely covered with white scales. Palpal structure as in Figs 90-94: VTA bulge-shaped; RTA straight, stiletto-shaped, directed antero-ventrad; the cymbium simple, with a poorly-marked cymbial lateral process; the tegulum small, poorly marked, without a tegular process; the functional tegulum narrow-elongated, with well-developed proximal (PP) and distal (DP) projections, both being wide and obtuse; the embolus stiletto-shaped, with a wide round base.

Female (paratype)

Measurements: carapace: 2.00 long, 1.45 wide, 0.85 high. Abdomen: 2.00 long, 1.40 wide. Ocular area: 0.95 long, 1.15 wide anteriorly, 1.13 wide posteriorly. Cheliceral length 0.50 . Clypeal height 0.18 . Diameter of AME 0.38. Length of leg segments: I $1.08+0.53+0.68+0.50+0.38$ (3.17); II $1.03+0.55$ $+0.60+0.50+0.30(2.98) ;$ III $1.40+0.70+0.80+1.05+0.45(4.40) ;$ IV $1.30+0.55+0.90+1.15+$ 0.55 (4.45). Leg formula IV,III, I,II. Leg spination: I: Fm d 0-1-1-4; Tb pr 1-1, v 1-2-2ap; Mt v 2-2ap. II: Fm d 0-1-1-4; Tb pr 1-0, v 1-1-2ap; Mt pr 1-1ap, v 2-2ap. III: Fm d 0-1-2-4; Pt pr and rt 0-1-0; Tb d 1-0, pr and rt 1-1-1, v 1-0-2ap; Mt d 1-1-0, pr and rt 1-0-2ap, v 0-1-2ap. IV: Fm d 0-1-1-3; Pt pr and rt 0-1-0; Tb d 1-0-0, pr and rt 1-1-1, v 1-2ap; Mt d 1-0-0, pr and rt 1-1-2ap, v 1-1-2ap. Coloration (in alcohol; Figs 101-104) as in the male, but differs as follows: white stripes on the carapace wider and longer, dorsum of the abdomen with two subparallel white stripes (no white spots), and legs I are identical to others, yellow with brownish (semi)rings and patches. Epigyne and spermathecae as in Figs 99-100: the

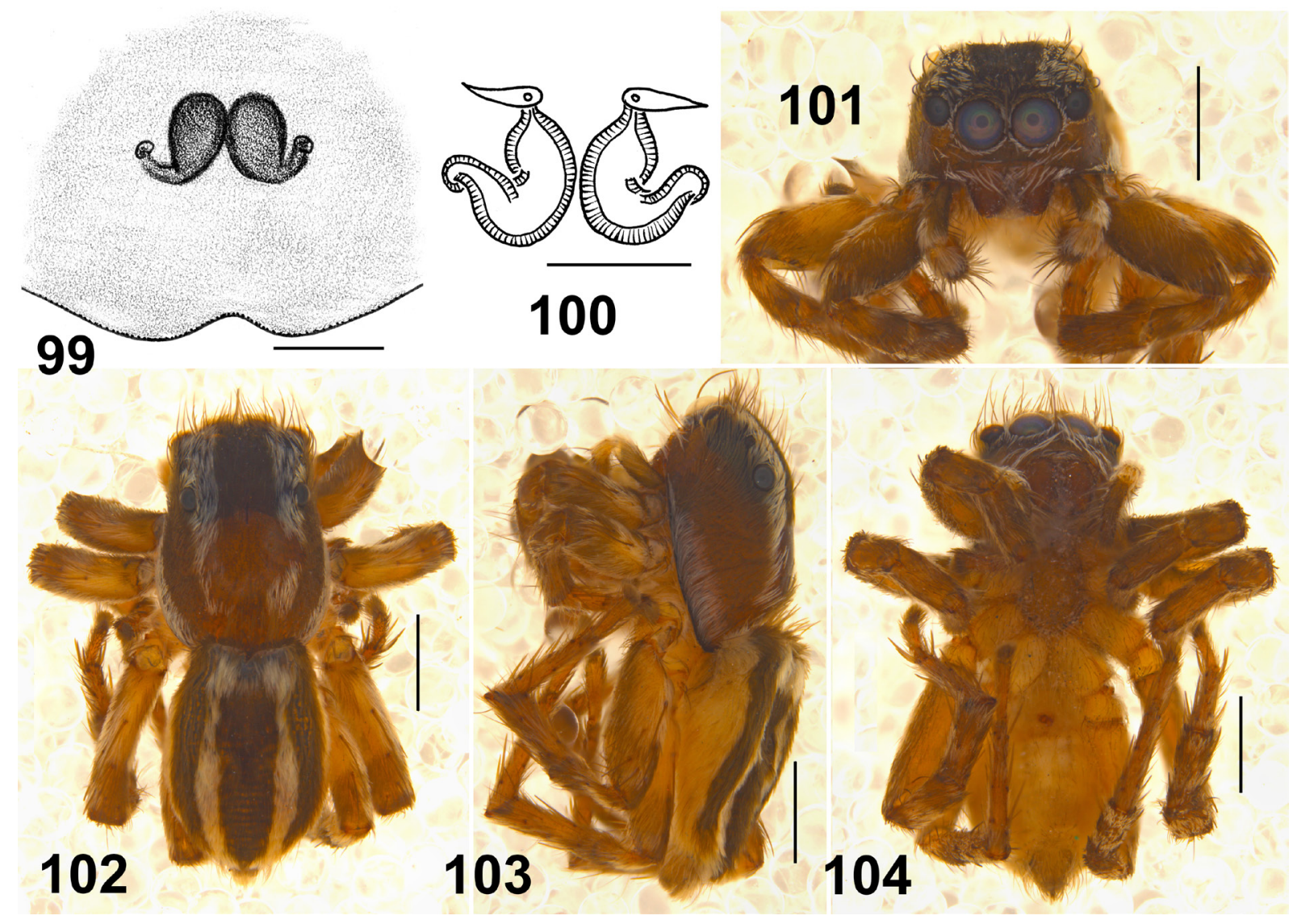

Figs 99-104. Stenaelurillus brandbergensis (Wesołowska, 2006), paratype, $q$ from Namibia (MRAC 216.021). 99. Epigyne, ventral view. 100. Spermathecae, dorsal view. 101-104. General appearance. Scale bars: $99-100=0.1 \mathrm{~mm} ; 101-104=1 \mathrm{~mm}$. 
epigynal plate flat, with no visible structures; the copulatory openings small, poorly visible and widely separated; the insemination ducts very short, directed towards each other and forming bean-shaped structures with the primary spermathecae.

\section{Distribution}

A few close localities around the Brandberg massif in Namibia (Fig. 511) (Wesołowska 2006).

Stenaelurillus darwini Wesołowska \& Russell-Smith, 2000

Figs 12, 105-118, 511

Stenaelurillus darwini Wesołowska \& Russell-Smith, 2000: 98, figs 269-276 (D $\overbrace{}^{\lambda}$ ) $)$; $\widehat{\jmath}$ holotype in MRAC, examined.

Stenaelurillus darwini - Wesołowska 2014b: 598, fig. 2A-E (D $\left.{ }^{\Uparrow}\right)$.

\section{Diagnosis}

This species can easily be distinguished from all other species of Stenaelurillus by the structure of DTA bearing a tuft of very long black bristles and the shape of the proximal projection of the functional tegulum (Figs 105-106) in the male, and by a pair of the prominent bulge-shaped protuberances of the epigyne and the conformation of the spermathecae (Figs 109-110) in the female. See also remarks below under Diagnosis of S. fuscatus.

\section{Material examined}

\section{Holotype}

TANZANIA: ${ }^{\wedge}$, Mkomazi GR, ca $4^{\circ} 00^{\prime} \mathrm{S}, 38^{\circ} 00^{\prime} \mathrm{E}$, pitfall traps in grassland, Feb. 1994, A. RussellSmith leg. (MRAC 207.976).

\section{Paratypes}

TANZANIA: 1 , , together with the holotype (MRAC 207.977); 4 $\lesssim, 2$ 우, Mkomazi GR, Ibaya camp, ca $3^{\circ} 58^{\prime}$ S, 37²6' E, pitfall traps, grassland, Feb. 1994, A. Russell-Smith leg. (MRAC 207.978).

\section{Other material}

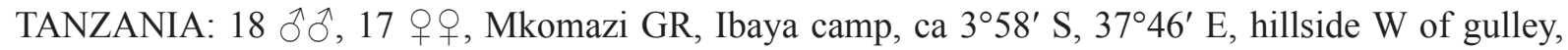

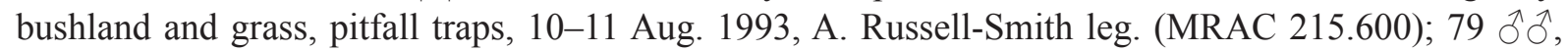

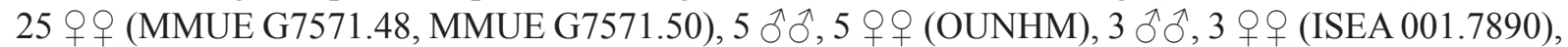
5 ふึ่, 5 우 (ZMMU), same reserve, Ibaya camp, unburned hillside grassland, pitfall traps, 1994-1996,

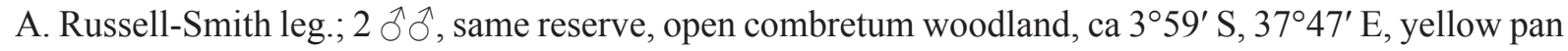
trap, 26 Nov. 1995, S. van Noort leg. (NCA 2010/4844).

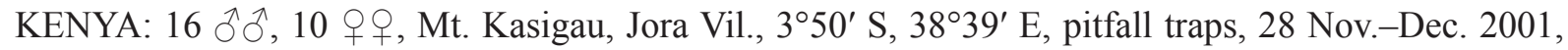
E. Selempo leg. (MRAC 213.038, MRAC 213.111, MRAC 212.901, MRAC 213.046, MRAC 213.057);

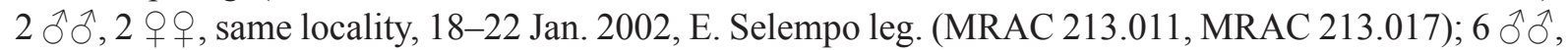
5 우, Kenya Coast, Tsavo, Taita Discovery Centre, ca $3^{\circ} 25^{\prime} \mathrm{S}, 38^{\circ} 46^{\prime}$ E, pitfall traps, 11 Nov. 2001-22 Jan. 2002, E. Selempo leg. (MRAC 213.046, MRAC 212.901, MRAC 213.121, MRAC 213.119).

\section{Description}

Male (from Tanzania, Mkomazi GR, Ibaya camp; MMUE G7571.50)

Measurements: carapace: 2.65 long, 1.90 wide, 1.10 high. Abdomen: 2.50 long, 1.85 wide. Ocular area: 1.13 long, 1.53 wide anteriorly, 1.48 wide posteriorly. Cheliceral length 0.63 . Clypeal height 0.25 . 
Diameter of AME 0.40. Length of leg segments: I $1.30+0.70+0.80+0.75+0.55$ (4.10); II $1.25+0.65$ $+0.75+0.70+0.55(3.90) ;$ III $1.85+0.90+1.15+1.50+0.55(5.95) ;$ IV $1.70+0.80+1.15+1.65+$ 0.65 (5.95). Leg formula III/IV,I,II. Leg spination: I: Fm d 0-1-1-5; Pt pr 0-1-0; Tb pr 1-1, rt 1ap, v 1-12ap; Mt pr 1-1ap, v 2-2ap. II: Fm d 0-1-2-5; Pt pr 0-1-0; Tb pr 1-1, v 1-1-2ap; Mt pr 2-1-1ap, rt 1-1ap, v 2-2ap. III: Fm d 0-1-2-5; Pt pr and rt 0-1-0; Tb d 1-0-0, pr 1-1-1-1, rt 1-1-1, v 1-0-2ap; Mt d 1-0-0, pr and rt 1-1-2ap, v 0-2-2ap. IV: Fm d 0-1-1-4; Pt pr and rt 0-1-0; Tb d 1-0-0, pr and rt 1-1-1, v 1-02ap; Mt d 1-0-0, pr 1-2-2ap, rt 1-1-2ap, v 0-1-2-2ap. Coloration (in alcohol; Figs 111-114). Carapace brownish yellow, densely covered with long brown recumbent scales and with black eye field; there are two longitudinal white stripes of scales on the thorax and two wide white marginal stripes. Clypeus and cheeks yellow, densely covered with long transparent hairs. Sternum yellow, densely covered with white hairs. Endites and labium yellow. Chelicerae yellow, tinged with brown. Abdomen: dorsum dark

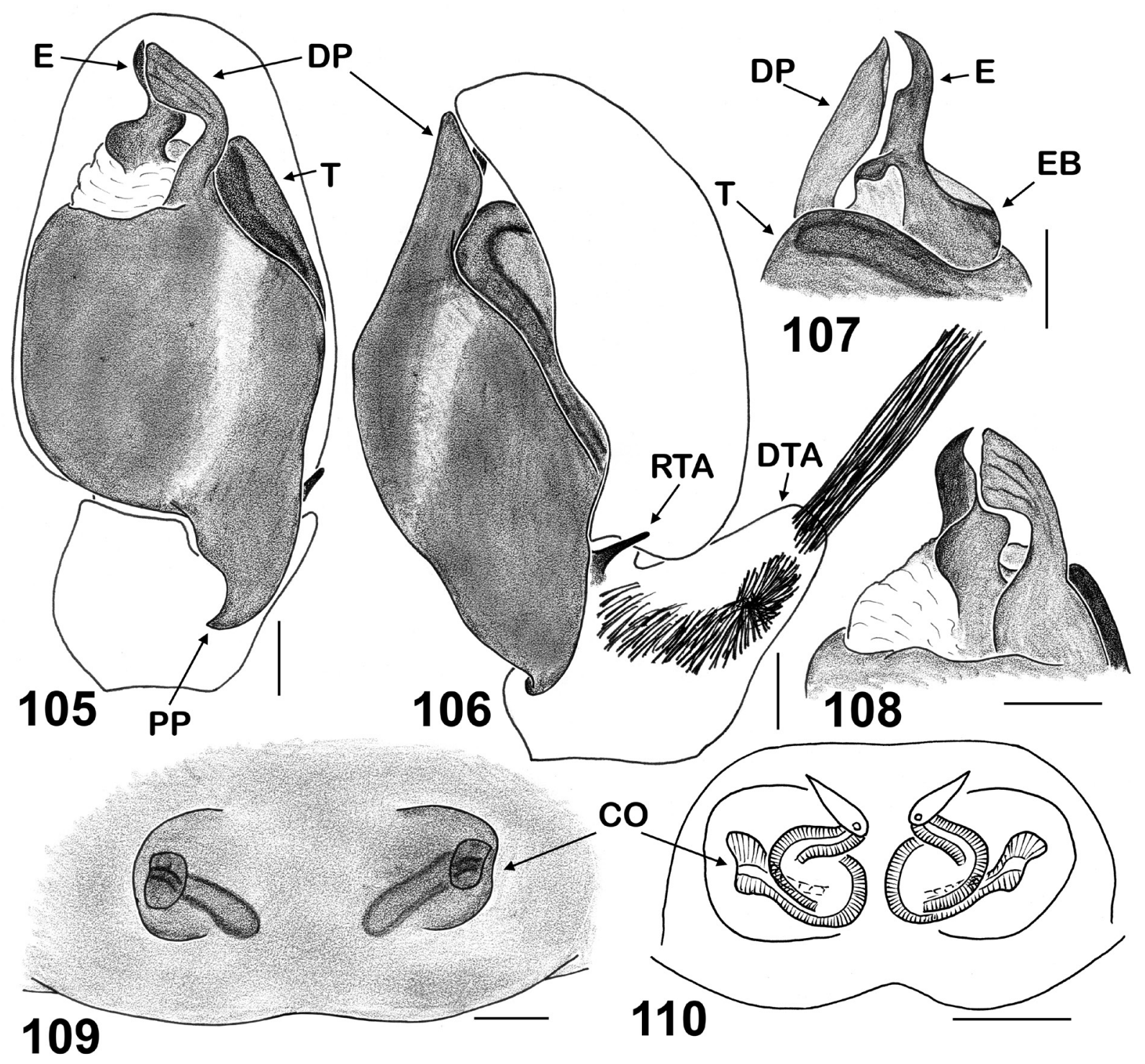

Figs 105-110. Stenaelurillus darwini Wesołowska \& Russell-Smith, 2000 from Tanzania (Mkomazi GR; MMUE G7571.48,50). 105. Male palp, ventral view. 106. Male palp, retrolateral view. 107. Embolic division, dorsal view. 108. Embolic division, median view. 109. Epigyne, ventral view. 110. Spermathecae, dorsal view. Abbreviations: see Material and methods. Scale bars: $0.1 \mathrm{~mm}$. 
brown, with a large scutum covering two thirds of the abdomen; there is a white spot in the centre of the scutum; the rear end and margins of the dorsum densely covered with brown hairs; the anterior margin of the abdomen bears bunches of very long and dense brown and white hairs; sides and venter whitish. Book-lung covers yellow. Spinnerets whitish, with brownish tinge; the dorsal pair with dark brown tips. Leg I yellow, but all segments anteriorly-ventrally densely covered with acumbent brown hairs. Legs II-IV brownish yellow. Palps brownish yellow, their Fm, Pt and cymbium anteriorly densely covered with brown hairs; Fm and Pt dorso-posteriorly covered with white and transparent hairs; tibial apophysis bears two bunches of strong black bristles: a bunch of long bristles apically and that of short bristles proximally. Palpal structure as in Figs 105-108: VTA poorly marked; RTA nail-shaped, directed dorsad; DTA present, as a thick, pointed dorsal process that bears a wide row of thick black bristles along its retrolateral side and a tuft of very long and thick black bristles at its apex; the cymbium simple, without a cymbial lateral process; the tegulum is relatively small, without a tegular process; the functional tegulum wide and elongated, with well-developed proximal (PP) and long, spade-shaped distal (DP) projections; the embolus relatively short and thick, with a beak-shaped tip and an anvil-shaped base.

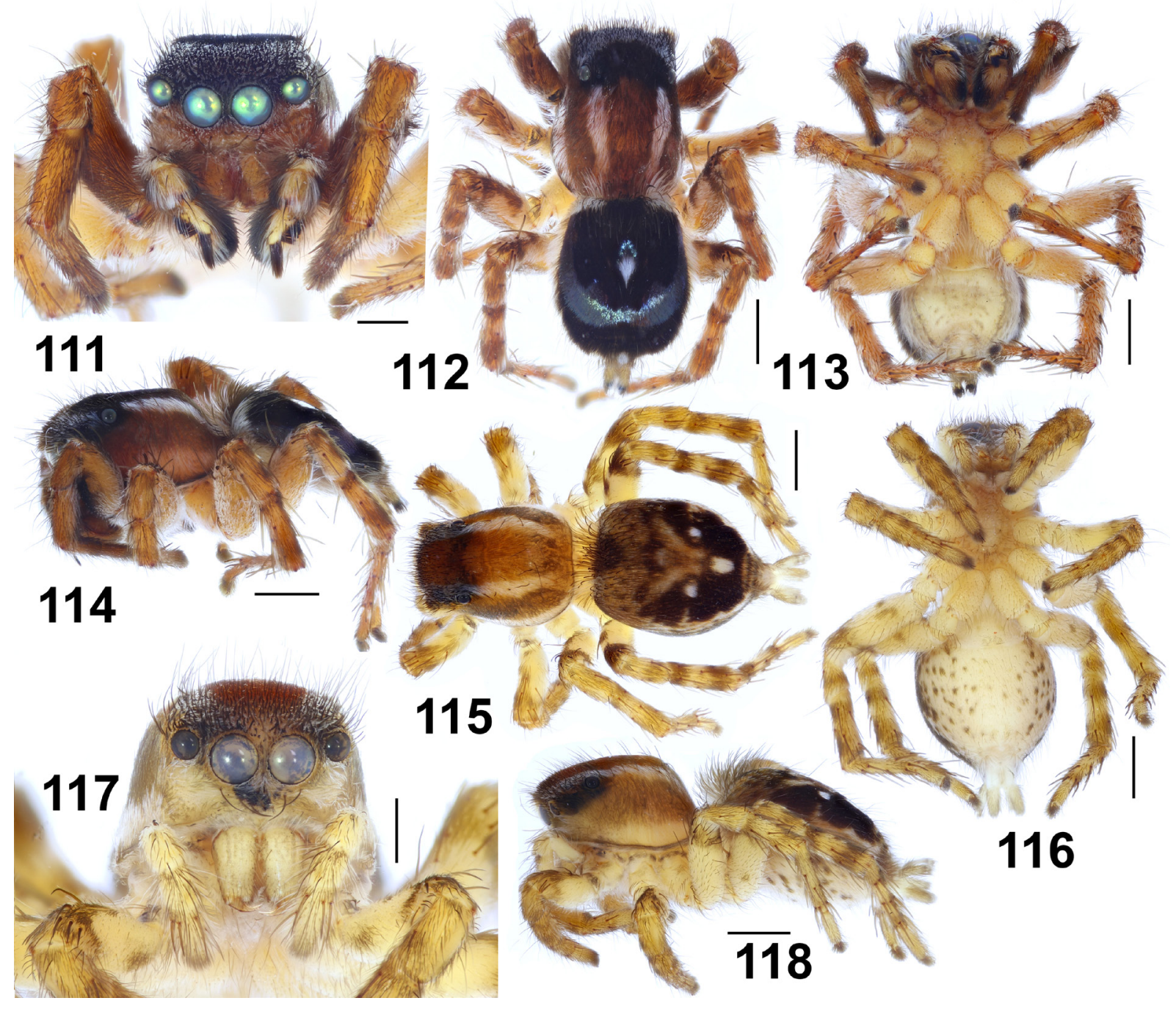

Figs 111-118. Stenaelurillus darwini Wesołowska \& Russell-Smith, 2000 from Tanzania (Mkomazi GR; MMUE G7571.48, 50), general appearance. 111-114. đ. 115-118. ․ Scale bars: $1 \mathrm{~mm}$. 
Female (from Tanzania, Mkomazi GR, Ibaya camp; MMUE G7571.50)

Measurements: carapace: 3.00 long, 2.30 wide, 1.40 high. Abdomen: 3.75 long, 2.80 wide. Ocular area: 1.25 long, 1.63 wide anteriorly, 1.63 wide posteriorly. Cheliceral length 0.70 . Clypeal height 0.25 . Diameter of AME 0.43. Length of leg segments: I $1.45+0.70+0.75+0.70+0.45$ (4.05); II $1.60+$ $0.80+0.75+0.75+0.45(4.35) ;$ III $2.25+1.15+1.45+1.75+0.65(7.25) ;$ IV $2.15+0.95+1.45+$ $1.90+0.70$ (7.15). Leg formula III,IV,II,I. Leg spination: I: Fm d 0-1-1-5; Pt pr 0-1-0; Tb pr 1-1, v 1-12ap; Mt pr 1-1ap, rt 1ap, v 2-2ap. II: Fm d 0-1-2-5; Pt pr 01-0; Tb pr 1-1, v 1-1-2ap; Mt pr 2-1-1ap, rt 1-2ap, v 2-2ap. III: Fm d 0-1-2-5; Pt pr and rt 0-1-0; Tb d 1-0-0, pr and rt 1-1-1-1, v 1-2ap; Mt d 1-0-0, pr and rt 1-1-2ap, v 0-2-2ap. IV: Fm d 0-1-1-5; Pt pr and rt 0-1-0; Tb d 1-0-0, pr and rt 1-1-1-1, v 2-02ap; Mt pr 2-2-2ap, rt 2-1-2ap, v 0-1-2-2ap. Coloration (in alcohol; Figs 115-118). Carapace brownish yellow, with dark brown eye field, densely covered with long brown recumbent scales; there are two longitudinal white stripes of scales on the thorax and two wide white marginal stripes. Clypeus and cheeks yellow, sparsely covered with yellow hairs. Sternum yellow, densely covered with white hairs. Endites and labium yellow. Chelicerae yellow, tinged with light brown. Abdomen: dorsum brown, with a white spot on its rear half, anterior margin of the abdomen densely covered with long brown and white hairs; sides yellow with brown speckles; venter yellow. Book-lung covers yellow. Spinnerets yellow, tinged with brown. All legs brownish yellow, with yellow round spots on Fm. Palps yellow. Epigyne and spermathecae as in Figs 109-110: the epigynal plate with a pair of round, widely separated bulgeshaped protuberances on which the copulatory openings are situated; the epigynal pocket not marked; the insemination ducts relatively short, tube-shaped, directed mediad, towards each other; the primary spermathecae medium-sized, S-shaped.

\section{Distribution}

Tanzania and Kenya (Fig. 511) (Wesołowska \& Russell-Smith 2000; Wesołowska 2014b; present data).

Stenaelurillus furcatus Wesołowska, 2014

Figs 20-21, 119-135, 511

Stenaelurillus furcatus Wesołowska, 2014b: 601, fig. 3A-G (D $\overbrace{}^{\top}+$ ); $\partial^{\Uparrow}$ holotype in BMNH, not examined.

\section{Diagnosis}

The males of $S$. furcatus can easily be distinguished from those of all other species of Stenaelurillus by the unique bifurcated RTA, the finger-shaped, pointed distal projection and the hook-shaped embolus (Figs 120,122); only the male of $S$. jagannathae from India has a similar conformation of the embolus (cf. Vidhel et al. 2015: figs 3-11). The female of $S$. furcatus is most similar to that of $S$. guttiger (Figs 227-230), from which it differs in having a much wider epigynal pocket situated right between the copulatory openings (disposed proximally in S. guttiger) and visibly narrower insemination ducts and primary receptacles. The female of $S$. furcatus is also similar to those of $S$. latibulbus and $S$. kavango (cf. Figs 334-335 and Wesołowska 2014b: fig. 5), but differs in the shape and proportions of the insemination ducts and the primary spermathecae (Figs 126-127).

\section{Material examined}

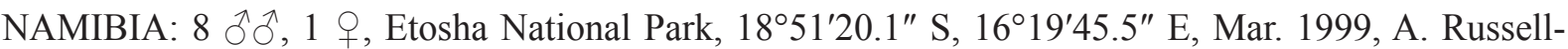
Smith leg. (MRAC 215.642).

\section{Description}

Male

Measurements: carapace: $2.20-2.40$ long, $1.50-1.75$ wide, 1.05 high. Abdomen: $1.70-2.30$ long, $1.65-$ 1.70 wide. Ocular area: 0.90 long, 1.35 wide anteriorly, 1.30 wide posteriorly. Cheliceral length 0.60 . 
Clypeal height 0.25-0.30. Diameter of AME 0.35-0.40. Length of leg segments: I $1.10+0.60+0.65+$ $0.45+0.45$ (3.25); II $1.15+0.70+0.70+0.60+0.60$ (3.75); III $1.70+0.90+1.15+1.35+0.60$ (5.70); IV $1.50+0.90+1.10+1.45+0.70$ (5.65). Leg formula III,IV,II,I. Leg spination: I: Fm d 0-1-1-5; Pt pr 1; Tb pr 1-1, v 1-1-2ap; Mt pr 1-1ap, rt 0-1ap, v 2-2ap. II: Fm d 0-1-2-5; Pt pr 1; Tb pr 1-1, v 1-12ap; Mt pr and rt 1-1ap, v 2-2ap. III: Fm d 1-2-5; Pt pr and rt 1; Tb d 1-0-0, pr and rt 1-1-1-1, v 0-1-2ap; Mt d 2-1-0, pr and rt 1-0-2ap, v 0-2-2ap. IV: Fm d 1-1-5; Pt pr and rt 1; Tb d 1-0-0, pr and rt 1-1-1-1, v 1-0-2ap; Mt d 2-1-0, pr 1-1-2ap, rt 1-0-2ap, v 1-2-2ap. Coloration (in alcohol; Figs 132-135). Carapace brown, covered with long dark brown recumbent scales, laterally with wide marginal stripes of white scales, dorsally with two longitudinal stripes of white scales starting from PMEs and running to the rear end of the carapace. Sternum yellow. Endites and labium yellow. Chelicerae dark brown, sparsely covered with long white hairs. Clypeus and cheeks brown, sparsely covered with long white hairs. Abdomen: dorsum brown, covered with dark brown recumbent scales, medially with a longitudinal stripe of white hairs; venter grey-yellow. Book-lung covers yellow. Spinnerets yellow, with brownish

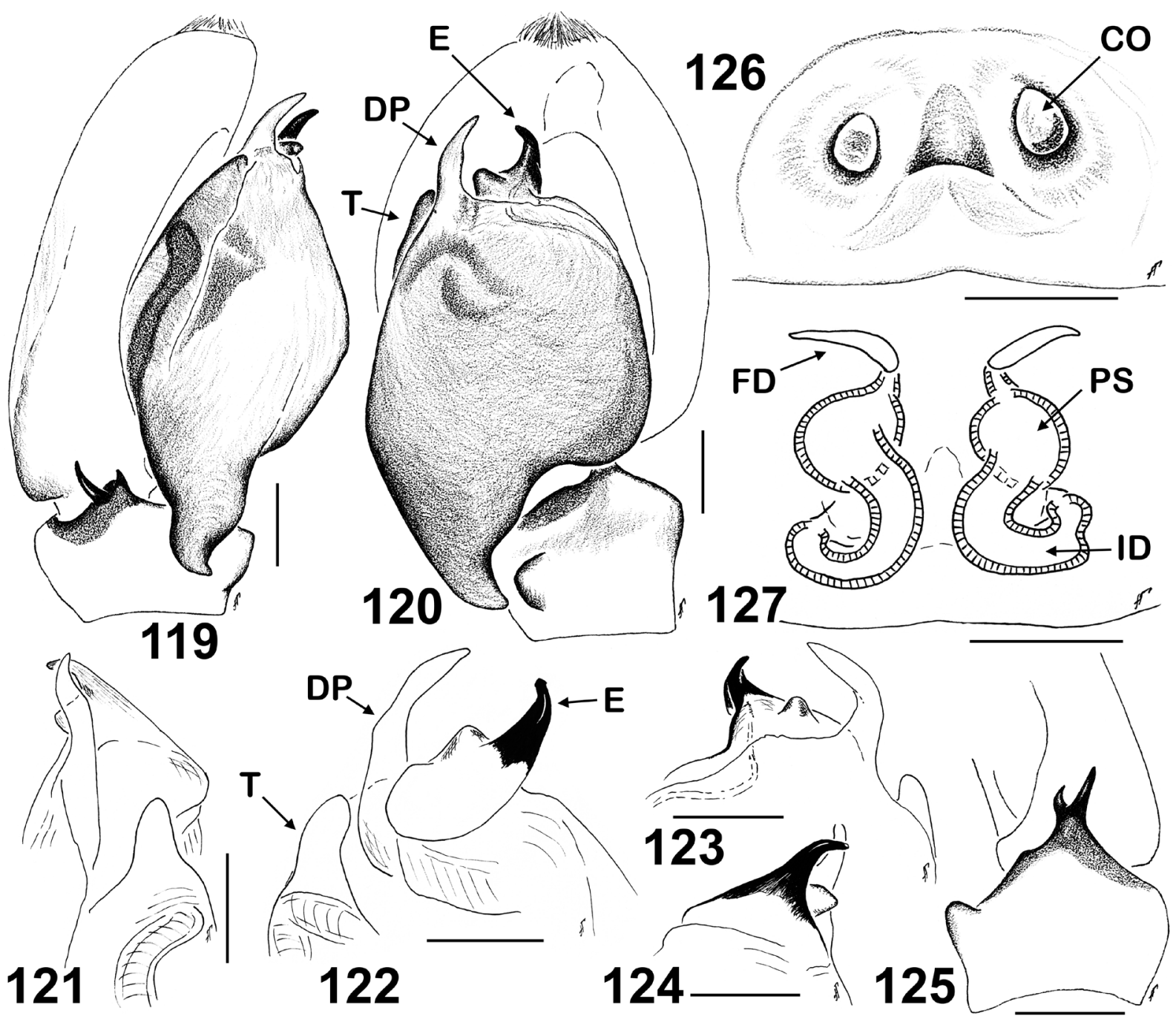

Figs 119-127. Stenaelurillus furcatus Wesołowska, 2014 from Namibia (Etosha National Park; MRAC 215.642). 119. Male palp, retrolateral view. 120. Male palp, ventral view. 121-124. Embolic division. 121. Retrolateral view. 122. Dorsal view. 123. Ventral view. 124. Median view. 125. RTA, retrolateral view. 126. Epigyne, ventral view. 127. Spermathecae, dorsal view. Abbreviations: see Material and methods. Scale bars: $0.1 \mathrm{~mm}$. 
(the ventral pair) to dark brown (the dorsal pair) tips. All legs yellow. Coxae II ventrally with dark brown spots. All Fm ventro-proximally with dark brown spots, which are poorly marked on legs I and IV in some specimens. All Pt ventrally with dark brown spots (poorly marked in some specimens). Tb, Mt and Tr I brown, covered with dark brown hairs. Tb II ventrally covered with dark brown hairs. Palps yellow, but Fm sparsely covered with long white hairs; Fm prolatero-distally, Tb and the proximal part of cymbium prolaterally covered with dark brown hairs. Palpal structure as in Figs 119-125: VTA bulgeshaped; RTA bifurcated, claw-like; the cymbium simple, without a cymbial lateral process; the tegulum small, poorly marked, without a tegular process; the functional tegulum elongated, with well-developed, pointed proximal (PP) and finger-shaped distal (DP) projections; the embolus thick, hook-shaped, with a heavy elongated base having a short projection directed distad.

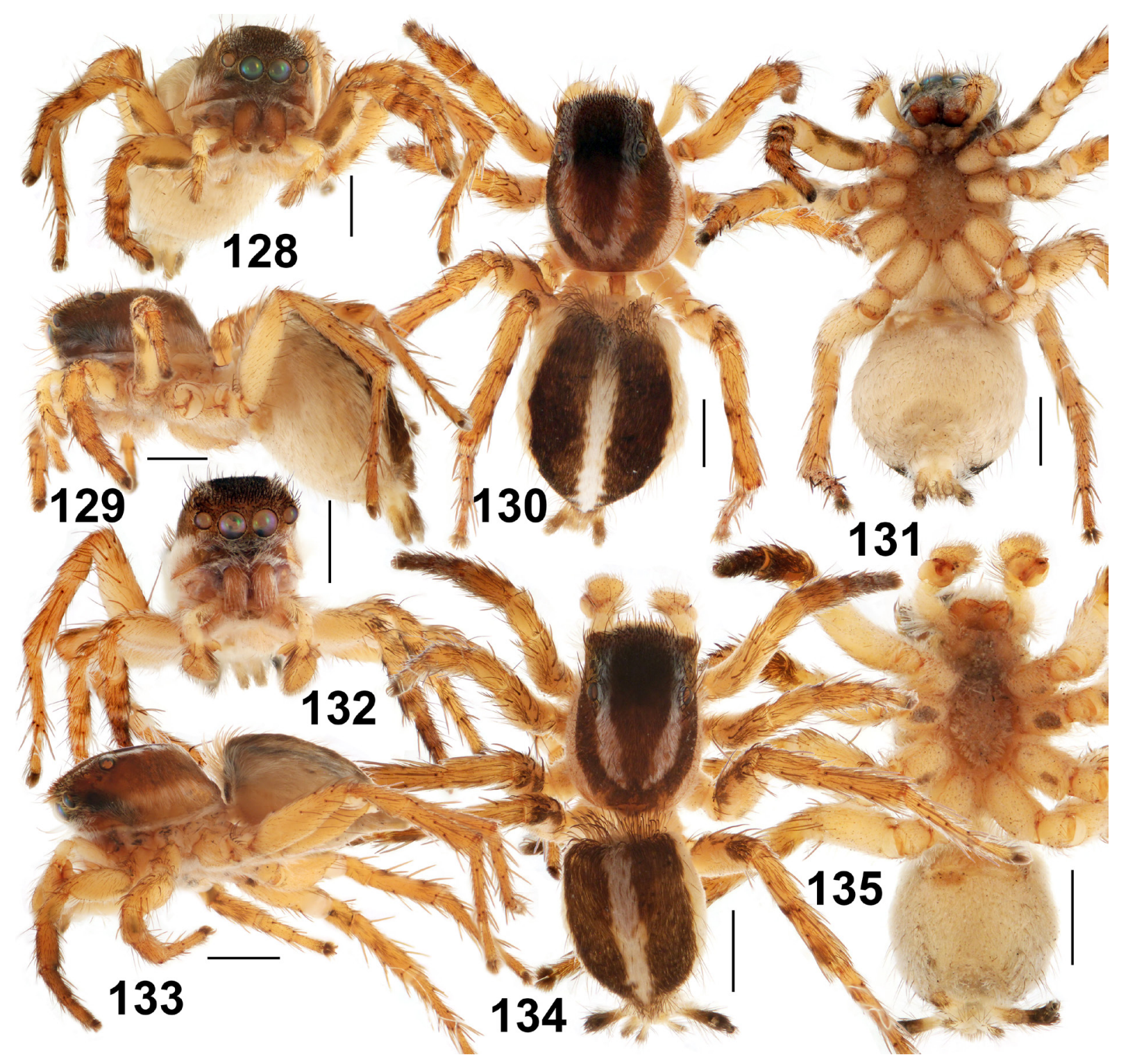

Figs 128-135. Stenaelurillus furcatus Wesołowska, 2014 from Namibia (Etosha National Park; MRAC 215.642), general appearance. 128-131. ㅇ. 132-135. $\hat{~}$. Scale bars: $1 \mathrm{~mm}$. 


\section{Female}

Measurements: carapace: 2.50 long, 2.15 wide, 1.50 high. Abdomen: 3.50 long, 2.55 wide. Ocular area: 1.00 long, 1.45 wide anteriorly, 1.40 wide posteriorly. Cheliceral length 0.65 . Clypeal height 0.35 . Diameter of AME 0.40. Length of leg segments: I $1.15+0.70+0.60+0.50+0.45$ (3.40); II $1.20+$ $0.75+0.65+0.55+0.45(3.60) ;$ III $2.00+1.00+1.40+1.55+0.65(6.60) ;$ IV $1.80+0.80+1.30+$ $1.70+0.70$ (6.30). Leg formula III,IV,II,I. Leg spination: I: Fm d 0-1-1-5; Pt pr 1; Tb pr 1-1, v 1-1-2ap; Mt pr 1-1ap, rt 0-1ap, v 2-2ap. II: Fm d 0-1-2-5; Pt pr 1; Tb pr 1-1, v 1-1-2ap; Mt pr 1-1ap, rt 0-1ap, v 2-2ap. III: Fm d 1-2-5; Pt pr and rt 1; Tb d 1-0-0, pr and rt 1-1-1-1, v 1-0-2ap; Mt d 2-1-0, pr and rt 1-0-2ap, v 0-2-2ap. IV: Fm d 1-1-4; Pt pr and rt 1; Tb d 1-0-0, pr and rt 1-1-1-1, v 1-0-2ap; Mt d 2-1-0, pr 1-1-2ap, rt 1-0-2ap, v 1-2-2ap. Coloration (in alcohol; Figs 128-131) as in the male. All legs yellow. Coxae without spots. Fm I and II prolaterally with a dark brown spot and retrolaterally with a small proximal dark brown spot. Fm III with small pro- and retrolateral proximal dark brown spots. Tb I and II prolaterally with two dark brown spots (proximal and distal). Fm III and IV dorsally with proximal and distal spots of dark brown scales. Tb IV with proximal and distal spots of dark brown scales. Palps yellow, but palpal Fm with a poorly marked prolateral brown spot. Epigyne and spermathecae as in Figs 126-127: the epigynal plate flat, without visible structures; epigynal pocket present, wide, cone-shaped, situated between the large ovoid, widely separated copulatory openings; the insemination ducts relatively short, tube-shaped, forming C-shaped figures; the primary spermathecae medium-sized and round.

\section{Distribution}

A few localities in Namibia (Fig. 511) (Wesołowska 2014b; present data).

Stenaelurillus fuscatus Wesołowska \& Russell-Smith, 2000

Figs 136-155, 512

Stenaelurillus fuscatus Wesołowska \& Russell-Smith, 2000: 101, figs 277-280 (D ${ }^{\Uparrow}$ ); §ै holotype in MRAC, examined.

\section{Diagnosis}

Of the described species, S. fuscatus is most similar to S. darwini (Figs 105-110) and S. uniguttatus (see Wesołowska 2014b: fig. 13). The males of S. fuscatus differ from both related species in having a very wide, square distal projection (DP) on the functional tegulum and a different arrangement of bunches of black shining hairs on the palpal tibia; the females of S. fuscatus can be distinguished from those of S. darwini by the much wider insemination ducts.

\section{Material examined}

Holotype

TANZANIA: ${ }^{\lambda}$, Mkomazi GR, Umba River, ca $4^{\circ} 00^{\prime} \mathrm{S}, 38^{\circ} 00^{\prime}$ E, riverine scrub, 18 Apr. 1995, A. Russell-Smith leg. (MRAC 207.953).

\section{Other material}

KENYA: 9 ふึฎ, 8 우, Kenya Coast, Taita Discovery Centre, ca $03^{\circ} 48^{\prime} \mathrm{S}, 38^{\circ} 38^{\prime}$ E, pitfall traps, 6-24 Jan. 2001, E. Selempo leg. (MRAC 213.080, MRAC 213.133, MRAC 212.904, MRAC 213.041); 1 , Mathews Range forest, ca $03^{\circ} 15^{\prime} \mathrm{N}, 37^{\circ} 20^{\prime}$ E, 1294 m a.s.1., on rocks, 11 Dec. 2002, D. van den Spiegel leg. (MRAC 212.576). 


\section{Description}

Male (holotype)

Measurements: carapace: 2.60 long, 2.00 wide, 1.35 high. Abdomen: 2.80 long, 2.00 wide. Ocular area: 1.10 long, 1.60 wide anteriorly, 1.55 wide posteriorly. Cheliceral length 0.70 . Clypeal height 0.30 .

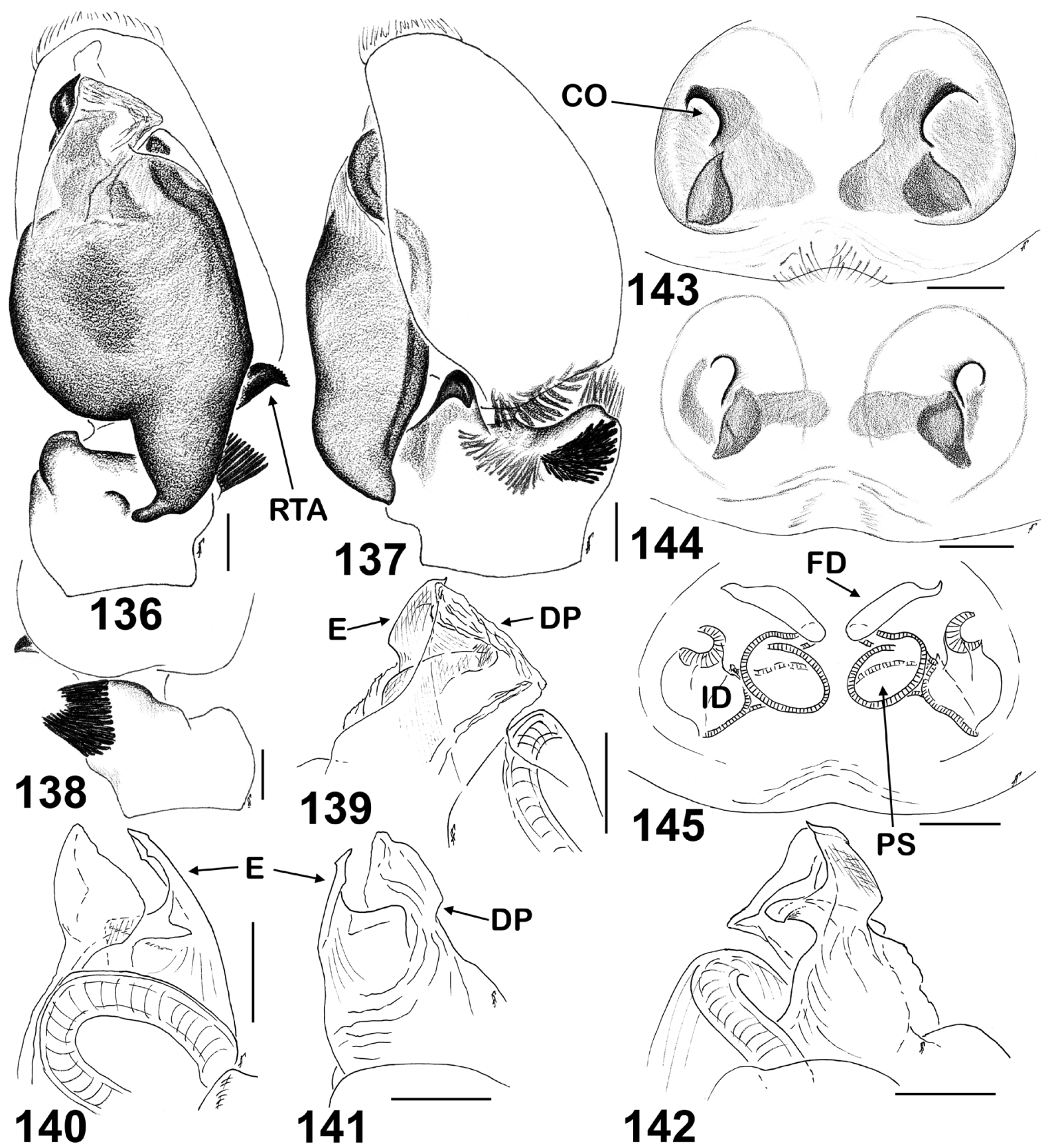

Figs 136-145. Stenaelurillus fuscatus Wesołowska \& Russell-Smith, 2000, $\widehat{\jmath}(136-142)$, and $q$ from Kenya (Taita Discovery Centre; MRAC 213.133) (143-145). 136. Male palp, ventral view. 137. Male palp, retrolateral view. 138. DTA, dorsal view. 139-142. Embolic division. 139. Ventral view. 140. Retrolateral view. 141. Median view. 142. Dorsal view. 143-144. Epigyne, ventral view. 145. Spermathecae, dorsal view. Scale bars: $0.1 \mathrm{~mm}$. Abbreviations: see Material and methods. 
Diameter of AME 0.45. Length of leg segments: I $1.20+0.75+0.85+0.60+0.50$ (3.90); II $1.20+0.75$ $+0.80+0.65+0.50(3.90) ;$ III $1.70+0.95+1.20+1.45+0.60(5.90) ;$ IV $1.70+0.90+1.15+1.60$ +0.70 (6.05). Leg formula IV,III,II/I. Leg spination: I: Fm d 0-1-1-5; Pt pr 1; Tb pr 1-1, v 1-2-2ap; Mt pr and rt 1-1ap, v 2-2ap. II: Fm d 0-1-2-5; Pt pr 1; Tb pr 1-1, v 1-1-2ap; Mt pr and rt 1-1-1ap, v 2-2ap. III: Fm d 1-0-2-5; Pt pr and rt 1; Tb d 1-0-0, pr and rt 1-1-1-1, v 1-0-2ap; Mt d 2-2-0, pr and rt 1-0-2ap, v 0-2-2ap. IV: Fm d 1-0-1-5; Pt pr and rt 1; Tb d 1-0-0, pr and rt 1-1-1-1, v 1-0-2ap; Mt d 2-2-0, pr 1-1-2ap, rt 1-0-2ap, v 0-2-2ap. Coloration (in alcohol; Figs 146-151). Carapace dark brown, covered with dark brown recumbent scales, with two longitudinal stripes of white scales running from PLEs to

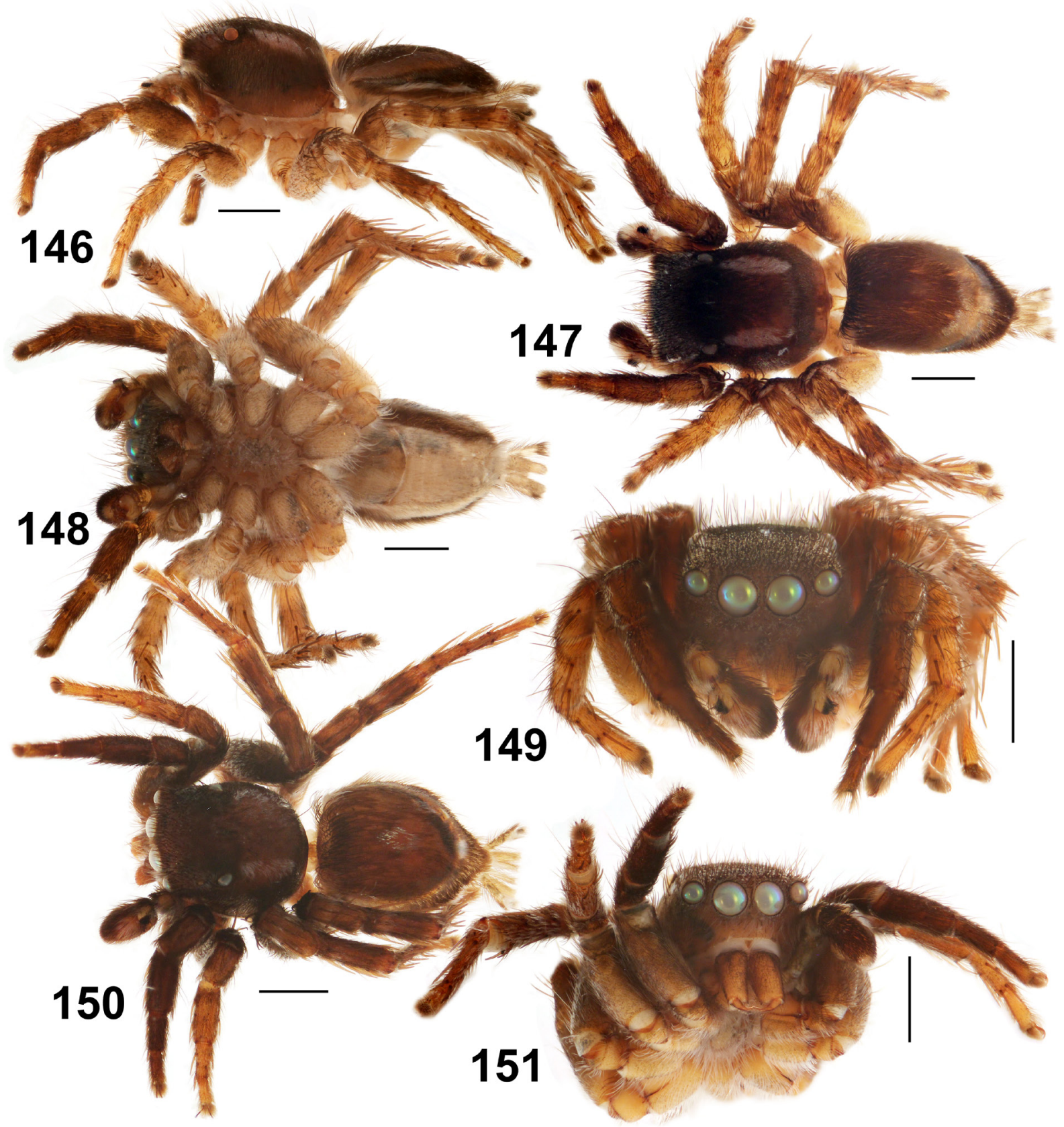

Figs 146-151. Stenaelurillus fuscatus Wesołowska \& Russell-Smith, 2000, holotype, ô (150-151) and $\delta$ from Kenya (Taita Discovery Centre; MRAC 213.133) (146-149), general appearance. Scale bars: $1 \mathrm{~mm}$. 
approximately $1 / 4$ of the carapace length. Clypeus brownish yellow, covered with white/transparent hairs. Sternum brownish yellow. Endites and labium brownish yellow. Chelicerae yellow-brown, covered with short dark brown hairs. Abdomen: dorsum dark brown, with dark brown scutum occupying $2 / 3$ of the abdomen length, covered with dark brown scales and with a small white spot behind the scutum; venter grey-yellow; sides with long hairs (brown dorsally and white ventrally). Book-lung covers yellow. Spinnerets yellow-brown. Legs I dark brown, covered with dark brown hairs. The remaining legs brown, covered with dark brown hairs. Palps brown, covered with dark brown hairs, except Fm retro-apically and $\mathrm{Pt}, \mathrm{Tb}$ and cymbium prolaterally, which are densely covered with white hairs. Palpal structure as in Figs 136-142: tibial apophysis with bunches of black shining hairs; VTA bulge-shaped; RTA hookshaped; the cymbium simple, without a cymbial lateral process; the tegulum small, poorly marked, without a tegular process; the functional tegulum elongated, with well-developed, pointed proximal (PP) and very wide, square distal (DP) projections; the embolus thick, hook-shaped, with a heavy base.

Female (MRAC 213.133)

Measurements: carapace: $2.50-3.00$ long, $1.95-2.35$ wide, $1.30-1.50$ high. Abdomen: $3.00-3.60$ long, 2.60-2.95 wide. Ocular area: $1.00-1.20$ long, $1.50-1.75$ wide anteriorly, $1.45-1.70$ wide posteriorly. Cheliceral length $0.60-0.70$. Clypeal height $0.25-0.30$. Diameter of AME $0.40-0.50$. Length of leg segments (big female): I $1.50+0.90+0.80+0.60+0.55$ (4.35); II $1.50+0.90+0.85+0.70+0.60$ (4.55); III $2.20+1.10+1.50+1.70+0.70$ (7.20); IV $2.15+1.00+1.45+1.90+0.75$ (7.25). Leg formula IV,III,II,I. Leg spination: I: Fm d 0-1-1-5; Pt pr 1; Tb pr 1-1, v 1-1-2ap; Mt pr 1-1ap, rt 1-1ap, v 2-2ap. II: Fm d 0-1-2-5; Pt pr 1; Tb pr 1-1, v 1-1-2ap; Mt pr and rt 1-1ap, v 2-2ap. III: Fm d 1-0-2-5;

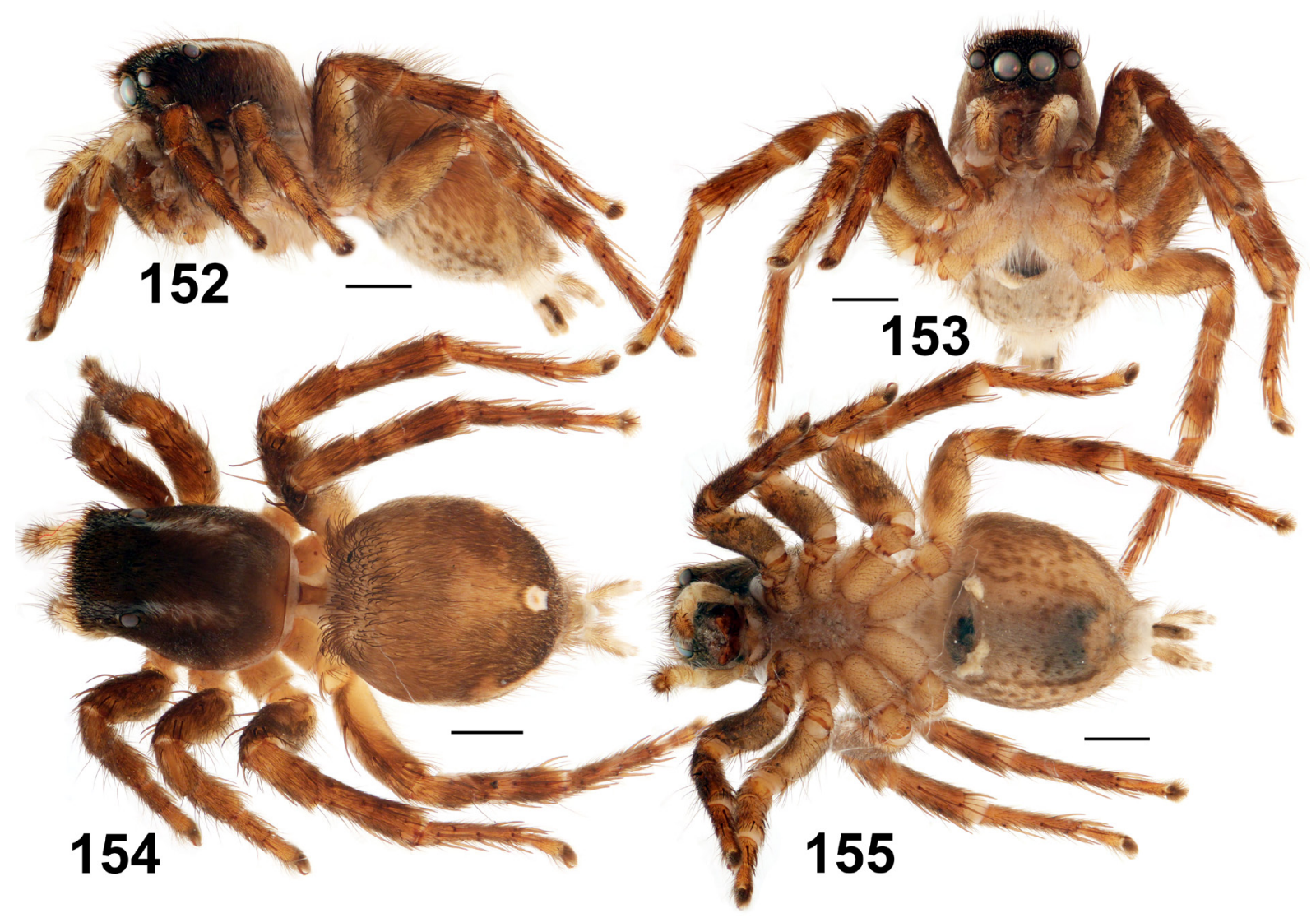

Figs 152-155. $q$ of Stenaelurillus fuscatus Wesołowska \& Russell-Smith, 2000 from Kenya (Taita Discovery Centre; MRAC 213.133), general appearance. Scale bars: $1 \mathrm{~mm}$. 
Pt pr and rt 1; Tb d 1-0-0, pr and rt 1-1-1-1, v 1-0-2ap; Mt d 2-2-0, pr and rt 1-0-2ap, v 0-2-2ap. IV: Fm d 1-0-1-5; Pt pr and rt 1; Tb d 1-0-0, pr and rt 1-1-1-1, v 1-0-2ap; Mt d 2-2-0, pr 1-1-2ap, rt 1-0-2ap, v 1-2-2ap. Coloration (in alcohol; Figs 152-155). Carapace dark brown, laterally covered with dark brown recumbent scales, dorsally with brown-yellow recumbent scales, with two longitudinal white stripes of scales running from PLEs to approximately $1 / 4$ of the abdomen length. Clypeus and cheeks yellowbrown, sparsely covered with brownish hairs. Endites and labium brown-yellow. Chelicerae brown. Abdomen: dorsum brown, with a poorly marked pattern of a central inverted triangle (its apex is directed posteriad) and an oval spot of white scales having a small brown dot in its centre; venter brownish yellow, with numerous brown speckles. Book-lung covers yellow. Spinnerets brownish yellow. Legs brown, covered with dark brown hairs and bristles. Palps yellow, sparsely covered with dark brown hairs and bristles. Epigyne and spermathecae as in Figs 143-145; the epigynal plate flat, without visible structures; the epigynal pocket poorly marked (as a wide invagination of the epigastric furrow); the copulatory openings as ovoid holes, widely separated and facing laterad; the insemination ducts very wide and short, running towards the median line; the primary spermathecae ovoid.

\section{Distribution}

A few localities in Kenya and Tanzania (Fig. 512) (Wesołowska \& Russell-Smith 2000; present data).

Stenaelurillus glaber Wesołowska \& Russell-Smith, 2011

Figs 156-164, 511

Stenaelurillus glaber Wesołowska \& Russell-Smith, 2011: 593, figs 151-152, 238-240 (Dð); ð holotype in BMNH, examined.

\section{Diagnosis}

By the conformation of the copulatory organs (Figs 156-160), the males of S. glaber are almost identical to those of S. hirsutus (Figs 239-242, 246-251), S. pilosus (Figs 406-410) and S. striolatus (Figs 463467). Males of all these species can easily be distinguished by the clypeal colour pattern: yellow clypeus with long sparse white hairs in S. glaber (Fig. 161), black with three vertical white stripes in S. hirsutus (Fig. 255), with a transverse dark brown band in S. pilosus (Fig. 413), and entirely dark brown/black in S. striolatus (Fig. 468). The shape of the distal projection (DP) of the functional tegulum also seems to be diagnostic (compare Fig. 156 with Figs 246, 406, 463). The female of S. glaber has not been described yet and cannot be diagnosed now.

\section{Material examined}

Holotype

NIGERIA: ${ }^{\circ}$, Kwara State, Mokwa, $9^{\circ} 17^{\prime} 34.1^{\prime \prime} \mathrm{N}, 5^{\circ} 03^{\prime} 16.8^{\prime \prime} \mathrm{E}$, cultivated savanna, in dead leaves, 13 Jul. 1974, A. Russell-Smith leg. (BMNH).

\section{Paratype}

NIGERIA: $1 \hat{\jmath}$, same collecting data as for holotype (BMNH).

\section{Description}

Male (holotype)

Measurements: carapace: 2.55 long, 1.75 wide, 1.30 high. Abdomen: 2.05 long, 1.40 wide. Ocular area: 1.18 long, 1.60 wide anteriorly, 1.56 wide posteriorly. Cheliceral length 0.50 . Clypeal height 0.20 . Diameter of AME 0.50. Length of leg segments: I $1.28+0.70+0.75+0.60+0.53$ (3.86); II $1.30+$ $0.63+0.75+0.58+0.50(3.76) ;$ III $1.95+0.90+1.25+1.40+0.58(4.08) ;$ IV $1.68+0.70+1.13+$ $1.38+0.60$ (5.49). Leg formula IV,III,I,II. Leg spination: I: Fm d 0-1-1-5; Pt pr 0-1-0; Tb pr 1-1, v 1-2- 
2ap; Mt pr and rt 1ap, v 2-2ap. II: Fm d 0-1-2-5; Pt pr 0-1-0; Tb pr 1-1-1, rt 0-1-1, v 1-1-2ap; Mt pr and rt 1-1ap, v 2-2ap. III: Fm d 0-1-2-4; Pt pr and rt 0-1-0; Tb d 1-0-0, pr 1-1-1-1, rt 1-1-1, v 1-0-2ap; Mt d 1-0-0, pr and rt 1-0-2ap, v 0-2-2ap. IV: Fm d 0-1-1-4; Pt pr and rt 0-1-0; Tb d 1-0-0, pr and rt 1-1-1, v 1-0-2ap; Mt d 1-0-0, pr and rt 1-1-2ap, v 0-2-2ap. Coloration (in alcohol; Figs 161-164). Carapace
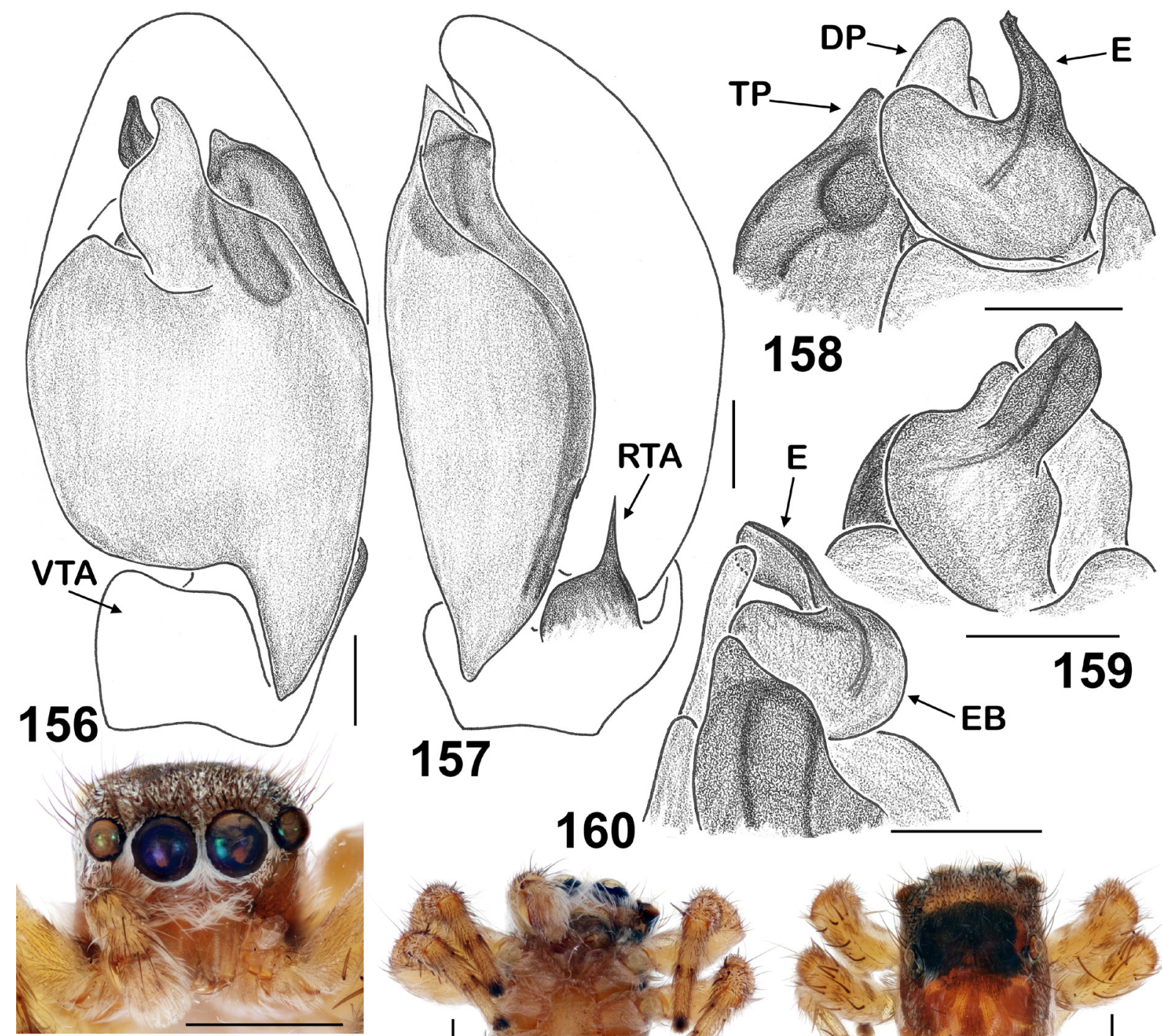

157
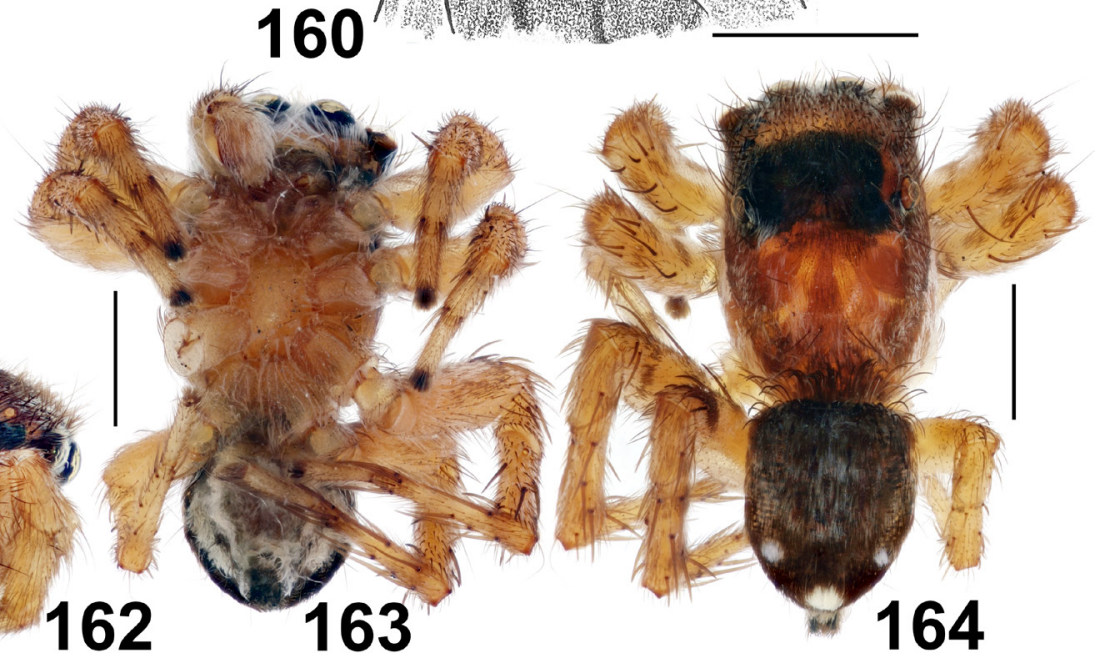

Figs 156-164. Stenaelurillus glaber Wesołowska \& Russell-Smith, 2011, holotype, ô (156-160) and paratype, $\widehat{\partial}$ from Nigeria (Mokwa) (161-164). 156. Male palp, ventral view. 157. Male palp, retrolateral view. 158. Embolic division, dorsal view. 159. Embolic division, median view. 160. Embolic division, retrolateral view. 161-164. General appearance. Abbreviations: see Material and methods. Scale bars: $156-160=0.1 \mathrm{~mm} ; 161-164=1 \mathrm{~mm}$. 
yellowish brown, densely covered with recumbent brown scales, with two pairs (dorsal and marginal) of wide longitudinal white stripes of recumbent scales. Eye field dark brown, with numerous short protruding brown bristles. Clypeus brownish yellow, sparsely covered with long white hairs. Eyes of the first row are ventrally edged by dense white hairs and scales. Sternum, labium, endites and chelicerae yellow. Abdomen: dorsum dark brown, with three large white spots on its rear half; sides and venter greyish yellow. Book-lung covers yellow. Spinnerets brown. Legs yellow, but all Fm dorso-distally with patches of brown recumbent scales. Palps entirely yellow. Palpal structure as in Figs 156-160: VTA bulge-shaped, poorly marked; RTA straight, stiletto-shaped, directed anteriad, with a wide base; the cymbial lateral process (CLP) absent; the tegulum small, with a short, cone-shaped tegular process (TP); the functional tegulum swollen, with well-developed proximal (PP) and distal (DP) projections; the embolus short, ribbon-shaped, with a wide round base.

\section{Female}

Unknown.

\section{Distribution}

The type locality only (Fig. 511).

Stenaelurillus guttatus (Wesołowska \& Cumming, 2002) comb. nov.

Figs 8-9, 16-17, 165-183, 511

Mashonarus guttatus Wesołowska \& Cumming, 2002: 167, figs 1-19 (D $\overbrace{}^{\lambda}+$ ); $\widehat{\jmath}$ holotype in MRAC, examined.

\section{Diagnosis}

By the conformation of the copulatory organs (the well-marked proximal projection of the functional tegulum, the stiletto-shaped embolus and the developed cymbial lateral projection, etc.), S. guttatus comb. nov. is most similar to $S$. brandbergensis comb. nov. and S. pseudoguttatus sp. nov. (cf. Figs 9094, 99-100, and 416-420). The males of S. guttatus comb. nov. differ in having a pointed distal projection (wide and obtuse in S. brandbergensis comb. nov., absent in S. pseudoguttatus sp. nov.) and the shortest RTA (as compared with the two related species). The females differ in having comparatively long insemination ducts (very short in S. brandbergensis comb. nov., not yet known in S. pseudoguttatus sp. nov., cf. Figs 172 and 100).

\section{Material examined}

Holotype

ZIMBABWE: $0^{\wedge}$, Harare, $17^{\circ} 15^{\prime} \mathrm{S}, 31^{\circ} 02^{\prime} \mathrm{E}$, garden, Jun. 1992, M.S. Cumming leg. (MRAC HT.211.425).

\section{Paratype}

ZIMBABWE: 1 , together with the holotype (MRAC PT.211.426).

\section{Other material}

BOTSWANA: 1 \%, North East Distr., nr Francistown, Selkirk Mine, $21^{\circ} 19^{\prime} \mathrm{S}, 27^{\circ} 43^{\prime} \mathrm{E}$, pitfall traps, 6 Jun.-22 Jul. 2008, D.H. Jacobs leg. (NCA 2016/1741); 1 đ, same locality, pitfall traps, 30 Oct.-6

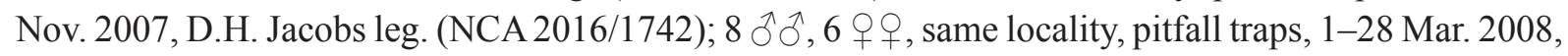
D.H. Jacobs leg. (NCA 2009/3736, NCA 2016/1743). 

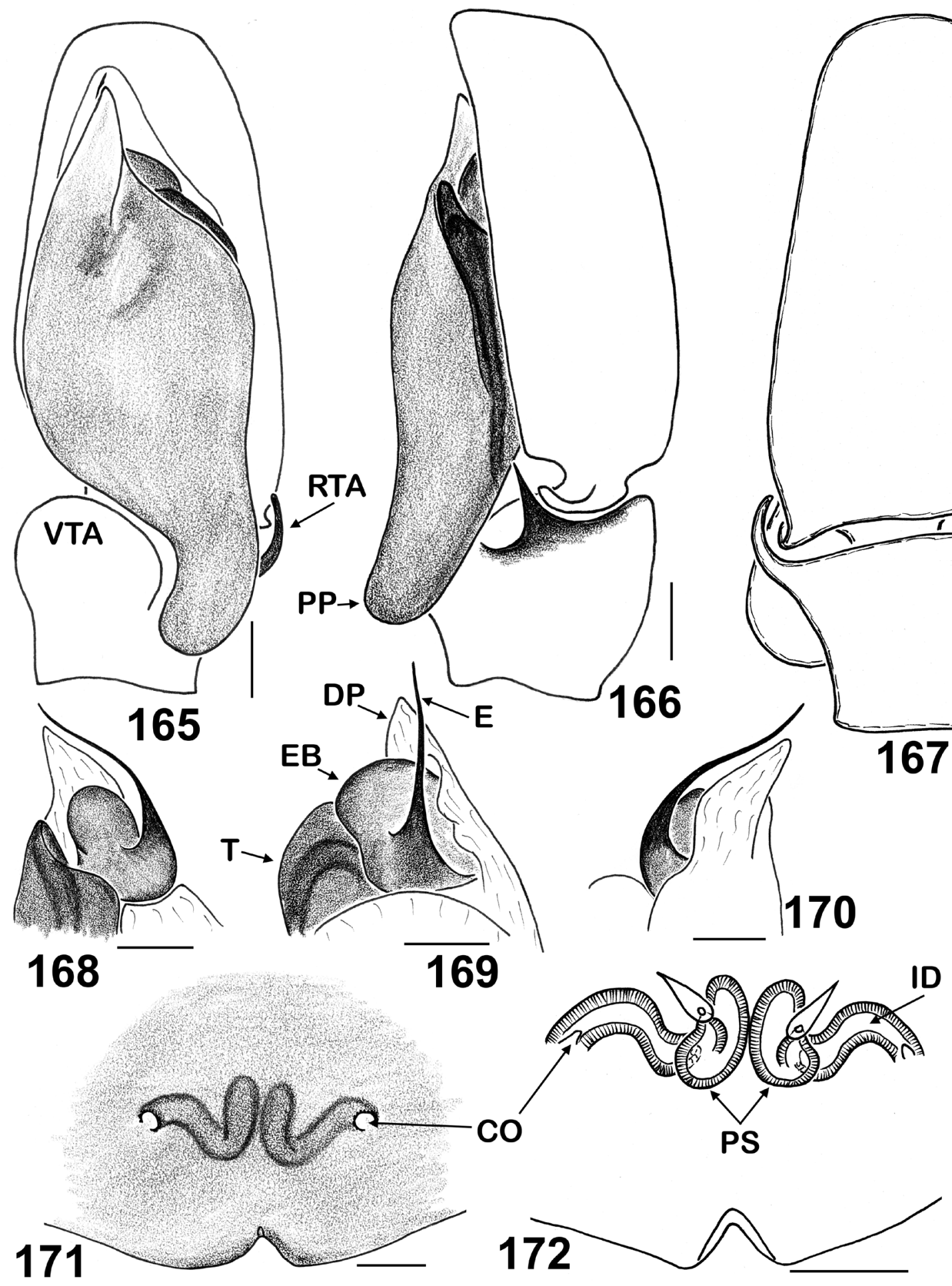

Figs 165-172. Stenaelurillus guttatus (Wesołowska \& Cumming, 2002) comb. nov., holotype, ð (165-170) and paratype, $q$ (171-172). 165. Male palp, ventral view. 166. Male palp, retrolateral view. 167. Male palp, dorsal view. 168. Embolic division, dorsal view. 169. Embolic division, median view. 170. Embolic division, retrolateral view. 171. Epigyne, ventral view. 172. Spermathecae, dorsal view. Abbreviations: see Material and methods. Scale bars: $0.1 \mathrm{~mm}$. 


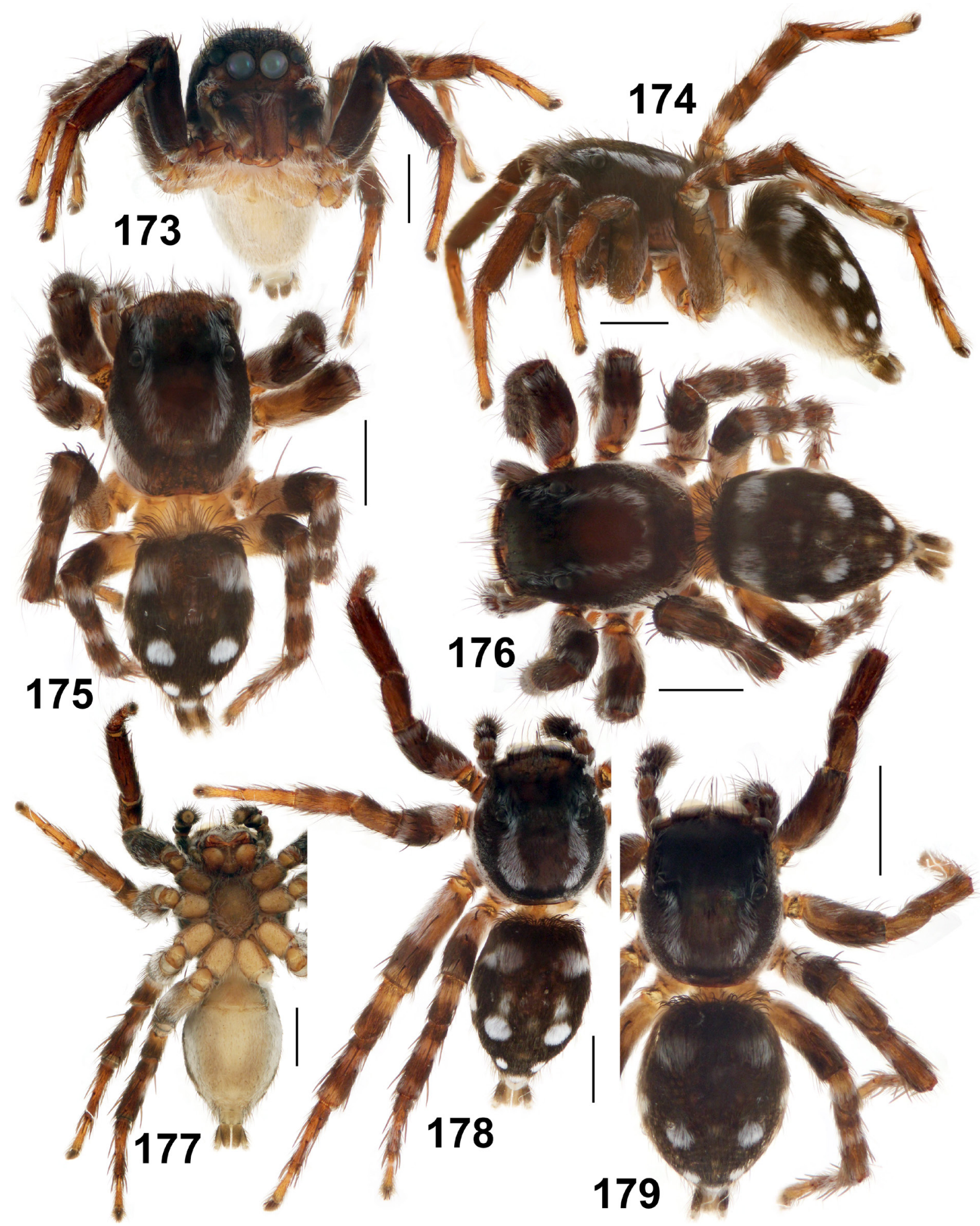

Figs 173-179. Stenaelurillus guttatus (Wesołowska \& Cumming, 2002) comb. nov., $\hat{\jmath}$, from Zambia (Namwala Kafue NP; NCA 2007/573), general appearance. Scale bars: $1 \mathrm{~mm}$. 


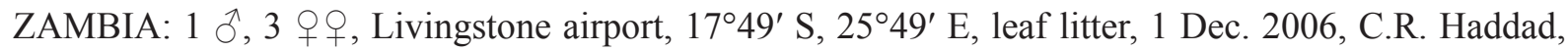

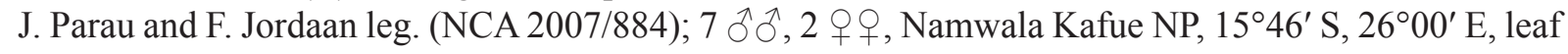
litter, 7 Dec. 2006, C.R. Haddad and J. Parau leg. (NCA 2007/573).

\section{Remarks}

The original type series of Mashonarus guttatus turned out to include two species. The male paratype from Namibia (MRAC 152.151) actually belongs to a separate and new species that is described below as $S$. pseudoguttatus sp. nov.

\section{Description}

Male (holotype)

Measurements: carapace: 2.70 long, 2.00 wide, 1.15 high. Abdomen: 2.50 long, 1.90 wide. Ocular area: 1.15 long, 1.48 wide anteriorly, 1.35 wide posteriorly. Cheliceral length 0.98 . Clypeal height 0.15 . Diameter of AME 0.43. Length of leg segments: I $1.70+0.93+1.35+1.10+0.55$ (5.63); II $1.45+$ $0.78+0.88+0.78+0.48(4.37) ;$ III $1.80+0.98+0.80+1.25+0.53(5.36) ;$ IV $1.55+0.78+1.18+$ $1.43+0.58$ (5.52). Leg formula I,IV,III,II. Leg spination: I: Fm d 0-1-1-5; Tb pr 2-1, v 1-1-2ap; Mt pr 1ap, v 2-2ap. II: Fm d 0-1-1-5; Tb pr 1-1, v 1-1-2ap; Mt pr 1-1ap, v 2-2ap. III: Fm d 0-1-1-5; Pt pr 0-1 0; Tb pr 1-1, rt 1-1-1, v 1-0-2ap; Mt d 1-1, pr and rt 0-2-2ap, v 0-2-2ap. IV: Fm d 0-1-1-3; Pt pr 0-1-0; $\mathrm{Tb}$ pr and rt 1-1-1, v 1-0-2ap; Mt d 1-1-0, pr, rt and v 1-1-2ap. Coloration (in alcohol; Figs 173-179). Carapace yellowish brown, with dark brown eye field, densely covered with long, recumbent brown scales; clypeus yellowish brown, sparsely covered with brown hairs. Sternum yellowish brown, densely covered with white hairs. Endites and labium yellowish brown. Chelicerae light brown. Abdomen:

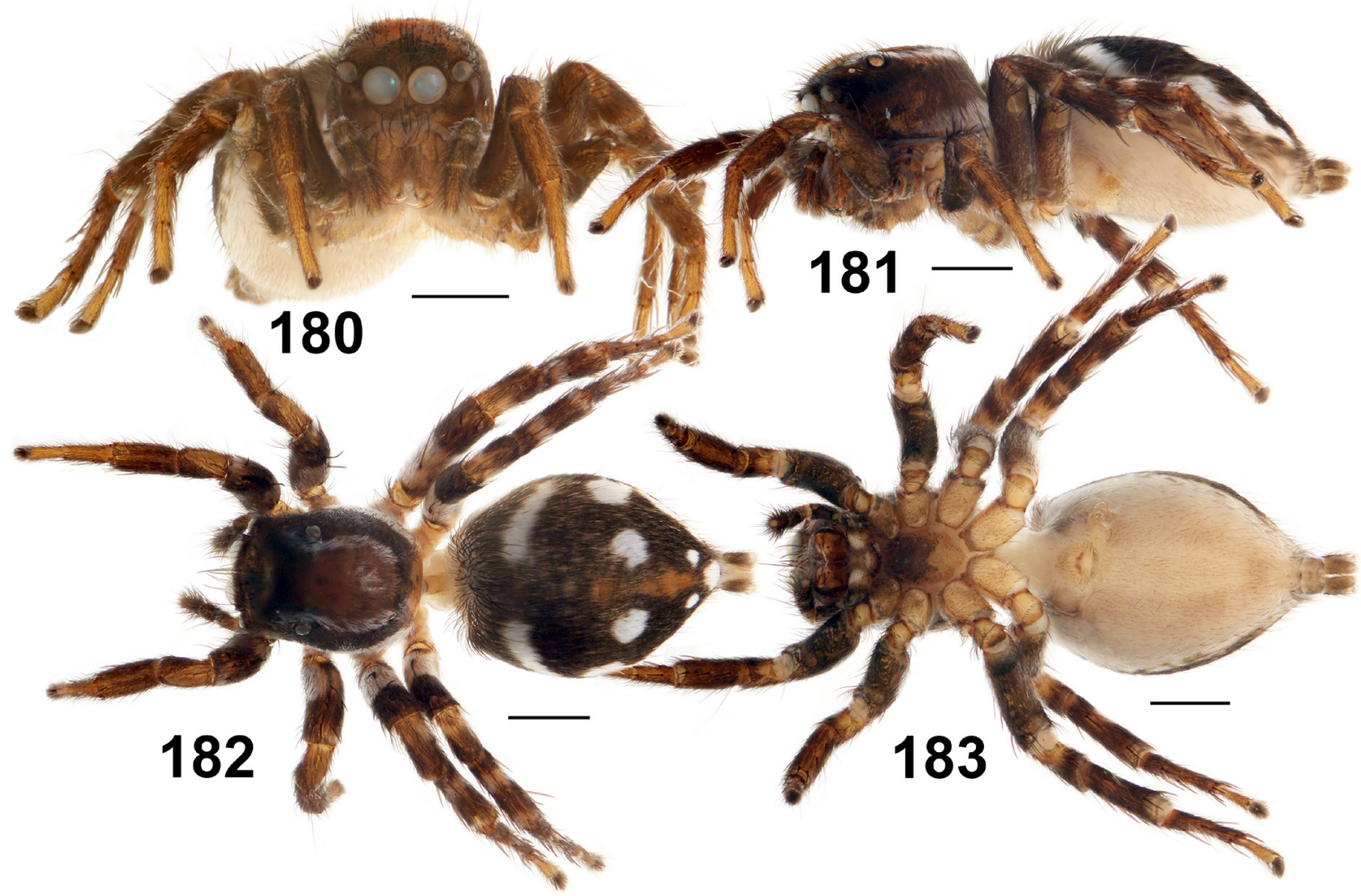

Figs 180-183. Stenaelurillus guttatus (Wesołowska \& Cumming, 2002) comb. nov., ๆ, from Botswana (near Francistown; NCA 2007/573), general appearance. Scale bars: $1 \mathrm{~mm}$. 
dorsum dark brown, with three pairs of white spots and white anal tubercle (Fig. 175); sides and venter greyish yellow. Book-lung covers grayish yellow. Spinnerets brownish. All legs: coxae and trochanters yellow, Fm, Pt and Tb brownish, Mt and Tr yellowish brown. Palps brownish. Palpal structure as in Figs 165-170; VTA bulge-shaped; RTA straight, stiletto-shape, directed anteriad; the cymbium with a well-developed cymbial lateral process; the tegulum small, poorly marked, without a visible tegular process; the functional tegulum narrow-elongated, with well-developed, wide and obtuse proximal projection (PP) and with a long, cone-shaped distal projection (DP); the embolus long, small swordshaped, with a wide round base.

Female (paratype)

Measurements: carapace: 2.65 long, 1.95 wide, 1.05 high. Abdomen: 3.20 long, 2.63 wide. Ocular area: 1.05 long, 1.38 wide anteriorly, 1.35 wide posteriorly. Cheliceral length 0.68 . Clypeal height 0.15 . Diameter of AME 0.43. Length of leg segments: I $1.30+0.75+0.83+0.73+0.48$ (4.09); II $1.30+$ $0.75+0.75+0.70+0.40(3.90) ;$ III $1.70+0.95+1.05+1.18+0.55(5.43) ;$ IV $1.70+0.83+1.10+$ $1.48+0.63$ (5.74). Leg formula IV, III,I,II. Leg spination: I: Fm d 0-1-1-4; Tb pr 1-2, v 1-1-2ap; Mt pr 1ap, v 2-2ap. II: Fm d 0-1-2-4; Tb pr 1-1, v 1-1-2ap; Mt pr 1-1ap, v 2-2ap. III: Fm d 0-1-2-4; Pt pr and rt 0-1-0; Tb d 1-0, pr and rt 1-1-1, v 1-2ap; Mt d 1-1-0, pr and rt 1-2ap, v 2-2ap. IV: Fm d 0-1-1-3; Pt pr and rt 0-1-0; Tb d 1-0, pr and rt 1-1-1, v 1-2ap; Mt d 1-1-0, pr and rt 1-1-2ap, v 2-0-2ap. Coloration (in alcohol; Figs 180-183). Carapace yellowish brown, with dark brown eye field, densely covered with long recumbent brown scales; there are two longitudinal white stripes of scales and white marginal bands of scales; clypeus and cheeks yellowish brown, sparsely covered with brown hairs. Sternum yellow, tinged with brown and densely covered with white hairs. Endites and labium yellow, tinged with brown. Chelicerae yellow, tinged with brown. Abdomen: dorsum dark brown, with three pairs of white spots and wide white lateral stripes; sides and venter yellow. Book-lung covers yellow. Spinnerets yellow, tinged with grey. All legs: coxae and trochanters yellow, the remaining segments yellowish brown. Palps yellowish brown. Epigyne and spermathecae as in Figs 171-172; the epigynal plate flat, with no visible structures; the copulatory openings small, round and widely separated; the insemination ducts short, as S-shaped tubes directed towards each other; the primary spermathecae bean-shaped.

\section{Distribution}

Botswana, Zambia, Zimbabwe (Fig. 511) (Wesołowska \& Cumming 2002: sub Mashonarus g.; present data). New to Botswana and Zambia.

Stenaelurillus guttiger (Simon, 1901)

Figs 22-23, 184-238, 512

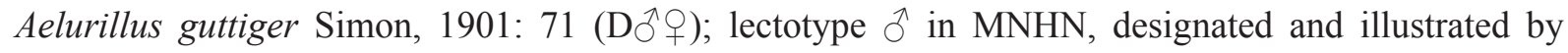
Haddad \& Wesołowska (2006), not examined.

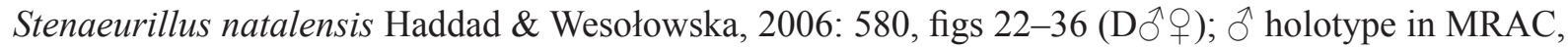
examined. Syn. nov.

\section{Diagnosis}

The male of S. guttiger can be distinguished from those of other species of Stenaelurillus known to us by the claw-shaped retrolateral tibial apophysis (Figs 185, 186, 194: RTA) and a combination of the spoonshaped distal projection with the claw-shaped embolus (Figs 184, 189, 193: DP and E). The female of S. guttiger is most similar to that of $S$. furcatus (Figs 126-127), but can easily be distinguished by the markedly narrower epigynal pocket disposed proximally of the copulatory openings (Figs 227, 229) (right between the copulatory organs in S. guttiger; Figs 126) and the visibly wider insemination ducts and primary receptacles. 


\section{Material examined}

Holotype (Stenaelurillus natalensis Haddad \& Wesołowska, 2006)

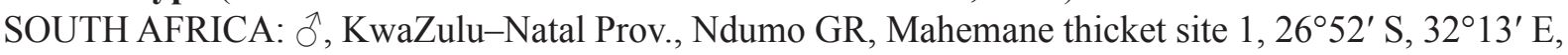
Odontotermes termite mound and nearby leaf litter, 15 Jun. 2005, C. Haddad leg. (MRAC 218.447).

Paratypes (Stenaelurillus natalensis Haddad \& Wesołowska, 2006)

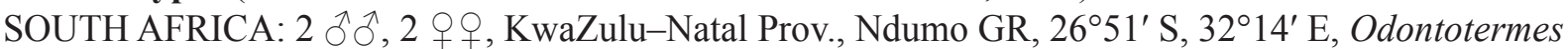
termite mound and nearby leaf litter, 15 Jun. 2005, C. Haddad leg. (MRAC 218.448); 1 §̊, 1 ᄋ, KwaZuluNatal Prov., Tembe Elephant Park, $27^{\circ} 01^{\prime} \mathrm{S}, 32^{\circ} 24^{\prime}$ E, pioneer grassland, pitfall traps, 4-24 Jan. 2002,

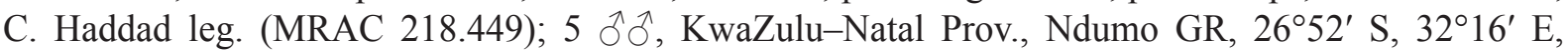
Acacia nigriscens woodland, on Odontotermes termite mound, 18 Jun. 2005, C.R. Haddad leg. (NCA

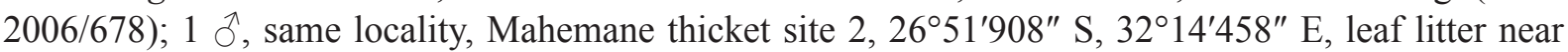
Odontotermes mound, 15 Jun. 2005, C.R. Haddad leg. (NCA 2006/673); 2 q 9 , same locality, crocodile farm, $26^{\circ} 54^{\prime} 426^{\prime \prime} \mathrm{S}, 32^{\circ} 19^{\prime} 185^{\prime \prime} \mathrm{E}$, on ground near termite galleries, 15 Jun. 2005, C.R. Haddad leg.

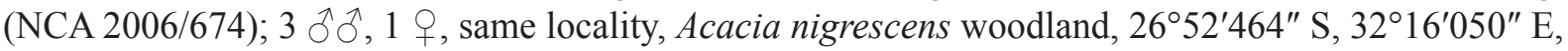
on sand near Odontotermes termite mound, 17-18 Jun. 2005, C.R. Haddad leg. (NCA 2006/675, NCA

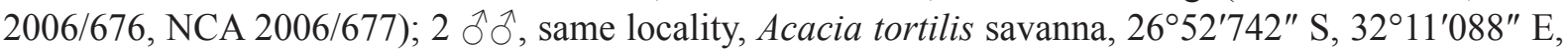
grassy leaf litter near Odontotermes mound, 23 Jun. 2005, C.R. Haddad leg. (NCA 2006/679); 2 우, same locality, Main Camp, broadleaf woodland, $26^{\circ} 54^{\prime} 581^{\prime \prime} \mathrm{S}, 32^{\circ} 18798^{\prime \prime} \mathrm{E}$, leaf litter near termite galleries, 26 Jan. 2006, C.R. Haddad and R. Lyle leg. (NCA 2006/680).

\section{Other material}

BOTSWANA: $7 \delta^{\top} \partial^{\lambda}, 4$ 우, North East Distr., Selkirk Mine, Francistown, $21^{\circ} 20^{\prime} \mathrm{S}, 27^{\circ} 42^{\prime} \mathrm{E}$, pitfall traps, 30 Oct. -6 Nov. 2006, D.H. Jacobs leg. (NCA 2009/5666, NCA 2009/5660, NCA 2009/5695);

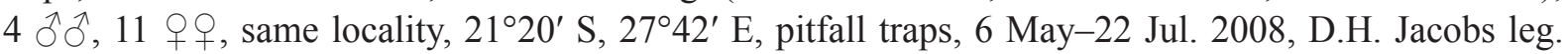
(NCA 2009/3742, NCA 2009/5658); 2 $\widehat{\jmath}, 3$ 웅, same locality, pitfall traps, 1-28 Mar. 2008, D.H. Jacobs leg. (NCA 2009/5659, NCA 2009/5656); 40 ふ઼ , same locality, 1 Mar.-5 Apr. 2008, D.H. Jacobs and M. Stiller leg. (NCA 2009/3733, NCA 2009/3744, NCA 2010/3198).

ZIMBABWE: 1 o , Matabeleland North Prov., Tsholotsho, ca $19^{\circ} 45^{\prime}$ S, $27^{\circ} 45^{\prime}$ E, 7-9 Oct. 2005, L. Sibanda leg. (NCA 2008/2566); 17 §ิ 0 , 5 우, same locality, on sandy ground, 7 Oct. 2005, L. Sibanda leg. (MRAC 224.660); 1 ô, Manicaland Prov., Save River, Birchenough Bridge, 1957'43" S, $32^{\circ} 20^{\prime} 39^{\prime \prime}$ E, Jan. 1938, V. FitzSimons leg. (TMSA 8096).

SOUTH AFRICA: Limpopo Prov.: 1 q, Tuinplaas, Springbokvlakte Settlers, Farm Tweekansen, $24^{\circ} 49^{\prime} \mathrm{S}, 28^{\circ} 57^{\prime}$ E, grass, pitfall traps, 17 Sep. 2002, M. van Jaarsveld leg. (NCA 2006/1280); 22 우웅, same locality, pitfall traps, grass, 26 Nov. 2003, M. van Jaarsveld leg. (NCA 2007/2449); 1 ઈ same locality, pitfall traps, grass, 21 Aug. 2002, M. van Jaarsveld leg. (NCA 2006/1286); 3 $\widehat{\partial}, 2$ 우, same locality, pitfall traps, grass, 26 Mar. 2003, M. van Jaarsveld leg. (NCA 2006/1288); 1 ๙ิ, same province and site, Bekendevlei (Site 1), 24 $4^{\circ} 9^{\prime} \mathrm{S}, 28^{\circ} 49^{\prime}$ E, pitfall traps, grass, 11 Jun. 2002, M. van Jaarsveld leg.

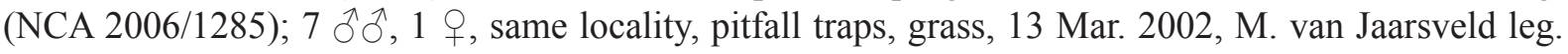

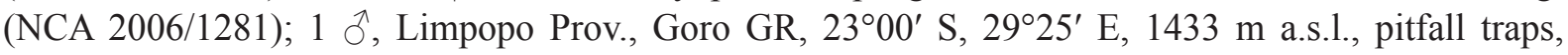
26 Jan. 2012, S.H. Foord leg. (UniVen); 1 Oे $^{\prime}$, Mooketsi Farm, $23^{\circ} 46^{\prime}$ S, $29^{\circ} 58^{\prime}$ E, 1538 m a.s.1., Eucalyptus and Acacia shrubs, 23 Apr. 2014, I.V. Mutavhatsindi and S.H. Foord leg. (UniVen); 2 ô ô, Soutpansberg, farm Stoke, $22^{\circ} 28^{\prime} \mathrm{S}, 2^{\circ} 52^{\prime} \mathrm{E}$, site A, pitfall traps, 6 Aug. 2009, collector unkown (NCA); 1 q, same

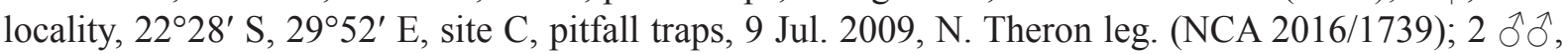
same locality, site A, pitfall traps, 6 Aug. 2009, N. Theron leg. (NCA 2016/1740); 1 ô, Western

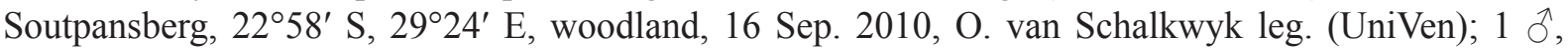
Blouberg GR, 22 59'08.9" S, 2902'07.6" E, Kirkia acuminata, 27 Nov. 2005, I. Sinthumule leg. (NCA

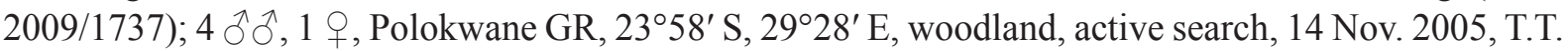


Khoza and M.A. Modiba leg. (NCA 2008/2067); 2 q , same locality, rocky outcrop, sweepnetting, 19 Apr. 2005, T.T. Khoza and M.A. Modiba leg. (NCA 2008/1240); 1 §, same locality, rocky outcrop, sweepnetting, 13 Dec. 2005, T.T. Khoza and M.A. Modiba leg. (NCA 2008/2070); 1 ô, 1 क , same locality, false grassland, pitfall traps, 14 Sep. 2005, T.T. Khoza and M.A. Modiba leg. (NCA 2008/2314); $1 \delta$, same locality, rocky outcrop, active search, 12 Dec. 2005, T.T. Khoza and M.A. Modiba leg. (NCA 2008/2069); 1 d, same locality, woodland, active search, 14 Mar. 2005, T.T. Khoza and M.A. Modib leg. (NCA 2008/2368); 1 §, 2 우, same locality, false grassland, active search, 4 Aug. 2005, T.T. Khoza and M.A. Modib leg. (NCA 2008/2250); 1 + , same locality, rocky outcrop, active search, 13 Feb. 2006, T.T. Khoza and M.A. Modib leg. (NCA 2008/1804); 1 ô, 1 \%, same locality, false grassland, active search, 8 Dec. 2005, T.T. Khoza and M.A. Modib leg. (NCA 2008/2202); 2 우, same locality, rocky outcrop, active search, 18 Apr. 2005, T.T. Khoza and M.A. Modib leg. (NCA 2008/1241); 1 , same locality, woodland, sweeping, 18 Aug. 2005, T.T. Khoza and M.A. Modib leg. (NCA 2008/1454); 4 §ð,, same locality, woodland, sweeping, 19 Sep. 2005, T.T. Khoza and M.A. Modib leg. (NCA 2008/1455); 3 $\widehat{\partial}$, Mogalakwena NR, farm Huilbosch, $22^{\circ} 42^{\prime}$ S, $28^{\circ} 48^{\prime}$ E, 746.8 m a.s.l., pitfall traps, bushland, 25 Jan. 2008 , S.H. Foord leg. (NCA 2016/1734, NCA 2016/1735, NCA 2016/1736); 1 ㅇ, Entabeni, ca $23^{\circ} 02^{\prime}$ S, $30^{\circ} 11^{\prime}$ E, pitfall traps, 13 Feb. 2008, S.H. Foord leg. (NCA 2016/1737); 1 क, Tshulu, ca $22^{\circ} 34^{\prime}$ S, $30^{\circ} 48^{\prime}$ E, pitfall traps, 21 Feb. 2008, S.H. Foord leg. (NCA 2016/1738); 3 우, Phalaborwa Distr., Mpumalanga, Kruger NP, Letaba airship, ca $5 \mathrm{~km} \mathrm{~N}$ of Letaba camp, $23^{\circ} 50^{\prime} \mathrm{S}, 31^{\circ} 34^{\prime} \mathrm{E}, 26-28$ Oct. $^{2} 2005$,

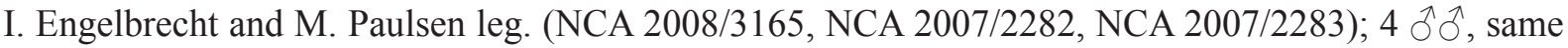
NP, Letaba section, intersection between S151 rd and Nwanetsi River, ca $15 \mathrm{~km} \mathrm{NW}$ of Letaba camp, $23^{\circ} 47^{\prime}$ S, 31 $1^{\circ} 28^{\prime}$ E, 27 Oct. 2005, I. Engelbrecht and M. Paulsen leg. (NCA 2007/2284); 1 ㅇ, same NP, Oliphants section, ca $1 \mathrm{~km}$ due $\mathrm{W}$ of Oliphants camp, 23 $3^{\circ} 59^{\prime} \mathrm{S}, 31^{\circ} 43^{\prime} \mathrm{E}, 27$ Oct. 2005, M. Paulsen and I. Engelbrecht leg. (NCA 2009/3738); 1 \%, same NP, active search, PC4, 8 Dec. 2005, K. Harris leg.

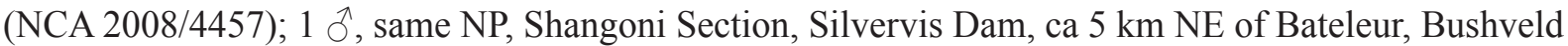
camp, $23^{\circ} 12^{\prime} \mathrm{S}, 31^{\circ} 13^{\prime} \mathrm{E}$, hillslopes NW of dam wall, $361 \mathrm{~m}$ a.s.l., active search, $5 \mathrm{Jan}$. 2007, SCSA members leg. (NCA 2009/3739); 1 $\hat{\text {, }}$, same NP, just N of S52 road crossing over Shingwedzi River, ca $15 \mathrm{~km}$ due SW of Shingwedzi rest camp, $23^{\circ} 09^{\prime} \mathrm{S}, 31^{\circ} 18^{\prime} \mathrm{E}$, active search, $5 \mathrm{Jan}$. 2007, SCSA members

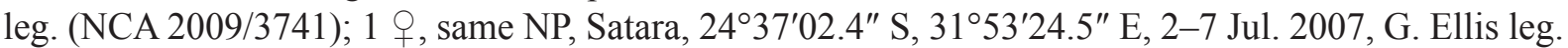

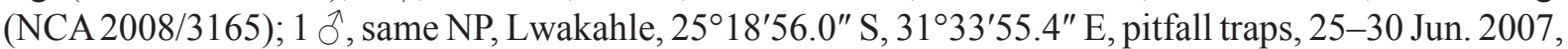

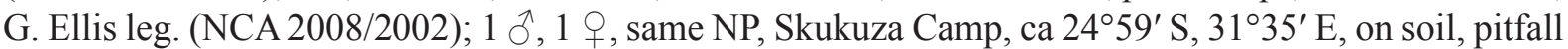
traps, 27 May 2006, K. Harris leg. (NCA 2007/4194, NCA 2007/4195); 2 우, same locality, pitfall traps PC7, 29 Sep. 2005, K. Harris leg. (NCA 2008/4458); 1 ô, same NP, Red Rocks, ca $23^{\circ} 10^{\prime} \mathrm{S}, 31^{\circ} 19^{\prime} \mathrm{E}$, 25 Apr. 2006, M. Cumming leg. (NCA 2008/1623); 1 đ̃, same NP, Nwambiya Pan \#41, 23 Nov. 1963,

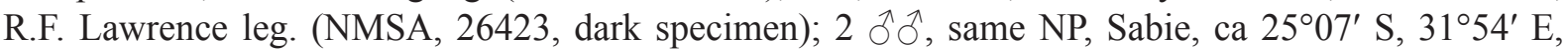
15 Feb. 1962, R.F. Lawrence leg. (NMSA); 1 đ, 2 웅, same NP, Pafuri (Wallers Camp), ca $22^{\circ} 25^{\prime}$ S, $31^{\circ} 02^{\prime}$ E, mixed woodland, pitfall traps, 18 Feb. 2008, S. Foord leg. (NCA 2009/2578, NCA 2009/2576); 1 9, same locality, pitfall traps, 18 Feb. 2008, S.H. Foord leg. (NCA 2009/3722); 1 ô same locality, mixed woodland, pitfall traps, 18 Feb. 2008, S.H. Foord leg. (NCA 2009/2581); 1 \%, same locality, savanna, by hand, 14 Feb. 2008, N. Hahn leg. (NCA 2009/2580); 1 đ̊, same NP, Pafuri camp, ca $22^{\circ} 25^{\prime}$ S, $31^{\circ} 02^{\prime} \mathrm{E}$, various methods, $10 \mathrm{Jan} .1989$, museum staff leg. (NMBA, 14915); 1 ๙ , same locality, various methods, 10 Jan. 1989, museum staff leg. (NMBA 02835); 2 우, same NP, Pafuri, ca $22^{\circ} 25^{\prime} \mathrm{S}, 31^{\circ} 02^{\prime} \mathrm{E}$, Mopani veld, 14 Jan. 1996, A. Leroy leg. (NCA 2007/2474, NCA 2007/2477); 2 우, Limpopo, Pafuri (Wallers Camp), ca $22^{\circ} 25^{\prime} \mathrm{S}, 31^{\circ} 02^{\prime} \mathrm{E}$, savanna, pirfall traps, $15-18$ Feb. 2008, S.H. Foord leg. (NCA 2009/2577, NCA 2009/2579); 1 Ô, Medikwe Heritage Site, Western Soutpansberg, nr Makhado, ca

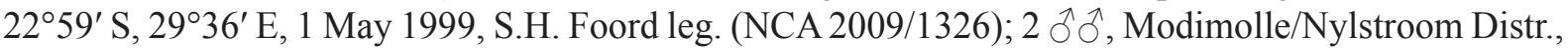
Jubaweni GR, $24^{\circ} 46^{\prime} \mathrm{S}, 28^{\circ} 44^{\prime} \mathrm{E}, 1065 \mathrm{~m}$ a.s.l., base of grass tussocks, by hand, 6 Oct. 2012, C.R.

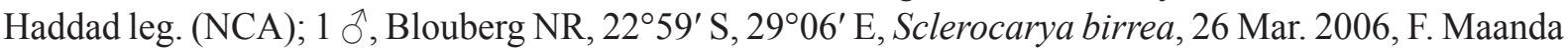

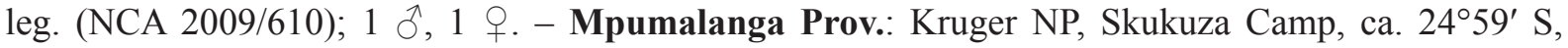

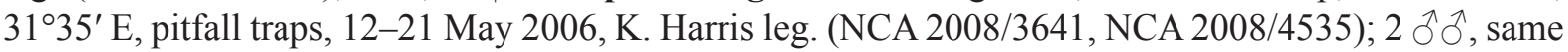
locality, active search, 28 Dec. 2005, K. Harris leg. (NCA 2008/4456); 1 ô, same locality, pitfall traps, 


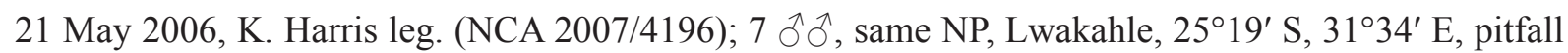
traps, 25-30 Jun. 2007, G. Ellis leg. (NCA 2008/1999); 1 ㅇ, same NP, Satara Camp, $25^{\circ} 08^{\prime}$ S, 31 ${ }^{\circ} 54^{\prime}$ E, pitfall traps, 18-23 Jun. 2007, G. Ellis leg. (NCA 2008/2001); 3 $\widehat{\jmath}, 1$,, Mpumalanga, Marble Hall, ca

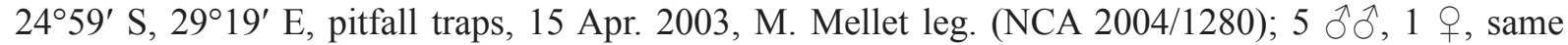
locality, Bt cotton, pitfall traps, 15 May 2002, M. Mellet leg. (NCA 2004/1281); 1 ô, ca $16 \mathrm{~km} \mathrm{~N}$ of Barberton, $25^{\circ} 38^{\prime} \mathrm{S}, 31^{\circ} 03^{\prime} \mathrm{E}$, ground traps, $10 \mathrm{Feb} .1987$, S. Endrödy-Younga leg. (TMSA 21523); 2 ō $^{\top}, 2$ 웅, Marble Hall, Wolwekraal, ca $24^{\circ} 58^{\prime}$ S, $29^{\circ} 17^{\prime}$ E, pitfall traps, 8 Nov. 1979, D. Uys leg.

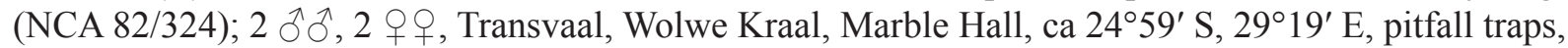

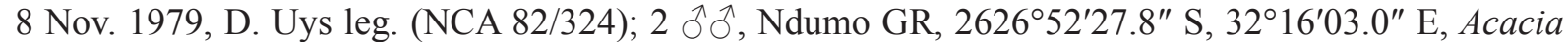
nigrescens woodland, in semi-shade, branches near termite galleries, 19 Jun. 2005, C. Haddad leg. (NCA 2006/676); 1 ऽ, 1 क , same locality and habitat, on sand nr Odontotermis termite mound, 17 Jun. 2005,

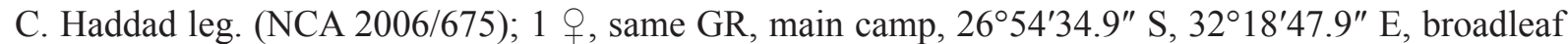
woodland, leaf litter nr termite galleries, 26 Jan. 2006, C. Haddad and R. Lyle leg. (NCA 2006/680); $2 \widehat{\partial} \partial^{\prime}$, same GR, $26^{\circ} 52^{\prime} 44.5^{\prime \prime} \mathrm{S}, 32^{\circ} 11^{\prime} 05.3^{\prime \prime} \mathrm{E}$, Acacia tortilis savanna, grassy leaf litter nr Odontotermis termite mound, 23 Jun. 2005, C. Haddad leg. (NCA 2006/679); 1 §, same GR, 26 51'54.5" S, $32^{\circ} 14^{\prime} 27.5^{\prime \prime}$ E, Mahemane thicket, leaf litter near Odontotermes mound, 15 Jun. 2005, C. Haddad leg. (NCA 2006/673). - KwaZulu-Natal Prov.: 1 đ̂, Ithala GR, Ngublu Loop, leaf litter, 1 Jul. 2007, C. Haddad leg. (NCA 2007/2810); 1 q, Ndumo GR, Crocodile Farm, 2654'25.6" S, 32¹9'11.1" E, under rocks, 12 Jan. 2007, C. Haddad leg. (NCA 2007/3064); 1 क, same locality, on ground nr termite galleries, 15 Jun. 2005, C. Haddad leg. (NCA 2006/674); 2 ऽึ, 3 웅, same GR, subtropical bush, under logs, 19 Jun. 2006, C. Haddad and F. Jordaan leg. (NCA 2006/1275); 1 q, same GR, Pongola River floodplain, Ezikebheni, 26 53'21.7" S, 32¹8'53.5" E, pitfall traps, 15-25 Jan. 2006, C. Haddad and R. Lyle leg. (NCA 2008/1876); 1 ${ }^{\prime}$, same GR, $26^{\circ} 52^{\prime} \mathrm{S}, 32^{\circ} 15^{\prime} \mathrm{E}$, Acacia nigriscens woodland, on Odontotermes termite mound, 18 Jun. 2005, C.R. Haddad leg. (NCA 2006/677); 1 ô, Hluhluwe/ Umfolozi NR, H953, 2 Dec. 2005, M. Mgobozi leg. (NCA 2007/2047); 1 đ, same locality, H652, 8 Oct. 2005, M. Mgobozi leg. (NCA 2007/2010); 1 ', Ophathe GR, $28^{\circ} 23^{\prime} \mathrm{S}, 31^{\circ} 23^{\prime} \mathrm{E}$, active search, under logs, 5 Jul. 2007, C. Haddad leg. (NCA 2007/2946); 1 ò $^{\wedge}$ same GR, $28^{\circ} 22^{\prime} \mathrm{S}, 31^{\circ} 23^{\prime} \mathrm{E}$, river bank,

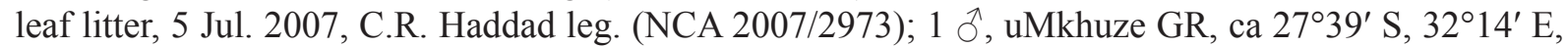

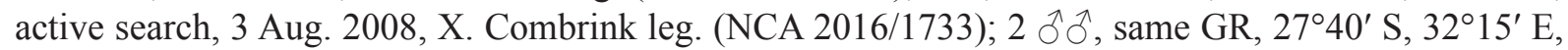
yellow pan trap, Acacia xanthophloea, 11 Nov. 2004, Earthwatch team 8 leg. (NCA 2015/4360); 1 , [Pretoria], Rietondale Research Station, $25^{\circ} 43^{\prime}$ S, $28^{\circ} 13^{\prime}$ E, on soil, pitfall traps, 19 Sep. 1998, J. Nkwana

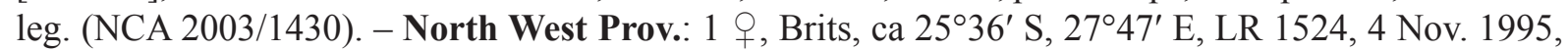
J. Leroy leg. (NCA 2007/2556); 1 đ’, 1 \%, Pilanesberg, Mogwase, ca $25^{\circ} 11^{\prime}$ S, $27^{\circ} 16^{\prime}$ E, pitfall traps, 15 Mar. 1999, R. Yarnell leg. (NCA 2003/1400, NCA 2003/1401). - Gauteng Prov.: 1 गे, Cullinan, Premier GR, $25^{\circ} 40^{\prime} \mathrm{S}, 28^{\circ} 29^{\prime}$ E, 10-11 Dec. 2001, TM staff leg. (TMSA 22772); $2 \delta^{\dagger} \delta^{\prime}$, Pretoria/ Tshwane, Buffelsdrift, ca $25^{\circ} 39^{\prime} \mathrm{S}, 28^{\circ} 21^{\prime}$ E, closed woodland, pan traps, 24 Jan. 2006, R. Koko leg.

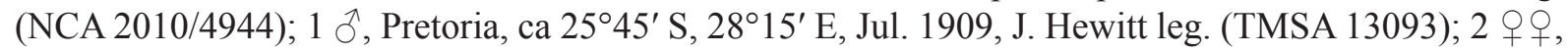
North-West Prov., Groot Marico, ca $25^{\circ} 00^{\prime}$ S, $26^{\circ} 25^{\prime}$ E, bush beating, 4 Dec. 1993, M. Filmer leg.

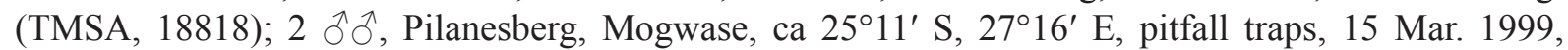
R. Yarnell leg. (NCA 2003/1402).

\section{Remarks}

The male leg and palp coloration of $S$. guttiger varies strongly; males with light and dark legs/palps coexist in the same local populations and thus can be found in the same museum samples.

The original data label for the lectotype of S. guttiger stands as 'Pretoria, Makapan' (=Mokopane); see Haddad \& Wesołowska (2006: 576). Unfortunately, we have been unable to re-examine the $\sigma^{\lambda}$ lectotype of $S$. guttiger designated by Haddad \& Wesołowska (2006). Having (re)examined the type series of S. natalensis (Figs 184-192, 204-206) and numerous specimens of S. guttiger from many localities (Figs 193-203), including Polokwane which is very close to one of the type localities (viz., Mokopane) 
mentioned by Haddad \& Wesołowska (2006), we have found out that all the studied specimens have an identical conformation of the copulatory organs and thus both species names are to be synonymized.

\section{Description}

Male

Description based on the following males: paratypes of S. natalensis, $5 \hat{\partial} \hat{\sigma}$ (NCA 2006/678); $4 \hat{\partial} \hat{\sigma}$

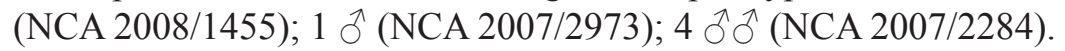

Measurements: carapace: $2.00-2.45$ long, $1.40-1.90$ wide, $1.00-1.55$ high. Abdomen: $1.80-2.40$ long, $1.35-1.90$ wide. Ocular area: $0.90-0.95$ long, $1.15-1.45$ wide anteriorly, $1.20-1.50$ wide posteriorly. Cheliceral length 0.45-0.70. Clypeal height 0.25-0.30. Diameter of AME 0.35-0.45. Length of leg segments (a paratype of S. natalensis): I $1.20+0.60+0.70+0.50+0.50$ (3.50); II $1.20+0.65+0.70+$ $0.50+0.45(3.50) ;$ III $1.75+0.90+1.05+1.20+0.50(5.40) ;$ IV $1.55+0.70+1.00+1.25+0.65(5.15)$. Leg formula III,IV,I/II. Leg spination (a paratype of S. natalensis): I: Fm d 0-1-1-5; Pt pr 0-1-0; Tb pr 1-1, v 1-1-2ap; Mt pr 1-1ap, rt 0-1ap, v 2-2ap. II: Fm d 0-1-2-5; Pt pr 0-1-0; Tb pr 1-1, v 1-1-2ap; Mt pr and rt 1-1ap, v 2-2ap. III: Fm d 1-0-2-5; Pt pr and rt 0-1-0; Tb d 1-0-0, pr and rt 1-1-1-1, v 1-0-2ap; Mt d 1-1-0, pr and rt 1-0-2ap, v 0-2-2ap. IV: Fm d 1-0-1-4; Pt pr and rt 0-1-0; Tb d 1-0-0, pr and rt 1-1-11, v 1-0-2ap; Mt d 1-1-0, pr 1-1-2ap, rt 1-0-2ap, v 1-2-2ap. Coloration (in alcohol: Figs 204-223; live specimens: Figs 224-226). Carapace dark brown, with almost black eye field, covered with long dark brown recumbent scales; there are two dorsal longitudinal white stripes and two lateral white stripes of scales, plus marginal stripes of dark brown scales. Clypeus and chelicerae could be brown to dark brown, sparsely covered with white hairs (in a specimen from Polokwane, NCA 2008/1455; Figs 211212), yellowish brown to brown, sparsely covered with white hairs (in the paratypes of $S$. natalensis, NCA 2006/678; Fig. 204), or dark brown, with the clypeus sparsely covered with whitish hairs while chelcerae densely with long white hairs (in the specimen from Ophathe, NCA 2007/2973; Figs 218, 222). Sternum yellow to yellowish brown. Endites and labium brownish yellow. Abdomen: dorsum dark brown, covered with dark brown recumbent scales, with a pattern of white wide stripe and V-shaped figure in its anterior half, and with three white spots (two smaller and one larger) on its rear half; some specimens have dark brown, almost black dorsum with only one caudal white spot; venter yellow, in some specimens with poorly marked brownish speckles. Book-lung covers yellow. Spinnerets: anterior and median pairs yellow; posterior pair dark brown. Legs yellow, brown or dark brown; Mt and Tr dark brown or black (e.g., in specimens with dark brown legs). Palps: yellow to brown (in a specimen from Polokwane, NCA 2008/1455; Figs 211-212); brown with yellow at the cymbium apex or yellow with the cymbium proximally covered with brown hairs (in the paratypes of $S$. natalensis, NCA 2006/678; Fig. 204); Fm and cymbium brown, Pt and Tb yellow, cymbium covered with white hairs (in the specimen from Ophathe, NCA 2007/2973; Figs 218, 222-223); or cymbium yellow, with the remaining segments brown to dark brown (in the specimen from Letaba, NCA 2007/2284; Fig. 219). Palpal structure as in Figs 194-203: VTA bulge-shaped, prominent; RTA claw-shaped, directed anteriad; the cymbium with a marked cymbial lateral process; the tegulum is relatively small, with a visible, obtuse tegular process (TP); the functional tegulum ovoid, with well-developed obtuse proximal (PP) and wide, spoon-shaped distal (DP) projections; the embolus short, claw-shaped, with a wide, round base.

\section{Female}

Description based on the following females: 3 q $q$ (NCA 2006/1275); 1 q (NCA 2008/2001); 1 q (NCA 2009/3738).

Measurements: carapace: $2.25-2.75$ long, $1.75-2.15$ wide, $1.15-1.40$ high. Abdomen: $2.0-2.90$ long, 1.85-2.20 wide. Ocular area: $0.90-1.00$ long, $1.30-1.60$ wide anteriorly, $1.35-1.65$ wide posteriorly. Cheliceral length $0.60-0.65$. Clypeal height 0.25-0.30. Diameter of AME 0.40-0.45. Length of leg segments (NCA 2006/1276): I $1.20+0.70+0.70+0.55+0.40$ (3.55); II $1.20+0.70+0.70+0.65+$ 

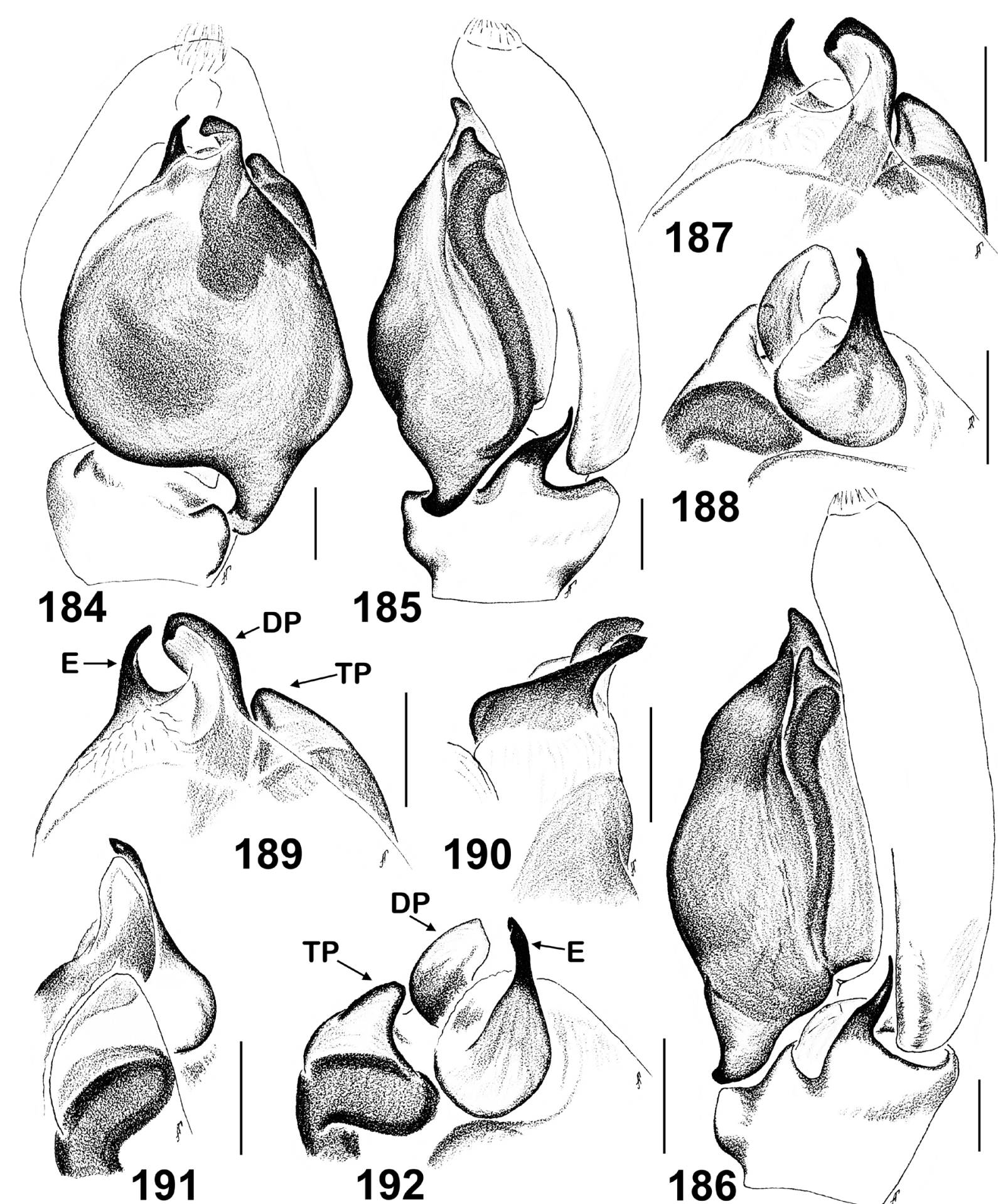

-DP
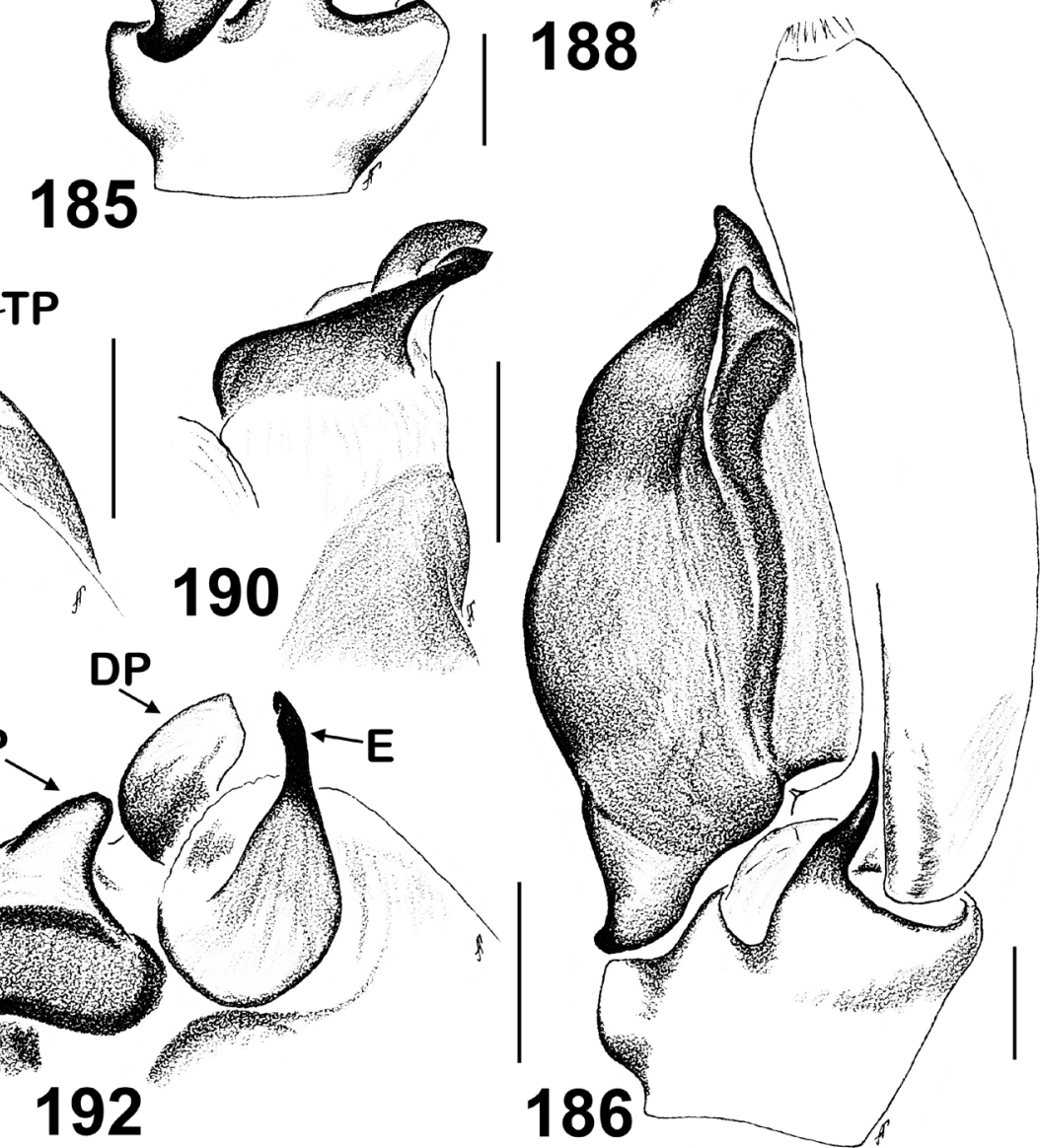

Figs 184-192. Male palp of Stenaelurillus guttiger (Simon, 1901). 184. Male palp, ventral view. 185186. Male palp, retrolateral view. 187-192. Embolic division. 187, 189. Ventral view. 188, 192. Dorsal view. 190. Median view. 191. Retrolateral view. Specimens: $186,189-192=$ paratype of $S$. natalensis Haddad \& Wesołowska, 2006 from South Africa (Ndumo GR; NCA 2006/678); 184-185, 187-188 from South Africa (Polokwane GR, NCA 2008/2067). Abbreviations: see Material and methods. Scale bars: $0.1 \mathrm{~mm}$. 
0.50 (3.75); III $1.90+1.00+1.20+1.40+0.60$ (6.10); IV $1.60+0.75+1.20+1.50+0.65$ (5.70). Leg formula III,IV,II,I. Leg spination (NCA 2006/1276): I: Fm d 0-1-1-5; Pt pr 0-1-0; Tb pr 1-1, v 1-1-2ap; Mt pr 1-1ap, v 2-2ap. II: Fm d 0-1-2-5; Pt pr 0-1-0; Tb pr 1-1, v 1-1-2ap; Mt pr 1-1ap, v 2-2ap. III: Fm d 1-2-5; Pt pr and rt 0-1-0; Tb d 1-0-0, pr and rt 1-1-1-1, v 1-0-2ap; Mt d 1-1-0, pr and rt 1-0-2ap, v 0-2-2ap. IV: Fm d 1-1-4; Pt pr and rt 0-1-0; Tb d 1-0-0, pr and rt 1-1-1-1, v 1-0-2ap; Mt d 1-1-0, pr

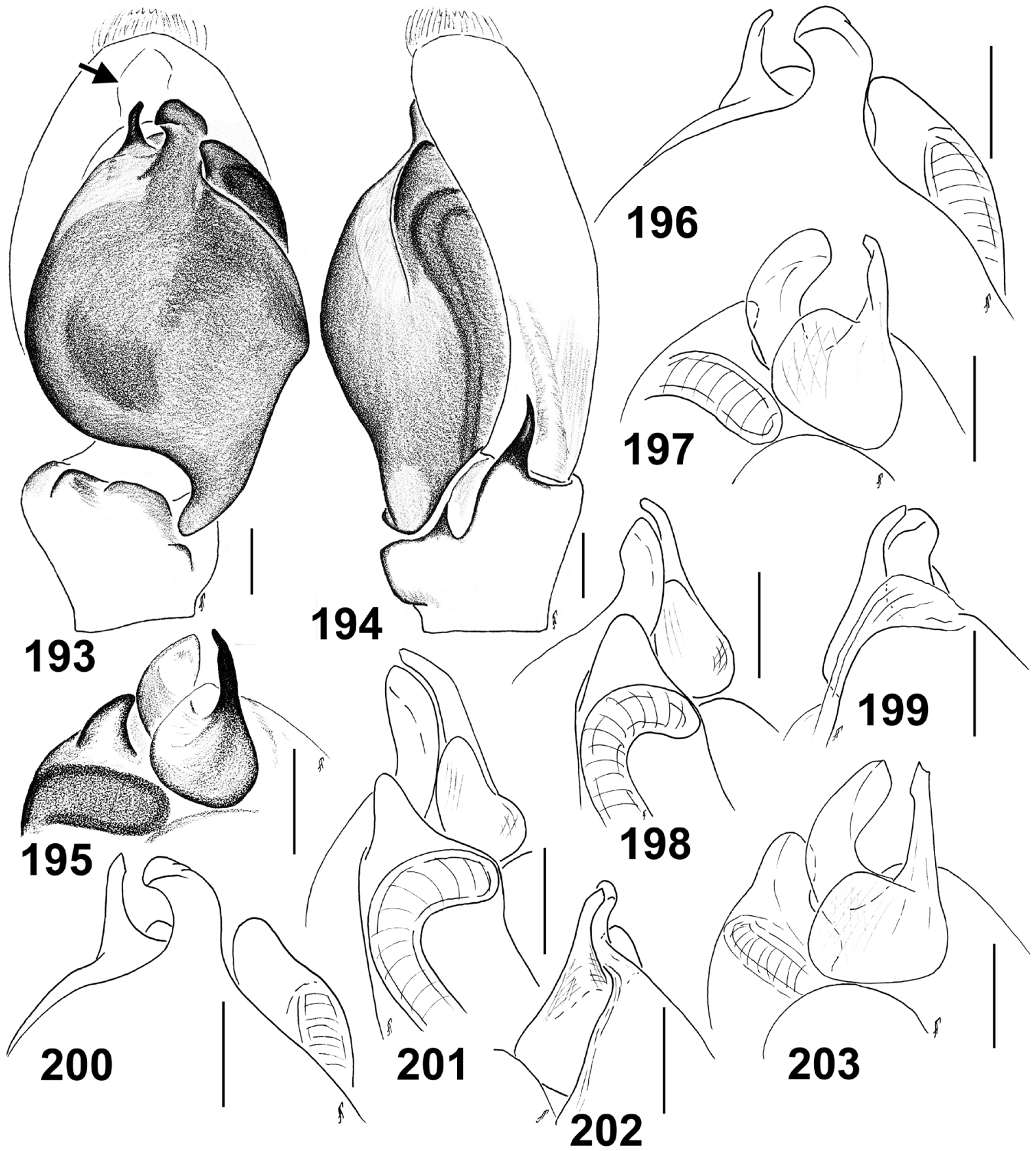

Figs 193-203. Male palp of Stenaelurillus guttiger (Simon, 1901). 193. Ventral view. 194. Retrolateral view. 195, 197, 203. Embolic division, dorsal view. 196, 200. Embolic division, ventral view. 198, 201. Embolic division, retrolateral view. 199, 202. Embolic division, median view. Specimens: $193-$ 194, 196-199 from Botswana (Francistown; NCA 2009/3744); 195 from South Africa (Ophathe GR; NCA 2007/2973); 200-203 from South Africa (Ndumo GR; NCA 2006/1275). Scale bars: $0.1 \mathrm{~mm}$. 
1-1-2ap, rt 1-0-2ap, v 1-2-2ap. Coloration (in alcohol; Figs 231-238) as in the male, but less bright and with less contrast. Eye field orange-brown. Mt and Tr I yellow to brownish yellow, as the remaining segments. Palps brown-yellow. Abdominal coloration varies, from as in the male to pale ones where only a median longitudinal white stripe and two white spots are poorly seen on the rear half of dorsum.

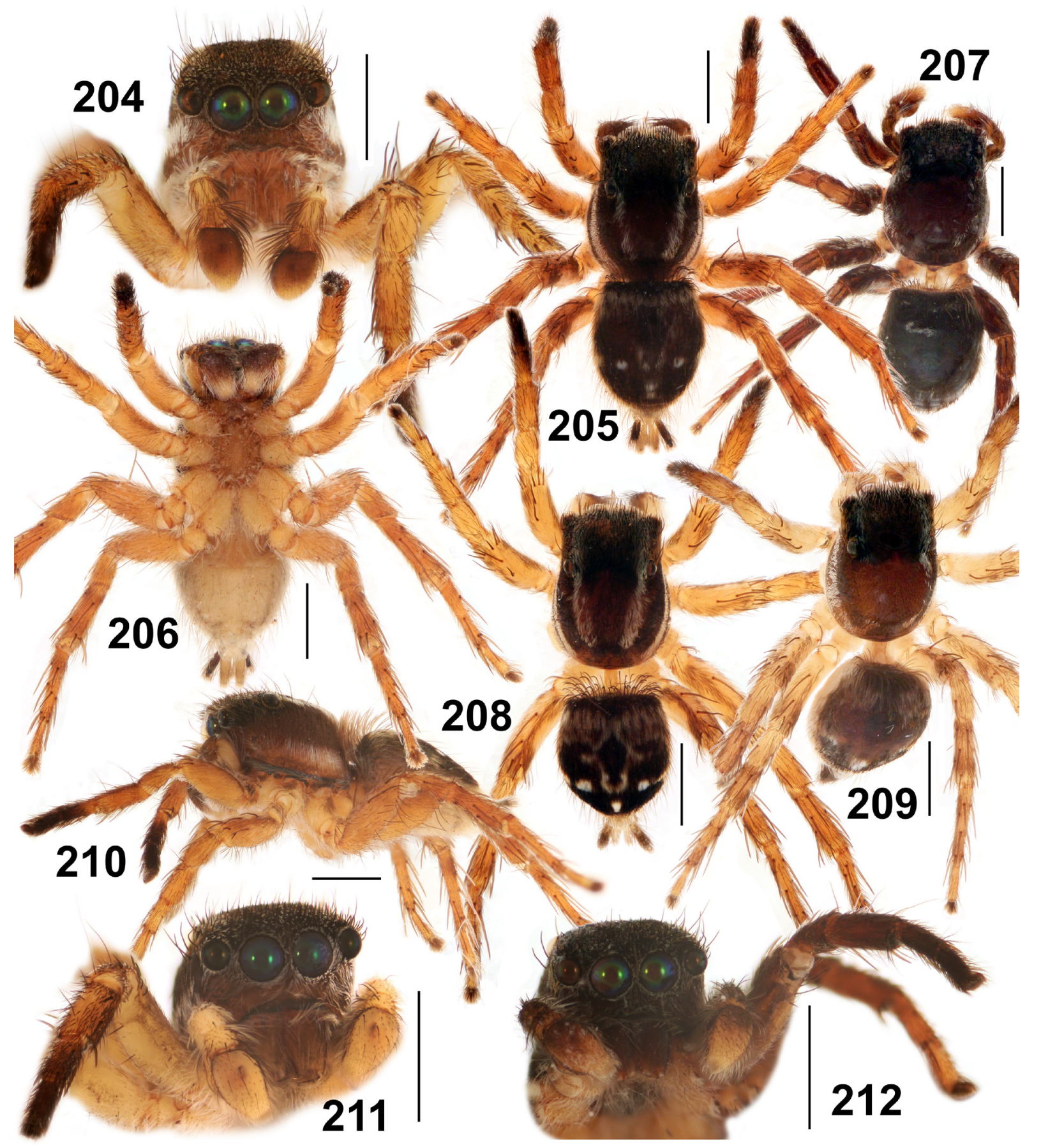

Figs 204-212. Stenaelurillus guttiger (Simon, 1901), $\widehat{\partial} \widehat{\partial}$, general appearance. Specimens: 204-206, 208, 210 paratype of S. natalensis Haddad \& Wesołowska, 2006 from South Africa (Ndumo GR; NCA 2006/678); 207, 209, 211-212 from South Africa (Polokwane GR; NCA 2008/2067). Scale bars: 1 mm. 


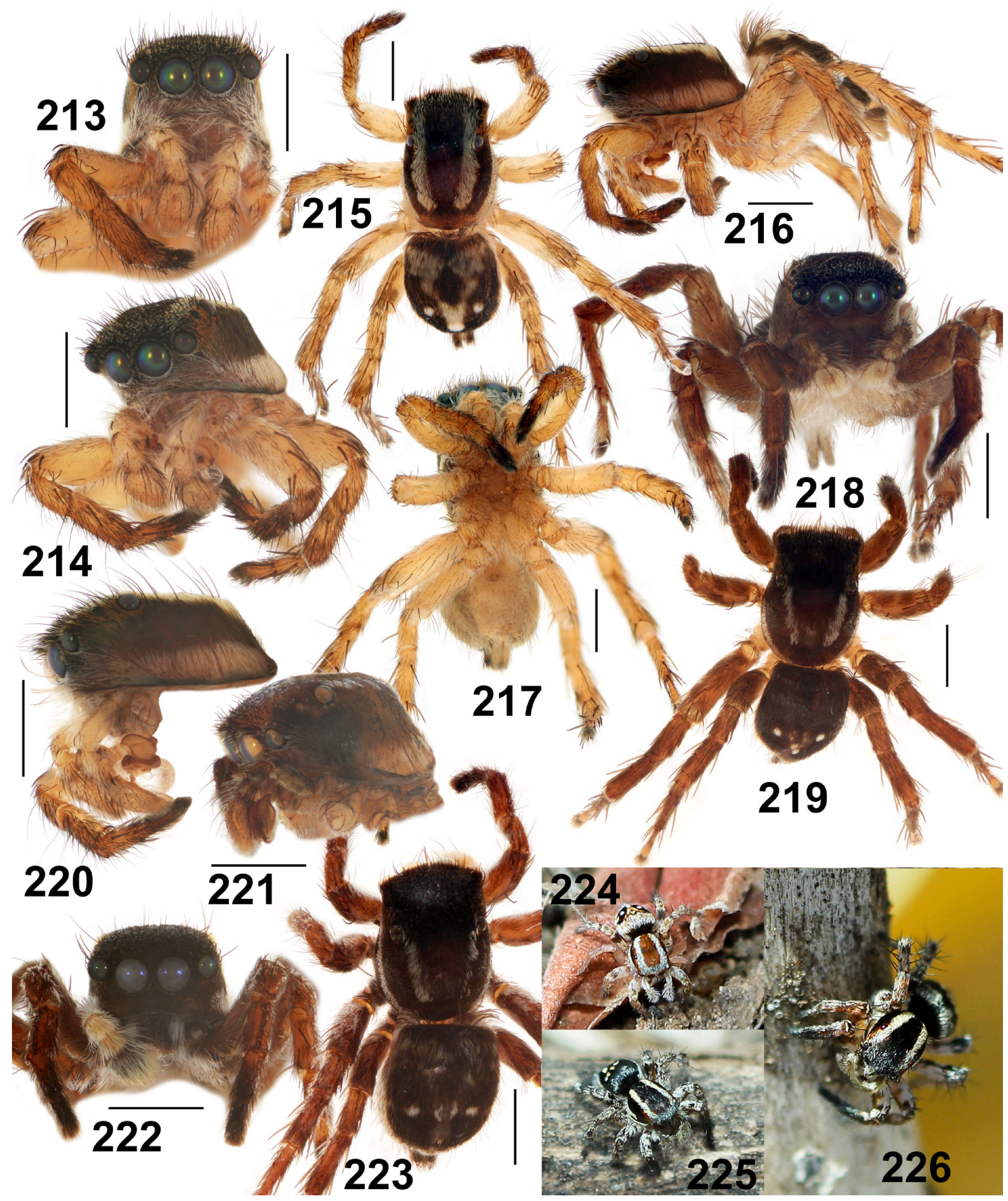

Figs 213-226. Stenaelurillus guttiger (Simon, 1901), $\widehat{\partial} \widehat{\partial}$, general appearance. Specimens: 213-217, 220-221 from Botswana (Francistown; NCA 2009/3744); 218, 222-223 from South Africa (Ophathe GR; NCA 2007/2973); 219 from South Africa (Kruger NP, Letaba; NCA 2007/2284); 224-226 from South Africa (Kruger NP, Shingwedzi Camp), photos ${ }^{\circledR}$ Galina Azarkina, juvenile (224) and two adult $\hat{0} \widehat{\delta}$ (225-226). Scale bars: $1 \mathrm{~mm}$. 
Epigyne and spermathecae as in Figs 227-230: the epigynal plate flat; the copulatory openings round, widely separated; epigynal pocket present, narrow and deep, its opening is shifted from the epigastric furrow by 1.5-2 diameters of the copulatory opening; the insemination ducts wide and short; the primary spermathecae oval, only slightly wider than the insemination ducts.

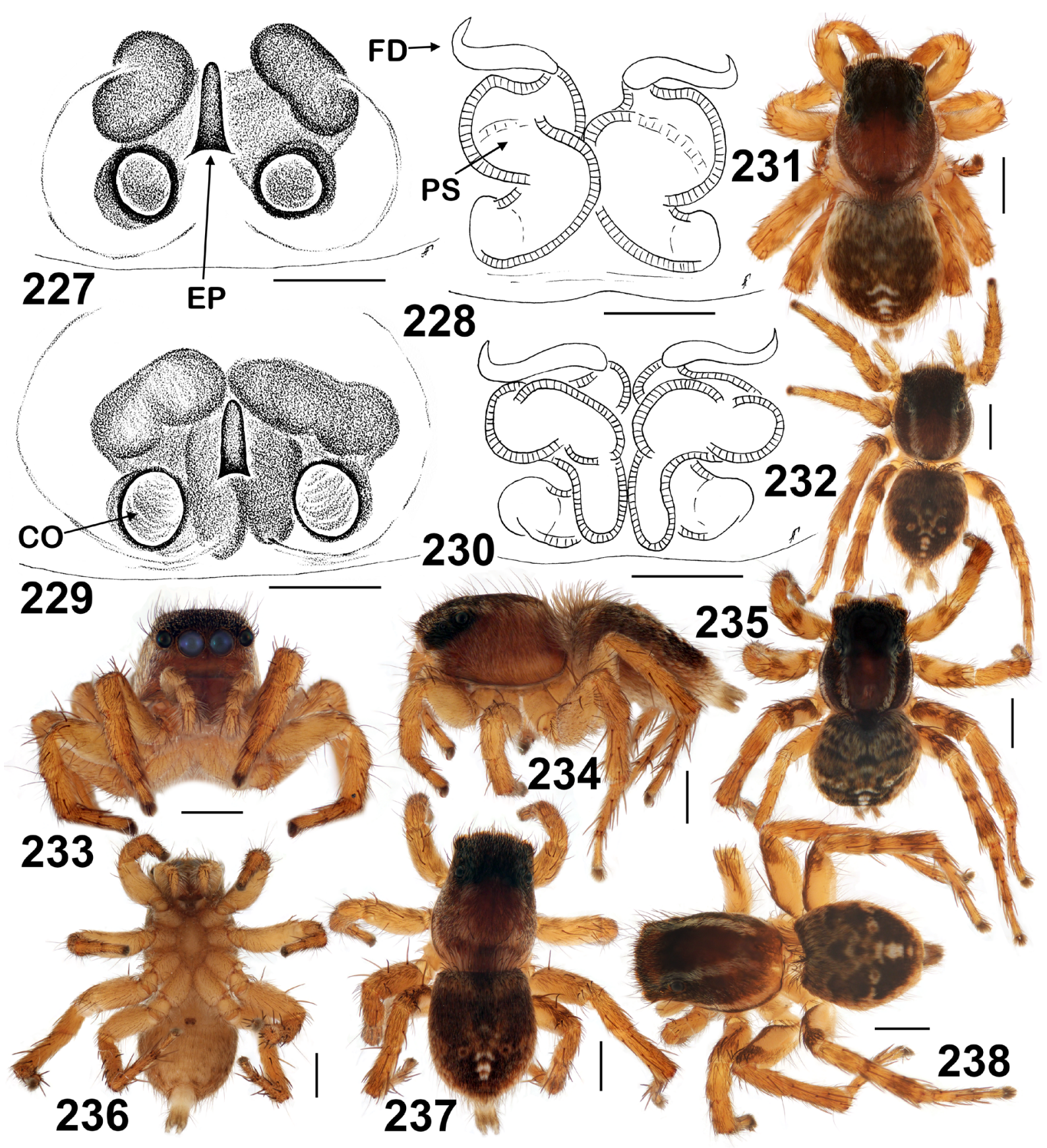

Figs 227-238. Stenaelurillus guttiger (Simon, 1901), + + . 227, 229. Epigyne, ventral view. 228, 230. Spermathecae, dorsal view. 231-238. General appearnce. Specimens: 227-228, 235, 238 from South Africa (Ndumo GR; NCA 2006/1275); 229-230, 232 from South Africa (Kruger NP, Satara; NCA 2008/2001); 231 from South Africa (Kruger NP, Pafuri; NCA 2007/2474); 233-234, 236-237 from South Africa (Kruger NP, Oliphants; NCA 2009/3738). Scale bars: 227-230 =0.1 mm; 231-238= $1 \mathrm{~mm}$. 


\section{Distribution}

Southern Africa (Fig. 512).

Stenaelurillus hirsutus Lessert, 1927

Figs 3, 239-263, 513

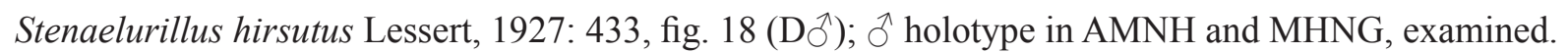

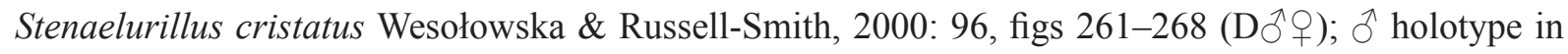
MRAC, examined.

\section{Diagnosis}

By the conformation of the copulatory organs (Figs 239-242, 246-251), the males of S. hirsutus are almost identical to those of $S$. glaber (Figs 156-160), S. pilosus (Figs 406-410), and S. striolatus (Figs 463-467). Males of all these species can easily be distinguished by the clypeal colour pattern: black with three vertical white stripes in S. hirsutus (Figs 245, 253, 255), yellow clypeus with long sparse white hairs in S. glaber (Fig. 161), with a transverse dark brown band in S. pilosus (Fig. 413), and entirely dark brown/black in S. striolatus (Fig. 468). The shape of the distal projection (DP) of the functional tegulum also seems to be diagnostic (cf. Figs 239, 246 with Figs 156, 406, 463). Besides, the eye field of S. hirsutus bears a dense bunch (like a mane) of dark brown and transparent hairs (Figs 243, 252); of the related species only S. pilosus has a similar but much less developed "mane" on the eye field (Fig. 416). The females of S. hirsutus (Figs 262-263) are most similar to and are poorly separable from those of S. pilosus (Figs 411-412); the shape of the primary spermathecae seems to be diagnostic: elongated, sac-shaped in S. hirsutus and round in S. pilosus.

\section{Material examined}

\section{Holotype}

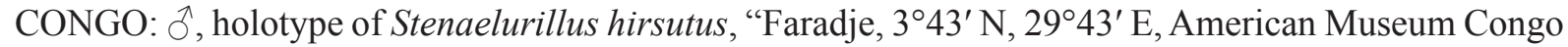
Expedition, det. R. de Lessert" (AMNH: carapace without legs on its left side, detached abdomen and detached right palp; MHNG: the left palp broken in two parts).

\section{Other types}

TANZANIA: ${ }^{\lambda}$, holotype of Stenaelurillis cristatus, Mkomazi GR, between Ndeya [= Ndea] and Mbula Hills, ca $03^{\circ} 53^{\prime}$ S, 3753' E, grassland, 24 Nov. 1994, A. Russell-Smith leg. (MRAC 208.011); 1 q, paratype of Stenaelurillis cristatus, same collecting data as for the holotype of Stenaelurillis cristatus (MRAC 208.012).

\section{Other material}

UGANDA: 1 ㅇ, Murchison falls, $2^{\circ} 17^{\prime}$ N, 31 ${ }^{\circ} 41^{\prime}$ E, 10 Nov. 1963, J.L. Cloudsley-Thompson leg. (MRAC 125.917).

KENYA: $1 \hat{\jmath}, 4$ 우, Rift Val. [Great Rift Valley], ca $0^{\circ} 26^{\prime} 33^{\prime \prime} \mathrm{N}, 36^{\circ} 14^{\prime} 24^{\prime \prime}$ E, Baringo [Lake], C.I.,

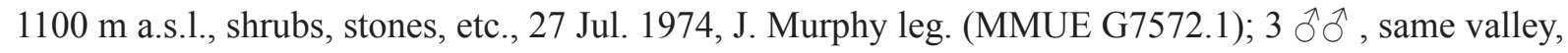
Mtemberr, 1400 m a.s.l., grassy scrub, 19 Aug. 1972, J. Murphy leg. (MMUE G7572.2); 1 , same valley, Kongelai, $1400 \mathrm{~m}$ a.s.l., dry scrub, 17 Aug. 1972, J. Murphy leg. (MMUE G7572.3); 2 $\partial^{\text {, }}$, same valley, Kacheliba, ca $1^{\circ} 17^{\prime} 24.6^{\prime \prime}$ N, 3504'47.0" E, 1400 m a.s.1., hot dry area, 1 Aug. 1972, J. Murphy leg. (MMUE G7572.4); 4 우, same valley, Keringet Dam, 2000 m a.s.1., shrubs, litter, etc., 23 Jul. 1974,

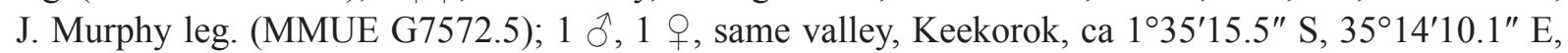
1500 m a.s.1., hotel ground, 24 Jul. 1972, J. Murphy leg. (MMUE G7572.8); 1 O, Lambwe, Homabay 
Farmers Training Centre, ca $00^{\circ} 40^{\prime} \mathrm{S}, 34^{\circ} 15^{\prime} \mathrm{E}$, beating maize, 13 Mar. 2003, C. Mibega leg. (NCA 2005/2130).

\section{Remarks}

Parts of the male holotype of Stenaelurillus hirsutus are kept in two museums: AMNH and MHNG. The former holds the body (the carapace detached from the abdomen and without legs on its left side) and the
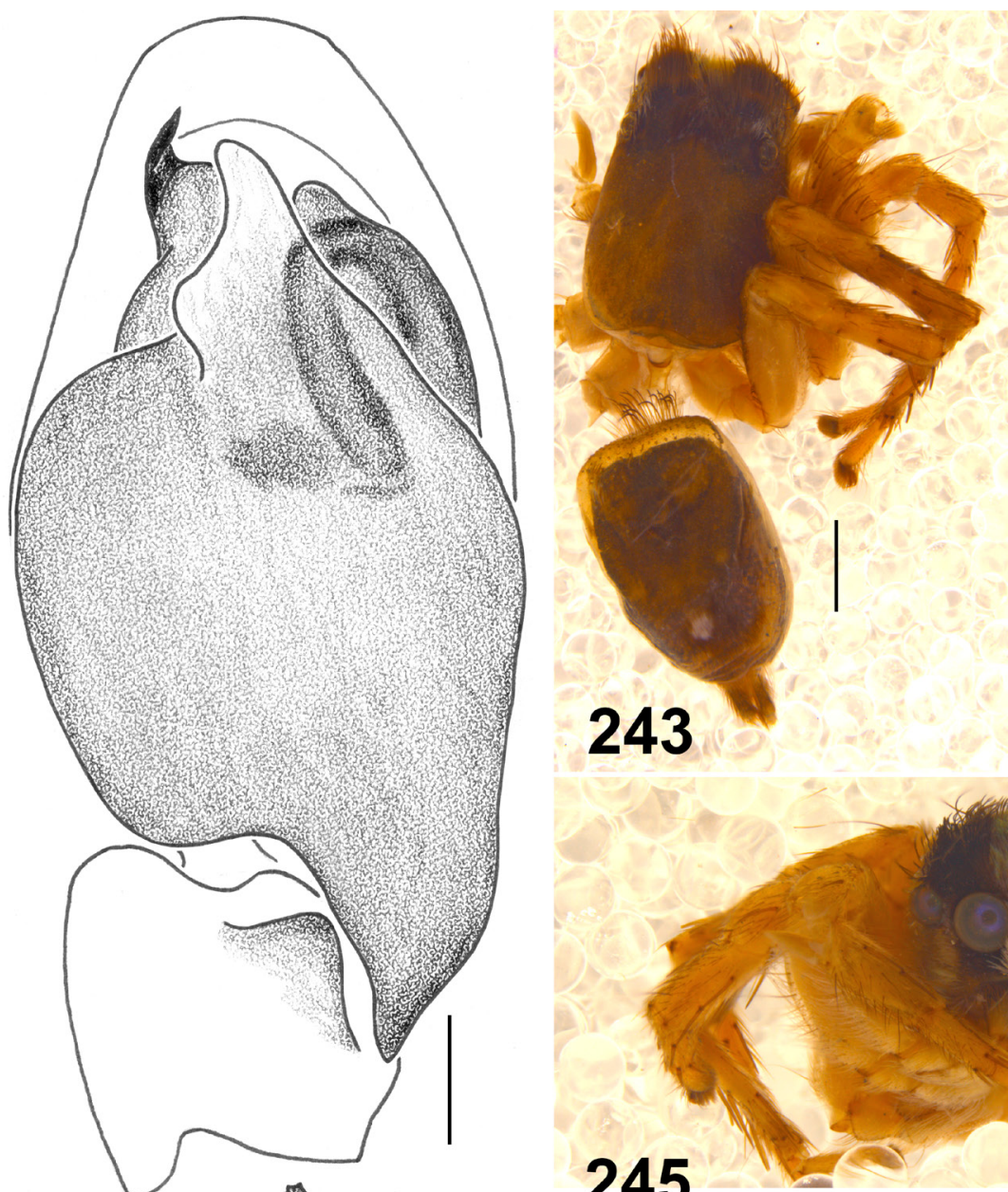

243
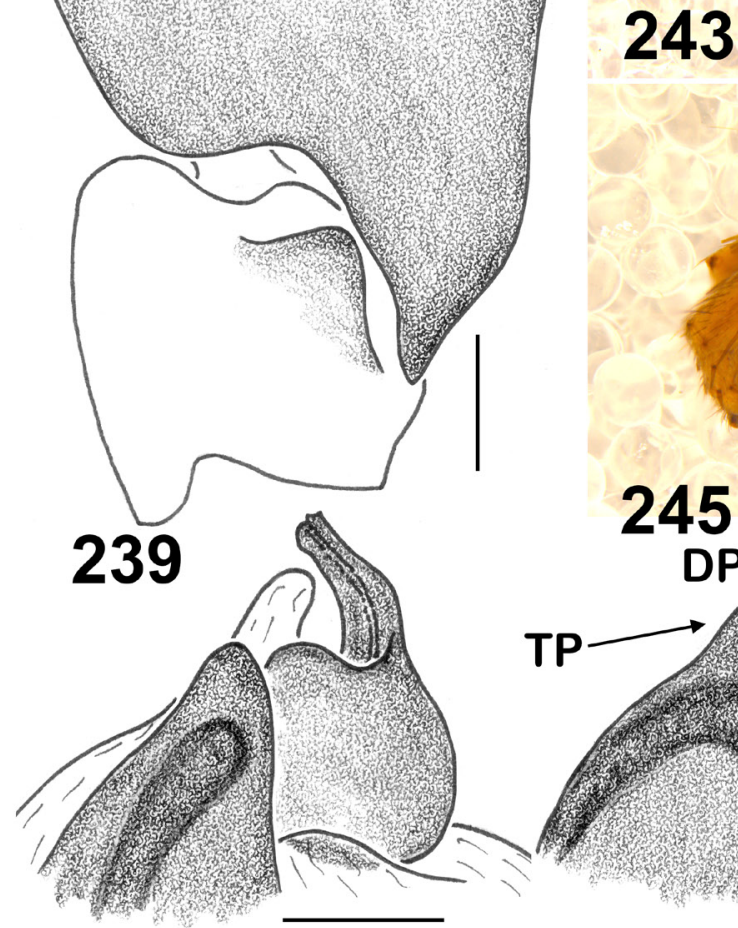

240

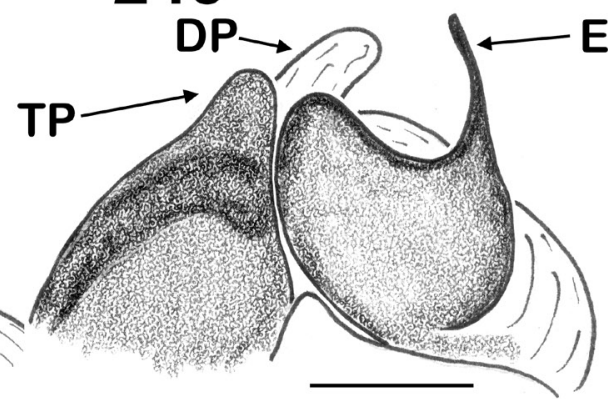

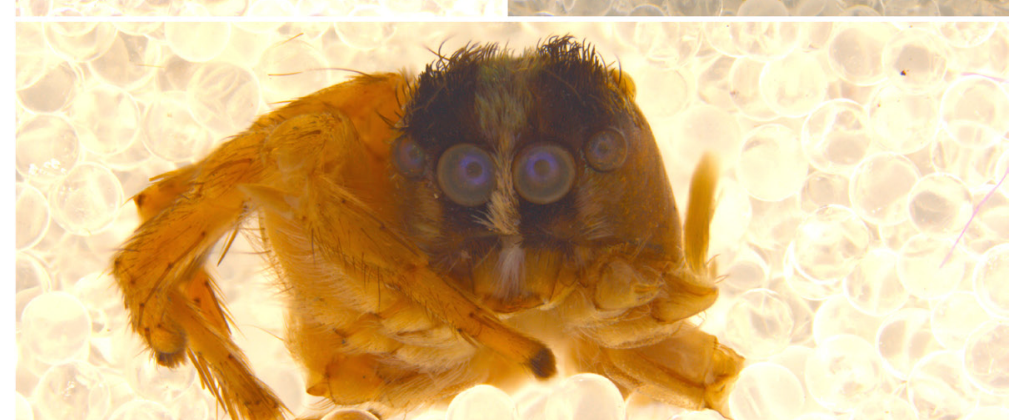
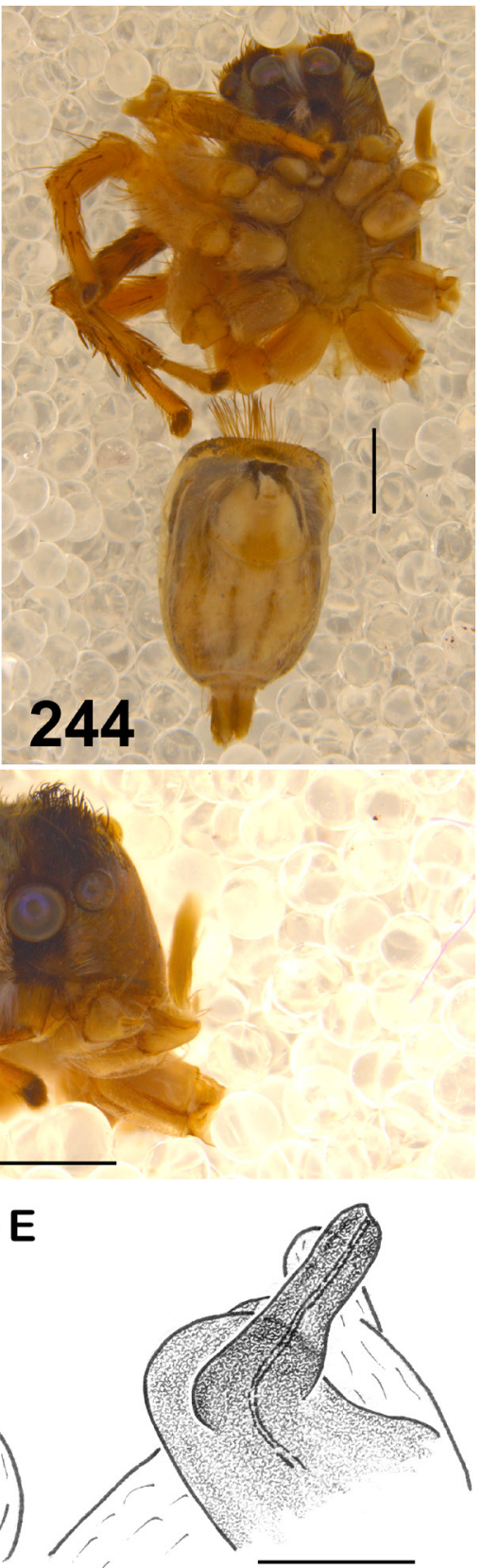

242

Figs 239-245. Stenaelurillus hirsutus Lessert, 1927, holotype. 239. Male palp, ventral view. 240. Embolic division, retrolateral view. 241. Embolic division, dorsal view. 242. Embolic division, median view. 243-245. General appearance. Abbreviations: see Material and methods. Scale bars: $239-242=0.1 \mathrm{~mm}$; $243-245=1 \mathrm{~mm}$. 
detached right palp, the latter holds the left male palp broken in two parts (the cymbium with the bulbus and the remaining segments of the palp).

\section{Description}

Male (holotype of S. cristatus, MRAC 208.011)

Measurements: carapace: 2.50 long, 1.80 wide, 1.40 high. Abdomen: 2.30 long, 1.65 wide. Ocular area: 0.90 long, 1.45 wide anteriorly, 1.40 wide posteriorly. Cheliceral length 0.60 . Clypeal height 0.35 . Diameter of AME 0.40. Length of leg segments: I $1.00+0.65+0.80+0.50+0.50$ (3.45); II $1.15+0.65$

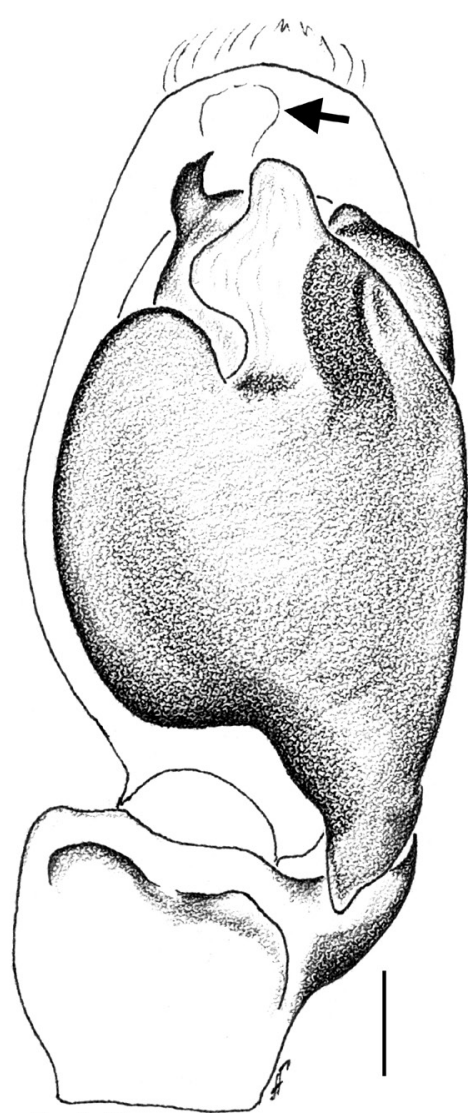

246

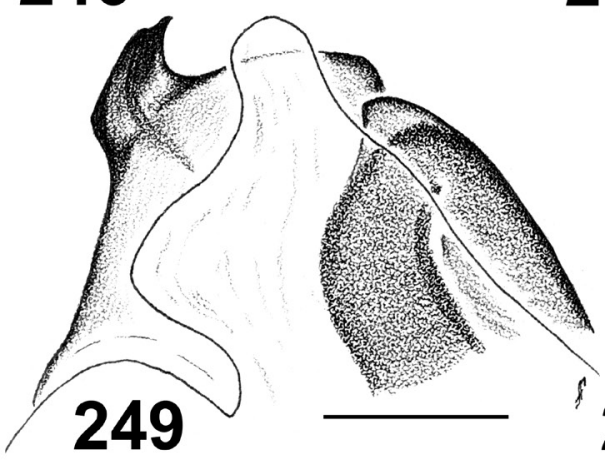

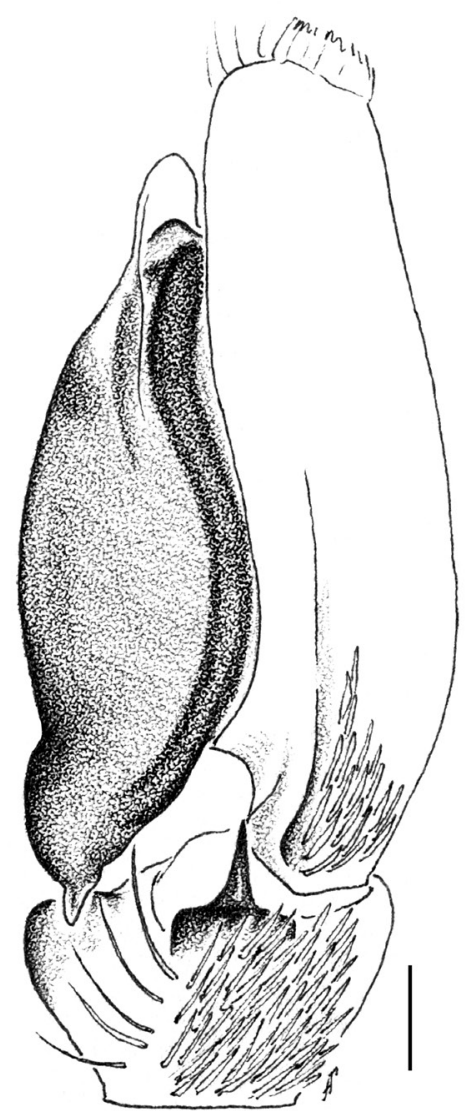

247

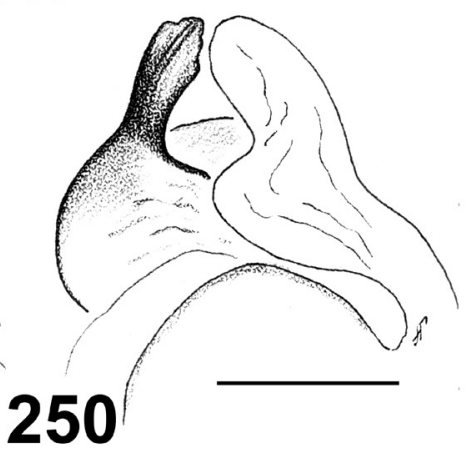

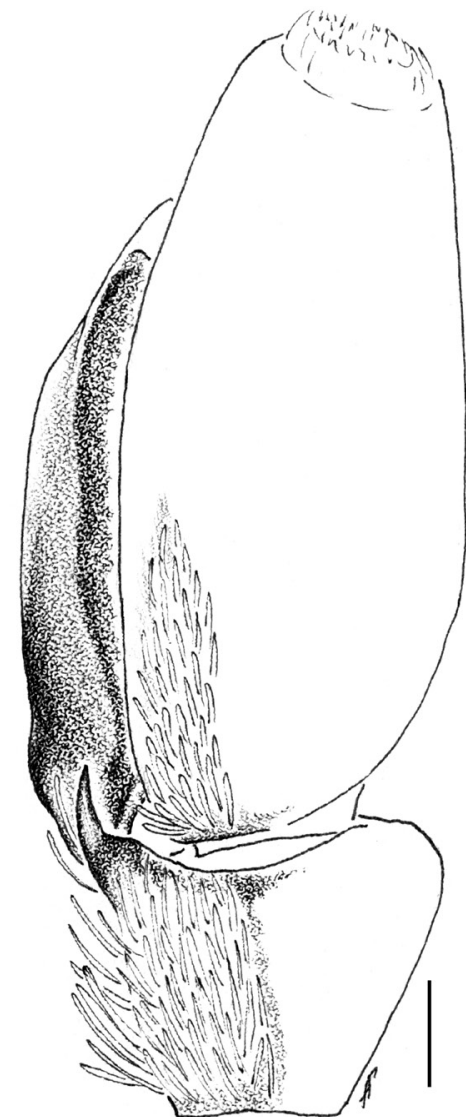

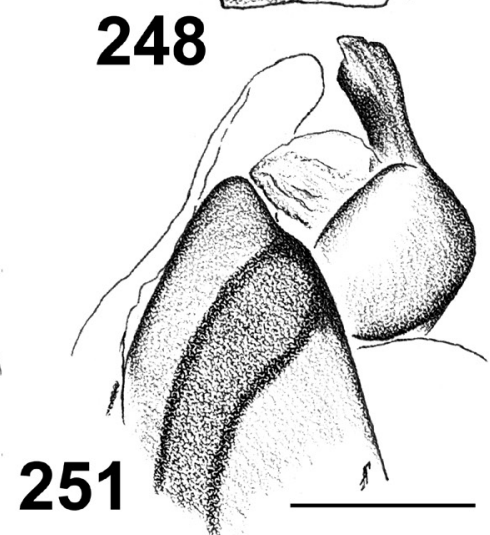

Figs 246-251. Stenaelurillus hirsutus Lessert, 1927 (holotype of Stenaelurillus cristatus Wesołowska \& Russell-Smith, 2000). 246. Male palp, ventral view. 247. Male palp, retrolateral view. 248. Male palp, dorsal view. 249. Embolic division, ventral view. 250. Embolic division, median view. 251. Embolic division, retrolateral view. Scale bars: $0.1 \mathrm{~mm}$. 
$+0.70+0.55+0.50(3.55) ;$ III $1.80+0.90+1.20+1.40+0.60(5.90) ;$ IV $1.50+0.75+1.10+1.40+$ 0.70 (5.45). Leg formula III,IV,II,I. Leg spination: I: Fm d 0-1-1-5; Pt pr 1; Tb pr 1-1, v 1-2-2ap; Mt pr and rt 0-1ap, v 2-2ap. II: Fm d 0-1-2-5; Pt pr 1; Tb pr 1-1, rt 0-1, v 1-1-2ap; Mt pr and rt 1-1ap, v 2-2ap. III: Fm d 1-0-2-5; Pt pr and rt 1; Tb d 1-0-0, pr and rt 1-1-1-1, v 1-0-2ap; Mt d 1-1-0, pr and rt 1-0-2ap, v 0-2-2ap. IV: Fm d 1-0-1-5; Pt pr and rt 1; Tb d 1-0-0, pr and rt 1-1-1-1, v 1-0-2ap; Mt d 1-1-0, pr 1-1-2ap, rt 1-0-2ap, v 0-2-2ap. Coloration (in alcohol; Figs 243-245, 252-257). Carapace dark brown, covered with dark brown recumbent scales, dorsally with two wide white stripes of scales running from PLEs to $3 / 4$ of the carapace length; laterally carapace with wide white bands of scales on its thorax and with dense and long brown hairs on its head; eye field densely covered with hairs that are shorter at the first eye row and become higher at PLEs; clypeus striped, with two wide vertical bands of short dark brown hairs below AMEs and three narrow stripes of white iridescent hairs (between AMEs and on cheeks) running up to the eye field. Sternum dark brown. Endites and labium light brown. Chelicerae brown, covered with brown hairs. Abdomen: dorsum dark brown, with two longitudinal narrow lines of white hairs on its anterior half and three white dots (smaller paired ones and a larger caudal one) on its rear

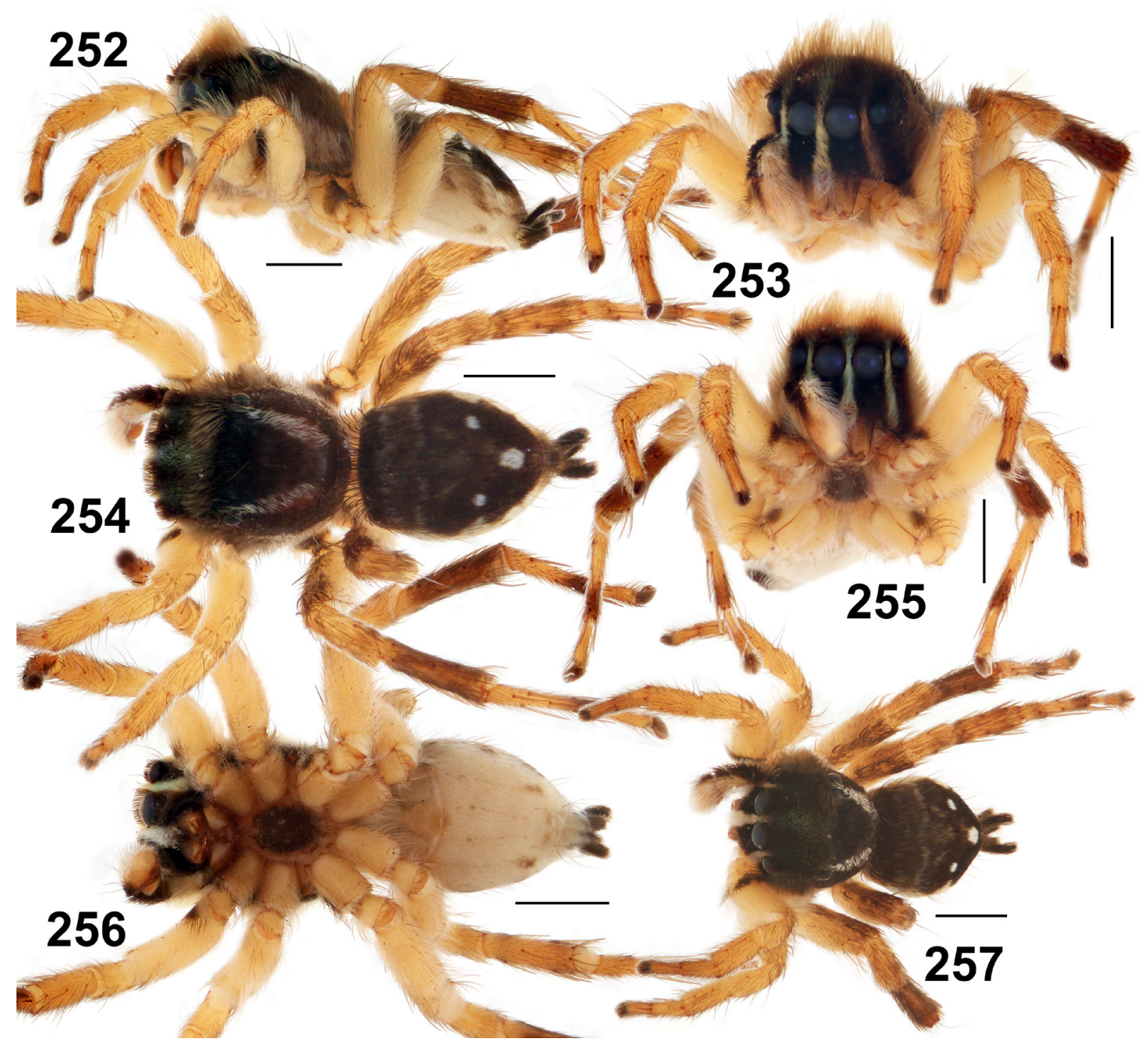

Figs 252-257. Stenaelurillus hirsutus Lessert, 1927 (holotype of Stenaelurillus cristatus Wesołowska \& Russell-Smith, 2000) from Tanzania (Mkomazi GR), general appearance. Scale bars: $1 \mathrm{~mm}$. 
half; venter yellow, with two small round spots on its caudal part. Book-lung covers yellow. Spinnerets dark brown. Legs brownish yellow. Fm I-II dorsally and ventrally with dense yellow hairs; Fm I basally with a prolatero-ventral dark brown transverse spot. Legs III-IV covered with dark brown hairs. Palps yellow, their Fm covered with yellow transparent iridescent hairs, dorsally dark brown; Pt, $\mathrm{Tb}$ and basal part of the cymbium prolaterally-dorsally densely covered with dark brown hairs, their remaining sides covered with white hairs. Palpal structure as in Figs 239-242, 246-251: VTA bulge-shaped; RTA thorn-shaped, directed anteriad; the cymbium without cymbial lateral process; the tegulum is relatively small, with poorly-developed, obtuse tegular process (TP); the functional tegulum elongated, with welldeveloped narrow proximal (PP) and wide distal (DP) projections; the embolus short ribbon-shaped, with a wide, round base.

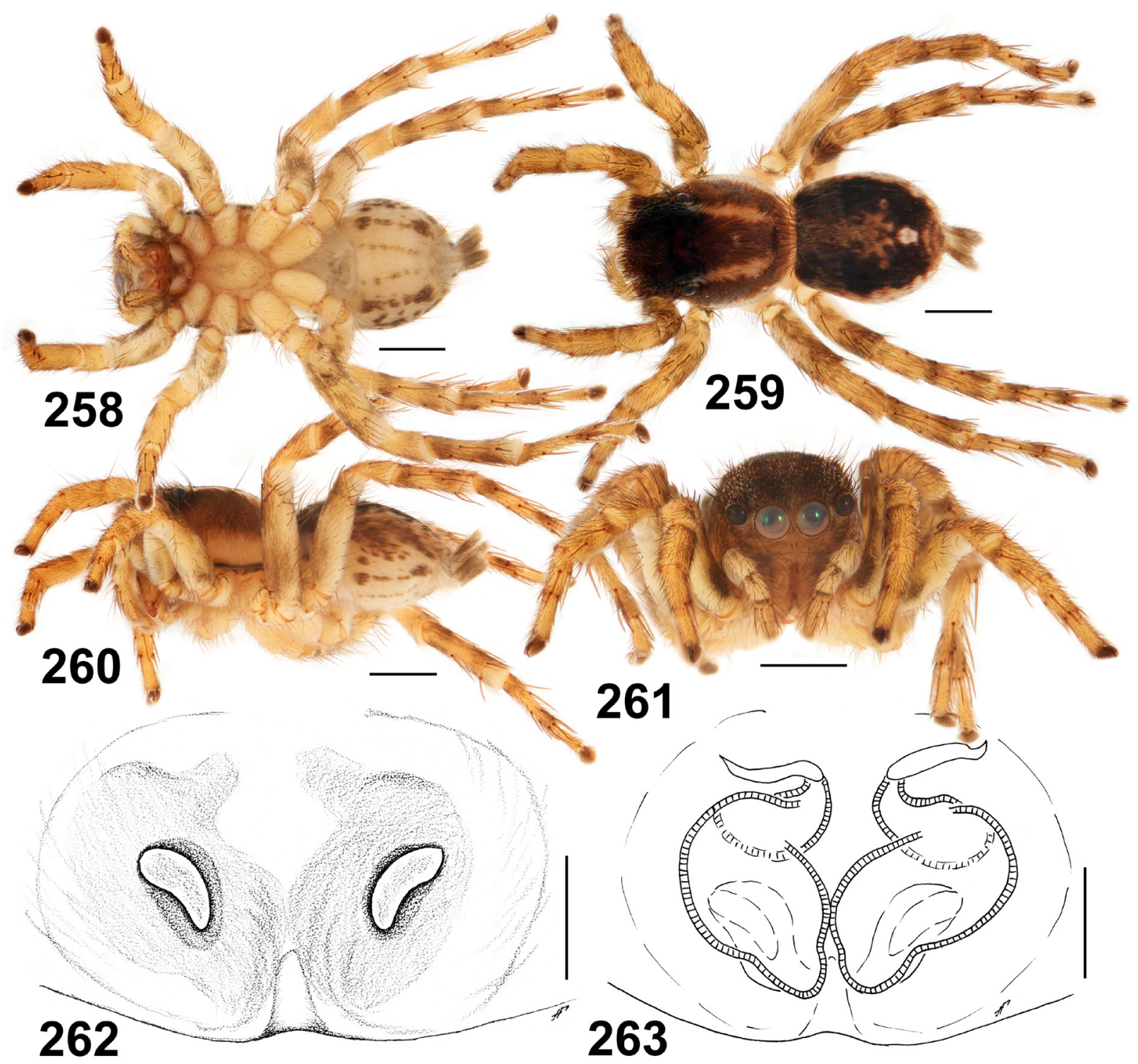

Figs 258-263. Stenaelurillus hirsutus Lessert, 1927, $q$ (paratype of Stenaelurillus cristatus Wesołowska \& Russell-Smith, 2000) from Tanzania (Mkomazi GR). 258-261. General appearance. 262. Epigyne, ventral view. 263. Spermathecae, dorsal view. Scale bars: $258-261=1 \mathrm{~mm} ; 262-263=0.1 \mathrm{~mm}$. 
Female (the allotype of $S$. cristatus, MRAC 208.012)

Measurements: carapace: 2.60 long, 2.05 wide, 1.60 high. Abdomen: 2.40 long, 2.05 wide. Ocular area: 1.10 long, 1.55 wide anteriorly, 1.50 wide posteriorly. Cheliceral length 0.80 . Clypeal height 0.35 . Diameter of AME 0.45. Length of leg segments: I $1.30+0.70+0.85+0.60+0.50$ (3.95); II $1.30+0.70$ $+0.70+0.55+0.50(3.75) ;$ III $2.10+1.00+1.30+1.50+0.65(6.55) ;$ IV $1.75+0.90+1.10+1.50+$ 0.80 (6.06). Leg formula III,IV,I,II. Leg spination: I: Fm d 0-1-1-5; Pt pr 1; Tb pr 1-1, v 1-1-2ap; Mt pr 0-1ap, v 2-2ap. II: Fm d 0-1-2-5; Pt pr 1; Tb pr 1-1, v 1-1-2ap; Mt pr 1-1ap, rt 0-1ap, v 2-2ap. III: Fm d 0-0-2-5; Pt pr and rt 1; Tb d 1-0-0, pr and rt 1-1-1-1, v 1-0-2ap; Mt d 1-1-0, pr and rt 1-0-2ap, v 0-22ap. IV: Fm d 0-1-1-4; Pt pr and rt 1; Tb d 1-0-0, pr and rt 1-1-1-1, v 1-0-2ap; Mt d 1-1-0, pr 1-1-2ap, rt 1-0-2ap, v 0-2-2ap. Coloration (in alcohol; Figs 258-261). Carapace brown, covered with dark brown recumbent scales, dorsally with two longitudinal yellow stripes covered with white recumbent scales and with wide lateral bands of white scale on sides. Sternum yellow. Endites and labium brown-yellow. Chelicerae brown-yellow. Clypeus and cheeks yellow, sparsely covered with brown hairs. Abdomen: dorsum dark brown, with a poorly marked leaf-shaped pattern along the middle line and with three dots: two smaller ones and a larger spot situated on the caudal part of the dorsum; venter yellow, with four rows of small brown dots. Book-lung covers yellow. Spinnerets brown. Legs yellow, covered with dark brown hairs. All Fm apically and Tb and Mt III-IV basally and apically with dark brown semi-rings. Epigyne and spermathecae as in Figs 252, 262: the epigynal plate flat; the copulatory openings beanshaped, widely separated; epigynal pocket present, narrow and deep; the insemination ducts very short, invisible in dorsal view; the primary spermathecae large, resembling $\mathrm{C}$-shaped sacs.

\section{Distribution}

Central and west Africa, roughly along the zone between $10^{\circ} \mathrm{N}$ and $10^{\circ} \mathrm{S}$ (Fig. 513).

\section{Stenaelurillus iubatus Wesołowska \& Russell-Smith, 2011}

Figs 264-279, 512

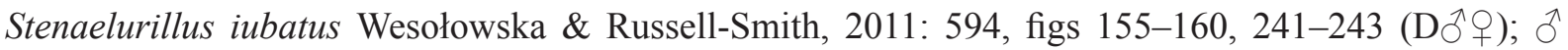
holotype from BMNH, not examined.

Stenaelurillus pilosus Wesołowska \& Russell-Smith, 2011: 595 (Dへ̊); in part, $\uparrow$ paratype (BMNH) (misidentification).

\section{Diagnosis}

This species can be distinguished from all other species of Stenaelurillus by the ribbon-shaped embolus with a very massive, swollen base and a characteristic bunch of long orangish brown hairs on the eye field (Figs 264-273) in the male, and by the transverse-oriented copulatory openings situated close to the epigastric furrow in the female (Fig. 278; see also Wesołowska \& Russell-Smith 2011: figs 159-160).

\section{Material examined}

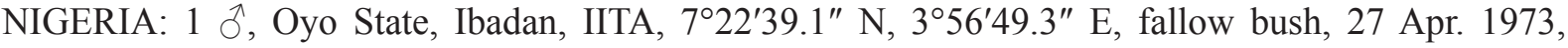
A. Russell-Smith leg. (MMUE G7583.3); 1 đ, same locality, on Zea mays, 21 Jul. 1981, A. RussellSmith leg. (MMUE G7583.4); 1 \&, Ibadan, road verge, 20 May 1973, A. Russell-Smith leg. (BMNH, paratype of $S$. pilosus).

\section{Remarks}

One female paratype from the type series of S. pilosus $(8 \hat{\jmath} \widehat{\partial}, 7$ + $q)$, designated by Wesołowska \& Russell-Smith (2011), turned out to belong to S. iubatus (see Figs 274-279); its description is given below. 


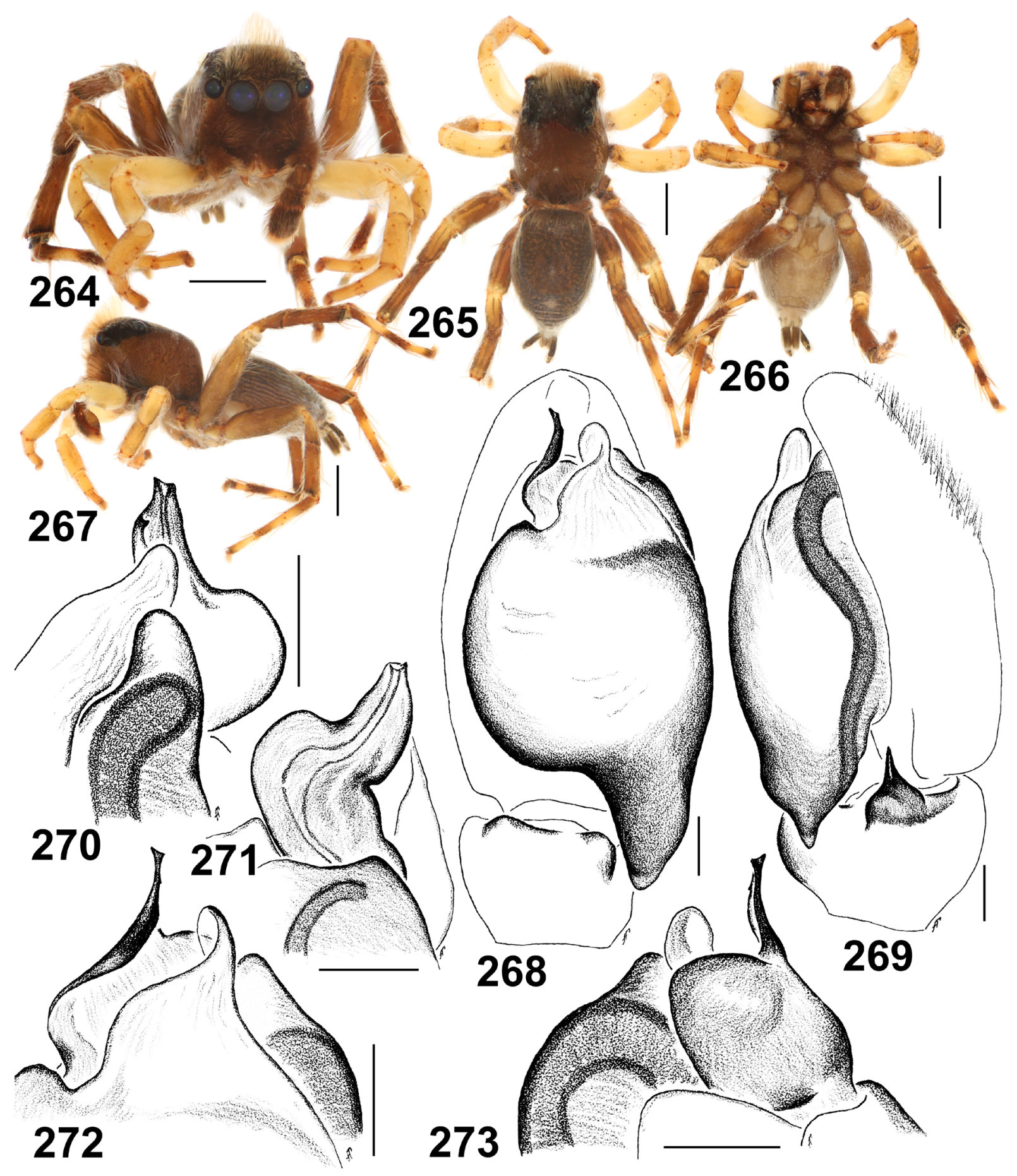

Figs 264-273. Stenaelurillus iubatus Wesołowska \& Russell-Smith, 2011, $\widehat{\partial}$, from Nigeria (Ibadan). 264-267. General appearance. 268. Male palp, ventral view. 269. Male palp, retrolateral view. 270273. Embolic division. 270. Retrolateral view. 271. Median view. 272. Ventral view. 273. Dorsal view. Scale bars: $264-267=1 \mathrm{~mm} ; 268-273=0.1 \mathrm{~mm}$. 


\section{Description}

Male (MMUE G7583.4)

Measurements: carapace: 2.70 long, 1.80 wide, 1.60 high. Abdomen: 2.30 long, 1.65 wide. Ocular area: 0.90 long, 0.95 wide anteriorly, 0.90 wide posteriorly. Chelicerae length 0.50 . Clypeal height 0.35 . Diameter of AME 0.45. Length of leg segments: I $1.10+0.70+0.80+0.60+0.45$ (3.65); II $1.20+0.70$ $+0.80+0.65+0.45(3.80) ;$ III $2.00+1.00+1.40+1.55+0.60(6.55) ;$ IV $1.55+0.75+1.10+1.50+$ 0.65 (5.55). Leg formula III,IV,II,I. Leg spination: I: Fm d 0-1-1-5; Pt pr 0-1-0; Tb pr 1-1-1, v 1-1-2ap; Mt pr 1-1ap, rt 0-1ap, v 2-2ap. II: Fm d 0-1-2-5; Pt pr 0-1-0; Tb pr 1-1, rt 0-1, v 1-1-2ap; Mt pr and rt 1-1ap, v 2-2ap. III: Fm d 1-2-5; Pt pr and rt 0-1-0; Tb d 1-0-0, pr and rt 1-1-1-1, v 1-0-2ap; Mt d 1-1-0, pr and rt 1-0-2ap, v 0-2-2ap. IV: Fm d 1-1-4; Pt pr and rt 0-1-0; Tb d 1-0-0, pr and rt 1-1-1-1, v 1-0-2ap; Mt d 1-1-0, pr 1-1-2ap, rt 1-0-2ap, v 1-1-2ap. Coloration (in alcohol; Figs 264-267). Carapace dark brown, covered with dark brown recumbent scales, with two longitudinal stripes of white scales on thorax; lateral sides of carapace covered with long white hairs that are especially dense on the ocular area. The front area of the eye field with a bunch of long orange brownish hairs directed anteriad. Clypeus and cheeks brown, densely covered with rather long brownish hairs. Sternum brownish. Endites and labium brownish. Chelicerae brown, covered with dark brown hairs. Abdomen yellowish brown, ventrally with
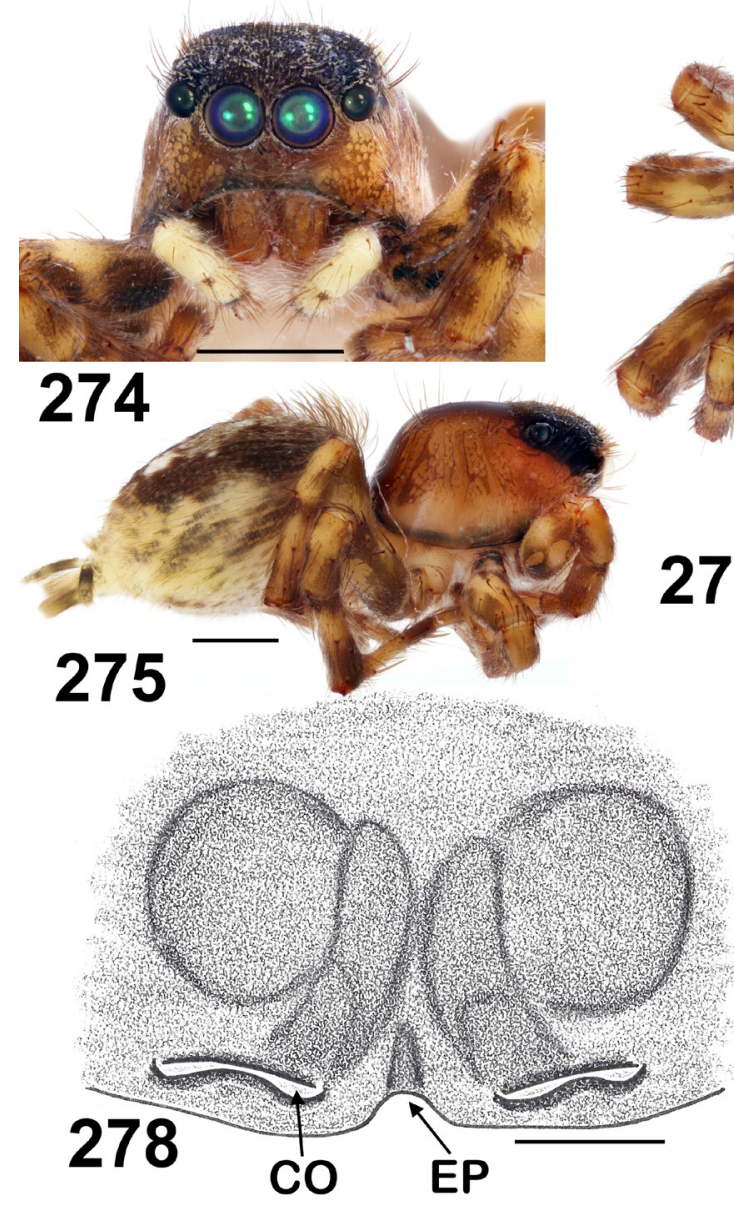

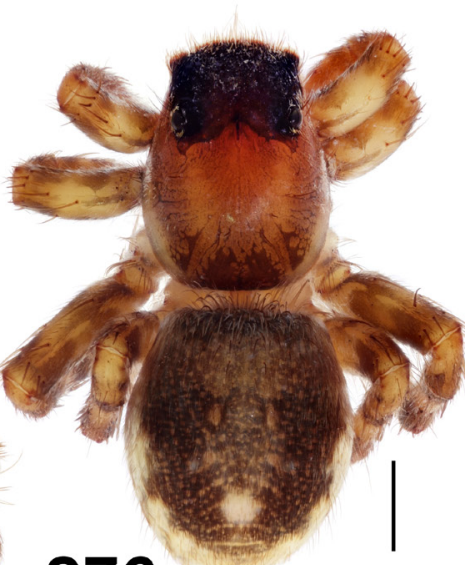

276

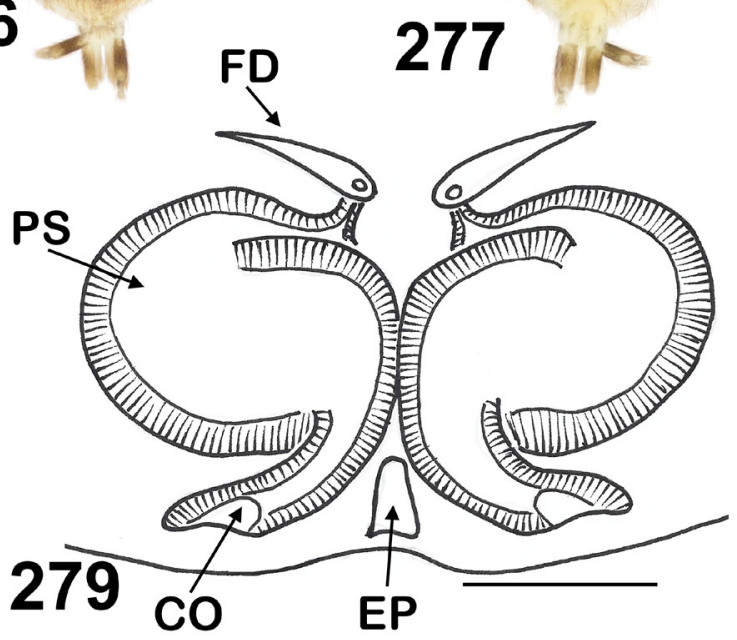

Figs 274-279. Stenaelurillus iubatus Wesołowska \& Russell-Smith, 2011, q (paratype of Stenaelurillus pilosus Wesołowska \& Russell-Smith, 2011) from Nigeria (Ibadan). 274-277. General appearance. 278. Epigyne, ventral view. 279. Spermathecae, dorsal view. Abbreviations: see Material and methods. Scale bars: $258-261=1 \mathrm{~mm} ; 262-263=0.1 \mathrm{~mm}$. 
longitudinal rows of yellow spots; dorsum dark brown, with dark brown scutum occupying $2 / 3$ of the frontal part of the abdomen. Spinnerets dark brown. Legs I-II: femora yellow, remaining segments brown. Legs III-IV dark brown. Palpal femora brown, covered with brown hairs. Palpal Pt, Tb and cymbium dark brown, covered with short brownish hairs. Cymbium yellow apically. Male palp as in Figs 268-273: VTA wide and low, looking like two bulges; RTA thorn-shaped, with a wide base, directed anteriad; the cymbium without a cymbial lateral process; the tegulum is relatively small, with poorlydeveloped, obtuse tegular process (TP); the functional tegulum well-marked, with a spoon-shaped distal projection (DP) and a long, wide distal projection (DP); the embolus wide and flat, ribbon-shaped, with a wide, massive swollen base.

\section{Female (paratype of S. pilosus, BMNH)}

Measurements: carapace: 2.95 long, 2.15 wide, 1.25 high. Abdomen: 3.25 long, 2.55 wide. Ocular area: 1.18 long, 1.53 wide anteriorly, 1.53 wide posteriorly. Cheliceral length 0.55 . Clypeal height 0.28 . Diameter of AME 0.45. Length of leg segments: I $1.45+0.68+0.75+0.63+0.50$ (4.01); II $1.40+$ $0.55+0.78+0.68+0.50(3.91) ;$ III $2.30+0.95+1.53+1.68+0.63(7.09) ;$ IV $1.98+0.88+1.30+1.70$ + 0.78 (6.64). Leg formula III,IV,I,II. Leg spination: I: Fm d 0-1-1-5; Pt pr 0-1-0; Tb pr 1-1, v 2-2-2ap; Mt pr and rt 1ap, v 2-2ap. II: Fm d 0-1-2-5; Pt pr 0-1-0; Tb pr 1-1, v 1-1-2ap; Mt pr 1-1ap, rt 1ap, v 2-2ap. III: Fm d 1-2-4; Pt pr and rt 0-1-0; Tb d 1-0-0, pr 0-2-1 ap, rt 1-2-1ap, v 0-1-2ap; Mt d 1-1, pr and rt 1-02ap, v 0-1-2ap. IV: Fm d 0-1-1-4; Pt pr and rt 0-1-0; Tb d 1-0-0, pr and rt 1-1-1-1, v 1-2ap; Mt pr 1-12ap, rt 1-1-1-2ap, v 1-1-2ap. The specimen is shabby. Coloration (in alcohol; Figs 274-277). Carapace brownish yellow, with wide yellow marginal stripes. Eye field dark brown, densely covered with small brown protruding bristles. Clypeus light brown. Sternum light yellow, densely covered with white hairs. Labium and endites light yellow. Chelicerae yellow, tinged with brown. Abdomen: dorsum brown, with a wide yellow marginal stripe along its rear half and a large central yellow spot; sides and venter yellow, with sparse brownish longitudinal stripes of scales. Book-lung covers light yellow, spinnerets yellowish grey. All legs yellow, with numerous brownish patches and (semi)rings. Palps yellow, with a dorso-basal brown spot on $\mathrm{Tb}$ and basal transverse brown stripes on Tr. Epigyne and spermathecae as in Figs 278-279: the epigynal plate flat; the copulatory openings as transverse, widely separated slits; epigynal pocket present, narrow and not very deep; insemination ducts very thick, C-shaped; primary spermathecae large and round.

\section{Distribution}

Two localities in Nigeria (Fig. 512) (Wesołowska \& Russell-Smith 2011; present data).

Stenaelurillus jocquei $\mathrm{sp}$. nov.

urn:1sid:zoobank.org:act:ECAC2893-2A7C-4606-A5B1-A2993A601295

Figs 280-316, 510

\section{Diagnosis}

By general appearance, especially of the males, the new species is similar to S. hirsutus, from which it can easily be distinguished by the presence of two rather than three white vertical lines (cf. Figs 313 and 255 ). Both species can also be distinguished by the conformation of the copulatory organs (cf. Figs 280 291 and 239-242, 246-251, 262-263): the longer, spiralled embolus in S. jocquei sp. nov. (straight in S. hirsutus), the epigynal pocket is situated almost in between the slit-shaped copulatory openings facing each other in S. jocquei sp. nov. (displaced to the epigastric furrow in S. hirsutus), and the round primary spermathecae in $S$. jocquei sp. nov. (elongated, sac-shaped ones in S. hirsutus). 


\section{Etymology}

This species is dedicated to our colleague and notable arachnologist, Dr Rudy Jocqué (Tervuren, Belgium), who collected the type series of this species and also facilitated the present study by providing numerous undetermined material of Stenaelurillus to one of us (GA).

\section{Material examined}

\section{Holotype}

CAMEROON: ${ }^{\top}$, Faro GR, ca $08^{\circ} 10^{\prime} \mathrm{N}, 12^{\circ} 35^{\prime}$ E, gallery forest, pitfall traps, 4 May 2007, R. Jocqué, K. Loosveldt, L. Baert and M. Alderweireldt leg. (MRAC 221.173).

\section{Paratypes}

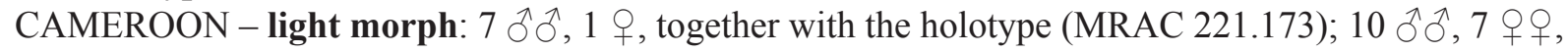
Faro GR, ca $08^{\circ} 10^{\prime} \mathrm{N}, 12^{\circ} 35^{\prime} \mathrm{E}$, gallery forest, pitfall traps, 2-5 May 2007, R. Jocqué, K. Loosveldt, L. Baert and M. Alderweireldt leg. (MRAC 221.132, MRAC 221.141, MRAC 221.202, MRAC 221.224, MRAC 225.498); 11 §ิ $\hat{\jmath}, 1$ q, same locality, wooded savanna, pitfall traps, 3-4 May 2007, R. Jocqué, K. Loosveldt, L. Baert and M. Alderweireldt leg. (MRAC 221.198, MRAC 225.494); 1 o, Hossere Gare, ca $09^{\circ} 11^{\prime} \mathrm{N}, 13^{\circ} 49^{\prime} \mathrm{E}$, litter among rocks, by hand, 4 May 2007, R. Jocqué, K. Loosveldt, L. Baert and M.

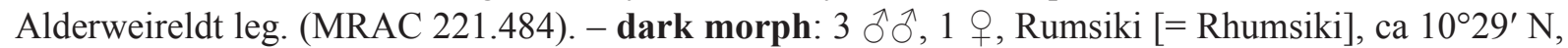
13³6' E, yellow pan traps, 1100 m a.s.1., 27 Jul. 1987, A. Pauly leg. (MRAC 225.488, MRAC 168.689).

\section{Remarks}

There are two colour morphs of $S$. jocquei sp. nov. of which the males visibly differ in the degree of development of pubescence on the eye field (cf. Figs 298-303 and 309-315). The males of the dark morph have a much stronger developed 'mane', with longer dark brown/black hairs and two clear vertical white lines, whereas those of the light morph have 'mane' consisting of shorter and light iridescent hairs. The male copulatory organs and females of both groups are identical (cf. Figs 280-287 and 292-295), and therefore we have assigned all of them to the same species.

\section{Description (light form)}

\section{Male (holotype)}

Measurements: carapace: 2.70 long, 1.90 wide, 1.40 high. Abdomen: 2.40 long, 1.75 wide. Ocular area: 1.15 long, 1.60 wide anteriorly, 1.50 wide posteriorly. Cheliceral length 0.65 . Clypeal height 0.40 . Diameter of AME 0.40. Length of leg segments: I $1.30+0.80+0.95+0.75+0.50$ (4.30); II $1.30+0.80$ $+0.80+0.70+0.50(4.10) ;$ III $1.80+1.00+1.30+1.50+0.65(6.25) ;$ IV $1.70+0.85+1.20+1.60+$ 0.75 (6.10). Leg formula III,IV,I,II. Leg spination: I: Fm d 0-1-1-5; Pt pr 0-1-0; Tb pr 1-1, v 1-2-2ap; Mt pr 1-1ap, v 2-2ap. II: Fm d 0-1-2-5; Pt pr 0-1-0; Tb pr 1-1, rt 0-1, v 1-1-2ap; Mt pr and rt 1-1ap, v 2-2ap. III: Fm d 1-2-5; Pt pr and rt 0-1-0; Tb d 1-0-0, pr and rt 1-1-1-1, v 1-0-2ap; Mt d 1-1-0, pr and rt 1-02ap, v 0-2-2ap. IV: Fm d 1-1-5; Pt pr and rt 0-1-0; Tb d 1-0-0, pr and rt 1-1-1-1, v 1-0-2ap; Mt d 1-1-0, pr 1-1-2ap, rt 1-0-2ap, v 0-2-2ap. Coloration (in alcohol; Figs 298-303). Carapace brown, covered with dark brown scales and with two longitudinal stripes of white scales running from PLEs to the rear end of the carapace; carapace margins with wide longitudinal bands of white scales. Eye field dark brown, its anterior half densely covered with long brownish iridescent hairs. Clypeus yellowish brown, medially with a line of yellowish iridescent hairs covering the area between AMEs to the eye field; hairs under AMEs short, brown and not iridescent, also occurring on the eye field. Cheeks and the anterior halves of the carapace sides covered with long iridescent, reflective hairs. Sternum yellow (in the holotype) to brown-yellow. Sternum, coxae and trochanters covered with short white yellowish hairs. Labium and endites yellow. Chelicerae yellow, sparsely covered with long/short brownish hairs. Abdomen: dorsum brownish, with a poorly marked scutum occupying the anterior half of the dorsum and with a pattern of three white spots situated on the posterior half and three white stripes as shown in Fig. 306; venter 

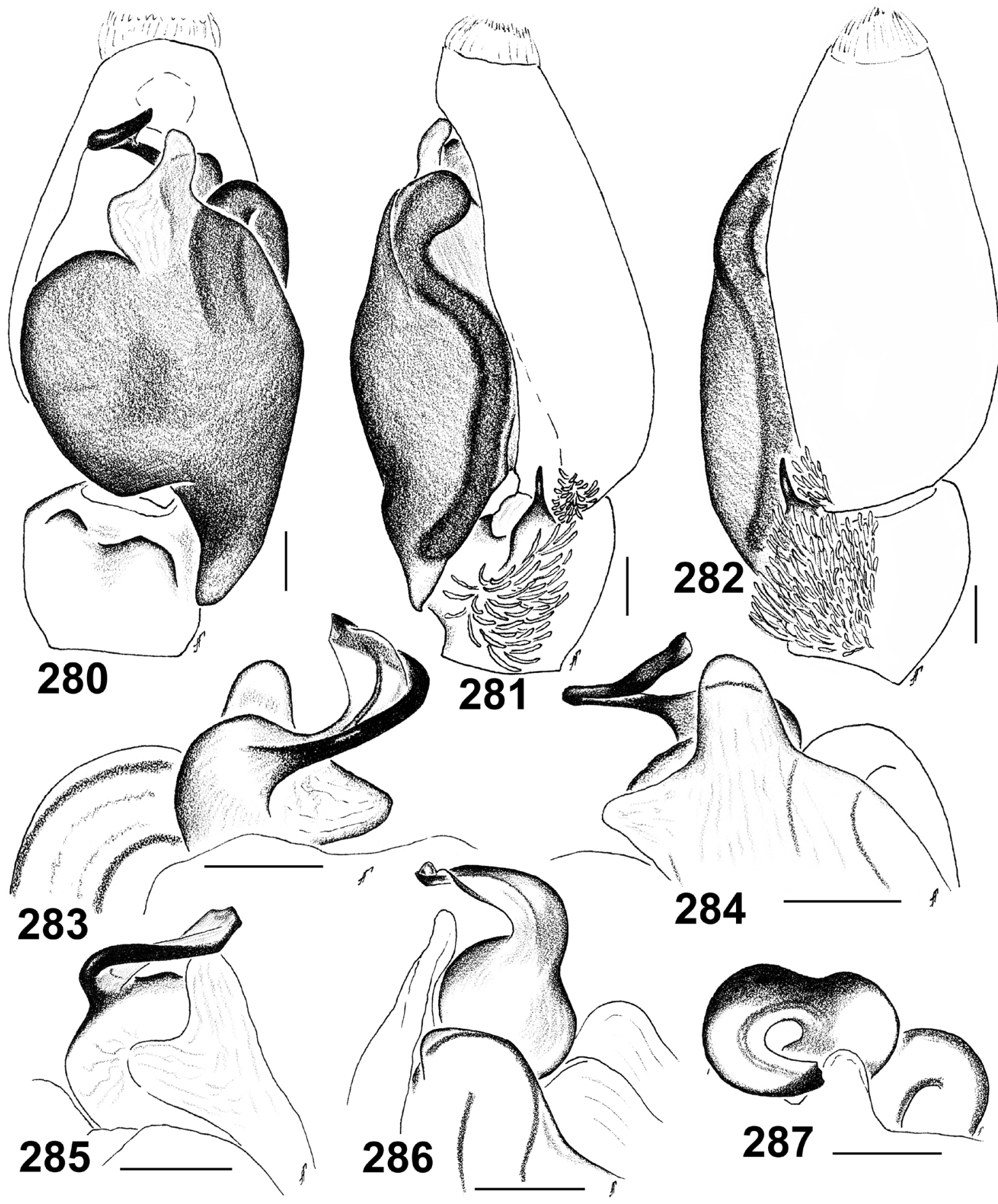

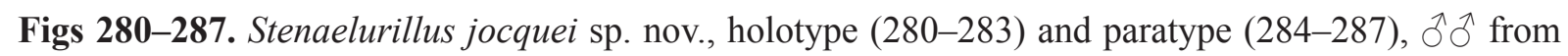
Cameroon (Faro GR), light form. 280-282. Male palp. 280. Ventral view. 281. Retrolateral view. 282. Dorso-retrolateral view. 283-287. Embolic division. 283. Dorsal view. 284. Ventral view. 285. Median view. 286. Retrolateral view. 287. Apical view. Scale bars: $0.1 \mathrm{~mm}$. 
yellow. Book-lung covers yellow. Spinnerets: anterior and median pairs brownish, posterior pair dark brown. All legs yellow, covered with brownish hairs, except for legs I, in which Pt apically, Ti, Mt and Tr completely dark brown, Ti and Mt ventrally covered with dense dark brown, almost back, hairs; Fm I and II dorsally and ventrally covered with long yellowish white hairs. Palps yellow; palpal Fm dorsally and retrolaterally covered with long yellowish white hairs, prolaterally with brown hairs; palpal $\mathrm{Tb}$ and Pt retrolaterally and retro-dorsally covered with dense, short brown hairs, prolaterally-dorsally with dense white yellowish hairs and prolaterally with brown hairs; cymbium densely covered with yellow-white hairs. Palpal structure as in Figs 280-287: VTA bulge-shaped; RTA spine-shaped, directed anteriad; the cymbium simple, without a cymbial lateral process; the tegulum small, poorly marked, without a tegular process; the functional tegulum elongated, with well-developed, pointed proximal (PP) and wide, almost bifurcated distal (DP) projections; the embolus spiralled, ribbon-shaped, with a heavy base.

\section{Female}

Measurements (the female with smaller abdomen from MRAC 221.202, the female with larger abdomen from MRAC 221.224). Carapace: 2.70 long, 2.20 wide, 1.45 high. Abdomen: 3.00-3.50 long, 2.55-2.80

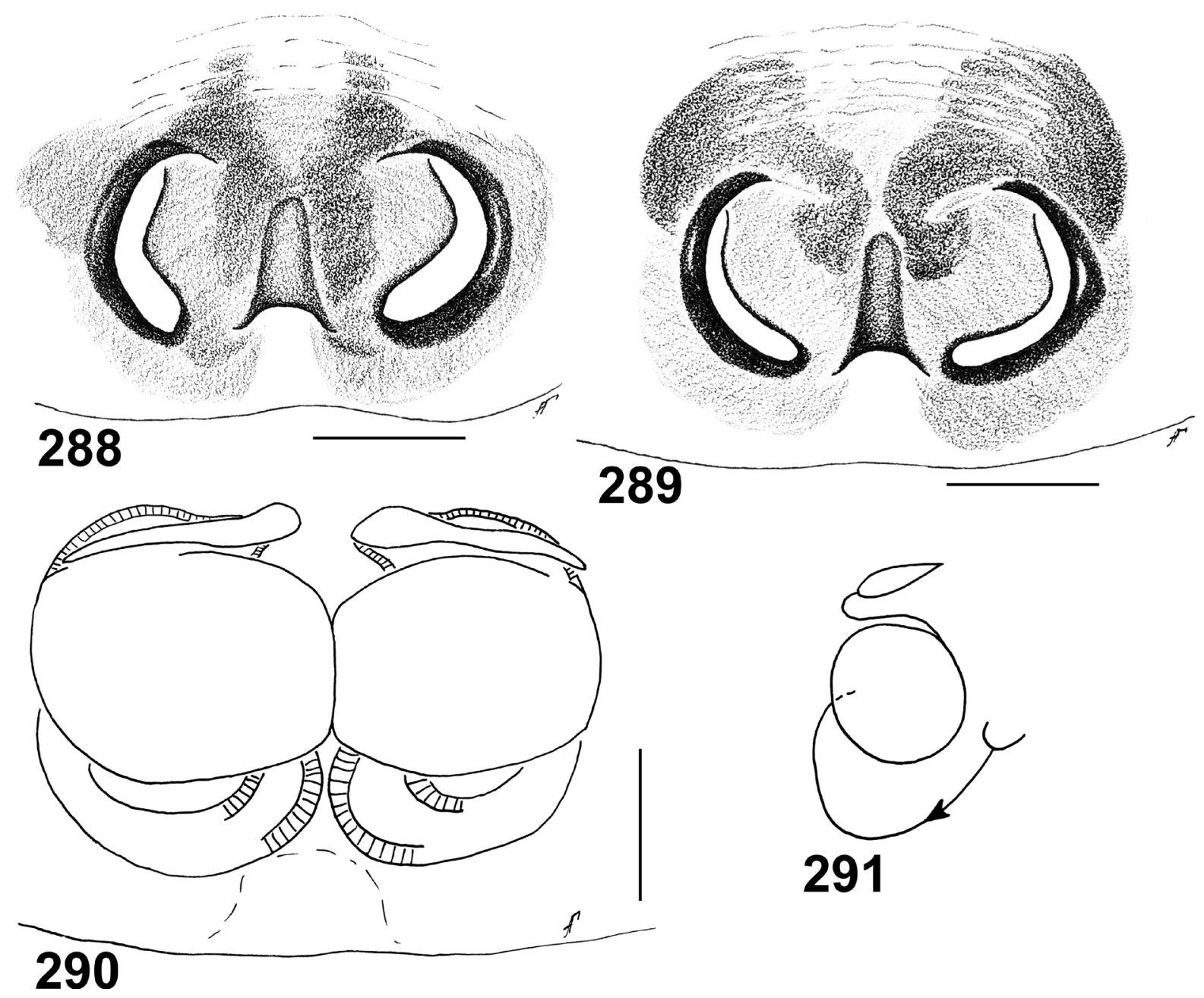

Figs 288-291. Stenaelurillus jocquei sp. nov., paratype $q$ from Cameroon (Faro GR; MRAC 221.132), light form. 288-289. Epigyne, ventral view. 290. Spermathecae, dorsal view. 291. Diagrammatic course of the insemination ducts of the spermathecae. Scale bars: $0.1 \mathrm{~mm}$. 
wide. Ocular area: 1.10 long, 1.65 wide anteriorly, 1.65 wide posteriorly. Cheliceral length 0.75 . Clypeal height 0.30. Diameter of AME 0.50. Length of leg segments (female from MRAC 221.202): I 1.50+0.85 $+0.85+0.70+0.50$ (4.40); II $1.50+0.90+0.70+0.70+0.50$ (4.30); III $2.10+1.20+1.40+1.65+$ 0.75 (7.10); IV $1.80+0.90+1.40+1.80+0.80$ (6.70). Leg formula III,IV,I,II. Leg spination (female from MRAC 221.202): I: Fm d 0-1-1-5; Pt pr 0-1-0; Tb pr 1-1, v 1-2-2ap; Mt pr 1-1ap, rt 0-1ap, v 2-2ap. II: Fm d 0-1-2-5; Pt pr 0-1-0; Tb pr 1-1, v 1-1-2ap; Mt pr 1-1ap, rt 0-1ap, v 2-2ap. III: Fm d 1-2-5; Pt pr
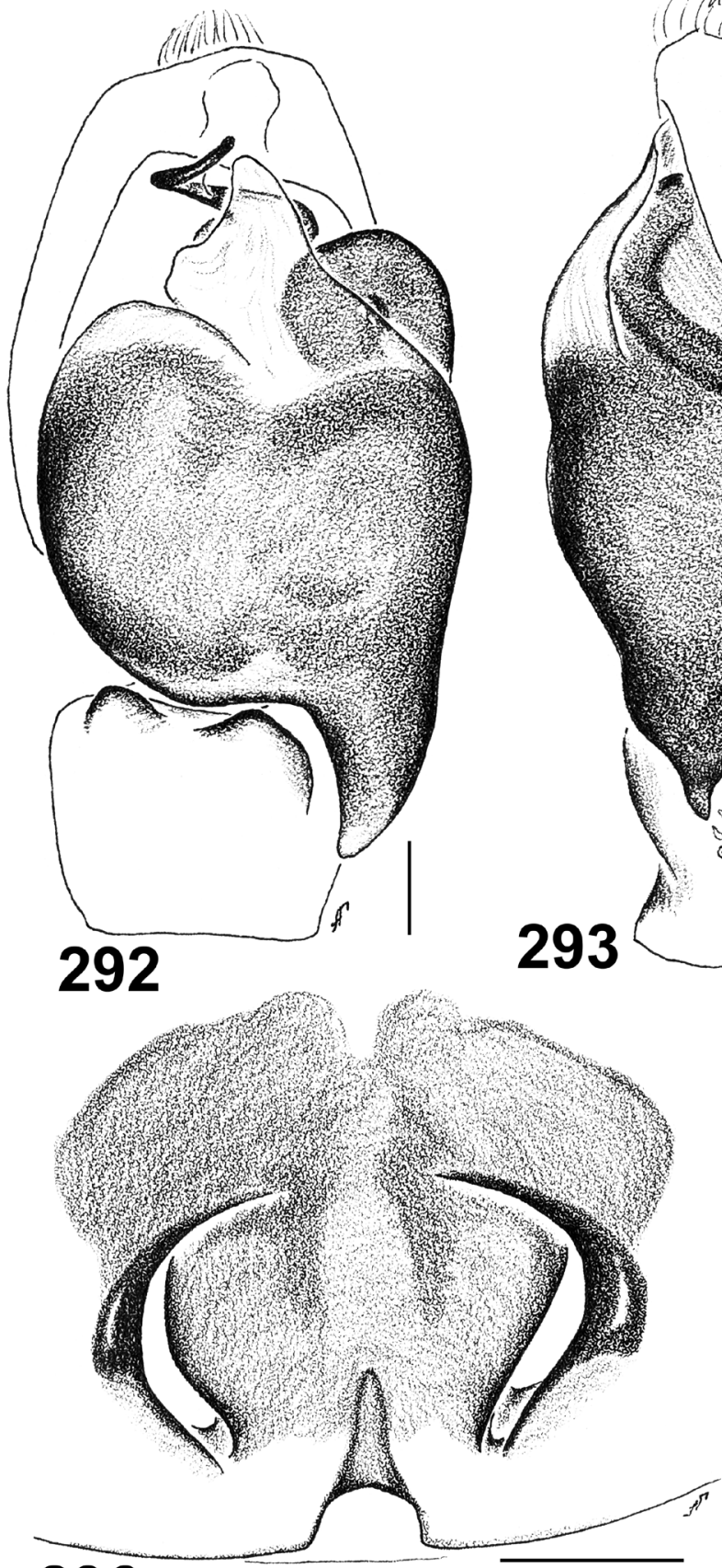

296
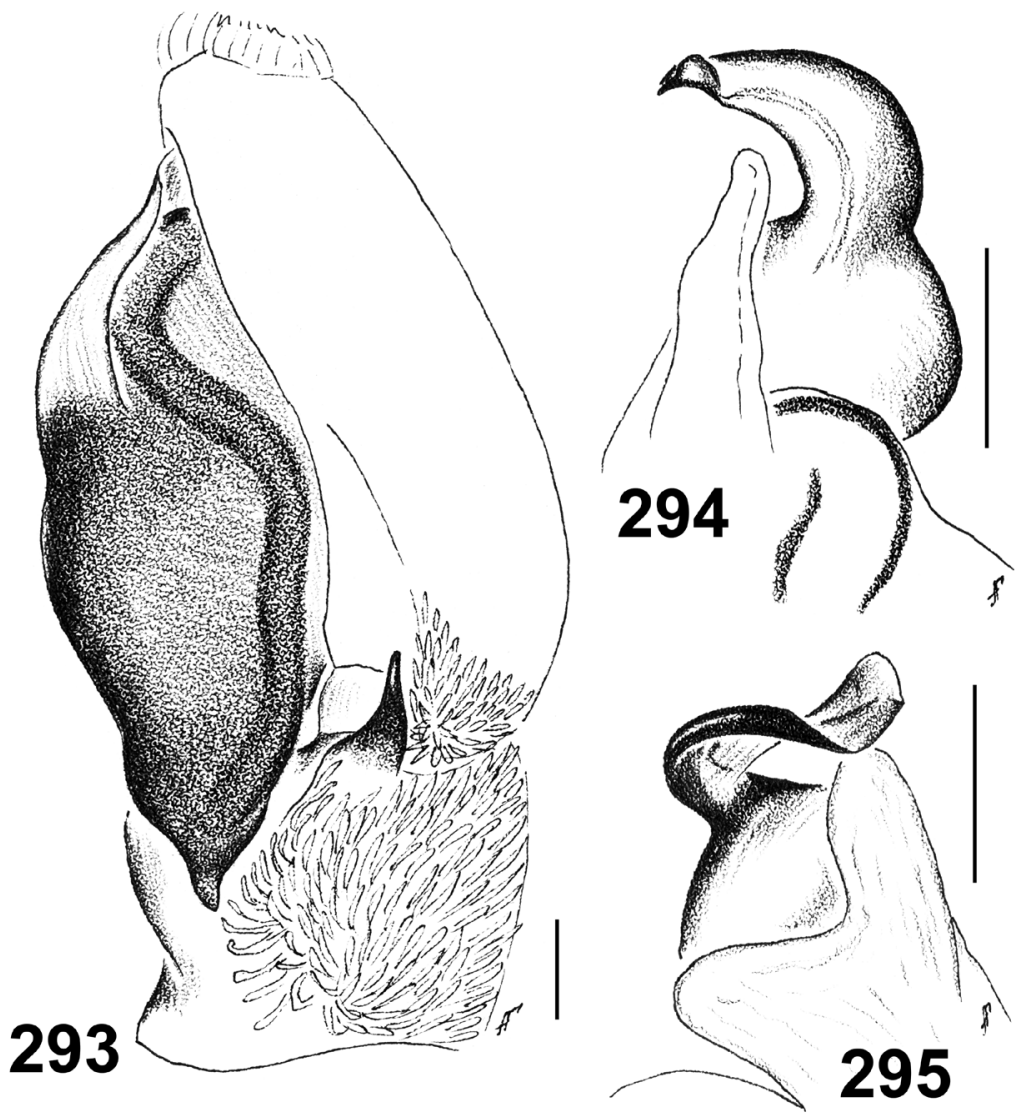

Figs 292-297. Stenaelurillus jocquei sp. nov., paratypes from Cameroon (Rumsiki; MRAC 168.689), dark form. 292. Male palp, ventral view. 293. Male palp, retrolateral view. 294. Embolic division, retrolateral view. 295. Embolic division, median view. 296. Epigyne, ventral view. 297. Spermathecae, dorsal view. Scale bars: $0.1 \mathrm{~mm}$. 
and rt 0-1-0; Tb d 1-0-0, pr and rt 1-1-1-1, v 1-0-2ap; Mt d 1-1-0, pr and rt 1-0-2ap, v 0-2-2ap. IV: Fm d 1-1-4; Pt pr and rt 0-1-0; Tb d 1-0-0, pr and rt 1-1-1-1, v 1-0-2ap; Mt d 1-1-0, pr 1-1-2ap, rt 1-0-2ap, v 1-1-2ap. Coloration (in alcohol; Figs 304-305, 307-308) as in the male, but lighter. Eye field, clypeus and cheeks without iridescent, reflective hairs. Clypeus and cheeks brown, covered with white hairs. Legs yellow, covered with brownish hairs; Fm I prolaterally with two dark brown spots, the remaining segments with poorly marked brownish semi-rings and patches. Palps yellow, covered with white hairs

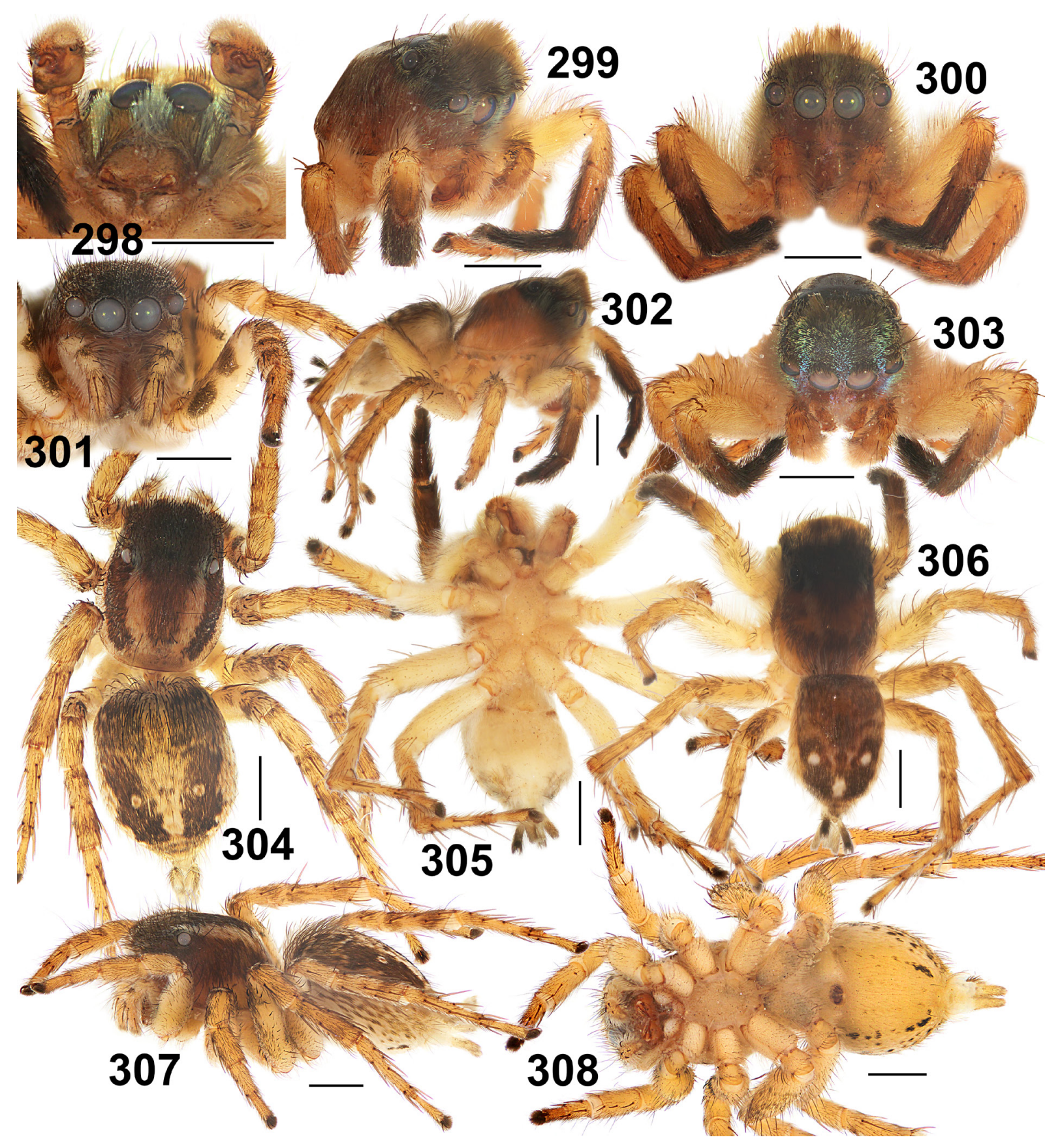

Figs 298-308. Stenaelurillus jocquei sp. nov., light form, general appearance, $\widehat{\partial} \widehat{\partial}(298-300,302-303$, 305-306) and + ㅇ $(301,304$, 307-308). 298-301, 303-304, 307-308. Paratypes from Cameroon (Faro GR). 302, 305-306. Holotype. Scale bars: $1 \mathrm{~mm}$. 
and brown bristles; palpal Fm dorsally with a row of dark brown bristles; palpal Tb proximally and dorsally with brown spot. Epigyne and spermathecae as in Figs 288-291; epigynal plate flat; epigynal pocket present, narrow and deep; the copulatory openings large, with heavily sclerotized rims, as a pair of slightly procurved furrows; the insemination ducts wide and short, tube-shaped, running towards the median line; the primary spermathecae large, weakly sclerotized, sac-shaped.

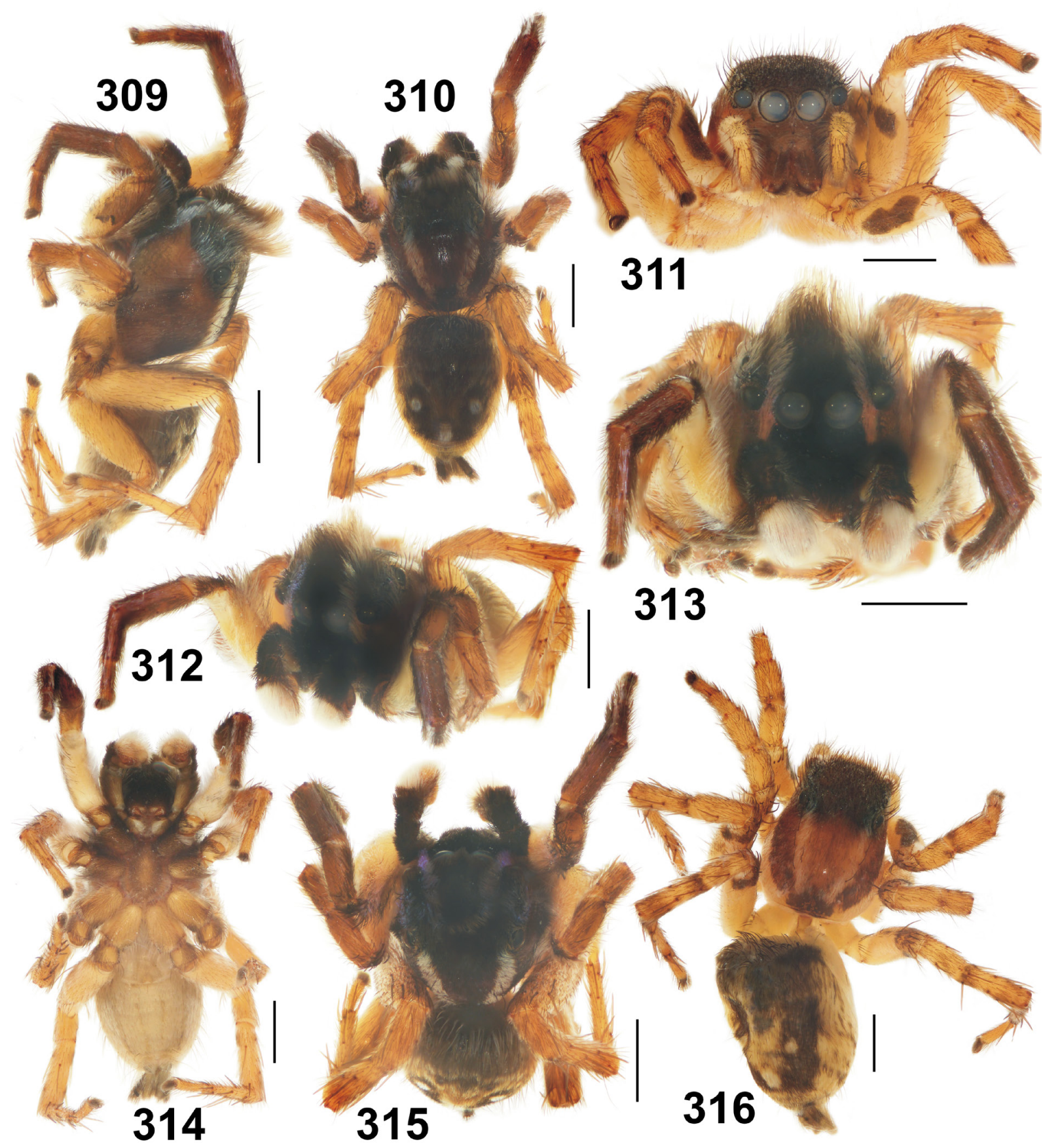

Figs 309-316. Stenaelurillus jocquei sp. nov., paratypes from Cameroon (Rumsiki), dark form. 309310, 312-315. О. 311, 316. . . Scale bars: $1 \mathrm{~mm}$. 


\section{Description (dark form)}

Male (MRAC 168.689)

Measurements: carapace: 2.60 long, 1.90 wide, 1.40 high. Abdomen: 2.50 long, 1.70 wide. Ocular area: 1.00 long, 1.50 wide anteriorly, 1.50 wide posteriorly. Cheliceral length 0.70 . Clypeal height 0.30 . Diameter of AME 0.40. Length of leg segments: I $1.35+0.80+0.95+0.75+0.50$ (4.35); II $1.35+$ $0.70+1.00+0.70+0.50(4.25) ;$ III $2.00+0.90+1.10+1.45+0.50(5.95) ;$ IV $1.60+0.70+1.15+$ $1.70+0.60$ (5.75). Leg formula III,IV,I,II. Leg spination: I: Fm d 0-1-1-5; Pt pr 1; Tb pr 1-1, v 1-2-2ap; Mt pr 1-1ap, rp 0-1ap, v 2-2ap. II: Fm d 0-1-2-5; Pt pr 1; Tb pr 1-1, v 1-1-2ap; Mt pr and rt 1-1ap, v 2-2ap. III: Fm d 1-2-5; Pt pr and rt 1; Tb d 1-0-0, pr and rt 1-1-1-1, v 1-0-2ap; Mt d 1-1-0, pr and rt 1-02ap, v 0-2-2ap. IV: Fm d 1-1-5; Pt pr and rt 1; Tb d 1-0-0, pr and rt 1-1-1-1, v 1-0-2ap; Mt d 1-1-0, pr 1-1-2ap, rt 1-0-2ap, v 0-2-2ap. Coloration (in alcohol; Figs 309-315). Carapace dorsally as in the light form. Sternum brown-yellow. Sternum, coxae and trochanters covered with dark brown hairs that are especially dense on legs I-II. Endites and labium brown-yellow. Chelicerae brown, densely covered with short dark brown (almost black) hairs. Clypeus dark brown, densely covered with short black hairs. Cheeks brown, with narrow stripes of iridescent hairs running between AMEs and ALEs and continuing on the eye field, where these hairs become longer. Abdomen as in the light form but darker. Book-lung covers light yellow. Spinnerets: ventral pair brown, dorsal pair dark brown. Fm I-II pale yellow, dorsally with long and dense white-brown hairs, prolaterally and ventrally with dense and long white hairs, prolaterally with short brown hairs. The remaining segments of legs I-II brown. Pt, Tb, Mt and $\operatorname{Tr}$ I covered with dark hairs that are more dense pro- and retrolaterally. Tb and Mt I with narrow lines of iridescent hairs situated above dense dark brown hairs. Legs III-IV brown-yellow, apically and sometimes proximally (Tb and Mt III-IV) brown, covered with short brown and white hairs. Palps brown, with yellow cymbium. Palpal Fm and Pt pro- and retrolaterally densely covered with dark brown (almost black) hairs that are longer on Fm. Palpal Pt prolaterally and dorsally densely covered with short dark brown (almost black) hairs and sparse brown hairs, prolatero-dorsally with white iridescent hairs. Cymbium covered with white iridescent hairs, retrolaterally, near the tibial apophysis, with short dark brown (almost black) hairs. Palpal structure as described above for the light form (Figs 292-295).

\section{Female}

As described for the light form (Fig. 316). Epigyne and spermathecae as described above for the light form (Figs 296-297).

\section{Distribution}

A few localities in Cameroon (Fig. 510).

Stenaelurillus kronestedti Próchniewicz \& Heçiak, 1994

Figs 317-329, 512

Stenaelurillus kronestedti Próchniewicz \& Heçiak, 1994: 39, figs 7a-k, 8a-e (Dð⿱中); ð holotype in NHRS, examined.

\section{Diagnosis}

This species is most similar to $S$. albopunctatus from Kenya (Figs 40-48), with both species having very similar coloration and an almost identical conformation of the embolic division in the males: viz., the hook-shaped embolus with an anvil-shaped basis. Stenaelurillus kronestedti can be readily distinguished from S. albopunctatus by the hook-shaped RTA, the pointed and narrower DTA and the position of the row of long and dense, black bristles on the DTA (Fig. 318) in the males and by the most widely separated copulatory openings (more than two diameters) and the markedly longer insemination ducts in the females (Fig. 323). 


\section{Material examined}

\section{Holotype}

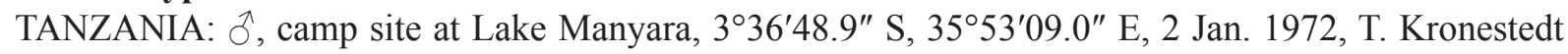
leg. (NHRS 043).

\section{Paratype}

TANZANIA: 1 , together with the holotype (NHRS 043).
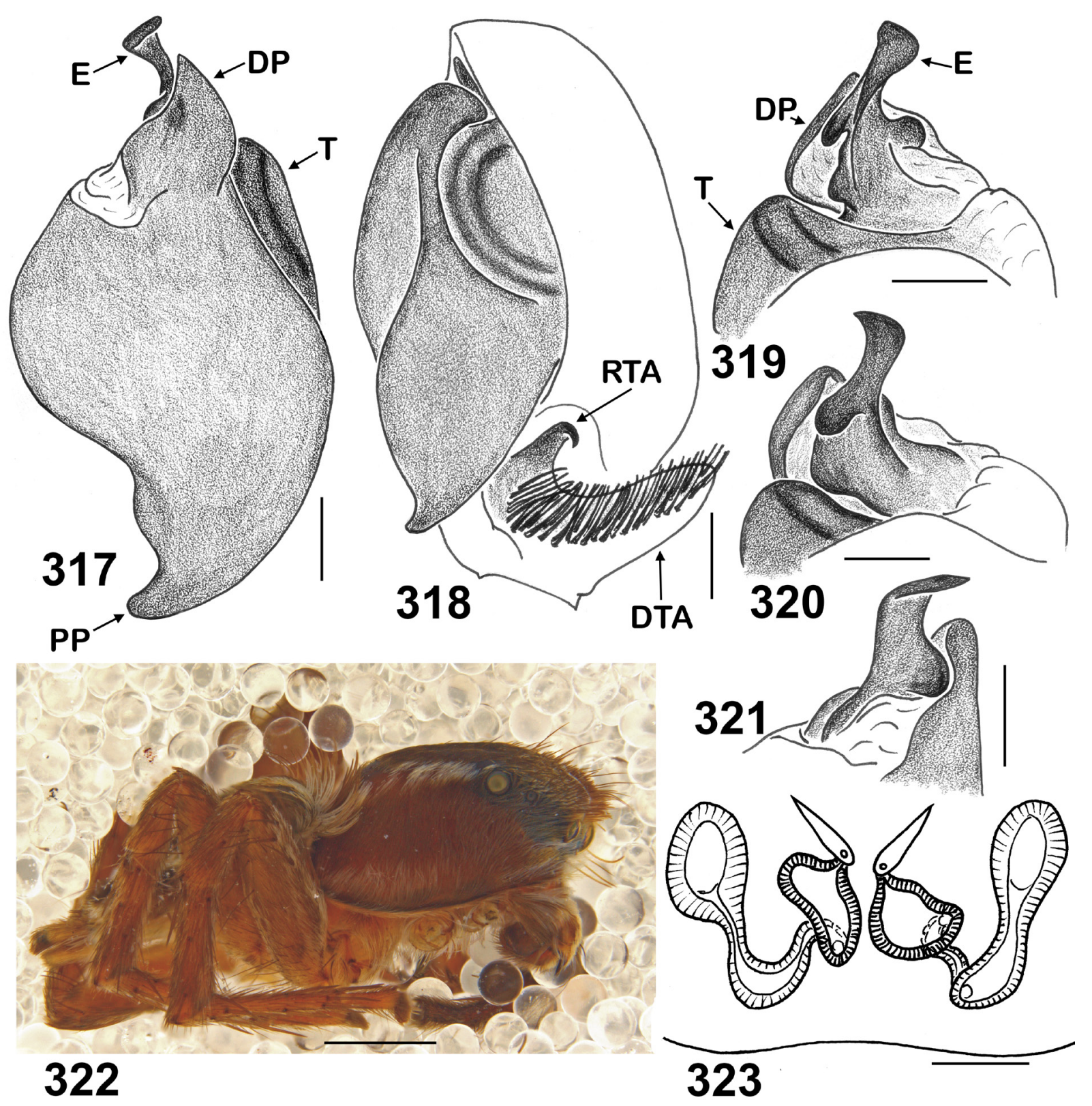

Figs 317-323. Stenaelurillus kronestedti Próchniewicz \& Heçiak, 1994, holotype, ô (317-322) and paratype $q$ (323). 317. Bulbus, ventral view. 318. Male palp, retrolateral view. 319. Embolic division, dorsal view. 320. Embolic division, retrolateral view. 321. Embolic division, median view. 322. General appearance. 323. Spermathecae, dorsal view. Abbreviations: see Material and methods. Scale bars: $317-$ $321,323=0.1 \mathrm{~mm} ; 322=1 \mathrm{~mm}$. 


\section{Description}

\section{Male}

Based on the holotype (Figs 322, 324-326); the left palp is detached and broken into three separate parts, several legs are detached).

Measurements: carapace: 2.75 long, 2.00 wide, 1.30 high. Abdomen: 2.45 long, 1.70 wide. Ocular area: 1.15 long, 1.56 wide anteriorly, 1.50 wide posteriorly. Cheliceral length 0.58 . Clypeal height 0.20 . Diameter of AME 0.43. Length of leg segments: I $1.40+0.68+0.80+0.60+0.53$ (4.01); II $1.43+$ $0.75+0.80+0.63+0.53(4.14) ;$ III $2.10+1.08+1.40+1.75+0.60(7.65) ;$ IV $2.00+0.90+1.35+$ $1.80+0.75$ (6.80). Leg formula III,IV,II,I. Leg spination: I: Fm d 0-1-1-5; Pt pr 0-1-0; Tb pr 1-1, v 1-12ap; Mt pr 1-1ap, v 2-2ap. II: Fm d 0-1-1-5; Pt pr 0-1-0; Tb pr 1-1, rt 0-1, v 1-1; Mt d, pr and rt 1-1ap, v 2-2ap. III: Fm d 0-1-1-5; Pt pr and rt 0-1-0; Tb d 1-0-0, pr and rt 1-1-1, v 1-0-2ap; Mt d 2-2, pr 1-0-2ap, rt 2ap, v 0-0-1-2ap. IV: Fm d 0-1-1-5; Pt pr and rt 0-1-0; Tb pr and rt 1-1-1, v 1-0-2ap; Mt d 2-2, pr 1-1-2ap, rt 1-0-2ap, v 0-2-2ap. Coloration (in alcohol; Figs 322, 324-326). Carapace red-brown, densely covered with brown recumbent scales, with two wide longitudunal stripes of white scales and wide marginal

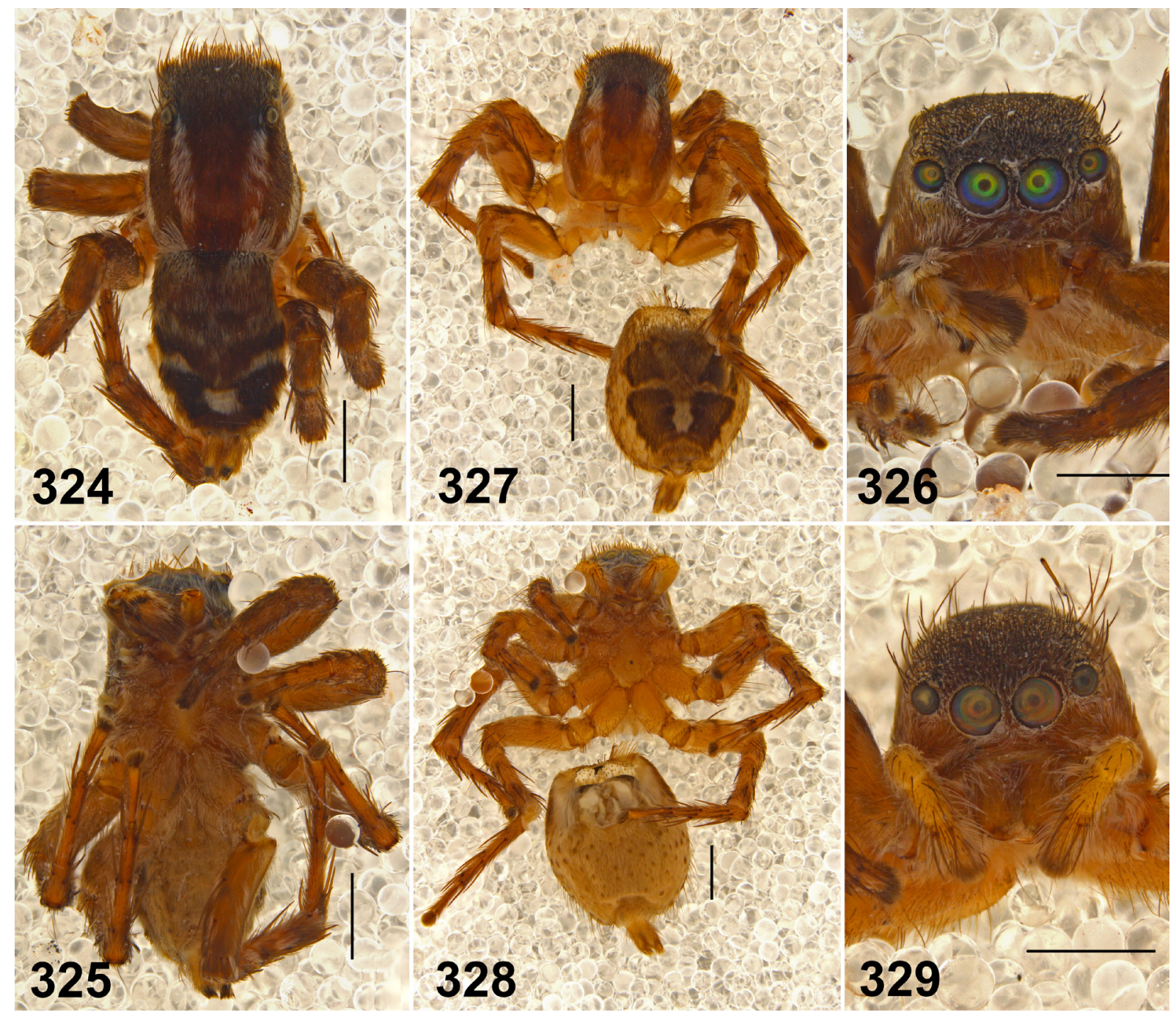

Figs 324-329. Stenaelurillus kronestedti Próchniewicz \& Heçiak, 1994, general appearance. 324326. Holotype. 327-329. Paratype, + . Scale bars: $1 \mathrm{~mm}$. 
white stripes of scales; eye field dark brown. Clypeus light brown, sparsely covered with white hairs. Sternum bright yellow, covered with long white hairs. Endites, labium and chelicerae bright yellow, tinged with brown. Abdomen: dorsum dark brown, densely covered with brown recumbent scales, with three white spots on its rear half and large brown scutum on its front half; sides and venter bright yellow, with sparse brown speckles. Book-lung covers bright yellow. Spinnerets yellow, but the dorsal pair with dark brown tips. All legs yellow, tinged with brown, but legs I darker: $\mathrm{Pt}, \mathrm{Tb}$ and Mt ventrally and $\mathrm{Tr}$ completely dark brown. Palps yellowish brown, dorsally covered with white hairs. Palpal structure as in Figs 317-321: VTA bulge-shaped; RTA hook-shaped, its ventral branch directed anteriad; DTA present as a thick, dorsally pointed process that bears a row of thick black bristles along its entire length; the cymbium without a cymbial lateral process; the tegulum is relatively small, without a tegular process; the functional tegulum wide and elongated, with well-developed proximal (PP) and wide, blade-shaped distal (DP) projections; the embolus relatively short and thick, with an anvil-shaped base.

Female (paratype, Figs 327-329)

Measurements: carapace: 3.10 long, 2.20 wide, 1.50 high. Abdomen: 3.25 long, 2.75 wide. Ocular area: 1.13 long, 1.58 wide anteriorly, 1.58 wide posteriorly. Cheliceral length 0.65 . Clypeal height 0.18 . Diameter of AME 0.45. Length of leg segments: I $1.50+0.73+0.75+0.45+0.40$ (3.83); II $1.50+$ $0.81+0.78+0.75+0.33$ (4.17); III $2.40+1.20+1.40+1.85+0.65(7.50) ;$ IV $2.25+1.00+1.50+$ $1.95+0.80$ (7.50). Leg formula III/IV,II,I. Leg spination: I: Fm d 0-1-1-5; Pt pr 0-1-0; Tb pr 1-1, v 1-12ap; Mt pr and rt 1-1ap, v 2-2ap. II: Fm d 0-1-1-5; Pt pr 0-1-0; Tb pr 1-2, v 1-1-2ap; Mt d 1-1, pr and rt 1-2ap, v 2-2ap. III: Fm d 0-1-2-5; Pt pr and rt 0-1-0; Tb d 1-0, pr and rt 1-1-1-1, v 1-0-2ap; Mt d 2-2, pr and rt 1-0-2ap, v 0-1-2ap. IV: Fm d 0-1-1-5; Pt pr and rt 0-1-0; Tb d 1-0, pr 1-1-2, rt 1-1-1, v 1-0-2ap; Mt d 1-1, pr and rt 1-1-2ap, v 1-2-2ap. Coloration (in alcohol; Figs 327-329). Carapace bright yellow, densely covered with brown recumbent scales, with two wide longitidunal stripes of white scales and wide marginal white stripes of scales; eye field dark brown. Clypeus yellow, sparsely covered with white hairs. Endites, labium and chelicerae bright yellow. Abdomen: dorsum yellow, with two wide brownish interrupted bands; sides and venter bright yellow, with sparse brownish speckles. Book-lung covers and spinnerets bright yellow. All legs yellow, with pale brown patches and tinge. Palps yellow. Spermathecae as in Fig. 323: epigynal plate flat, triangle-shaped, with rounded widely separated copulatory openings (see Próchniewicz \& Hęciak 1994: fig. 8b); the epigynal pocket absent; the insemination ducts V-shaped, running towards the median line; the primary spermathecae bean-shaped.

\section{Distribution}

The type locality only (Fig. 512).

Stenaelurillus latibulbis Wesołowska, 2014

Figs 330-335, 513

Stenaelurillus latibulbis Wesołowska, 2014b: 605, figs 6A-E (D $\overbrace{}^{\lambda}+$ ); $\widehat{\sigma}$ holotype in MRAC, not examined.

\section{Diagnosis}

The female of S. latibulbus is closest to that of S. kavango from Namibia (cf. Wesołowska, 2014b: fig. 5), but can easily be distinguished by the much shorter insemination ducts and the round, rather than bean-shaped, primary spermathecae (Fig. 335); yet, the copulatory openings are strongly sclerotized (Fig. 334) as compared to all the species of Stenaelurillus known to us. The male was described and diagnosed by Wesołowska (2014b: figs 6A-C), and seems to differ in the characteristic shape of the VTA, the distal projection of the functional tegulum and the conformation of the embolus, which unfortunately 
was shown by Wesołowska (2014b) too diagrammatically. See also remarks above under Diagnosis of S. fuscatus.

\section{Material examined}

ZAMBIA: 1 \%, Luambe, ca $12^{\circ} 27^{\prime}$ S, 32 $2^{\circ} 08^{\prime}$ E, 25 Aug. 1956, R.P. Th. de Caters leg. (MRAC 91613, MRAC 91614).

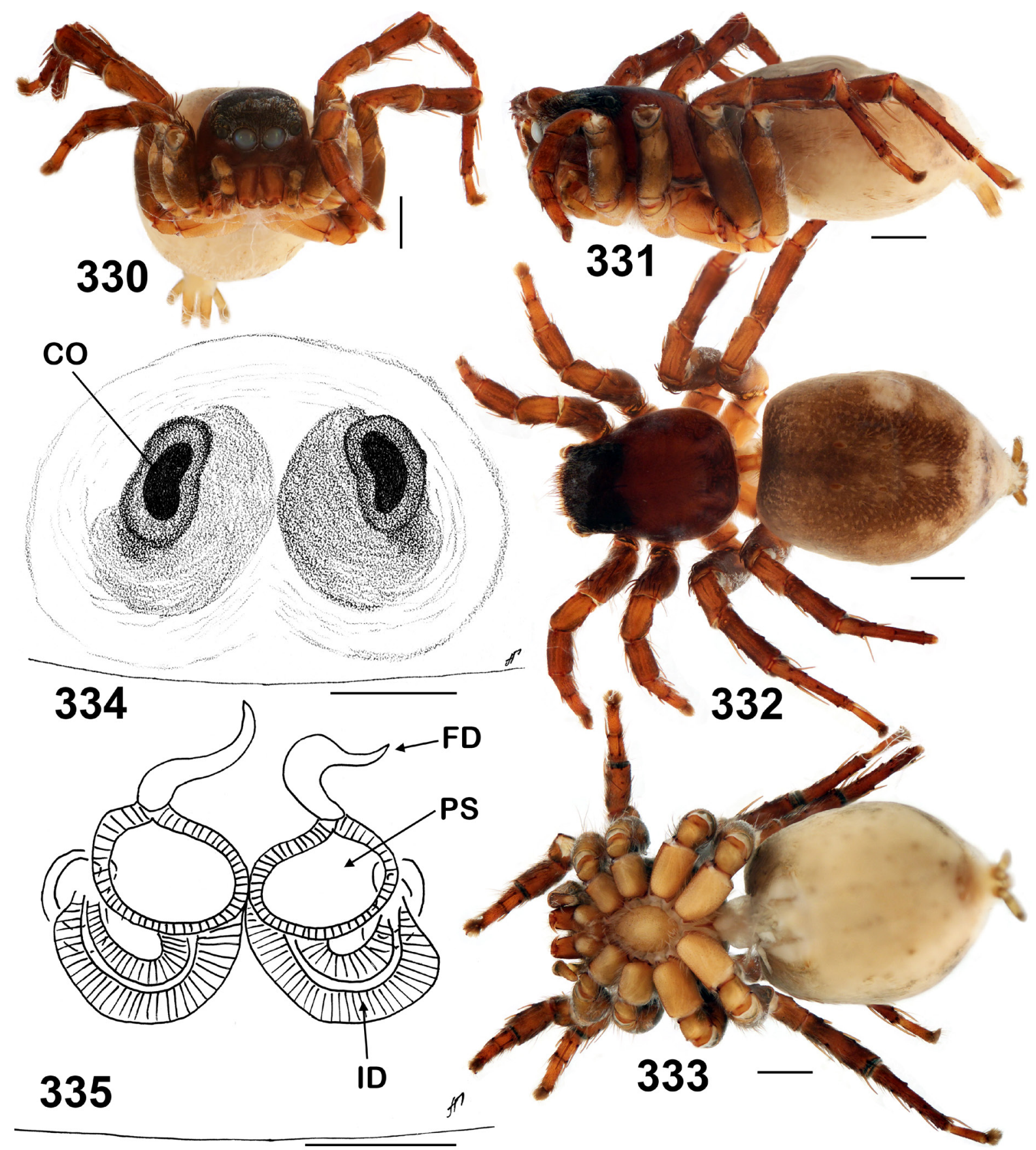

Figs 330-335. Stenaelurillus latibulbis Wesołowska, 2014, $q$ from Zambia (Luambe). 330-333. General appearance. 334. Epigyne, ventral view. 335. Spermathecae, dorsal view. Abbreviations: see Material and methods. Scale bars: $330-333=1 \mathrm{~mm} ; 334-335=0.1 \mathrm{~mm}$. 


\section{Description}

Male

See Wesołowska (2014b).

Female (in poor condition, almost without scales)

Measurements: carapace: 3.40 long, 2.50 wide, 1.60 high. Abdomen: 4.80 long, 3.65 wide. Ocular area: 1.10 long, 1.65 wide anteriorly, 1.60 wide posteriorly. Cheliceral length 0.70 . Clypeal height 0.40 . Diameter of AME 0.50. Length of leg segments: I $1.50+0.90+0.80+0.60+0.60$ (4.40); II $1.50+0.90$ $+0.85+0.60+0.60(4.45) ;$ III $2.30+1.30+1.60+1.80+0.70(7.70) ;$ IV $2.30+1.15+1.60+2.10+$ 0.75 (7.90). Leg formula IV,III,II,I. Leg spination: I: Fm d 0-1-1-5; Pt pr 1; Tb pr 1-1, v 1-1-2ap; Mt pr 0-1ap, v 2-2ap. II: Fm d 0-1-2-5; Pt pr 1; Tb pr 1-1, v 1-1-2ap; Mt pr 1-1ap, rt 0-1ap, v 2-2ap. III: Fm d 1-0-2-5; Pt pr and rt 1; Tb d 1-0-0, pr and rt 1-1-1-1, v 1-0-2ap; Mt d 2-1-0, pr and rt 1-0-2ap, v 0-22ap. IV: Fm d 1-0-1-5; Pt pr and rt 1; Tb d 1-0-0, pr and rt 1-1-1-1, v 1-0-2ap; Mt d 2-1-0, pr 1-1-2ap, rt 1-0-2ap, v 1-0-2ap. Coloration (in alcohol; Figs 330-333). Carapace brown, eye field dark brown. Clypeus and cheeks dark brown, covered with dark brown hairs. Sternum yellow. Endites and labium dark yellow. Chelicerae brown. Abdomen: dorsum brown, with a pair of large dorso-lateral white spots on its rear half and a wide triangular white figure on its caudal part; venter yellow, with small dots of dark brown hairs forming two rows. Book-lung covers pale yellow. Spinnerets brown-yellow. All legs brown, covered with dark brown hairs. Epigyne and spermathecae as in Figs 334-335; the epigynal plate flat, without visible structures; the copulatory openings look like a pair of black beans, widely separated; the insemination ducts wide and heavily sclerotized, forming $\mathrm{C}$-shaped tubes running towards the median line; the primary spermathecae round.

\section{Distribution}

Two localities in Congo and one in Zambia (Fig. 513) (Wesołowska 2014b; present data). This is the first record of this species since its original description.

Stenaelurillus lesserti Reimoser, 1934

Figs 87-89, 336-337, 509

Stenaelurillus lesserti Reimoser, 1934: 504, figs 25-26 (D ${ }^{\wedge}$ \%); syntypes in MNHN, not examined.

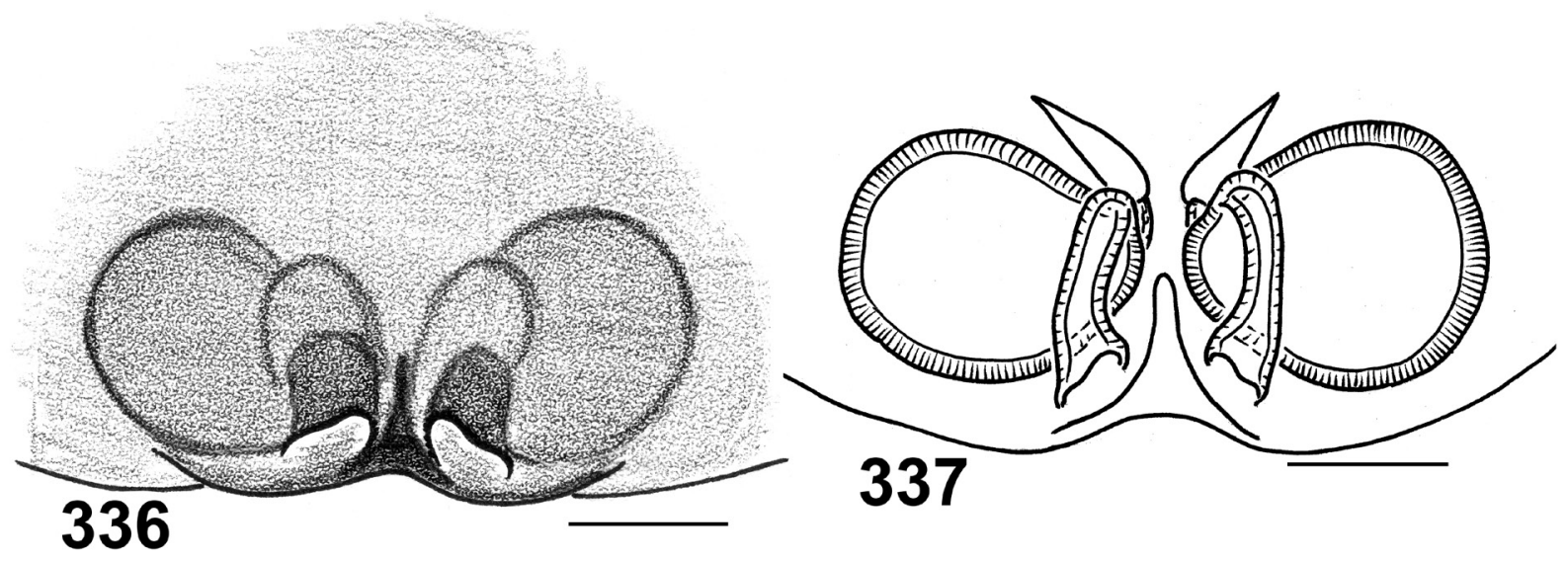

Figs 336-337. Stenaelurillus lesserti Reimoser, 1934, q from Sri Lanka (Pollonaruwa). 336. Epigyne, ventral view. 337. Spermathecae, dorsal view. Scale bars: $0.1 \mathrm{~mm}$. 


\section{Material examined}

INDIA: 1 q, Pondicherry [= Puduchery], ca $11^{\circ} 54^{\prime}$ N , 794 48' E, 1909, M. Maindron leg. (MNHN 5367).

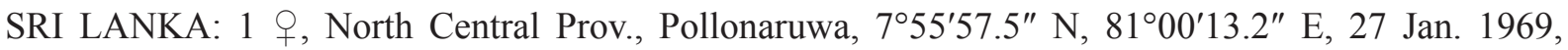
P. Lehtinen leg. (ZMTU).

\section{Remarks}

Sebastian et al. (2015: figs 6A-C) and Caleb \& Sanap (2016: figs 10-11) reported on a female of $S$. lesserti that differs from the syntype $q$ of $S$. lesserti, re-described and illustrated by Wesołowska (2014a: figs 3B-D). However, the male and female syntypes were not collected together and therefore the syntype $q$ of $S$. lesserti reported by Wesołowska (2014a) seems to belong to a different species that is close to $S$. arambagensis. The matter requires special attention in the future, when more numerous specimens of Stenaleurillus from India are available. The correct sex matching for $S$. lesserti was also presented by Prajapati et al. (2016).

\section{Distribution}

Southern India and Sri Lanka (Wesołowska 2014a; Sebastian et al. 2015; Prajapati et al. 2016; Caleb \& Sanap 2016; present data) (Fig. 509).

Stenaelurillus mirabilis Wesołowska \& Russell-Smith, 2000

Figs 338-351, 514

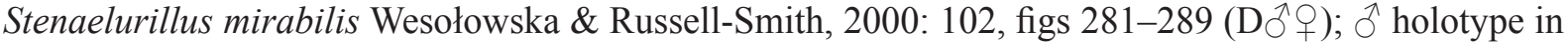
MRAC, examined.

\section{Diagnosis}

This species can easily be distinguished from all other species of Stenaelurillus by the presence of a proximal spur-shaped process on the functional tegulum (Figs 338-339) in the male, and by the characteristic conformation of both the epigyne and the spermathecae (Figs 342-343).

\section{Material examined}

\section{Holotype}

TANZANIA: ${ }^{\wedge}$, Mkomazi GR, $4^{\circ} 00^{\prime} \mathrm{S}, 38^{\circ} 00^{\prime} \mathrm{E}$, pitfall traps in grassland, Feb. 1994, A. Russell-Smith leg. (MRAC 207.987).

\section{Paratypes}

TANZANIA: $2 q q$, together with the holotype (MRAC 207.988); $10 \hat{\partial}$, together with the holotype (MRAC 207.988; in Wesołowska \& Russell-Smith (2000: 102), the sample under this accession number is mentioned as containing the single female allotype (not available); $1 \hat{0}$, Mkomazi GR, Ibaya camp, $04^{\circ} 00^{\prime}$ S, $38^{\circ} 00^{\prime}$ E, Feb. 1994, A. Russell-Smith leg. (MRAC 207.996); 2 우, same locality, cadada plot, 1-2 Feb. 1996, A. Russell-Smith leg. (MRAC 208.004).

\section{Other material}

TANZANIA: $1 \partial^{\curvearrowright}$, Mkomazi GR, $4^{\circ} 00^{\prime} \mathrm{S}, 38^{\circ} 00^{\prime} \mathrm{E}$, pitfall traps in grassland, Feb. 1994, A. Russell-Smith

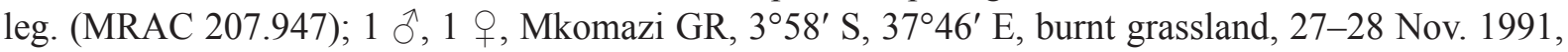

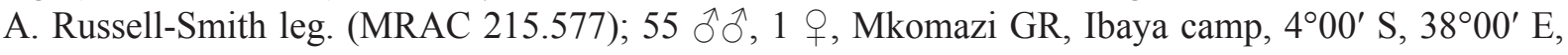
degraded bushland, 25 pitfalls, hillside E of gulley, 10-11 Aug. 1993, M. Ritchie and R. Makusi leg. (MRAC 215.574); 30 우오, same reserve, ca $7 \mathrm{~km} \mathrm{SE}$ of Ibaya, $4^{\circ} 00^{\prime} \mathrm{S}, 38^{\circ} 00^{\prime} \mathrm{E}, 19-20$ Aug. 1993, M. Ritchie and R. Makusi leg. (MRAC 215.573); $100 \hat{\delta} \widehat{\partial}, 38$ q $q$ (MMUE G7571.51,59), $10 \hat{\delta} \widehat{\partial}$, 


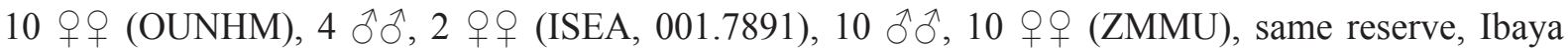
camp, $4^{\circ} 00^{\prime} \mathrm{S}, 38^{\circ} 00^{\prime} \mathrm{E}$, burned bushland, pitfall traps, 1994-1996, A. Russell-Smith leg.; $1 \mathrm{o}^{\top}$, same reserve, above Ibaya Camp, 03⒌ $9^{\prime} \mathrm{S}, 37^{\circ} 47^{\prime} \mathrm{E}$, in litter of montane forest, 7 May 1996, H.G. Robertson leg. (NCA 2010/4840); $1{ }^{\prime}$, same reserve, valley behind Ibaya Camp, 3⒌ $58^{\prime} \mathrm{S}, 37^{\circ} 48^{\prime} \mathrm{E}$, leaf litter, next

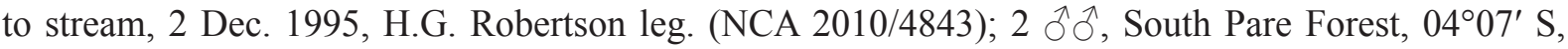
3752' E, Winkler-trap, 28 Nov. 1995, H.G. Robertson leg. (NCA 2010/4845).
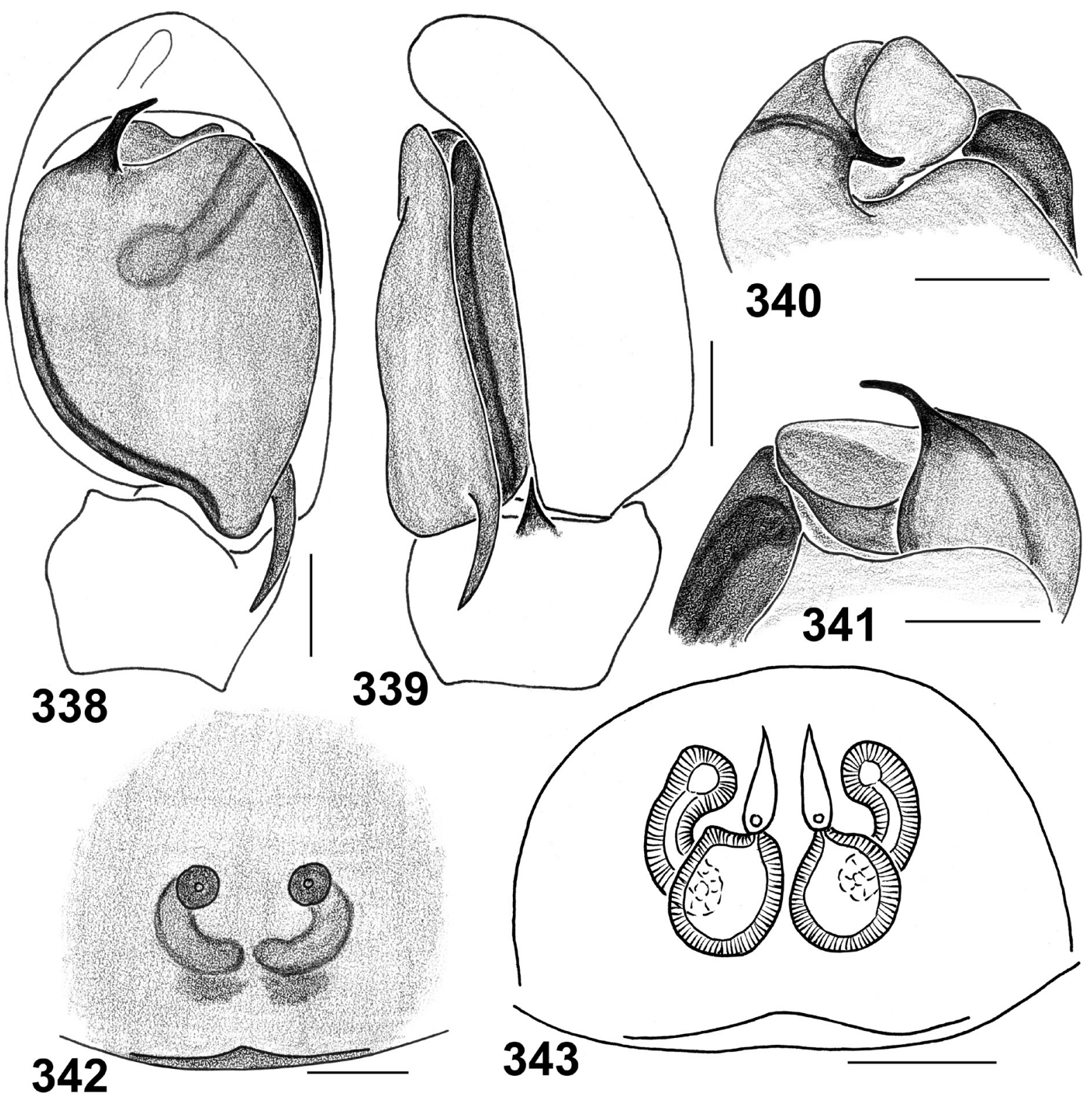

Figs 338-343. Stenaelurillus mirabilis Wesołowska \& Russell-Smith, 2000, from Tanzania (Mkomazi GR, Ibaya camp). 338. Male palp, ventral view. 339. Male palp, retrolateral view. 340. Embolic division, apical view. 341. Embolic division, dorsal view. 342. Epigyne, ventral view. 343. Spermathecae, dorsal view. Scale bars: $0.1 \mathrm{~mm}$. 


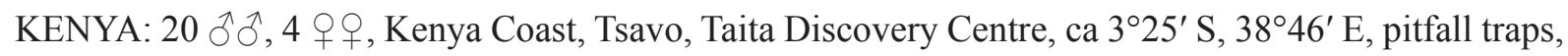
8 Jan.-24 Feb. 2002, E. Selempo leg. (MRAC 212.923, MRAC 212.957, MRAC 212.923); 7 §ึ ô, same locality, 1 Nov.-15 Dec. 2001, E. Selempo leg. (MRAC 213.126, MRAC 213.084, MRAC 213.064).

\section{Description}

Male (Tanzania, Mkomazi GR; MMUE G7571.51)

Measurements: carapace: 1.75 long, 1.33 wide, 0.95 high. Abdomen: 2.00 long, 1.23 wide. Ocular area: 0.88 long, 1.08 wide anteriorly, 1.03 wide posteriorly. Cheliceral length 0.50 . Clypeal height 0.15 . Diameter of AME 0.30. Length of leg segments: I $0.88+0.38+0.53+0.40+0.40$ (2.59); II $0.95+$ $0.45+0.48+0.43+0.38(2.69) ;$ III $1.45+0.65+1.00+1.04+0.50(4.64) ;$ IV $1.20+0.53+0.85+$ $1.10+0.63$ (4.31). Leg formula III,IV,II,I. Leg spination: I: Fm d 0-1-1-5; Pt pr 0-1-0; Tb pr 1-1, v 1-02ap; Mt pr 1-1ap, v 2-2ap. II: Fm d 0-1-1-5; Pt pr and rt 0-1-0; Tb pr 1-1-1, v 2ap; Mt pr and rt 1-2ap, v

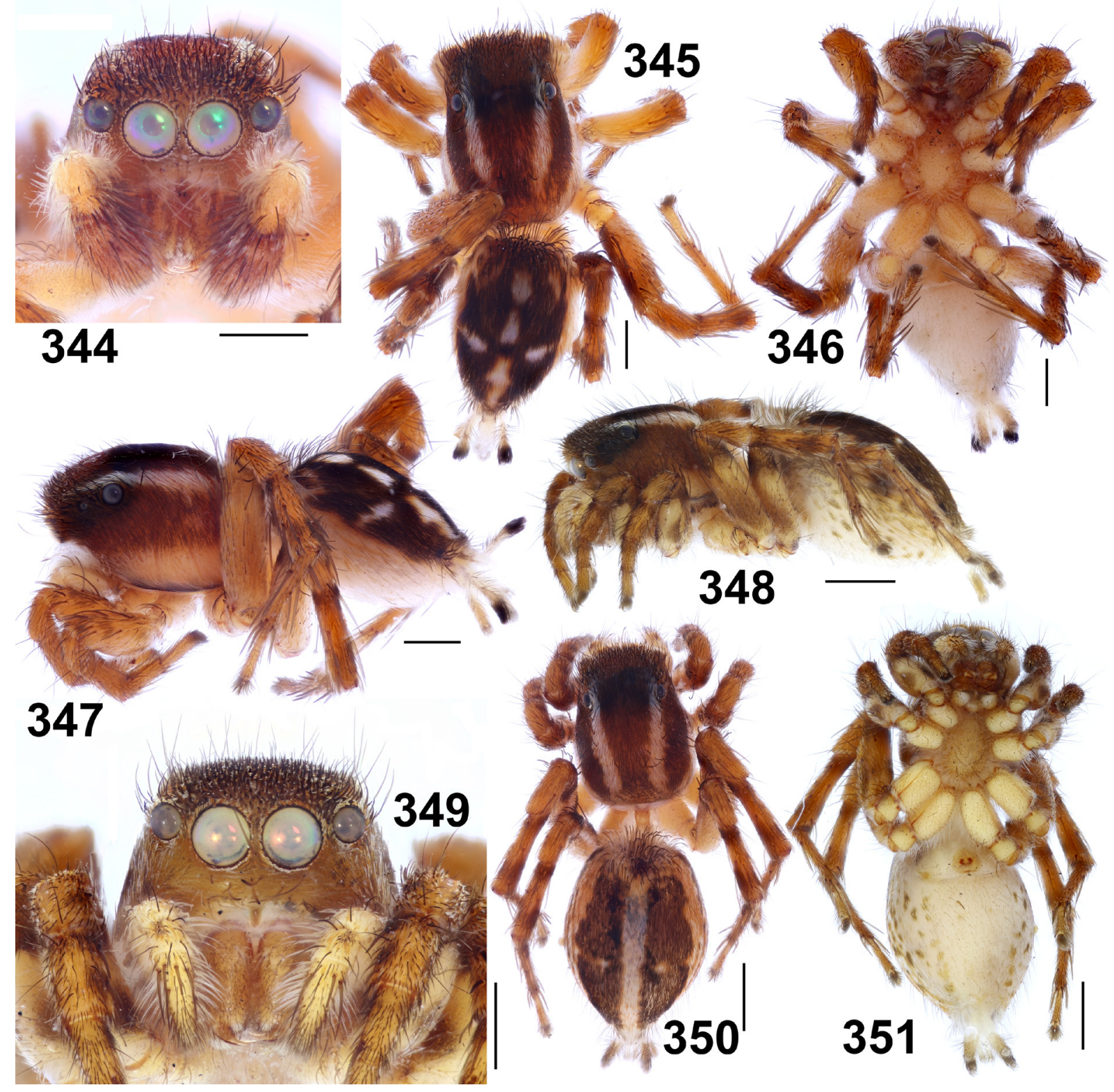

Figs 344-351. Stenaelurillus mirabilis Wesołowska \& Russell-Smith, 2000, from Tanzania (Mkomazi GR, Ibaya camp), general appearance. 344-347. $\widehat{~}$. 348-351. ㅇ. Scale bars: $1 \mathrm{~mm}$. 
2-2ap. III: Fm d 0-1-2-5; Pt pr and rt 0-1-0; Tb d 1-0-0, pr and rt 1-1-1, v 1-0-2ap; Mt d 1-1-0, pr and rt 1-1-2ap, v 2ap. IV: Fm d 0-1-1-4; Pt pr and rt 0-1-0; Tb d 1-0-0, pr and rt 1-1-1, v 1-2ap; Mt d 1-0-0, pr and rt 1-1-2ap, v 0-1-1-2ap. Coloration (in alcohol; Figs 344-347). Carapace yellow, densely covered with long brown recumbent scales; there are two longitudinal white stripes on the thorax and two wide white marginal stripes; clypeus and cheeks yellow, with long sparse orange hairs. Sternum light yellow, densely covered with white hairs. Endites and labium light yellow. Chelicerae light yellow. Abdomen: dorsum brown, with five white spots as shown in Fig. 345; sides yellow, with orange longitudinal stripes; venter light yellow. Book-lung covers yellow, tinged with brown. Spinnerets whitish, but the dorsal pair with dark brown tips. Legs: coxae and trochanters light yellow; remaining segments yellow, with brownish patches and (semi)rings. Palps light yellow. Palpal structure as in Figs 338-341; VTA bulgeshaped, poorly marked; RTA straight, thorn-shaped; the cymbium simple, without a cymbial lateral process; the tegulum small, poorly marked, without marked tegular process; the functional tegulum narrow-elongated, with no distal projection and a poorly-developed proximal projection (PP); instead there is a very long, spur-shaped proximal process; the embolus short, thin and slightly bent apically, with a large, flat, spoon-shaped base.

Female (Tanzania, Mkomazi GR; MMUE G7571.59)

Measurements: carapace: 2.05 long, 1.65 wide, 1.10 high. Abdomen: 2.90 long, 1.95 wide. Ocular area: 0.95 long, 1.20 wide anteriorly, 1.15 wide posteriorly. Cheliceral length 0.65 . Clypeal height 0.18 . Diameter of AME 0.46. Length of leg segments: I $1.00+0.50+0.55+0.40+0.40$ (2.85); II $1.00+0.53$ $+0.55+0.53+0.30(2.91)$; III $1.75+0.85+1.1 .3+1.25+0.53(5.51) ;$ IV $1.60+0.70+1.05+1.38+$ 0.55 (5.28). Leg formula III,IV,II,I. Leg spination: I: Fm d 0-1-1-4; Pt pr 0-1-0; Tb pr 1-1, v 1-2ap; Mt pr 2ap, v 2-2ap. II: Fm d 0-1-2-5; Pt pr and rt 0-1-0; Tb pr 1-1, v 1-2ap; Mt pr 1-1ap, v 2-2ap. III: Fm d 0-1-2-5; Pt pr and rt 0-1-0; Tb d 1-0-0, pr and rt 1-1-1, v 1-2ap; Mt d 1-1, pr and rt 1-2ap, v 0-0-2-2ap. IV: Fm d 0-1-1-3; Pt pr and rt 0-1-0; Tb d 1-0-0, pr and rt 1-1-1, v 1-0-2ap; Mt pr 1-1-2ap, rt 1-1-1-2ap, v 0-1-1-2ap. Coloration (in alcohol; Figs 348-351) as in the male, but differs as follows: abdominal dorsum with two wide brown longitudinal stripes; abdominal sides yellow, with orange longitudinal lines and brown speckles; all spinnerets yellow, tinged with brownish. Epigyne and spermathecae as in Figs 342-343; the epigynal plate flat, without fossae, its rear edge visibly sclerotized; the copulatory openings widely separated, resembling a pair of sclerotized round plates; insemination ducts short and slightly bent, running proximad, visible through the integument as a pair of dark bent figures directed towards each other; the primary spermathecae round.

\section{Distribution}

Tanzania and Kenya (Fig. 514) (Wesołowska \& Russell-Smith 2000; Wesołowska 2014b; present data).

Stenaelurillus modestus Wesołowska, 2014

Figs 352-368, 513

Stenaelurillus modestus Wesolowska, 2014b: 608, figs 8A-E (D ${ }^{\wedge}$ ) $)$; $\overbrace{}^{\Uparrow}$ holotype in NCA, not examined.

\section{Diagnosis}

This species can easily be distinguished from all other described species of Stenaelurillus by the spiralled embolus, resembling that of the males in Phlegra species (Figs 354-355), and by the characteristic deep notch of the rear edge of the epigynal plate in which the deep epigynal pocket is situated (Fig. 359).

\section{Material examined}

SOUTH AFRICA: 1 ภ, 1 , KwaZulu-Natal Prov., uMkhuze GR, iSimangaliso Wetland Park, ca $27^{\circ} 40^{\prime}$ S, 32 ${ }^{\circ} 5^{\prime}$ E, active search, 13 Jul.-2 Aug. 2008, X. Combrink leg. (NCA 2011/2544, NCA 2011/2550); 

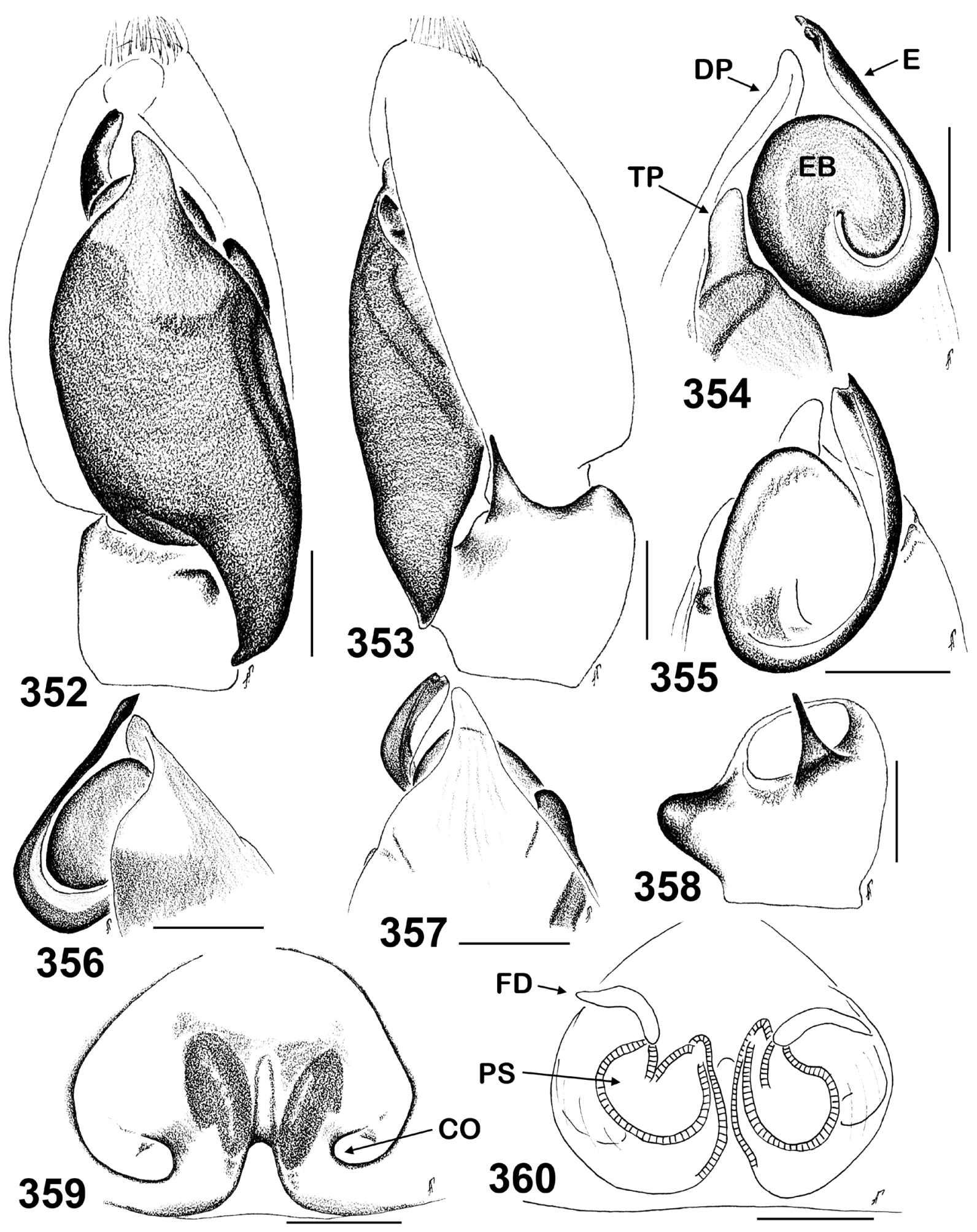

Figs 352-360. Stenaelurillus modestus Wesołowska, 2014, from South Africa (uMkhuze GR). 352. Male palp, ventral view. 353. Male palp, retrolateral view. 354-357. Embolic division. 354. Retrolateral view. 355. Dorsal view. 356. Median view. 357. Ventral view. 358. VTA and RTA, retrolateral view. 359. Epigyne, ventral view. 360. Spermathecae, dorsal view. Abbreviations: see Material and methods. Scale bars: $0.1 \mathrm{~mm}$. 


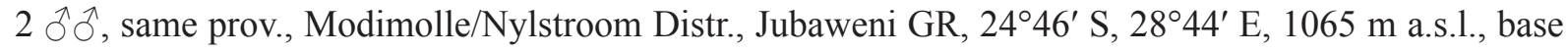
of grass tussocks, by hand, 6 Oct. 2012, C.R. Haddad leg. (NCA).

\section{Description}

Male

Measurements: carapace: 2.20 long, 1.75 wide, 1.20 high. Abdomen: 2.00 long, 2.00 wide. Ocular area: 0.85 long, 1.40 wide anteriorly, 1.30 wide posteriorly. Cheliceral length 0.55 . Clypeal height 0.25 . Diameter of AME 0.40. Length of leg segments: I $1.10+0.50+0.60+0.50+0.40$ (3.10); II $1.10+$ $0.60+0.70+0.55+0.40(3.35) ;$ III $1.50+0.80+0.90+1.10+0.60(4.90) ;$ IV $1.50+0.70+0.80+$ $1.10+0.65$ (4.75). Leg formula III,IV,II,I. Leg spination: I: Fm d 1-1-5; Tb pr 1-0, v 1-1-2ap; Mt pr 1-1ap, rt 0-1ap, v 2-2ap. II: Fm d 1-2-5; Tb pr 1-1, v 1-1-2ap; Mt pr and rt 1-1ap, v 2-2ap. III: Fm d 1-25; Pt pr and rt 1; Tb d 1-0-0, pr and rt 1-1-1-1, v 1-0-2ap; Mt d 2-2-0, pr and rt 1-0-2ap, v 1-1-2ap. IV: Fm d 1-1-5; Pt pr and rt 1; Tb d 1-0-0, pr and rt 1-1-1-1, v 1-0-2ap; Mt d 2-2-0, pr 1-1-2ap, rt 1-0-2ap, v 0-22ap. Coloration (in alcohol; Figs 361-363, 365). Carapace brown, with dark brown (almost black) eye field, dorsally with two narrow longitudinal stripes of white scales running from PLEs to the rear margin of the carapace; each side with a white spot of scales near coxae III. Sternum yellow-brown. Labium and endites brown. Chelicerae brown, covered with dark brown hairs. Clypeus and cheeks brown, with two transverse stripes of white hairs connecting cheeks and short symmetric narrow stripes of white hairs

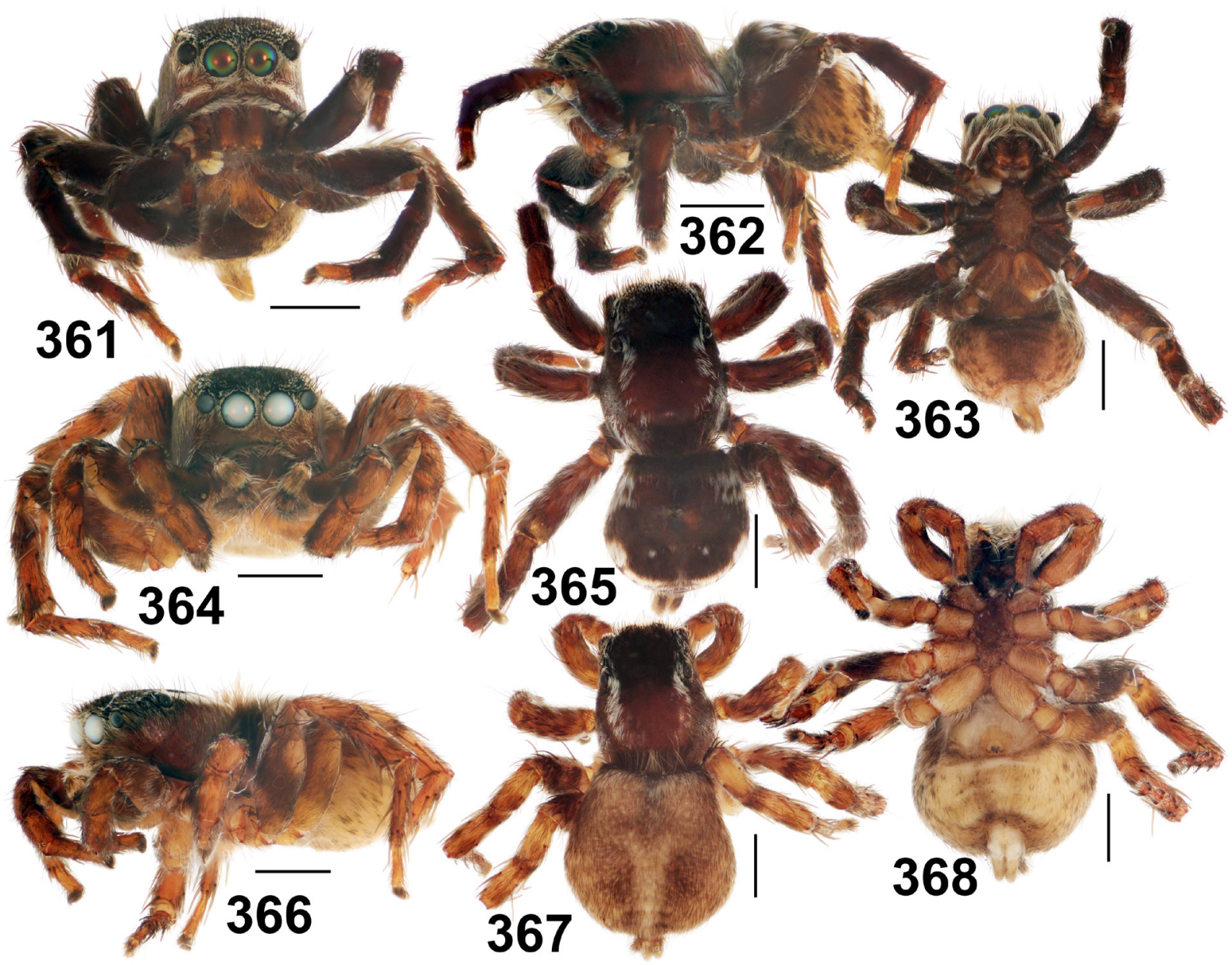

Figs 361-368. Stenaelurillus modestus Wesołowska, 2014, from South Africa (uMkhuze GR), general appearance. 361-363, 365. $\overbrace{}^{\top}$. 364, 366-368. ‥ Scale bars: $1 \mathrm{~mm}$. 
originating from ALEs. Abdomen: dorsum dark brown, with three pairs of symmetric large lateral pale yellow spots (one pair on the anterior half and two others on the posterior one) and two paired dorsal median white spots; venter brown-yellow. Book-lung covers yellow-brown. Spinnerets: ventral pair yellow, dorsal pair brown. All legs dark brown. Palpal Fm and Pt brown, Tb and cymbium dark brown, covered with brown hairs. Palpal structure as in Figs 352-358: VTA bulge-shaped; RTA straight, thornshaped; the cymbium simple, without a cymbial lateral process; the tegulum small, poorly marked, with a visible, finger-shaped tegular process (TP); the functional tegulum narrow-elongated, with welldeveloped proximal (PP) and distal (DP) projections; the embolus thick and spiralled, with a wide flat base (as in some Phlegra species).

\section{Female}

Measurements: carapace: 2.40 long, 1.90 wide, 1.30 high. Abdomen: 2.80 long, 2.65 wide. Ocular area: 0.85 long, 1.40 wide anteriorly, 1.40 wide posteriorly. Cheliceral length 0.50 . Clypeal height 0.20 . Diameter of AME 0.40. Length of leg segments: I $1.20+0.60+0.70+0.55+0.35$ (3.40); II $1.20+0.70$ $+0.70+0.50+0.45(3.55) ;$ III $1.70+0.80+1.10+1.20+0.60(5.40) ;$ IV $1.70+0.70+1.15+1.30+$ 0.65 (5.50). Leg formula IV,III,II,I. Leg spination: I: Fm d 1-1-5; Tb pr 1-1, v 1-1-2ap; Mt pr 1-1ap, rt 0-1ap, v 2-2ap. II: Fm d 1-1-5; Tb pr 1-1, v 1-1-2ap; Mt pr 1-1ap, rt 0-1ap, v 2-2ap. III: Fm d 1-2-5; Pt pr and rt 1; Tb d 1-0-0, pr and rt 1-1-1-1, v 1-0-2ap; Mt d 2-2-0, pr and rt 1-0-2ap, v 0-2-2ap. IV: Fm d 1-1-5; Pt pr and rt 1; Tb d 1-0-0, pr and rt 1-1-1-1, v 1-0-2ap; Mt d 2-2-0, pr 1-1-2ap, rt 1-0-2ap, v 1-12ap. Coloration (in alcohol; Figs 364, 366-368). Carapace brown, with dark brown eye field, dorsally with two longitudinal stripes of white scales running from PLEs to the rear margin of the carapace; sides of the thorax with marginal stripes of white scales. Clypeus and cheeks light brown, sparsely covered with short brownish hairs. Sternum brown-yellow. Endites and labium brown-yellow. Chelicerae brown. Abdomen: dorsum light brown, with a Y-shaped median brownish yellow stripe on its rear half; venter yellow. Book-lung covers yellow. Spinnerets brownish yellow. All legs and palps yellowish brown. Epigyne and spermathecae as in Figs 359-360; the epigynal plate transverse-ovoid, its rear edge with a deep notch in which the narrow and deep epigynal pocket is situated; the copulatory openings widely separated, facing laterad; insemination ducts short, running towards each other and then joining and running distad (see also Wesołowska 2014b: fig. 8E); the primary spermathecae bean-shaped.

\section{Distribution}

A few localities in South Africa (Fig. 513).

Stenaelurillus nigricaudus Simon, 1886

Figs 1-2, 10, 14-15, 30-33, 369-405, 510

Stenaelurillus nigricauda Simon, 1886: 351 (Dへ); đ̊ holotype in MNHN, not examined.

Aelurillus sahariensis Berland \& Millot, 1941: 301, fig. 1 (D 9 ); $ᄋ$ holotype in MNHN, examined. Syn. nov.

\section{Diagnosis}

This species is most similar to $S$. senegalensis sp. nov., with both species having almost identical body coloration (cf. Figs 435-441). The only colour difference is that of the ventral sides of Tb and Mt I in the males: dark brown in S. nigricaudus (Figs 391-391) and yellow in S. senegalensis sp. nov. (Figs 435437). The males of both species can easily be distinguished by the conformation and relative length of the embolus, which is comparatively short, hook-shaped and situated on the functional tegulum apically at 12 o'clock in S. nigricaudus, and comparatively long (almost twice as long as the length of the tegulum) and straight, and situated on the functional tegulum at about 10 o'clock in S. senegalensis sp. nov. (cf. Figs $369,378,425)$. The female of $S$. nigricaudus can be separated from that of $S$. senegalensis sp. nov. 

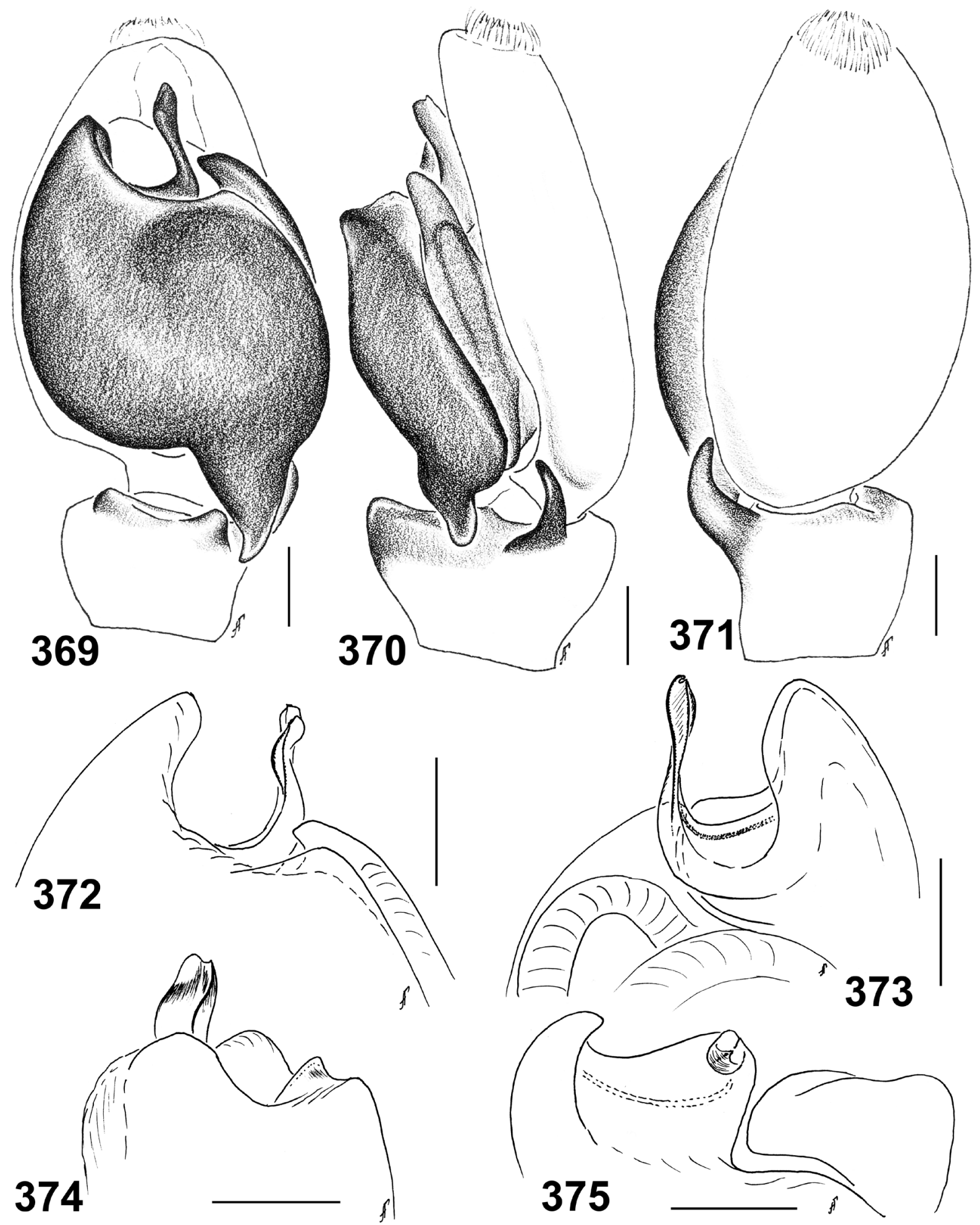

Figs 369-375. Stenaelurillus nigricaudus Simon, 1886, from Senegal (Richard Toll). 369-371. Male palp. 369. Ventral view. 370. Retrolateral view. 371. Dorsal view. 372-375. Embolic division. 372. Ventroapical view. 373. Dorsal view. 374. Median view. 375. Apical view. Scale bars: $0.1 \mathrm{~mm}$. 
by the presence of the deep epigynal pocket, which is absent from the latter species (cf. Figs 395-398, 429); the spermathecae of both species are virtually indistinguishable.

\section{Material examined}

\section{Holotype}

MALI: , holotype of Aelurillus sahariensis Berland \& Millot, 1941, Sahara, Aguelhok, $19^{\circ} 27^{\prime} \mathrm{N}$, $0^{\circ} 51^{\prime} \mathrm{E}$, Oct. 1937 (MNHN 2.662; the epigyne is lost!).

\section{Other material}

BURKINA FASO: $13 \partial^{\lambda}, 6$ 우, Sissamba, ca $13^{\circ} 30^{\prime} \mathrm{N}, 2^{\circ} 28^{\prime} \mathrm{W}$, yellow plate, 9 Oct.-10 Nov. 1993, De Visscher \& Balança leg. (MRAC); $32 \overbrace{}^{\lambda} 0^{\lambda}, 33$ 우, Soulou, ca $13^{\circ} 46^{\prime} \mathrm{N}, 2^{\circ} 28^{\prime} \mathrm{W}$, yellow plate,

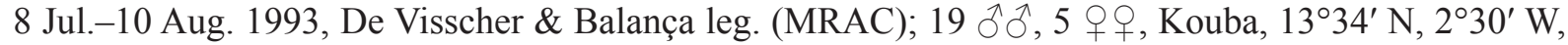
pitfall traps, 22 Sep.-30 Oct. 1993, De Visscher \& Balança leg. (MRAC).
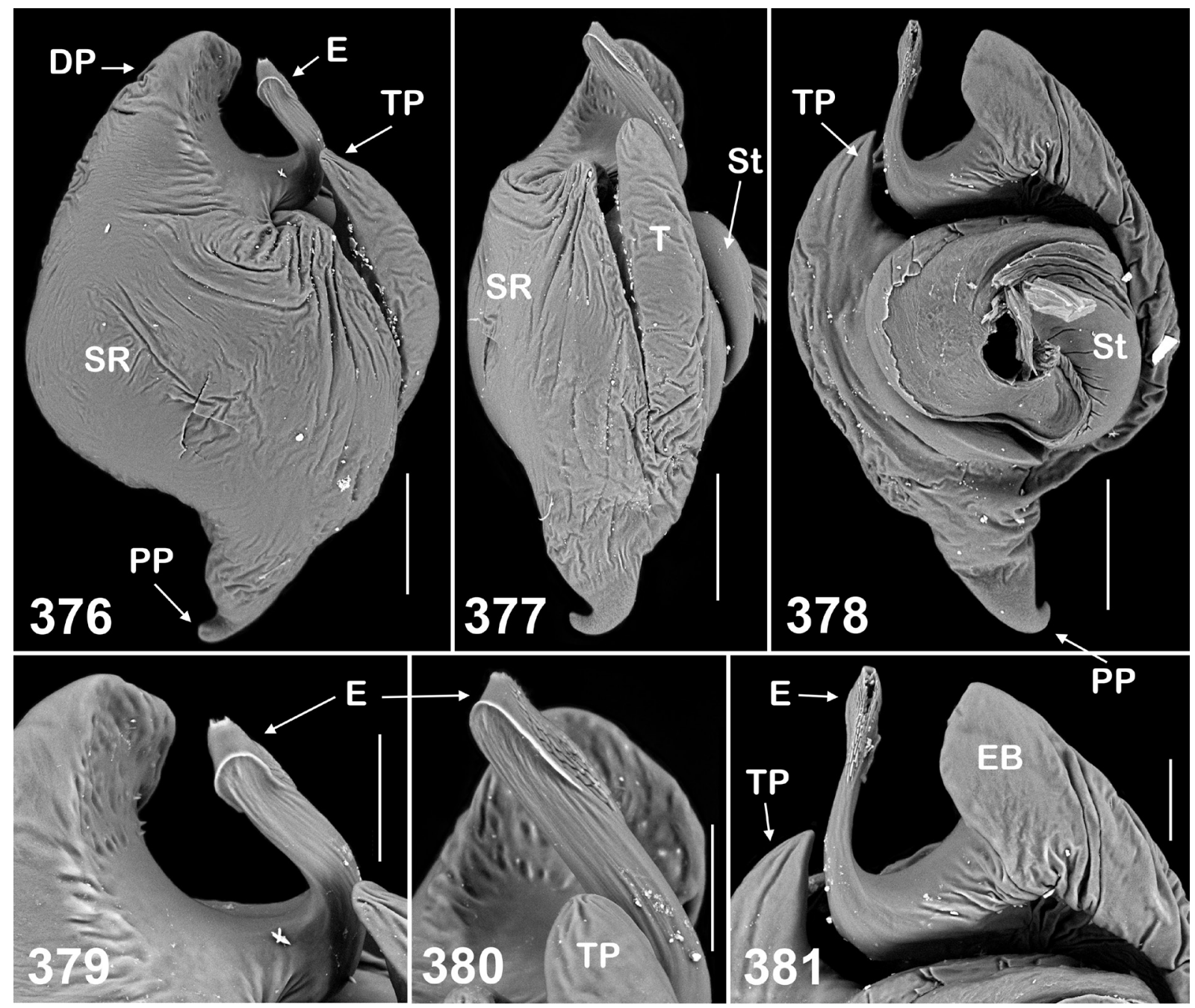

Figs 376-381. Stenaelurillus nigricaudus Simon, 1886, from Senegal (Richard Toll), scanning electron micrographs. 376. Bulbus of male palp, ventral view. 377. Male palp, retrolateral view. 378. Male palp, dorsal view. 379. Embolic division, ventral view. 380. Embolic division, retrolateral view. 381. Embolic division, dorsal view. Abbreviations: see Material and methods. Scale bars: $0.1 \mathrm{~mm}$. 
SENEGAL: $34 \hat{\partial^{\lambda}}, 7$ 우, ca $20 \mathrm{~km} \mathrm{~S}$ of Richard Toll, $16^{\circ} 20^{\prime} \mathrm{N}, 15^{\circ} 30^{\prime} \mathrm{W}$, savanna, pitfall traps, 23 Sep.-3 Oct. 1991, H. van der Valk leg. (MRAC).

\section{Remarks}

We have re-examined the male holotype of Aelurillus sahariensis and found that this species does not belong to Aelurillus as it possesses the main diagnostic characters of the genus Stenaelurillus: viz.,

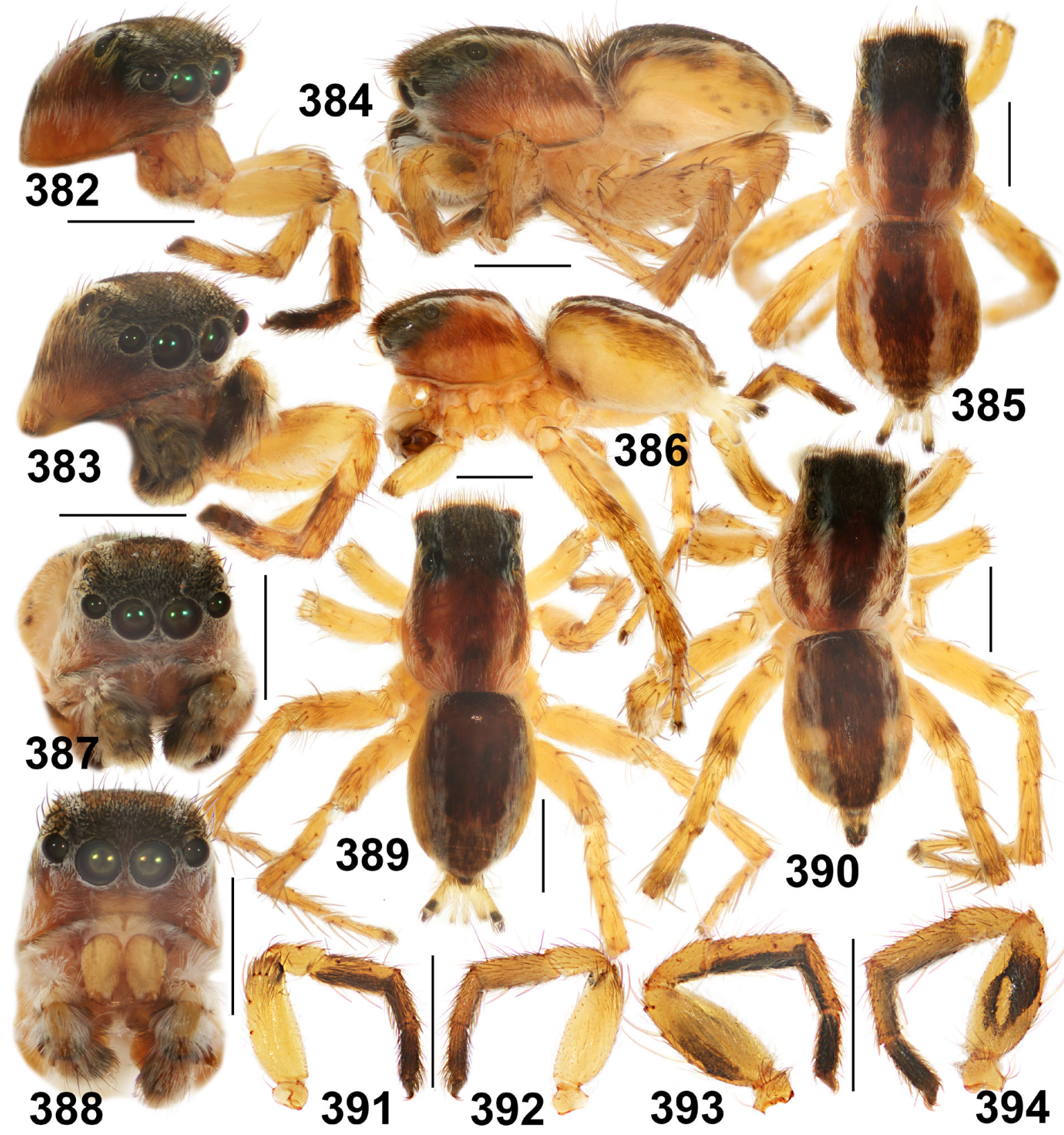

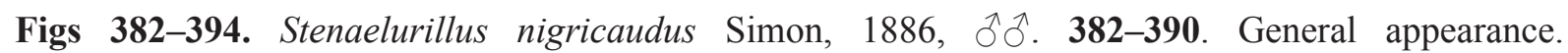
391, 393. Legs 1, prolaterally. 392, 394. Legs 1, retrolaterally. Specimens: 382, 385-386, 388-389, 391392 from Burkina Faso; 383-384, 387, 390, 393-394 from Senegal (Richard Toll). Scale bars: 1 mm. 
the characteristic body shape and coloration (see Berland \& Millot 1941: fig. 1A); the anterior row of eyes wider than the posterior one (as in all other species of Stenaelurillus); leg formula III,IV,II,I and the relatively long spinnerets, tarsal claws narrow, with well-developed and numerous teeth (all these characters are typical of Stenaelurillus). Although the holotype does not have the epigyne, it is safe to conclude that this species is to be treated as a junior synonym of $S$. nigricaudus because the body coloration of the holotype is identical to that of the latter species (cf. Figs 400-405 and Berland \& Millot 1941: fig. 1A) and its epigyne, as illustrated by Berland \& Millot (1941: fig. 1B), possesses

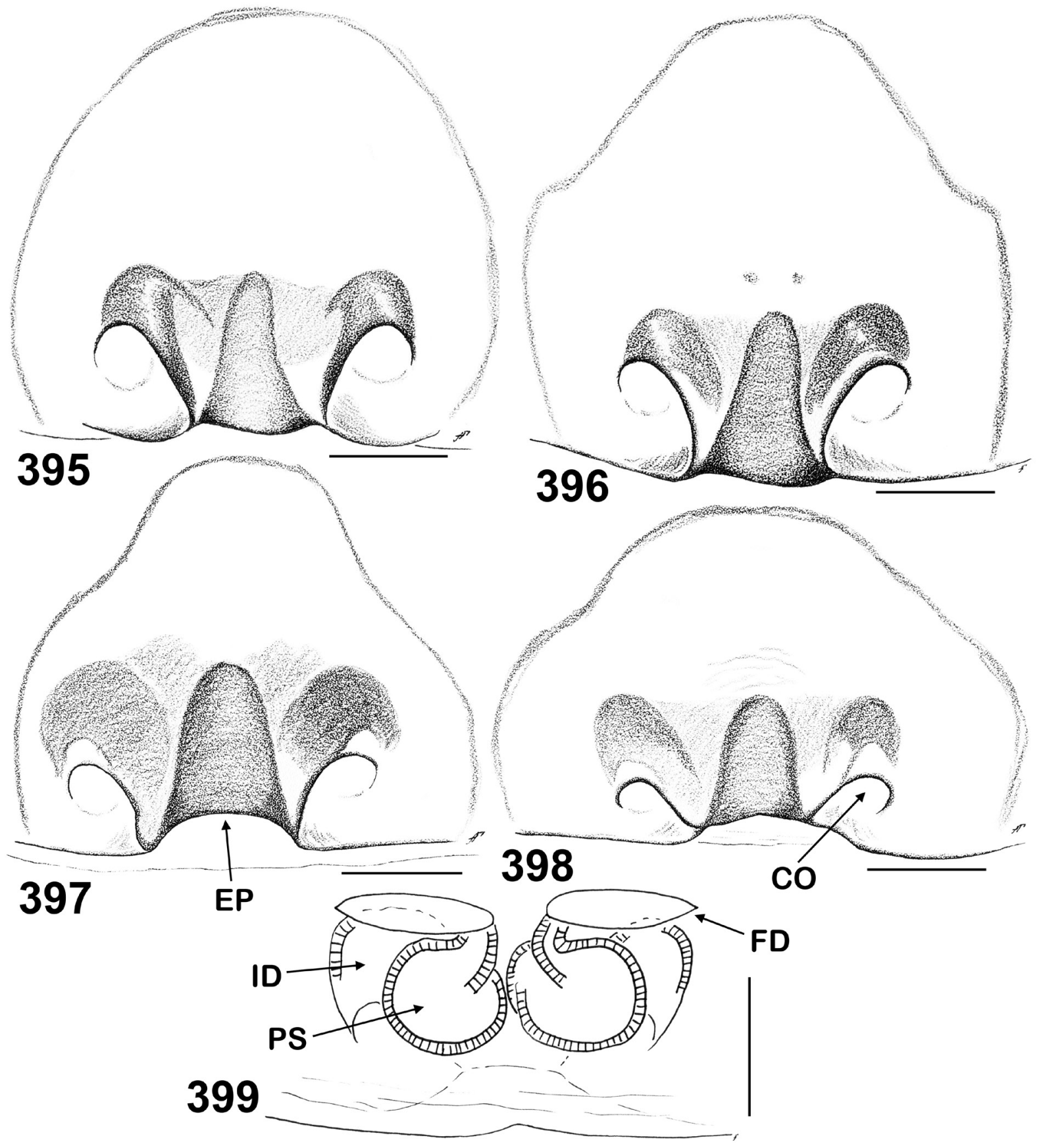

Figs 395-399. Stenaelurillus nigricaudus Simon, 1886. 395-398. Epigyne, ventral view. 399. Spermathecae, dorsal view. Specimens: 395-396, 399 from Senegal (Richard Toll); 397-398 from Burkina Faso. Abbreviations: see Material and methods. Scale bars: $1 \mathrm{~mm}$. 
a deep epigynal pocket, which is diagnostic of S. nigricaudus (cf. Figs 395-398). Finally, the record of A. sahariensis lies within the known range of $S$. nigricaudus (Fig. 510). Thus, the name Aelurillus sahariensis is here considered a junior synonym of $S$. nigricaudus.

\section{Description}

\section{Male}

Measurements (specimens from Burkina Faso, MRAC 225.270). Carapace: 2.00-2.30 long, 1.35-1.60 wide, $1.00-1.05$ high. Abdomen: $2.00-2.40$ long, $1.35-1.75$ wide. Ocular area: $0.70-0.80$ long, $1.10-$ 1.30 wide anteriorly, $1.00-1.20$ wide posteriorly. Cheliceral length $0.50-0.60$. Clypeal height 0.20 . Diameter of AME 0.35. Length of leg segments (male from Senegal, MRAC 201.167): I $1.00+0.60+$ $0.75+0.65+0.50(3.50) ;$ II $1.00+0.60+0.70+0.70+0.40(3.40) ;$ III $1.65+0.85+1.00+1.35+$ 0.50 (5.35); IV $1.50+0.90+1.05+1.40+0.60$ (5.45). Leg formula IV,III,I,II. Leg spination (specimen from Senegal, MRAC 201.167): I: Fm d 0-1-1-5; Pt pr 0-1-0; Tb pr 1-1, v 1-1-2ap; Mt pr 1-1ap, v 2-2ap. II: Fm d 0-1-2-5; Pt pr and rt 0-1-0; Tb pr 1-1, rt 0-1-0, v 1-0-2ap; Mt pr and rt 1-1ap, v 2-2ap. III: Fm d 0-1-2-5; Pt pr and rt 0-1-0; Tb d 1-0-0, pr and rt 1-1-1-1, v 1-0-2ap; Mt d 1-1-0, pr and rt 1-0-2ap, v 0-2-2ap. IV: Fm d 0-1-1-5; Pt pr and rt 0-1-0; Tb d 1-0-0, pr and rt 1-1-1-1, v 1-0-2ap; Mt d 1-1-0, pr 1-12ap, rt 1-0-2ap, v 1-2-2ap. Coloration (in alcohol; specimens from MRAC 225.270 and MRAC 201.167;

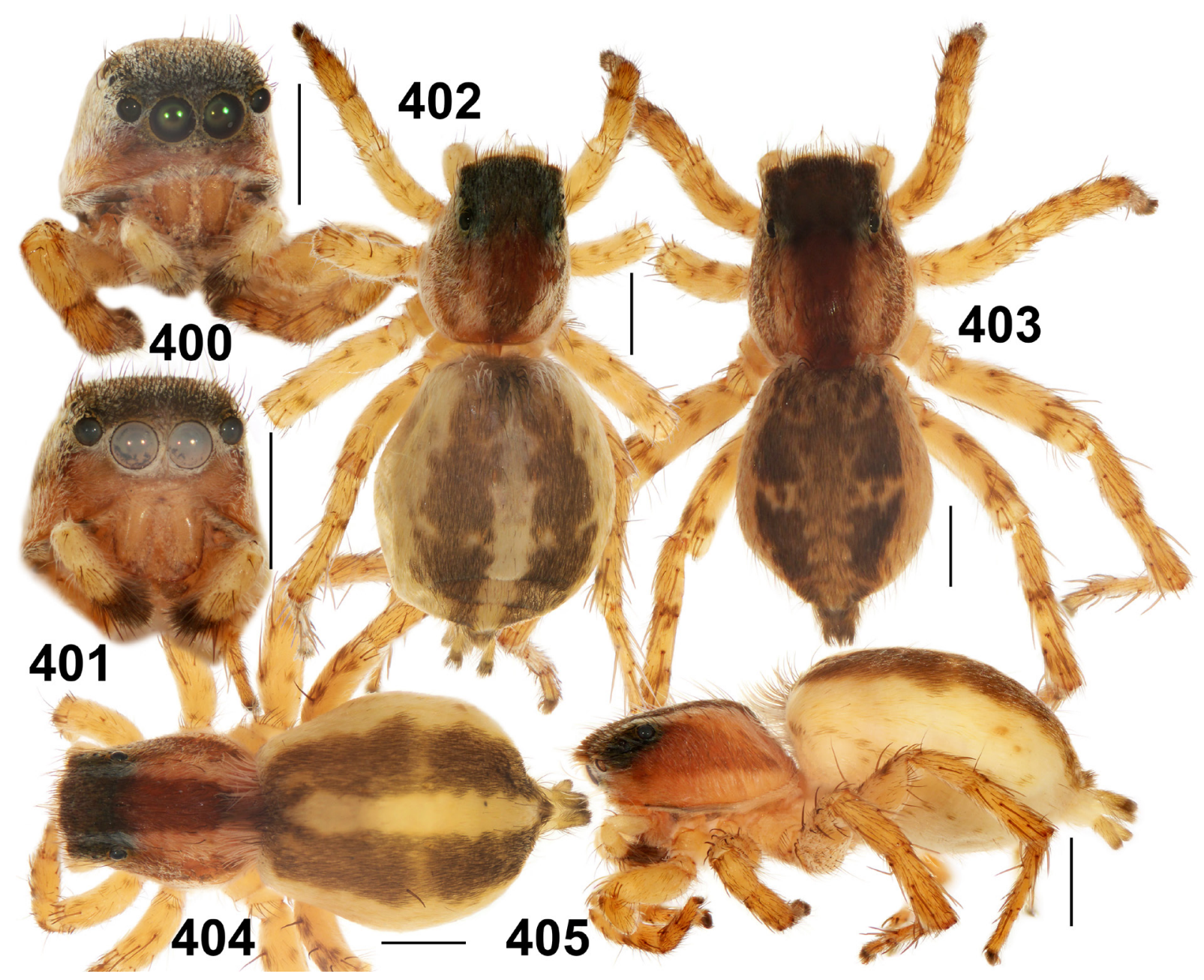

Figs 400-405. Stenaelurillus nigricaudus Simon, 1886, $q$, , general appearance. 400, 402-403. Senegal (Richard Toll). 401, 404-405. Burkina Faso. Scale bars: $1 \mathrm{~mm}$. 
Figs 382-394). Carapace brown, covered with dark brown scales; dorsally with two longitudinal yellow stripes running from ALEs to the rear end and covered with white scales. Sides of carapace with wide marginal yellow stripes covered with white scales. Sternum yellow. Endites and labium yellow. Chelicerae brown-yellow, covered with short white and brown hairs. Clypeus yellow to brownish yellow, cheeks light brown and covered with short whitish hairs. Abdomen yellow: dorsum brown, with a wide median longitudinal stripe covered with short brown scales and two narrow longitudinal lines of white hairs on each side of the median stripe; some specimens also have two transverse yellow spots along the median line (absent in the males from Burkina Faso); venter with thin, longitudinal median lines of brown hairs. Spinnerets yellow, with dark brown apexes. Book-lung covers yellow. All legs yellow. Tr I dark brown, Mt and Tb I ventrally dark brown. Specimens from Senegal have Fm I with a large pro- and retrolateral dark brown spot. Palps yellow to dark brown, densely covered with long white hairs; femora ventrally and all segments prolaterally dark brown and covered with long dark brown hairs. Palpal structure as in Figs 369-381: VTA bulge-shaped; RTA thick and relatively short, hook-shaped, visibly directed medioanteriad; the cymbium simple, without a cymbial lateral process; the tegulum small and elongated, with a well-developed tegular process; the functional tegulum wide and elongated, with a well-developed, pointed proximal (PP) projection and a wide distal (DP) projection, which is fused with the embolic base; the embolus hook-shaped, situated apically on the functional tegulum, at 12 o'clock, with a heavy base that is fused with the DP.

Female (specimens from Senegal, MRAC 201.167)

Measurements: carapace: 2.30 long, 2.00 wide, 1.35 high. Abdomen: 2.30-3.50 long, 2.40-2.90 wide. Ocular area: 1.00 long, 1.40 wide anteriorly, 1.35 wide posteriorly. Cheliceral length 0.65 . Clypeal height 0.30. Diameter of AME 0.40. Length of leg segments (female from Burkina Faso, MRAC 225.270): I $1.10+0.65+0.55+0.50+0.35(3.15) ;$ II $1.10+0.65+0.55+0.60+0.40(3.30) ;$ III $1.75+1.00+1.15$ $+1.45+0.60$ (5.95); IV $1.55+0.60+1.10+1.50+0.60$ (5.35). Leg formula III,IV,II,I. Leg spination (specimen from Burkina Faso, MRAC 225.270): I: Fm d 0-1-1-5; Pt pr 0-1-0; Tb pr 1-1, v 1-1-2ap; Mt v 2-2ap. II: Fm d 0-1-2-5; Pt pr 0-1-0; Tb pr 1-1, v 1-1-2ap; Mt pr 1-1ap, v 2-2ap. III: Fm d 0-1-2-5; Pt pr and rt 0-1-0; Tb d 1-0-0, pr and rt 1-1-1-1, v 1-0-2ap; Mt d 1-1-0, pr and rt 1-0-2ap, v 0-2-2ap. IV: Fm d 0-1-1-4; Pt pr and rt 0-1-0; Tb d 1-0-0, pr and rt 1-1-1-1, v 1-0-2ap; Mt d 1-1-0, pr 1-1-2ap, rt 1-02ap, v 0-2-2ap. Coloration (in alcohol; Figs 400-405). Carapace as in the male. Abdomen dorsally with wide longitudinal stripes covered with brown scales, medially with two transverse yellow spots, which in some specimens have dark brown dots inside them; median yellow stripe covered with white hairs and rare brown bristles, but in some specimens it is completely covered with brown hairs. Spinnerets yellow to brownish, brown apically. Legs yellow, with brown dots and semi-rings. Palps yellow, covered with white hairs, except for brown tarsi covered with dark brown hairs. Epigyne and spermathecae as in Figs 395-399: the epigynal plate flat, its rear edge concave; epigynal pocket present and well-developed (narrow and deep); the copulatory openings widely separated, facing backwards; the insemination ducts short, wide and bent dorsally; the primary spermathecae large and round.

\section{Distribution}

NW part of the Afrotropical Region (Gambia, Senegal, Mali, Niger, Burkina Faso) and SW part of the Palaearcic Region (Algeria) (Fig. 510).

Stenaelurillus pilosus Wesołowska \& Russell-Smith, 2011 Figs 406-416, 514

Stenaelurillus pilosus Wesołowska \& Russell-Smith, 2011: 595, figs 161-166, 244-246 (Dへ̊); ð holotype in BMNH, examined. 


\section{Diagnosis}

By the conformation of the copulatory organs (Figs 406-410), the males of $S$. pilosus are almost identical to those of $S$. glaber (Figs 156-160), S. hirsutus (Figs 239-242, 246-251), and S. striolatus (Figs 463-467). Males of all these species can easily be distinguished by the clypeal colour pattern: with a transverse dark brown band in S. pilosus (Fig. 413), yellow clypeus with long sparse white hairs in S. glaber (Fig. 161), black with three vertical white stripes in S. hirsutus (Fig. 255), and entirely dark brown/black in S. striolatus (Fig. 468). The shape of the distal projection (DP) of the functional tegulum also seems to be diagnostic (cf. Fig. 406 with Figs 156, 239, 463). The females of S. pilosus

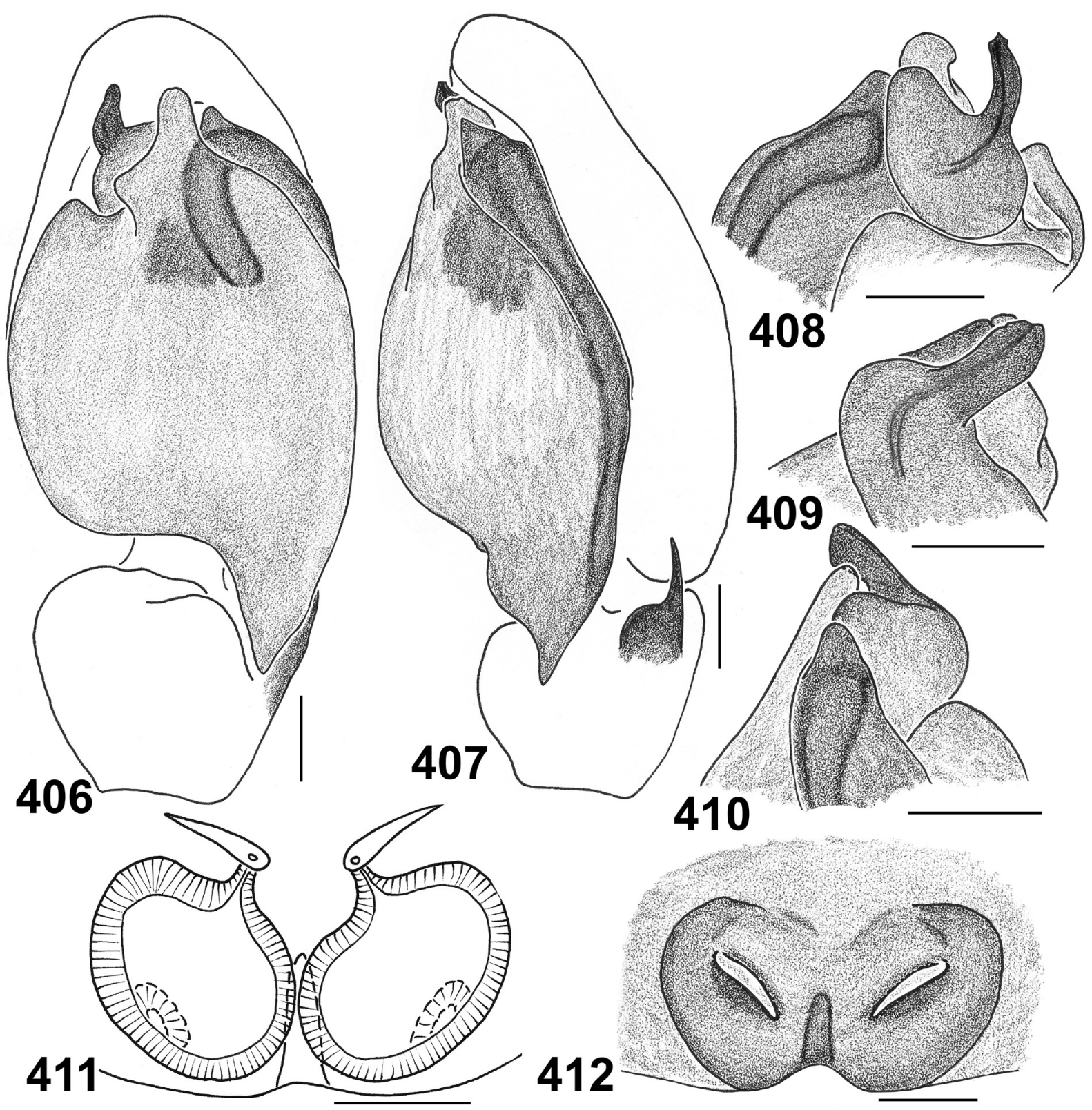

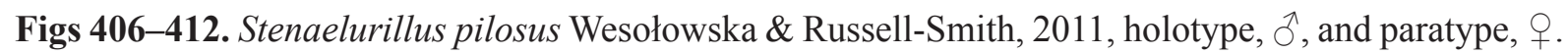
406. Male palp, ventral view. 407. Male palp, retrolateral view. 408-410. Embolic division. 408. Dorsal view. 409. Median view. 410. Retrolateral view. 411. Spermathecae, dorsal view. 412. Epigyne, ventral view. Scale bars: $0.1 \mathrm{~mm}$. 
(Figs 411-412) are most similar to and are poorly separable from those of $S$. hirsutus (Figs 262-263); the shape of the primary spermathecae seems to be diagnostic: round in S. pilosus and elongated, sacshaped in S. hirsutus.

\section{Material examined}

\section{Holotype}

NIGERIA: Jै, Ibadan, IITA, 7²2'39.1" N, 356'49.3" E, fallow bush, 8 Feb. 1973, A. Russell-Smith leg. (BMNH).

\section{Paratypes}

NIGERIA: $4 \widehat{\jmath}, 4$ 우, together with the holotype (BMNH).

\section{Other material}

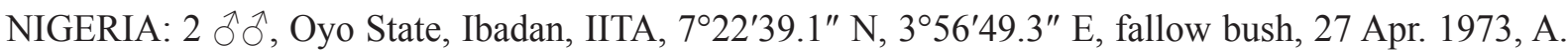
Russell-Smith leg. (MMUE G7583.5).

\section{Description}

\section{Male (holotype)}

Measurements: carapace: 2.55 long, 1.85 wide, 1.40 high. Abdomen: 2.40 long, 1.70 wide. Ocular area: 1.10 long, 1.53 wide anteriorly, 1.48 wide posteriorly. Cheliceral length 0.53 . Clypeal height 0.38 . Diameter of AME 0.43. Length of leg segments: I $1.28+0.68+0.70+0.60+0.53$ (3.79); II $1.25+$ $0.69+0.65+0.63+0.48(3.70) ;$ III $1.88+0.88+1.10+1.28+0.53(5.67) ;$ IV $1.55+0.70+1.05+$ $1.28+0.53$ (5.11). Leg formula III,IV,I,II. Leg spination: I: Fm d 0-1-1-5; Pt pr 0-1-0; Tb pr 1-1, v 1-22ap; Mt pr and rt 1ap, v 2-2ap. II: Fm d 0-1-1-5; Pt pr 0-1-0; Tb pr 1-1, v 1-1-2ap; Mt pr 1-1ap, rt 1 ap, v 2-2ap. III: Fm d 0-1-2-4; Pt pr and rt 0-1-0; Tb d 1-0-0, pr 1-1-1, rt 1-1-1-1, v 1-0-2ap; Mt d 1-1, pr and rt 1-0-2ap, v 0-2-2ap. IV: Fm d 0-1-1-4; Pt pr and rt 0-1-0; Tb d 1-0-0, pr 1-1-1, rt 1-2-1, v 1-0-2ap; Mt pr 1-2ap, rt 1-1-1, v 0-1-1-2ap. Coloration (in alcohol; Figs 413-416). Carapace yellowish brown, with two pairs of longitudinal (dorsal and lateral) yellow stripes covered with white recumbent scales;

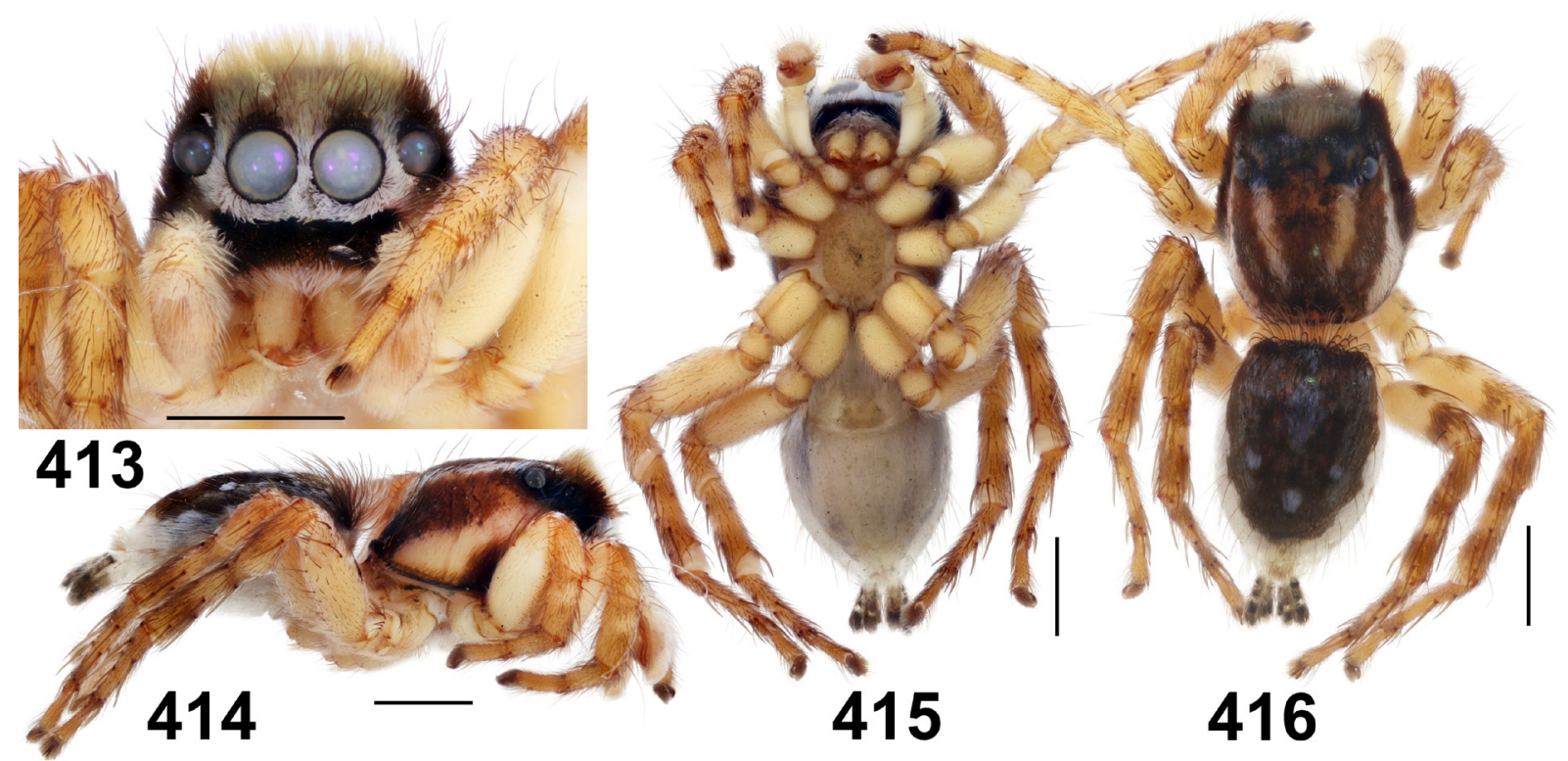

Figs 413-416. Stenaelurillus pilosus Wesołowska \& Russell-Smith, 2011, holotype, §, general appearance. Scale bars: $1 \mathrm{~mm}$. 
sides (on their front halves) bear bunches of dense brown hairs. Eye field brown, with a mane-like bunch of brownish and transparent hairs. Eyes of the first row are surrounded by dense white hairs, clypeus covered with dark brown hairs and scales (Fig. 416). Sternum light yellow, densely covered with white hairs. Labium, endites and chelicerae light yellow. Abdomen: dorsum dark brown, with paired white spots; sides and venter light yellow. Book-lung covers light yellow, spinnerets brownish. All legs yellow, Fm III-IV apically with patches of brown scales. All palps light yellow. Palpal structure as in Figs 406410: VTA bulge-shaped, poorly marked; RTA straight, with wide base and sharpened, stiletto-like tip; the cymbial lateral process (CLP) is poorly marked; the tegulum small, poorly marked, with a short, cone-shaped tegular process (TP); the functional tegulum with a well-developed proximal projection (PP), its distal projection (DP) flat and bifurcated; the embolus short, ribbon-shaped, with a wide base.

Female (a paratype)

Measurements: carapace: 3.10 long, 2.25 wide, 1.80 high. Abdomen: 2.85 long, 2.20 wide. Ocular area: 1.35 long, 1.73 wide anteriorly, 1.65 wide posteriorly. Cheliceral length 0.78 . Clypeal height 0.29 . Diameter of AME 0.48. Length of leg segments: I $1.50+0.80+0.78+0.60+0.53$ (4.21); II $1.50+$ $0.83+0.78+0.68+0.48(4.27) ;$ III $2.23+1.05+1.42+1.60+0.65(6.95) ;$ IV $2.00+0.93+1.33+1.65$ + 0.68 (6.59). Leg formula III,IV,II,I. Leg spination: I: Fm d 0-1-1-5; Pt pr 0-1-0; Tb pr 1-1, v 1-2-2ap; Mt pr and rt 1ap, v 2-2ap. II: Fm d 0-1-2-5; Pt pr 0-1-0; Tb pr 1-1, v 1-1-2ap; Mt pr 1-1ap, rt 1ap, v 2-2ap. III: Fm d 0-1-2-5; Pt pr and rt 0-1-0; Tb pr and rt 1-1-1-1, v 1-2ap; Mt d 0-1-0, pr 1-1-2ap, rt 1-0-2ap, v 0-1-2ap. IV: Fm d 0-1-1-5; Pt pr and rt 0-1-0; Tb d 1-0, pr and rt 1-1-1, v 1-2ap; Mt pr and rt 1-1-2ap, v 0-1-1-2ap. Coloration (in alcohol) as in the male, except for the following: eye field without a manelike bunch of hairs; carapace sides without lateral bunches of brown hairs; clypeus yellow, with sparse white hairs. Epigyne and spermathecae as in Figs 411-412: the epigynal plate flat, its rear edge visibly concave; epigynal pocket present, narrow and deep; the copulatory openings resemble transverse slits and are widely separated; the insemination ducts very short, inconspicuous in dorsal view; the primary spermathecae large and round.

\section{Distribution}

The type locality only (Fig. 514).

Stenaelurillus pseudoguttatus sp. nov. urn:lsid:zoobank.org:act:210AF195-E8CB-4FFB-9509-9CDBDC3B58AB

Figs $417-425,514$

Mashonarus guttatus Wesołowska \& Cumming, 2002: 167, figs 1-19 (in part, paratype $\widehat{\jmath}$ from Namibia).

\section{Diagnosis}

By the conformation of the copulatory organs (the shape of the embolus and the developed cymbial lateral projection), S. pseudoguttatus sp. nov. is most similar to $S$. brandbergensis comb. nov. and S. guttatus comb. nov. (cf. Figs 90-94 and 165-170), but can easily be distinguished from both related species by its having the longest, sword-shaped embolus, the largest open cymbial pocket and by the absence of a distal projection on the functional tegulum. The female of $S$. pseudoguttatus sp. nov. remains unknown.

\section{Etymology}

The specific epithet is a compound form of the Greek $\Psi \epsilon v \delta o$ ('pseudo'), 'false', and the Latin word 'guttatus', 'speckled'; the name is a reflection of the fact that the holotype of this species was found in the original type series of $S$. guttatus comb. nov. 


\section{Material examined}

\section{Holotype}

NAMIBIA: $\widehat{\jmath}$, male paratype of Mashonarus guttatus Wesołowska \& Cumming, 2002, Rundu-Kavango, ca $17^{\circ} 55^{\prime}$ S, $19^{\circ} 45^{\prime}$ E, Okavango Riv., May 1979, M.E. Baddeley leg. (MRAC 152.151).

\section{Remarks}

The series of paratypes of Mashonarus guttatus turned out to be heterogenous and contained one male that belonged to a different species, which is described herein as new.
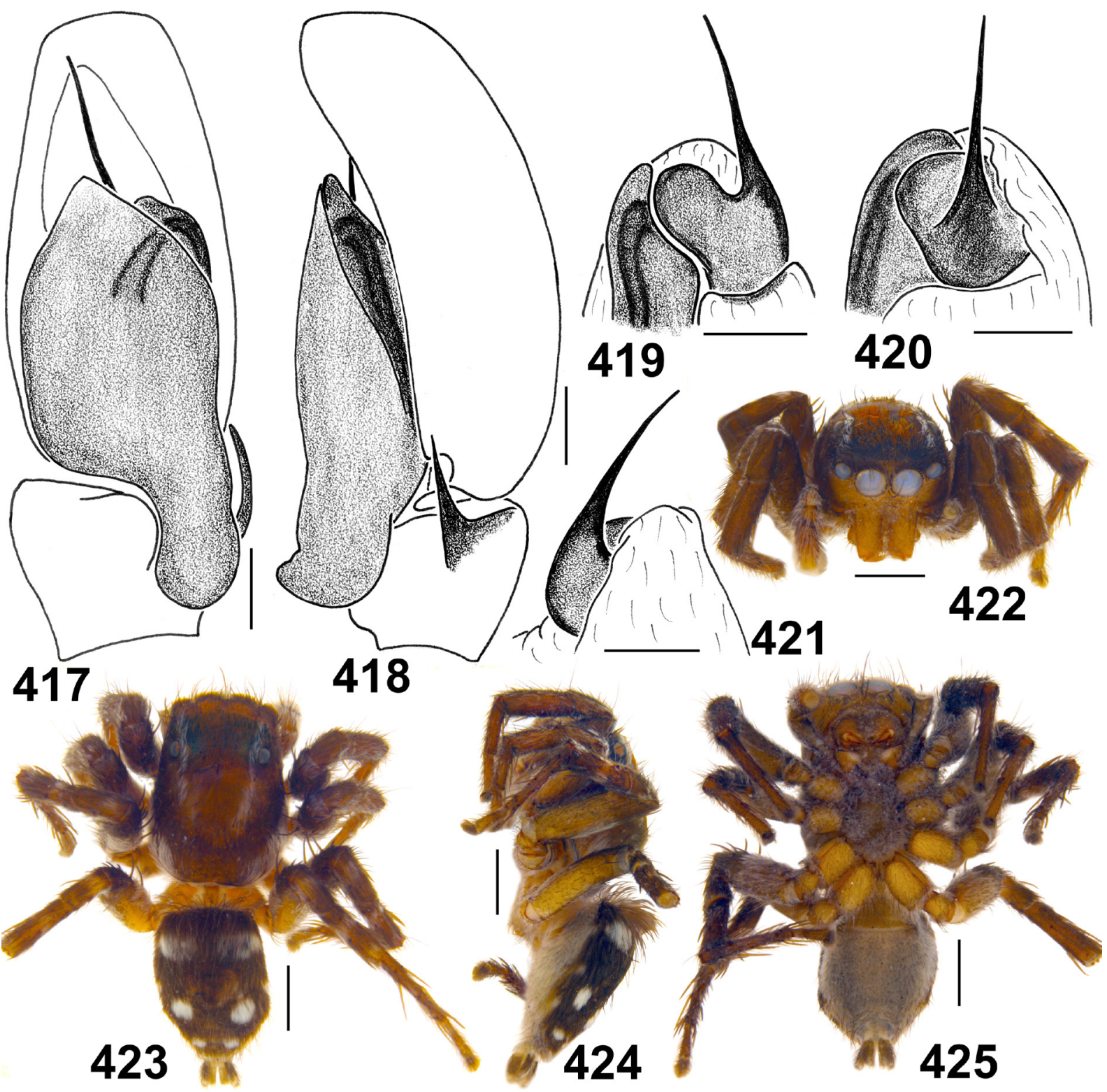

Figs 417-425. Stenaelurillus pseudoguttatus sp. nov., paratype, $\partial$, of Mashonarus guttatus Wesołowska \& Cumming, 2002; MRAC 152.151). 417. Male palp, ventral view. 418. Male palp, retrolateral view. 419-421. Embolic division. 419. Retrolateral view. 420. Dorsal view. 421. Median view. 422-425. General appearance. Scale bars: $417-421=0.1 \mathrm{~mm} ; 422-425=1 \mathrm{~mm}$. 


\section{Description}

Male (holotype)

Measurements: carapace: 2.28 long, 1.63 wide, 0.93 high. Abdomen: 2.05 long, 1.38 wide. Ocular area: 1.00 long, 1.30 wide anteriorly, 1.23 wide posteriorly. Cheliceral length 0.75 . Clypeal height 0.13 . Diameter of AME 0.38. Length of leg segments: I $1.25+0.65+0.83+0.70+0.50$ (3.93); II $1.25+0.63+$ $0.71+0.70+0.38(3.67) ;$ III $1.60+0.70+1.00+1.18+0.45(4.93) ;$ IV $1.45+0.63+1.00+1.28+0.53$ (4.89). Leg formula III,IV,I,II. Leg spination: I: Fm d 0-1-1-4; Tb pr 1-1, v 1-1-2ap; Mt pr 1ap, v 2-2ap. II: Fm d 0-1-1-5; Tb pr 1-1, v 1-1-2ap; Mt pr 1-1ap, v 2-2ap. III: Fm d 0-1-2-5; Pt pr 0-1-0; Tb d 1-0, pr and rt 1-1, v 1-1-2ap; Mt d 0-1-0, pr and rt 1-0-2ap, v 0-2-2ap. IV: Fm d 0-1-1-3; Pt pr 0-1-0; Tb d 1-00 , pr and rt 1-1-1, v 0-1-2ap; Mt pr, rt and v 1-1-2ap. Coloration (in alcohol; Figs 422-425). Carapace yellowish brown, with black eye field, densely covered with long brown recumbent scales; there are two longitudinal white narrow stripes; clypeus yellow, covered with yellow hairs. Sternum yellow, tinged with brown and densely covered with white hairs. Endites and labium yellow. Chelicerae yellowish brown. Abdomen: dorsum dark brown, with three pairs of white spots; sides and venter grayish yellow. Book-lung covers yellow. Spinnerets yellow grayish. All legs: coxae and trochanters yellow, Fm yellow on their basal halves and brown on their distal halves, the remaining segments yellowish brown. Palps yellowish brown. Palpal structure as in Figs 417-421; VTA bulge-shaped; RTA straight, stiletto-shaped, directed anteriad; the cymbium simple, with a poorly-marked cymbial lateral process; the tegulum small, poorly marked, without a visible tegular process; the functional tegulum narrow-elongated, with a well-developed, wide and obtuse proximal (PP) projection and without a distal projection; the embolus long, sword-shaped, with a wide round base.

\section{Female}

Unknown.

\section{Distribution}

Namibia, the type locality only (Fig. 514).

Stenaelurillus senegalensis sp. nov. urn:1sid:zoobank.org:act:F3DC4328-0106-4FE7-8A3D-19569B3E91A6

Figs 426-441, 510

\section{Diagnosis}

The new species is most similar to $S$. nigricaudus, with both species having almost identical body coloration (cf. Figs 435-441 and 382-390, 400-405). The only colour difference is that of the ventral sides of Tb and Mt I in the males: yellow in S. senegalensis sp. nov. (Fig 435-437) and dark brown in S. nigricaudus (Figs 391-394). The males of both species can easily be distinguished by the conformation and relative length of the embolus, which is comparatively long (almost twice as long as the tegulum length) and straight, and situated on the functional tegulum at about 10 o'clock in the new species and comparatively short, hook-shaped and situated apically at 12 o'clock in S. nigricaudus (cf. Figs 426 and 369). The female of S. senegalensis sp. nov. can be separated from that of S. nigricaudus by the absence of the deep epigynal pocket, which is present in the latter species; the epigynal plate in S. senegalensis sp. nov. visibly overhangs the epigastric furrow. The spermathecae of both species are virtually indistinguishable.

\section{Etymology}

The specific epithet is named after the country of origin, Senegal. 


\section{Material examined}

Holotype

SENEGAL: ${ }^{\wedge}$, ca $20 \mathrm{~km} \mathrm{~S}$ of Richard Toll, ca $16^{\circ} 27^{\prime} 32.0^{\prime \prime} \mathrm{N}, 15^{\circ} 41^{\prime} 38.4^{\prime \prime} \mathrm{W}$, savanna, pitfall traps, 23 Sep. 1991, H. van der Valk leg. (MRAC ex-201.167).

\section{Paratypes}

SENEGAL: 6 $ð, 1$, together with the holotype (MRAC ex-201.167).

\section{Description}

Male

Measurements (the smaller male $=$ the holotype, the larger one $=$ a paratype). Carapace: $1.70-2.10$ long, 1.40-1.60 wide, 1.00-1.10 high. Abdomen: $1.60-2.00$ long, 1.30-1.45 wide. Ocular area: $0.75-0.90$ long, $1.00-1.10$ wide anteriorly, $0.90-1.00$ wide posteriorly. Cheliceral length $0.45-0.55$. Clypeal height 0.25 . Diameter of AME 0.30-0.35. Length of leg segments (the bigger male, paratype): I $1.00+0.45+$ $0.60+0.50+0.45(3.00) ;$ II $1.00+0.55+0.55+0.50+0.40(3.00) ;$ III $1.60+0.80+1.00+1.40+0.55$ (5.35); IV $1.50+0.60+1.10+1.45+0.65$ (4.30). Leg formula III,IV,II/I. Leg spination: I: Fm d 0-11-5; Pt pr 0-1-0; Tb pr 1-1, v 1-1-2ap; Mt pr 0-1ap, v 2-2ap. II: Fm d 0-1-2-5; Pt pr 0-1-01; Tb pr 1-1, v 1-1-2ap; Mt pr 1-1, v 2-2ap. III: Fm d 0-1-2-5; Pt pr and rt 0-1-0; Tb d 1-0-0, pr and rt 1-1-1-1, v 1-0-2ap; Mt d 1-1-0, pr 1-1-2ap, rt 1-0-2ap, v 0-1-2ap or 0-2-2ap. IV: Fm d 0-1-2-5; Pt pr and rt 0-1-0; Tb d 1-0-0, pr and rt 1-1-1-1, v 1-0-2ap or 2-0-2ap; Mt d 1-1-0, pr and rt 1-1-2ap, v 1-2-2ap. Coloration (in alcohol; Figs 435-437, 439). Carapace brown, covered with brown scales, with two longitudinal wide stripes originating from PLEs and running toward the rear end of the carapace, covered with white scales; sides with marginal stripes of white scales. Eye field dark brown, covered with yellow-white scales and dark brown long bristles. Sternum yellow. Endites and labium yellow. Chelicerae yellow, covered with white hairs. Clypeus high, yellow (in the holotype) to brown-yellow (in the paratypes), densely covered with long white hairs. Abdomen: venter yellow; dorsum with scutum covering $2 / 3$ of the abdomen length, dorsum dark brown, with four white-yellow spots (two on the anterior half and two on the posterior one) and wide median stripe covered with brown hairs on the posterior half; spots are poorly marked in some specimens. Book-lung covers yellow. Spinnerets: the first two pairs yellow, the dorsal pair dark brown. Legs I dark brown. Tb and Mt III and IV with two dorsal semi-rings of dark brown hairs. Palps yellow, covered with white hairs; palpal Tb prolaterally with long brown hairs; cymbium dorsally with sparse brown bristles. Palpal structure as in Figs 426-428, 431-434: VTA bulge-shaped; RTA thick and straight, directed anteriad and slightly bent mediad; the cymbium simple, without the cymbial lateral process; the tegulum small and elongated, with a well-developed, finger-shaped tegular process; the functional tegulum wide and elongated, with a well-developed, pointed proximal (PP) projection and without a distal projection; the embolus straight and long, almost as long as one half of the tegulum length, with the wide base fused to the apical edge of the functional tegulum.

Female (paratype, Figs 438, 440-441)

Measurements: carapace: 2.50 long, 2.00 wide, 1.30 high. Abdomen: 3.45 long, 2.65 wide. Ocular area: 0.95 long, 1.50 wide anteriorly, 1.40 wide posteriorly. Cheliceral length 0.65 . Clypeal height 0.30 . Diameter of AME 0.40. Length of leg segments: I $1.20+0.65+0.70+0.60+0.50$ (3.65); II $1.20+$ $0.65+0.65+0.55+0.50(3.55)$; III $1.95+1.10+1.30+1.60+0.60(6.55) ;$ IV $1.85+0.75+1.40+$ $1.70+0.80$ (6.50). Leg formula III,IV,I,II. Leg spination: I: Fm d 0-1-1-5; Pt pr 0-1-0; Tb pr 1-1, v 1-12ap; Mt pr 0-1ap, v 2-2ap. II: Fm d 0-1-2-5; Pt pr 0-1-0; Tb pr 1-1, v 1-1-2ap; Mt pr 1-1, v 2-2ap. III: Fm d 0-1-2-5; Pt pr and rt 0-1-0; Tb d 1-0-0, pr and rt 1-1-1-1, v 1-0-2ap; Mt d 1-1-0, pr 1-1-2, rt 1-0-2, v 1-02ap. IV: Fm d 0-1-1-4; Pt pr and rt 0-1-0; Tb d 1-0-0, pr and rt 1-1-1-1, v 1-0-2ap; Mt d 1-1-0, pr and rt 1-1-2, v 1-2-2ap. Coloration (in alcohol; Figs 438, 440-441). Carapace brown, covered with dark brown hairs and with two longitudinal dorsal stripes covered with white scales, running from ALEs (narrow in the area of the eye field) to the rear end of the carapace (wide in the thorax); sides with marginal stripes 


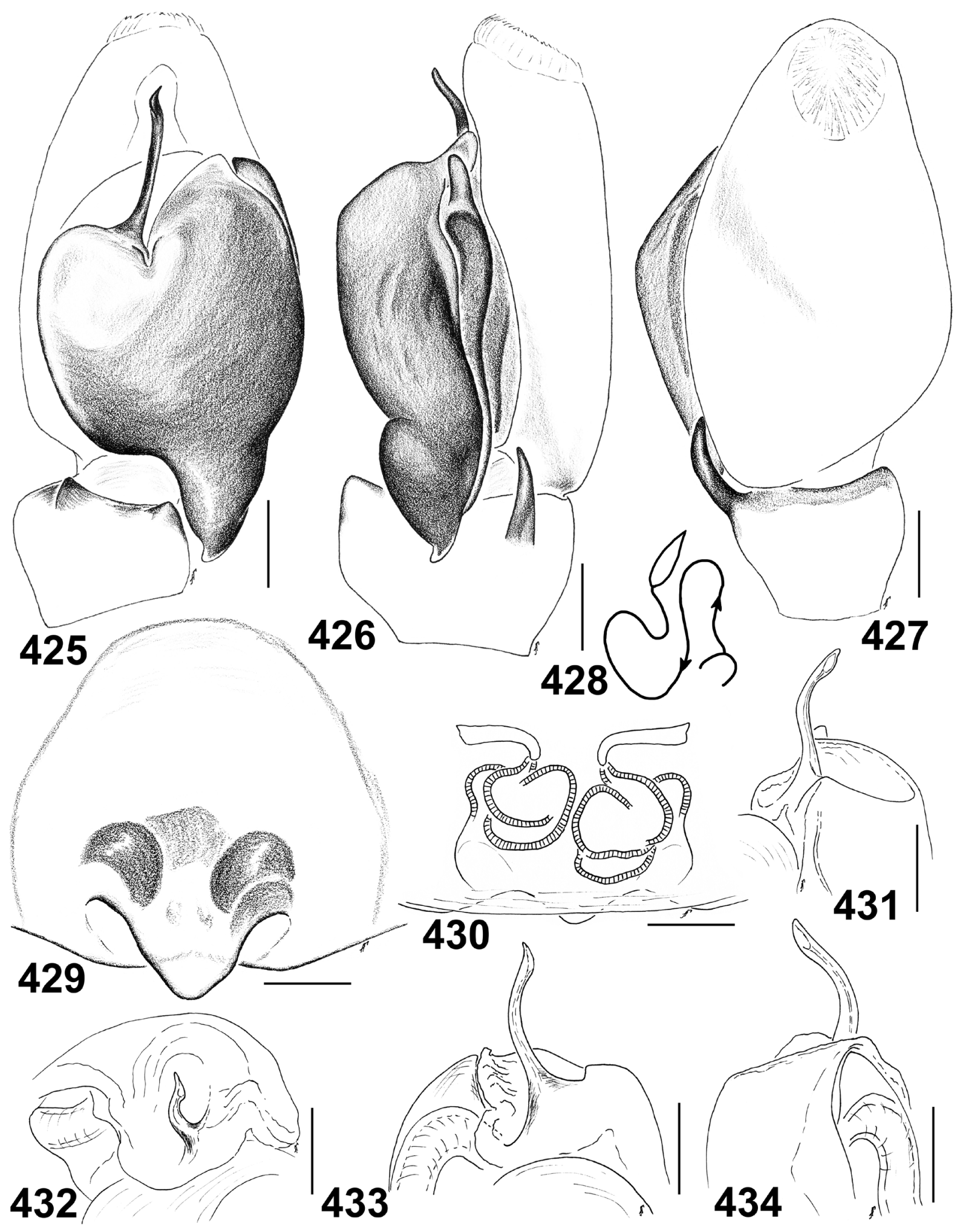

Figs 426-434. Stenaelurillus senegalensis sp. nov., holotype, ô (425-427) and paratypes (428-434). 425-427. Male palp. 425. Ventral view. 426. Retrolateral view. 427. Dorsal view. 428. Diagrammatic course of the insemination ducts. 429. Epigyne, ventral view. 430. Spermathecae, dorsal view. 431434. Embolic division. 431. Median view. 432. Apical view. 433. Dorsal view. 434. Retrolateral view. Scale bars: $0.1 \mathrm{~mm}$. 
of white scales. Sternum yellow. Endites and labium brownish yellow. Chelicerae yellow, covered with white hairs. Clypeus high, brownish yellow, covered with white hairs. Abdomen: venter grey-yellow; dorsum yellow, covered with white hairs and with two wide longitudinal stripes covered with brown hairs; median dorsal stripe yellow, anteriorly tinged with brown and covered with white hairs and sparse brown hairs and bristles. Book-lung covers yellow. Spinnerets yellow, with brown tips. Legs yellow, with patches and semi-rings of dark brown hairs. Palps yellow, but their Tr dark brown. Epigyne and spermathecae as in Figs 429-430: the epigynal plate flat, its rear end overhangs the epigastric furrow; epigynal pocket absent; copulatory openings widely separated, facing backwards; insemination ducts short and wide, bent dorsally; primary spermathecae large and round.

\section{Distribution}

The type locality only (Fig. 510).

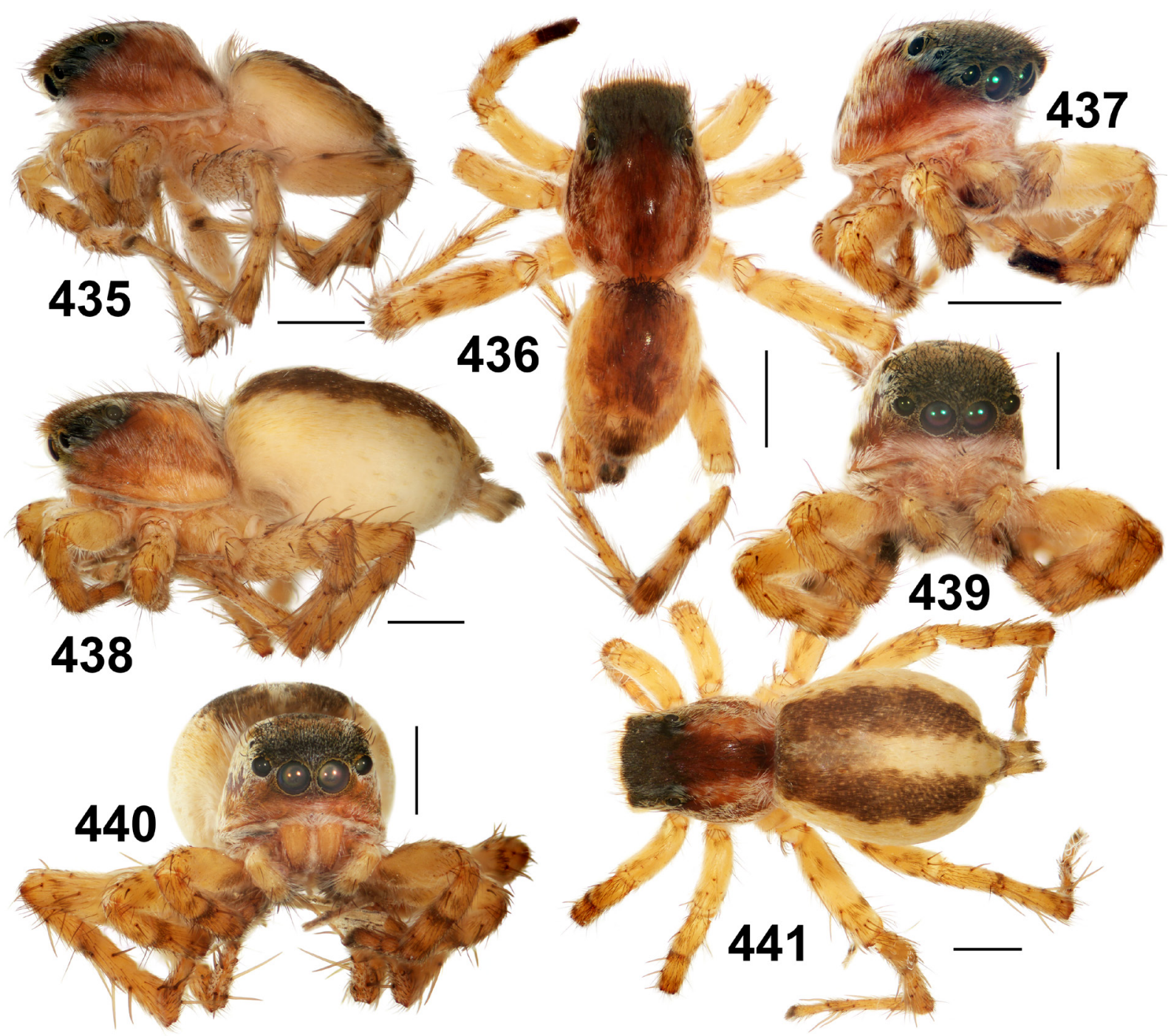

Figs 435-441. Stenaelurillus senegalensis sp. nov., paratypes, general appearance. $\mathbf{4 3 5}-\mathbf{4 3 7}, \mathbf{4 3 9}$. 438, 440-441. ㅇ. Scale bars: $1 \mathrm{~mm}$. 
Stenaelurillus siyamae sp. nov.

urn:Isid:zoobank.org:act:A0346942-CE12-48A3-9E4B-BAB165A84908

Figs 442-447, 510

\section{Diagnosis}

By the body coloration, this species is very similar to another Sudanese species, S. sudanicus also described and known only from the holotype female (Figs 452-453), but can easily be distinguished from it by the position of the copulatory openings (widely separated, facing each other in S. siyamae sp. nov. and disposed to the epigastric furrow, facing backwards in S. sudanicus) and the longer, S-shaped insemination ducts (cf. Figs 443 and 453).

\section{Etymology}

This species is named after the collector of the holotype, Ms M. Siyam (South Sudan).

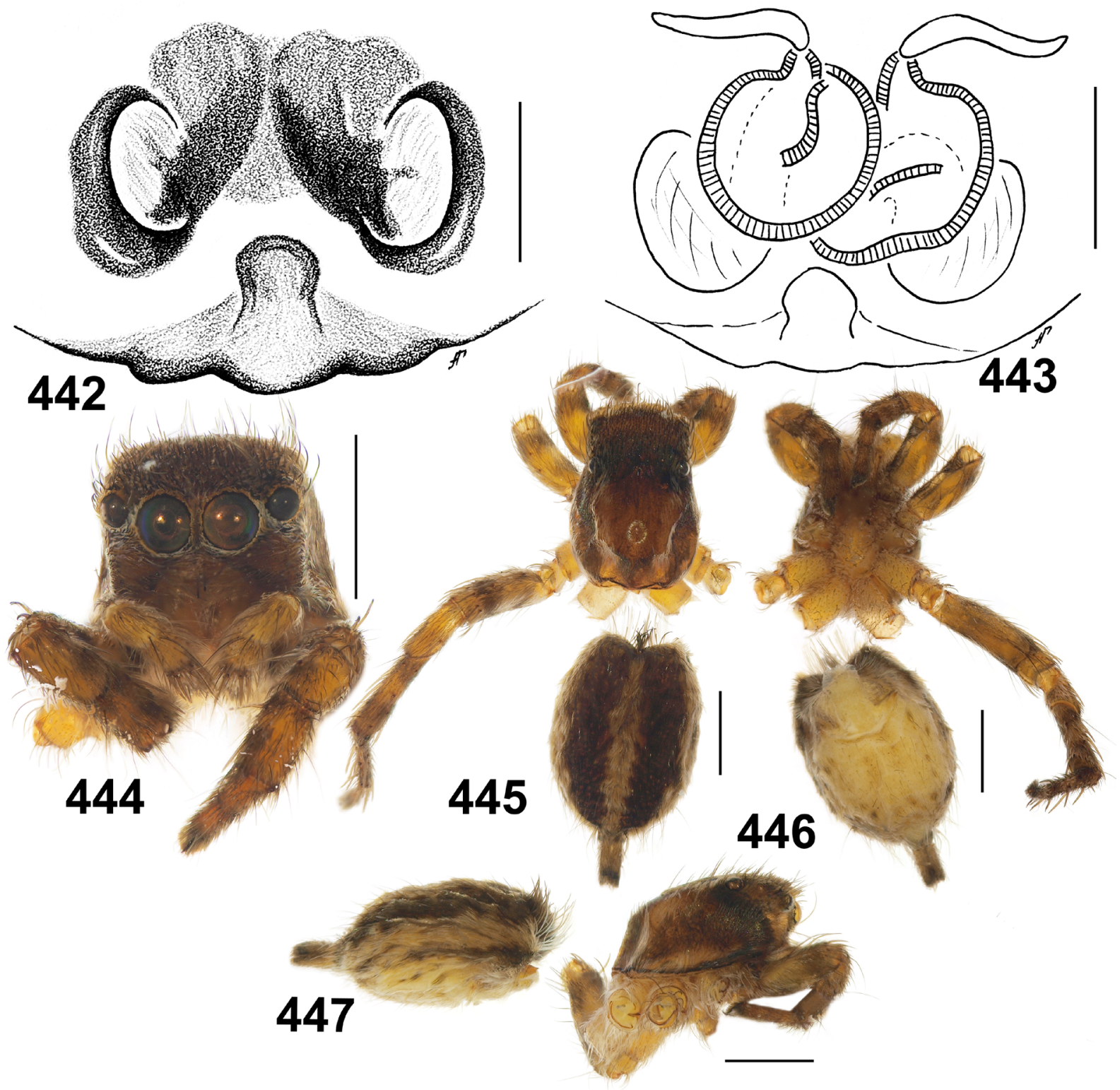

Figs442-447. Stenaelurillus siyamaesp. nov., holotype, 9 .442. Epigyne, ventral view. 443. Spermathecae, dorsal view. 444-447. General appearance. Scale bars: 442-443=0.1 mm; 444-447=1 mm. 


\section{Material examined}

\section{Holotype}

SUDAN: + , Dinder NP, Khor Galaga [= Khor Qalaqu], Crocodile Lake, 12³9'3.81" N, 3501' $8.12^{\prime \prime}$ E, 467 m a.s.1., pitfall traps, 4 Apr. 2013, M. Siyam leg. (ZMB Arach 48785).

\section{Comparative material examined}

SUDAN: 1 q, holotype of Stenaelurillus sudanicus Wesołowska, 2014 (Figs 448-453, 510), Northern Province, Kerma, $1^{\circ} 36^{\prime}$ N, $30^{\circ} 24^{\prime}$ E, in house, Jan. 1989, L. Chaix leg. (MHNG).

\section{Description}

Male

Unknown.

\section{Female}

The holotype is badly damaged, with almost all legs being detached from the carapace.

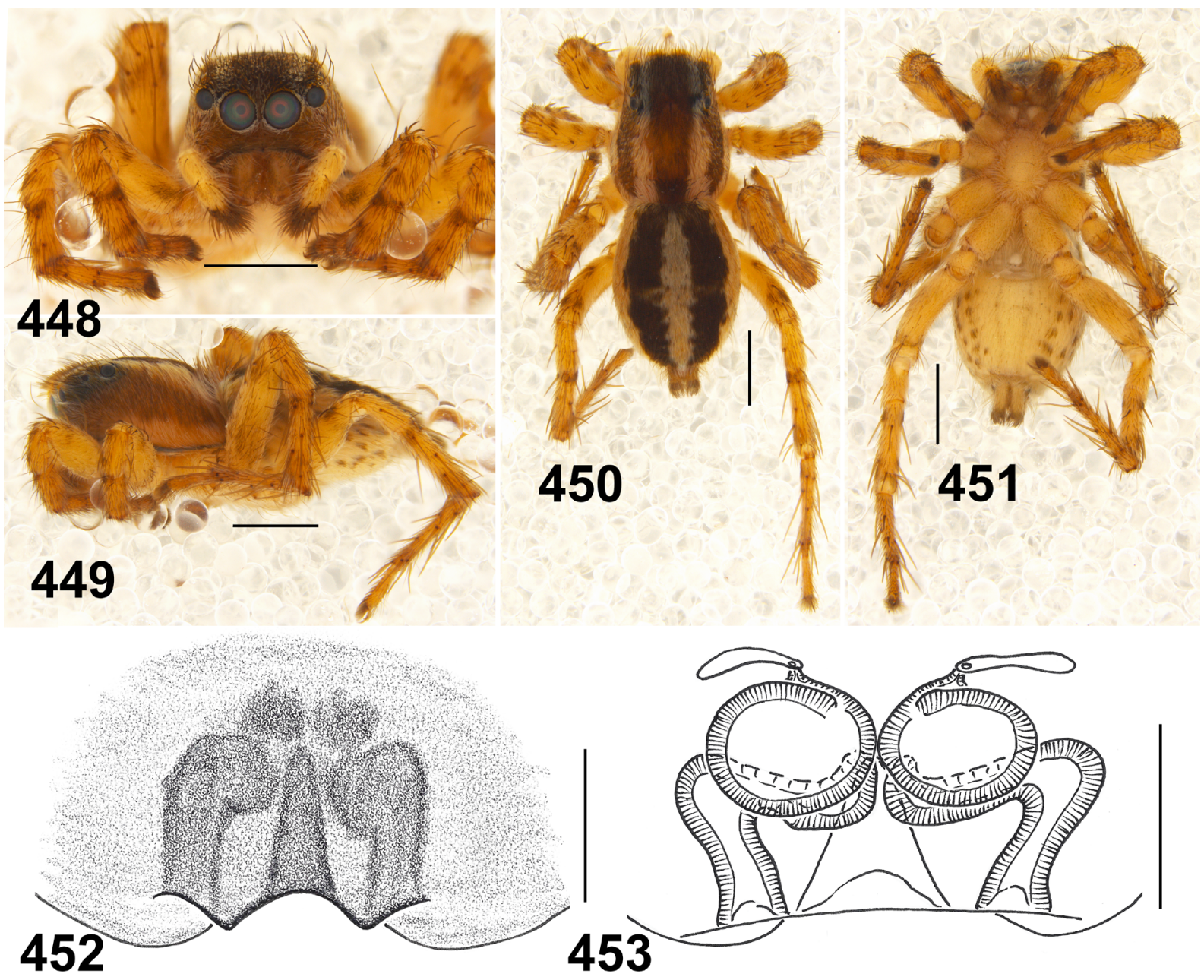

Figs 448-453. Stenaelurillus sudanicus Wesołowska, 2014, holotype, $q$. 448-451. General appearance. 452. Epigyne, ventral view. 453. Spermathecae, dorsal view. Scale bars: 448-451 $=1 \mathrm{~mm} ; 452-453=$ $0.1 \mathrm{~mm}$. 
Measurements: carapace: 2.00 long, 1.60 wide, 1.00 high. Abdomen: 2.30 long, 1.80 wide. Ocular area: 0.90 long, 1.30 wide anteriorly, 1.25 wide posteriorly. Cheliceral length 0.50 . Clypeal height 0.25 . Diameter of AME 0.35. Leg spination: I: Fm d 0-1-1-5; Pt pr 1; Tb pr 1-1, v 1-2; Mt pr 0-1ap, v 2-2ap. Coloration (in alcohol; Figs 444-447). Carapace brown, covered with dark brown hairs, with two longitudinal stripes covered with white scales; sides with marginal stripes of white hairs. Sternum yellow. Endites and labium brownish yellow. Chelicerae brownish yellow, covered with white hairs. Clypeus high, yellowish brown, covered with brownish hairs and with a dark brown stripe running from the carapace sides towards ALEs. Abdomen: venter greyish yellow; dorsum brownish, with two longitudinal wide brown stripes covered with brownish hairs and a narrow longitudinal median stripe covered with white hairs; each side with two longitudinal stripes covered with white hairs. Book-lung covers yellow-grey. Spinnerets brownish yellow, with brown tips. Legs brownish yellow, with patches and semi-rings of dark brown hairs. Palps yellow, covered with white hairs and brown bristles. Epigyne and spermathecae as in Figs 442-443: the epigynal plate flat, round, with a pair of very large, ovoid copulatory openings, widely separated and facing towards each other; epigynal pocket present, wide and deep; insemination ducts short and wide; primary spermathecae large, bean-shaped.

\section{Distribution}

The type locality only (Fig. 510).

Stenaelurillus strandi Caporiacco, 1939

Figs 454-462, 510

Stenaelurillus strandi Caporiacco, 1939: 374, fig. 24 (Dへ); $\overbrace{}^{\Uparrow}$ holotype in MSNF, examined.

\section{Diagnosis}

This species differs from all other described species of Stenaelurillus in having the smallest and thinnest, almost spine-shaped embolus (Figs 457-458).

\section{Material examined}

\section{Holotype}

ETHIOPIA: ô, Moyale, 332'23.9" N, 3903'10.2" E, “paese Borana, Maggio 1937, leg. Zava Hali” [in the original description (Caporiacco 1939: 374) the date is given as 15 May 1937] (MSNF 411).

\section{Other material}

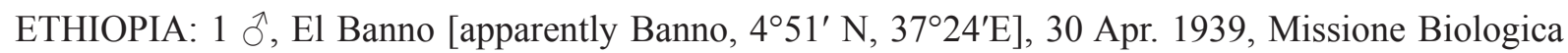
Sagan-Omo, 1939, E. Zavattari leg. (MSNF).

\section{Remarks}

The female of S. strandi remains unknown. However, it is likely that either S. sudanicus (Figs 448-453; see also Wesołowska 2014b: fig. 12B-C), or S. siyamae sp. nov. (see above; Figs 442-447), both known only from single females from Sudan, might actually be the female of $S$. strandi. The matter requires special attention in the future, when both sexes have been collected together for all these species.

\section{Description}

Male (holotype)

Measurements: carapace: 2.90 long, 2.25 wide, 1.60 high. Abdomen: 2.60 long, 1.85 wide. Ocular area: 1.20 long, 1.55 wide anteriorly, 1.53 wide posteriorly. Cheliceral length 0.28 . Clypeal height 0.28 . Diameter of AME 0.45. Length of leg segments: I $1.50+0.70+0.80+0.70+0.60$ (4.30); II $1.45+0.70$ $+0.80+0.80+0.55(4.30)$; III $1.95+0.80+1.30+1.50+(\operatorname{Tr}$ is missing $) ;$ IV $1.95+0.90+1.30+1.75+$ 
0.79 (4.69). Leg formula IV/III,II/I (Tr III is missing). Leg spination: I: Fm d 0-1-1-5; Pt pr 0-1-0; Tb pr 1-1, v 0-1-1ap; Mt pr and rt 1-1ap, v 2-2ap. II: Fm d 0-1-1-5; Pt pr 0-1-0; Tb pr and rt 1-1-1, v 2-2ap; Mt pr and rt 1-1ap. III: Fm d 0-1-1-5; Pt pr and rt 0-1-0; Tb d 1-0-0, pr and rt 1-1-1, v 1-1-0-1ap; Mt d 0-1-0, pr and rt 1-1ap, v 0-1-1ap. IV: Fm d 0-1-1-4; Pt pr and rt 0-1-0; Tb d 1-0-0, pr and rt 1-1-1, v 1-0-1ap; Mt d 1-0-0, pr and rt 1-1-2ap, v 1-2-2ap. Coloration (in alcohol; Figs 461-462). Carapace red-brown, covered with brown scales; eye field dark brown, densely covered with protruding bristles; clypeus and chelicerae dark brown, sparsely covered with white hairs. Sternum yellowish brown, covered with long white hairs. Labium and endites light brown. Abdomen: dorsum and sides dark red-brown; dorsum with red-brown shining scutum covering almost its full length and anteriorly with bunch of long brown hairs; venter yellow, with two longitudinal brown lines. Book-lung covers yellowish brown. Spinnerets

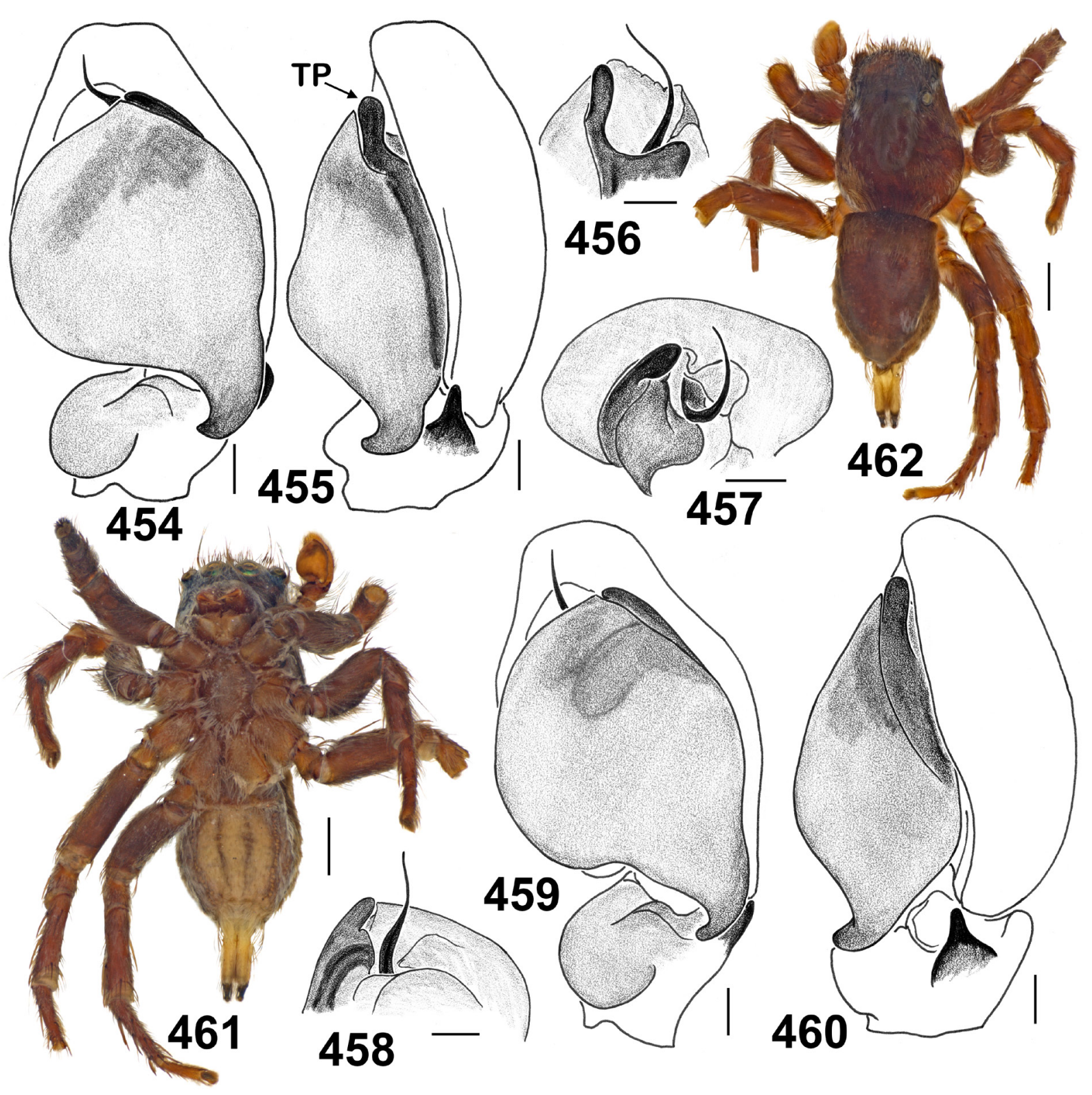

Figs 454-462. Stenaelurillus strandi Caporiacco, 1939, holotype, §̊ (459-462) and paratype (454-458). 454, 459. Male palp, ventral view. 455, 460. Male palp, retrolateral view. 456-458. Embolic division. 456. Retrolateral view. 457. Apical view. 458. Median view. 461-462. General appearance. Scale bars: $454-460=0.1 \mathrm{~mm} ; 461-462=1 \mathrm{~mm}$. 
long and light yellow, but the dorsal pair with dark brown apices. All legs: coxae yellowish brown, covered with white hairs; remaining segments brown, sparsely covered with white and brown hairs, but Mt and Tr I ventrally black. Palps brownish yellow. Palpal structure as in Figs 454-460: VTA bulgeshaped; RTA straight, finger-shaped, with an obtuse tip; the cymbial lateral process (CLP) is marked; the tegulum small, poorly marked, with a well-developed tegular process (TP); the functional tegulum swollen, with a well-developed proximal projection (PP); embolus short, spine-shaped, partly hidden in the apical cymbial pocket.

\section{Female}

Unknown.

\section{Distribution}

Two close localities in Ethiopia only (Fig. 510).

Stenaelurillus striolatus Wesołowska \& Russell-Smith, 2011

Figs 463-471, 512

Stenaelurillus striolatus Wesołowska \& Russell-Smith, 2011: 597, figs153-154, 247-249 (Dへ̂); ð holotype in BMNH, examined.

\section{Diagnosis}

By the dense lateral pubescence on the carapace and the conformation of the copulatory organs (Figs 468-469), the males in S. striolatus are most similar to those of S. bandama sp. nov. and S. hirsutus (cf. Figs 63-78, 239-257), but can easily be distinguished by the entirely dark brown/black hair cover of the clypeus (Fig. 468; with three white vertical lines in both related species, Figs 74, 255). The embolic division of all three species is very similar and poorly distinguishable. The female of S. striolatus remains unknown. See also remarks above under the Diagnoses of S. glaber and S. pilosus.

\section{Material examined}

\section{Holotype}

NIGERIA: ${ }^{\circ}$, Kwara State, Borgu Game Reserve, ca $11^{\circ} 05^{\prime} 01.4^{\prime \prime}$ N, $8^{\circ} 36^{\prime} 57.9^{\prime \prime}$ E, flood debris on bank of river, 5-6 May 1973, A. Russell-Smith leg. (BMNH).

\section{Paratype}

NIGERIA: $1 \hat{\partial}$, together with the holotype (BMNH).

\section{Description}

Male (holotype)

Measurements: carapace: 2.70 long, 2.30 wide, 1.20 high. Abdomen: 2.40 long, 1.50 wide. Ocular area: 1.20 long, 1.50 wide anteriorly, 1.48 wide posteriorly. Cheliceral length 0.58 . Clypeal height 0.28 . Diameter of AME 0.40. Length of leg segments: I $1.30+0.65+0.73+0.63+0.45$ (3.76); II $1.33+$ $0.70+0.65+0.65+0.48(3.81) ;$ III $1.95+0.93+1.23+1.38+0.53(4.02) ;$ IV $1.63+0.75+1.13+$ $1.40+0.65$ (5.56). Leg formula IV,III,II,I. Leg spination: I: Fm d 0-1-1-5; Pt pr 0-1-0; Tb pr 1-1, v 0-21ap; Mt pr and rt 1ap, v 2-2ap. II: Fm d 0-1-2-5; Pt pr 0-1-0; Tb pr and rt 1-1, v 1-1-2ap; Mt pr and rt 1-1ap, v 2-2ap. III: Fm d 0-1-2-5; Pt pr and rt 0-1-0; Tb d 1-0-0, pr and rt 1-1-1-1, v 1-0-2ap; Mt d 1-1-0, pr and rt 1-0-2ap, v 0-2-2ap. IV: Fm d 0-1-1-4; Pt pr and rt 0-1-0; Tb d 1-0-0, pr and rt 1-1-1-1, v 1-2ap; Mt d 1-1-0, pr 1-1-2ap, rt 1-0-2ap, v 0-2-2ap. Coloration (in alcohol; Figs 468-471). Carapace yellow, with dark brown (almost black) eye field covered with numerous short erect brown bristles. There is a median brown stripe of recumbent scales; carapace sides are covered with white recumbent scales. 
Cheeks are densely covered with long brown hairs passing into the dense clypeal cover of long dark brown (almost black) hairs. Sternum light yellow, densely covered with white hairs. Labium, endites and chelicerae light yellow. Abdomen: dorsum dark brown, with a wide median white stripe; sides and venter light yellow. Book-lung covers light yellow, spinnerets brownish. All legs and palps entirely yellow. Palpal structure as in Figs 463-467: VTA bulge-shaped, poorly marked; RTA straight, stiletto-

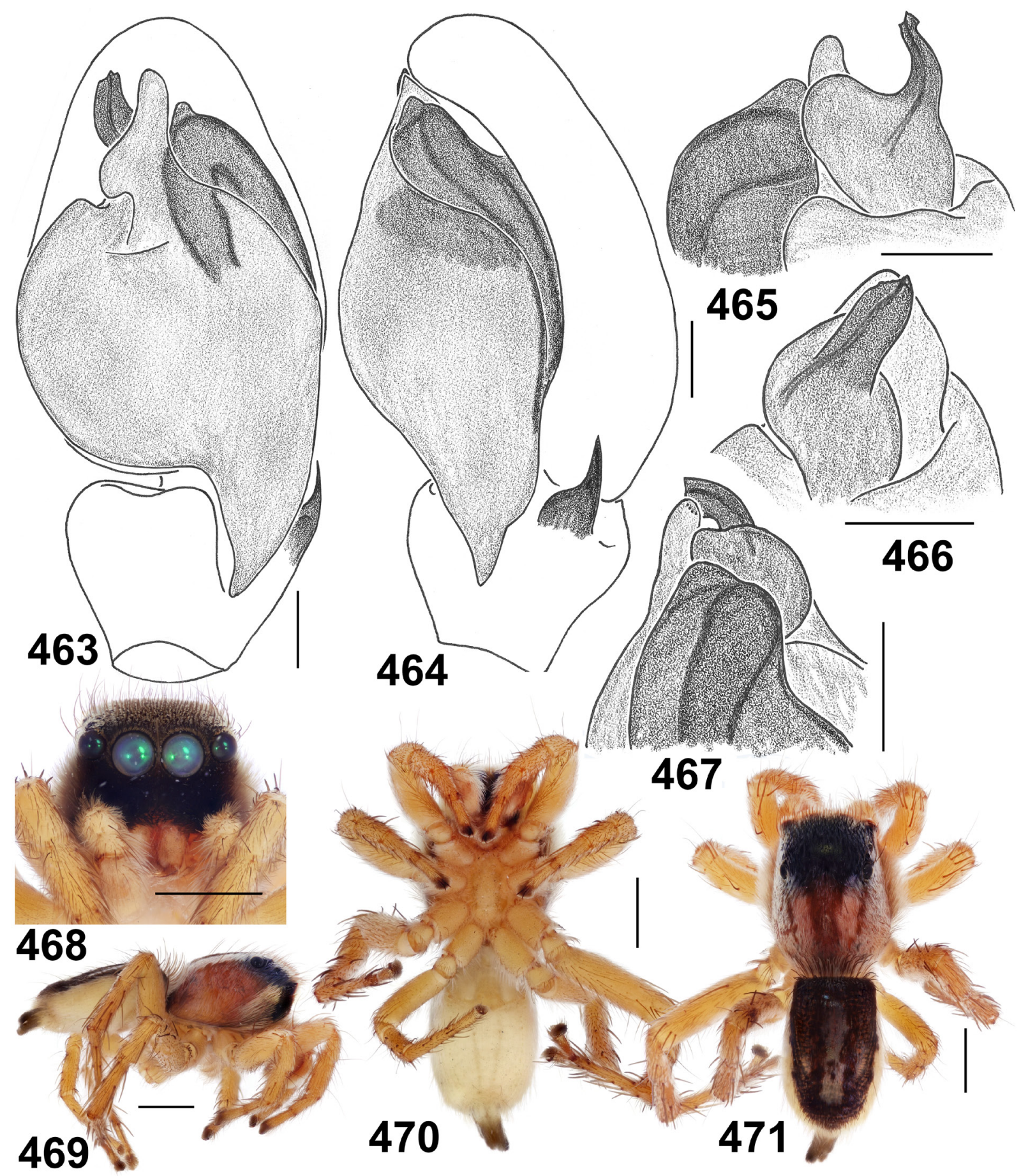

Figs 463-471. Stenaelurillus striolatus Wesołowska \& Russell-Smith, 2011, holotype, ô. 463. Palp, ventral view. 464. Palp, retrolateral view. 465. Embolic division, dorsal view. 466. Embolic division, median view. 467. Embolic division, retrolateral view. 468-471. General appearance. Scale bars: 463$467=0.1 \mathrm{~mm} ; 468-471=0.5 \mathrm{~mm}$. 
shaped, directed anteriad, with a wide base; the cymbial lateral process (CLP) absent; the tegulum small, with a short, cone-shaped tegular process (TP); the functional tegulum swollen, with a well-developed proximal (PP) and distal (DP) projections, the latter bifircated; the embolus short, ribbon-shaped, with a wide round base.

\section{Female}

Unknown.

\section{Distribution}

The type locality only (Fig. 512).

Stenaelurillus termitophagus (Wesołowska \& Cumming, 1999) comb. nov. Figs 4-5, 7, 11, 18-19, 472-487, 514

Microheros termitophagus Wesolowska \& Cumming, 1999: 204, figs 1-21 (D $\overbrace{}^{\Uparrow}+$ ); $\overbrace{}^{\Uparrow}$ holotype in NCA, not examined.

\section{Diagnosis}

This species differs from all other species of Stenaelurillus known to us in having the longest, whipshaped embolus and the presence of the largest, well-developed cymbial pocket in the males (Figs 472474), as well as the elevated flaps of the epigyne and the long insemination ducts running 360 degrees in the females (Figs 476-478).

\section{Material examined}

BOTSWANA: 1 ô, 1 male palp, Okavango [Delta], Maxwee, Mopane Woodland, 19 $29^{\prime} \mathrm{S}, 23^{\circ} 45^{\prime} \mathrm{E}$, pitfall traps, 30 Jun. 1976, A. Russell-Smith leg. (BMNH); 1 \%, island in Moanachira River, $19^{\circ} 10^{\prime}$ S, $23^{\circ} 42^{\prime}$ E, short grass in Senegalia nigrescens (Oliver, 1871) woodland, 17 Jul. 1977, A. Russell-Smith

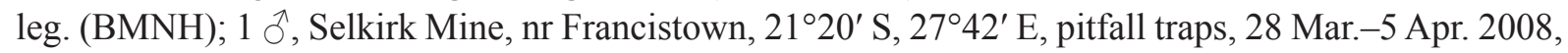
D.H. Jacobs leg. (NCA 2009/3746).

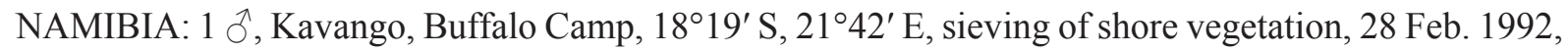
M. Uhlig leg. (ISEA 001.7157).

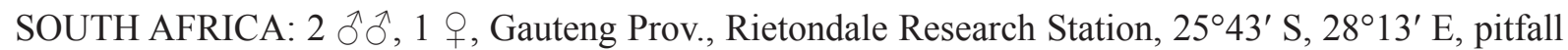
traps, 16 Jul. 1998, J. Nkwana leg. (NCA 2008/5065, NCA 2008/5068, NCA 2007/2791); 3 §ోô, 1 中, same prov., Doompoort, Buffelsdrift Conservancy, Farm Buffelsdrift (nr Die Ark), $25^{\circ} 36^{\prime} \mathrm{S}$, $28^{\circ} 19^{\prime}$ E, pan traps, closed woodland, 25 Jan. 2006, P. Koko leg. (NCA 2010/4945); 1 ㅇ, same prov., Pretoria/ Tshwane, ca $25^{\circ} 39^{\prime} \mathrm{S}, 28^{\circ} 21^{\prime} \mathrm{E}$, in building, by hand, 2 Jun. 1986, M. Filmer leg. (NCA 86/94); 1 ㄱ, 10 우 으, Limpopo Prov., Polokwane, Polokwane GR, $23^{\circ} 58^{\prime} \mathrm{S}, 29^{\circ} 28^{\prime} \mathrm{E}$, active search, woodland, 18 Apr.-16 Jun. 2005, T.T. Khoza and M.A. Modib leg. (NCA 2008/2384, NCA 2008/2375); 1 q, same locality, open savanna, active search, 11 Apr.-22 Jul. 2005, T.T. Khoza and M.A. Modib leg. (NCA 2008/2312); 1 đ’, 1 \%, same prov., Settlers, Farm Tweekansen, $25^{\circ} 29^{\prime}$ S, $28^{\circ} 34^{\prime}$ E, pitfall traps, grass, 7 May 2002, M. van Jaarsveld leg. (NCA 2010/5314, NCA 2008/2370); 2 ồ, 1 , same prov., Vivo,

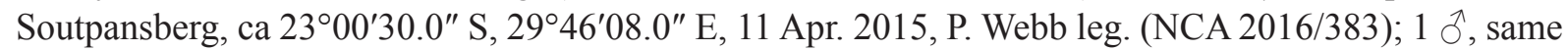

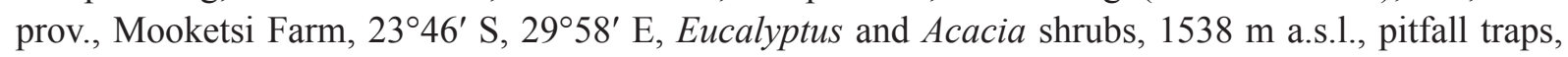
23 Apr. 2014, I.V. Mutavhatsindi and S.H. Foord leg. (UniVen); 2 ઈิð, 2 우, KwaZulu-Natal Province, Pietermaritzburg, nr Oribi Airfield, ca $29^{\circ} 38^{\prime}$ S, 30 $23^{\circ}$ E, thornbush, 14 Apr. 1976, F. Wanless and A. Russell-Smith leg. (MMUE G7583.6). 


\section{Description}

Male (Botswana, Mopane Woodland)

Measurements: carapace 3.15 long, 2.45 wide and 1.80 high at PLE. Ocular area: 1.33 long, 1.80 wide anteriorly and 1.73 wide posteriorly. Diameter of AME 0.45 . Clypeal height 0.13 , chelicera length 0.78 . Abdomen 3.25 long, 2.35 wide. Length of leg segments: I $1.65+0.90+1.00+0.80+0.60$ (4.95);

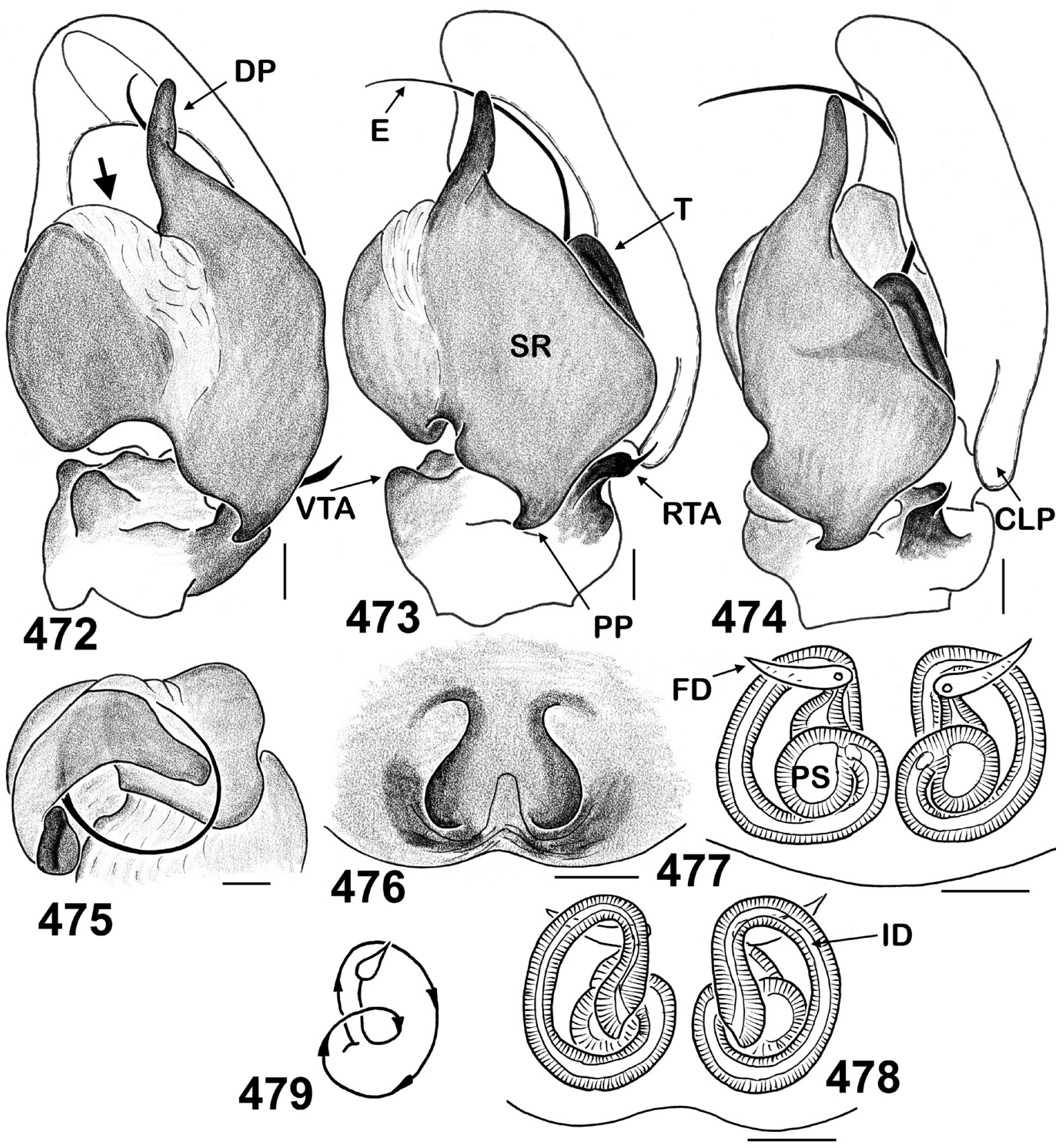

Figs 472-479. Stenaelurillus termitophagus (Wesołowska \& Cumming, 1999) comb. nov., § from Botswana, (Mopane Woodland) and $q$ from Botswana (island in Moanachira River). 472-474. Male palp. 472. Ventral view. 473. Ventro-retrolateral view. 474. Retrolateral view. 475. Embolic division, apical view. 476. Epigyne, ventral view. 477. Spermathecae, dorsal view. 478. Spermathecae, ventral view. 479. Diagrammatic course of the insemination ducts. Abbreviations: see Material and methods. Scale bars: $0.1 \mathrm{~mm}$. 
II $1.70+0.90+0.95+0.85+0.60(5.00) ;$ III $2.45+1.25+1.55+2.00+0.75(8.00) ;$ IV $2.25+1.05+$ $1.50+2.10+0.85$ (7.75). Leg formula III,IV,II,I. Leg spination: I: Fm d 0-1-1-4; Pt pr 0-1-0; Tb pr 1-1, v 0-1-2ap; Mt pr and 1ap, v 2-2ap. II: Fm d 0-1-2-4; Pr pr 0-1-0; Tb pr 1-1, v 1-1-2ap; Mt pr and rt 1-1ap, v 2-2ap. III: Fm d 0-1-2-4; Pt pr and rt 0-1-0; Tb d 1-0, pr and rt 1-1-1, v 2ap; Mt d 1-1-0, pr and rt 1-0-2ap, v 0-2-2ap. IV: Fm d 0-1-2-4; Pt pr and rt 0-1-0; Tb d 1-0-0, pr and rt 1-1-1, v 1-0-2ap; Mt d 1-0-0, pr and rt 1-1-2ap, v 1-1-2ap. Coloration (in alcohol; Figs 484-487). Carapace light brownish yellow (almost orange), densely covered with brown hair-like scales, with two longitudinal white stripes and two wide white marginal bands of white hair-like scales. Clypeus light brownish yellow, with a transverse stripe of dense white hairs. Sternum light yellow, covered with white hairs. Endites and labium light yellow. Chelicerae brownish yellow, anteriorly covered with brown hair-like scales and with two vertical stripes of white hair-like scales. Abdomen: dorsum dark brown (cover of brown hairlike scales), with a longitudinal white stripe and two lateral white stripes of hair-like scales; sides densely covered with white hair-like scales; venter light yellow, with short longitudinal brown stripes of hairs on its rear half. Book-lung covers light yellow. Spinnerets: anterior and median pairs light yellow, with brownish apices; posterior pair dark brown. Legs: Fm, Mt and Tr yellow, with brownish (semi)rings; Pt and Tb darker, brown, with dark brown (semi)rings. Palps yellow. Palpal structure as in Figs 472-475: VTA bulge-shaped; RTA wide, with a spine-shaped tip; the cymbium with a developed cymbial lateral process (CLP); the functional tegulum swollen, with well-developed proximal (PP) and distal, fingershaped (DP) projections; the embolus whip-shaped, partly hidden in the open, apical cymbial pocket.

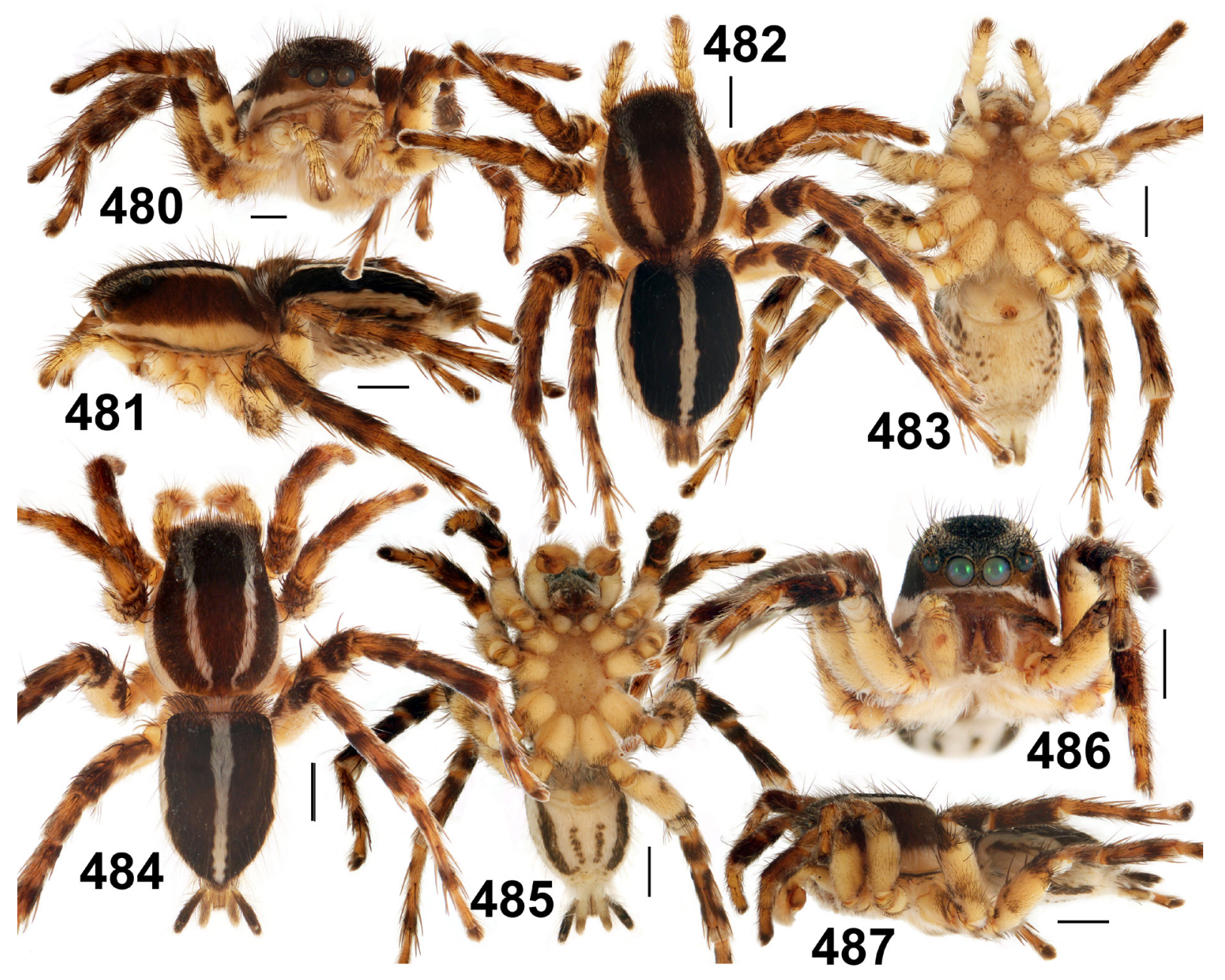

Figs 480-487. Stenaelurillus termitophagus (Wesołowska \& Cumming, 1999) comb. nov. from South Africa (Doompoort, NCA 2010/4945), general appearance. 480-483. ‥ 484-487. $\lesssim$. Scale bars: $1 \mathrm{~mm}$. 
Female (Botswana, island in Moanachira River)

Measurements: carapace 3.60 long, 2.70 wide and 1.90 high at PLE. Ocular area: 1.18 long, 1.78 wide anteriorly and 1.83 wide posteriorly. Diameter of AME 0.48. Clypeal height 0.25, chelicera length 0.55. Abdomen 4.05 long, 3.10 wide. Length of leg segments: I $1.65+0.80+0.85+0.70+0.50$ (4.50); II $1.75+0.75+0.90+0.80+0.65(4.85) ;$ III $2.70+1.30+1.70+2.20+0.70(8.60) ;$ IV $2.60+1.15+$ $1.70+2.25+0.80$ (8.50). Leg formula III,IV,II,I. Leg spination: II: Fm d 0-1-1-5; Pt pr 0-1-0; Tb pr 1-1, v 1-1-2ap; Mt pr and 1ap, v 1-2ap. II: Fm d 0-1-2-4; Pr pr 0-1-0; Tb pr 1-1, v 1-1-2ap; Mt pr 1-1ap, rt 1ap, v 1-2ap. III: Fm d 0-1-2-5; Pt pr and rt 0-1-0; Tb d 1-0, pr and rt 1-1-2, v 1-0-2ap; Mt d 1-1-0, pr and rt 1-0-2ap, v 0-0-2-2ap. IV: Fm d 0-1-1-5; Pt pr and rt 0-1-0; Tb d 1-0-0, pr and rt 1-1-1-1, v 1-0-2ap; Mt d 1-0-0, pr and rt 1-1-1, v 1-2ap. Coloration (in alcohol; Figs 480-483), as in the male but lighter and differs as follows: palps light yellow; chelicerae brownish yellow, without vertical white stripes; venter without longitudinal brown stripes; posterior spinnerets yellow; Fm of all legs light yellow with brownish tips, the remaining segments brownish yellow. Epigyne and spermathecae as in Figs 476-479: epigynal plate with two S-shaped, elevated flaps, under which the copulatory openings are hidden; insemination ducts relatively long, running 360 degrees; primary spermathecae medium-sized, pearshaped.

\section{Distribution}

Southern Africa (Fig. 514).

Stenaelurillus zambiensis Wesołowska, 2014

Figs 488-498, 513

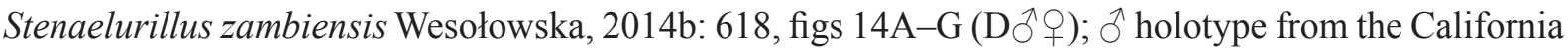
Academy of Sciences, San Francisco, USA; not examined.

\section{Diagnosis}

This species can easily be distinguished from all other species of Stenaelurillus by the unique, hookshaped RTA that is bent laterad (Figs 492-493) in the male, and by the conformation of the female copulatory organs: viz., the epigyne with two large rounded fossae and the thin, tube-shaped and straight insemination ducts directed anteriad (see Wesołowska 2014b: figs 14F-G).

\section{Material examined}

MALAWI: $3 \widehat{\partial} \partial^{\prime}$, Central Region, Lilongwe, Lilongwe Nature Reserve, ca $13^{\circ} 58^{\prime} \mathrm{S}, 33^{\circ} 47^{\prime} \mathrm{E}$, on path, Combretum Loeffling \& Schreb. woodland, 25 May 1991, A. Russell-Smith leg. (MMUE G7583.7).

\section{Description}

Male

Measurements: carapace: 2.60 long, 2.05 wide, 1.25 high. Abdomen: 2.50 long, 2.00 wide. Ocular area: 1.00 long, 1.50 wide anteriorly, 1.45 wide posteriorly. Chelicerae length 0.70 . Clypeus height 0.25 . Diameter of AME 0.40. Length of leg segments: I $1.20+0.70+0.80+0.55+0.50(3.75)$; II $1.25+0.70$ $+0.80+0.50+0.50(3.75) ;$ III $2.00+1.00+1.25+1.30+0.90(6.45) ;$ IV $1.80+0.90+1.25+1.55+$ 0.80 (6.30). Leg formula III,IV,II/I. Leg spination: I: Fm d 0-1-1-5; Pt pr 0-1-0; Tb pr 1-1, v 1-0-2ap; Mt pr 1-1ap, rt 0-1ap or 1-1ap, v 2-2ap. II: Fm d 0-1-2-5; Pt pr 0-1-0; Tb pr 1-1, v 1-0-2ap; Mt pr and rt 1-1ap, v 2-2ap. III: Fm d 1-2-5; Pt pr and rt 0-1-0; Tb d 1-0-0, pr and rt 1-1-1-1, v 1-0-2ap; Mt d 1-10, pr 1-1-2ap, rt 1-0-2ap, v 0-2-2ap. IV: Fm d 1-1-5; Pt pr and rt 0-1-0; Tb d 1-0-0, pr and rt 1-1-1-1, v 1-0-2ap; Mt d 1-1-0, pr 1-2-2ap, rt 1-0-2ap, v 1-2-2ap. Coloration (in alcohol; Figs 488-491). Carapace brownish yellow, covered with brownish recumbent scales, with two longitudinal stripes of white scales running from PLEs towards the rear end of the carapace. Eye field dark brown, covered with brown 
shining recumbent scales. Sternum yellow. Endites and labium yellow. Chelicerae brownish yellow, sparsely covered with brownish hairs Abdomen: dorsum brown, with the scutum occupying $2 / 3$ of its length and covered with brown shining scales, venter yellow with rows of poorly marked grey-brown dots in its caudal part. Spinnerets brown-yellow, the dorsal pair apically dark brown. Male palp as in

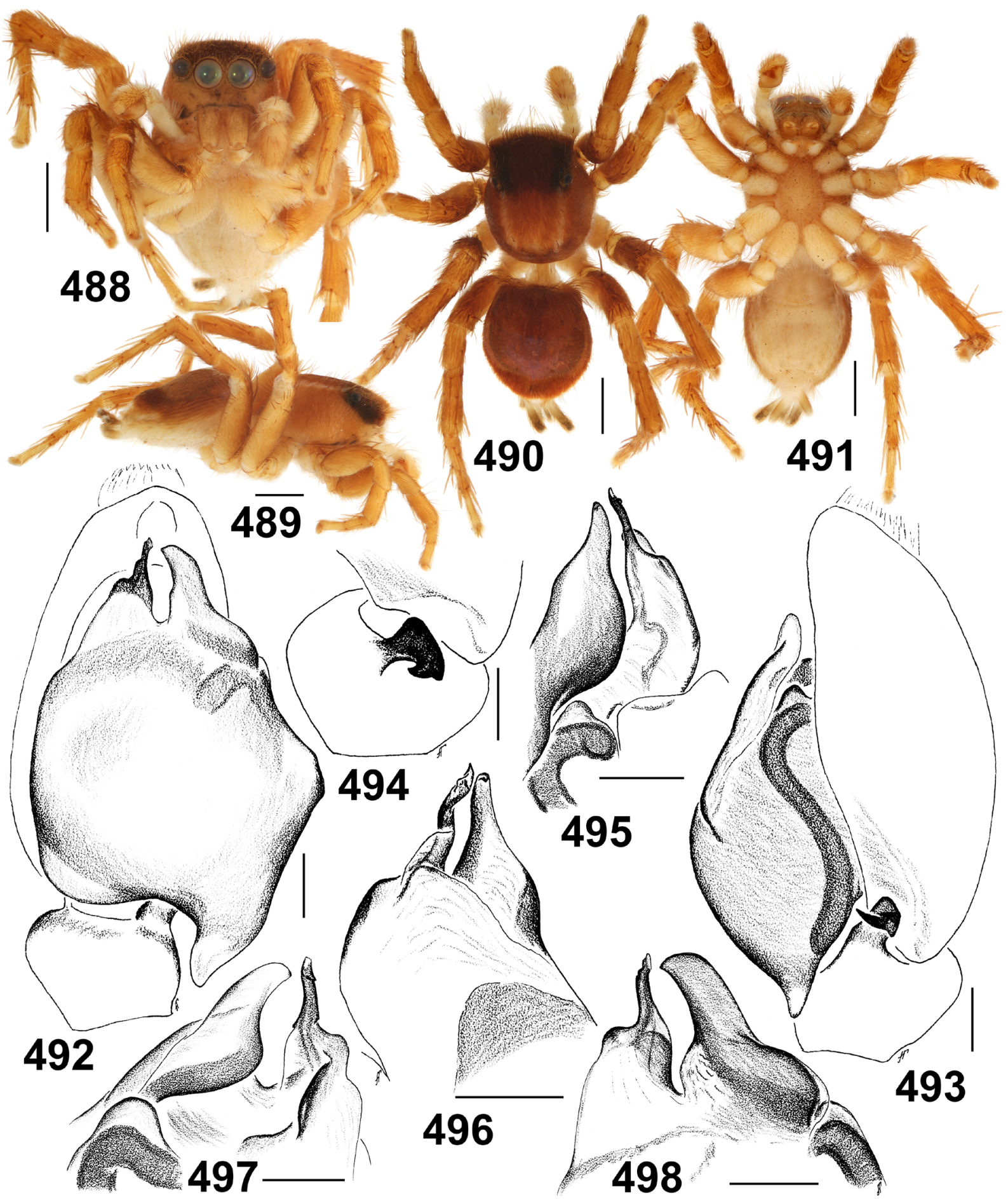

Figs 488-498. Stenaelurillus zambiensis Wesołowska, 2014, ㅇ from Malawi (Lilongwe NR). 488491. General appearance. 492. Male palp, ventral view. 493. Male palp, retrolateral view. 494. RTA, dorsal view. 495-498. Embolic division. 495. Prolateral view. 496. Retrolateral view. 497. Dorsal view. 498. Ventral view. Scale bars: $488-491=1 \mathrm{~mm}$; $492-498=0.1 \mathrm{~mm}$. 
Figs 492-498: VTA poorly developed. almost invisible; RTA hook-shaped, bent laterad; cymbial lateral process absent; the tegulum small, poorly marked, without a tegular process; the functional tegulum swollen, with well-developed distal (DP) and proximal (PP) projections; the embolus short, spineshaped, with a ribbed base.

\section{Female}

See Wesołowska (2014b).

\section{Distribution}

Three localities in Malawi, Zambia and Zimbabwe (Fig. 513) (Wesołowska 2014b; present data). New record for Malawi.

\section{Species excluded from Stenaelurillus}

Aelurillus ambiguus (Denis, 1966) comb. nov.

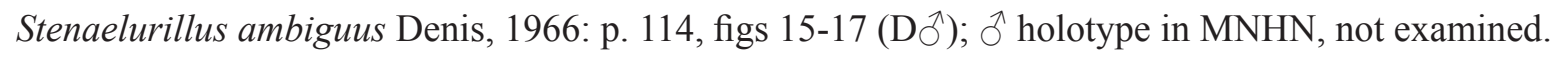

\section{Remarks}

This species was described from a single male from Libya (oasis Fezzân, Wādī al Ḥayāh District, Lake Tadem'ka) (see Denis 1966: figs 16-17). Based on the original description and illustrations, the holotype male possesses the main diagnostic characters of the genus Aelurillus Simon, 1884: viz., the shape of the tegulum and its position in relation to the cymbium, the absence of a tegular process, the shape and apical position of the visible part of the embolic division, and the presence of a singular retrolateral apophysis with a wide basis. Thus, it is safe to conclude that S. ambiguus Denis, 1966 is to be transferred to Aelurillus. The taxonomic status and validity of this species require further study; it seems to be close to Aelurillus stanislawi (Prószyński, 1999), known from Ethiopia and the Levant (WSC 2017).

Evarcha werneri (Simon, 1906) comb. nov.

Figs 499-503, 515

Stenaelurillus werneri Simon, 1906: 1174 (D ${ }^{\top}+$ ) $)$ lectotype $\bigcirc$ (designated here) in NHMW, examined. Evarcha elegans Wesołowska \& Russell-Smith, 2000: 26, figs 37-44 (D`ㅇ); type series in MRAC, not examined. Syn. nov.

Stenaelurillus werneri - Prószyński 1984: 139 (†).

\section{Diagnosis}

The female of E. werneri comb. nov. (Figs 502-503) is most similar to that of the widespread African species Hyllus dotatus (Peckham \& Peckham, 1903) (see Wesołowska \& Russell-Smith 2000: sub Evarcha d.), but differs in having a wider epigynal plate. A diagnosis for the male and a detailed description of this species were provided by Wesołowska \& Russell-Smith (2000: sub Evarcha elegans).

\section{Material examined}

Lectotype (designated here)

AFRICA: + , from “Afrika, Mongalla, Werner 1905” [Mongalla, $5.18002^{\circ} \mathrm{N}, 31.76798^{\circ} \mathrm{E}$, currently in South Sudan] (NHMW). 


\section{Other material}

NAMIBIA: $1 \overbrace{}^{\lambda}$, Karas Region, Okahondja shore, Washing, 26 $6^{\circ} 39^{\prime}$ S, $16^{\circ} 52^{\prime}$ E, 12 Sep. 1974, S. Endrödy-

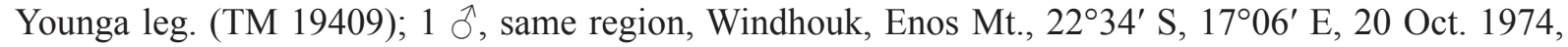
S. Endrödy-Younga leg. (TM 19216).

SOUTH AFRICA: $1 \delta^{\lambda}$, Limpopo Province, Pafuri (Wallers Camp), $22^{\circ} 25^{\prime} \mathrm{S}, 31^{\circ} 02^{\prime} \mathrm{E}$, pitfall traps,

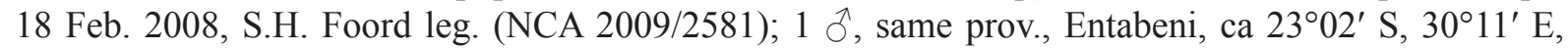
11 Feb. 2008, N. Hahn leg. (NCA 2016/1727).

\section{Remarks}

According to the original description (Simon 1906: 1174), the author examined and described both the male and the female of this species (syntypes). In his diagnosis, Simon (1906: 1174) mentioned

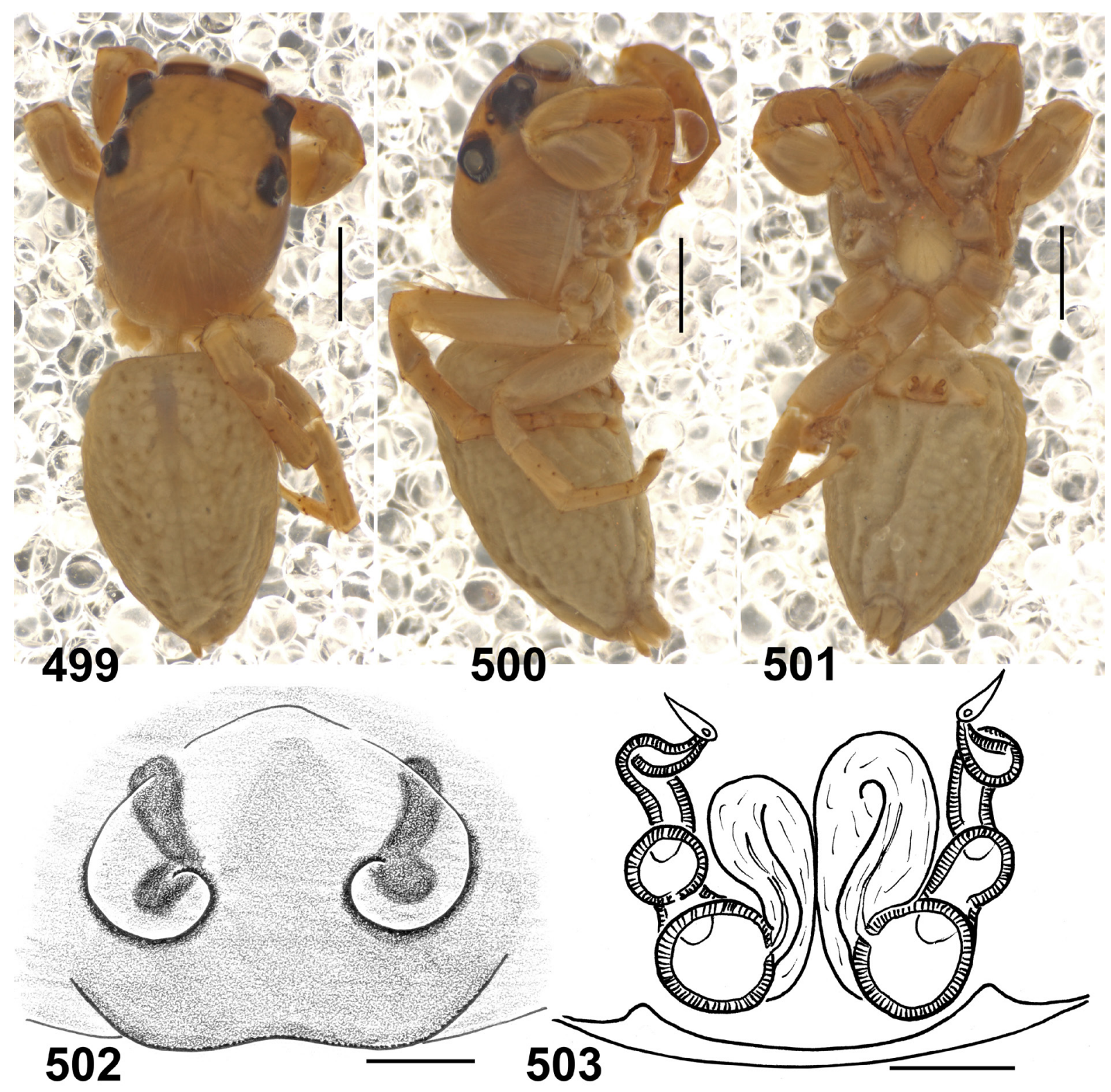

Figs 499-503. Evarcha werneri (Simon, 1906) comb. nov. (lectotype $q$ of Stenaelurillus werneri Simon, 1906). 499-501. General appearance. 502. Epigyne, ventral view. 503. Spermathecae, dorsal view. Scale bars: $499-501=1 \mathrm{~mm} ; 502-503=0.1 \mathrm{~mm}$. 
that the male of $S$. werneri was close to that of $S$. triguttatus, which is currently known from Nepal and Tibet (Wesołowska 2014a). Unfortunately, the whereabouts of the male are unknown; it is absent from either the NHMW or the MNHN. In order to assess the validity and taxonomic affinities of this species and to stabilize its taxonomic status, the studied syntype female was designated as the lectotype of $S$. werneri.

The wide transverse plate of the epigyne and the conformation of spermathecae (viz., S-shaped membranous insemination ducts ending up by the heavily sclerotized, multi-chambered primary receptacles; Fig. 503) are evidence that this species is to be transferred to the genus Evarcha Simon, 1902. The larger problem of the generic assignment of this and many other African species of Hyllus/ Evarcha is beyond the scope of the present paper and will be considered elsewhere.

Having re-examined the lectotype female of Stenaelurillus werneri, it has become evident that the conformation of its copulatory organs (Figs 502-503) is identical with those of Evarcha elegans (cf. Wesołowska \& Russell-Smith 2000: figs 42-44) and therefore both species names are to be synonymized.

\section{Description}

\section{Male}

See Wesołowska \& Russell-Smith (2000: sub. E. elegans).

Female (lectotype, designated here)

The specimen is in poor condition, visibly faded and with half of its legs on both sides being detached from the body (Figs 499-501). Measurements: carapace 2.45 long, 1.70 wide and 1.20 high at PLE. Ocular area: 1.13 long, 1.53 wide anteriorly and 1.68 wide posteriorly. Diameter of AME 0.48. Clypeal height 0.18 , chelicera length 0.63 . Abdomen 3.05 long, 1.70 wide. Length of leg segments: I $1.08+0.60$ $+0.75+0.55+0.40(3.38) ;$ II $1.00+0.55+0.58+0.40+0.40(2.93) ;$ III $1.65+0.78+0.95+0.83+$ 0.55 (4.76); IV $1.30+0.53+0.53+0.80+0.43$ (3.59). Leg formula III,IV,I,II. Leg spination: I: Fm d 0-1-1-5; Pt pr 0-1-0; Tb pr 1-1, rt 0-1, v 2-2-2ap; Mt pr 1-1ap, v 2-2ap. II: Fm d 0-1-2-4; Pr pr 0-1-0; Tb pr 1-1-1, v 2-2ap; Mt pr 1-1ap, v 2-2ap. III: Fm d 1-0-2-4; Pt pr and rt 0-1-0; Tb pr and rt 1-1-1, v 1-02ap; Mt pr, rt and v 1-0-2ap. IV: Fm d 1-2-3; Pt pr and rt 0-1-0; Tb pr and rt 1-1-1, v 1-0-2ap; Mt pr, rt and v 1-0-2ap. Coloration (in alcohol; Figs 499-501). The specimen is markedly faded. Entire body, all legs, book-lung covers, spinnerets and palps pale yellow, with no visible colour pattern or patches; only black areas around eyes. Clypeus pale yellow, without hair/scale cover. Epigyne and spermathecae as in Figs 502-503: epigyne as a transverse, slightly procurved plate (as in all Evarcha species); insemination ducts wide and membranous; receptacle elongated, its basal section round and markedly larger than distal sections.

\section{Distribution}

South Sudan (Simon 1906: sub. Stenaelurillus w.), Namibia (present data), Ethiopia, Tanzania and South Africa (Wesołowska \& Russell-Smith 2000; Wesołowska \& Tomasiewicz 2008; Wesołowska \& Haddad 2009; all sub. E. elegans) (Fig. 515).

Phlegra davidi (Caleb, Mungkung \& Mathai, 2015) comb. nov.

Figs 504-506

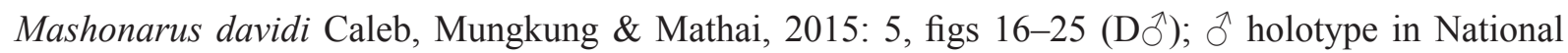
Centre for Biological Sciences (Bangalore, Karnataka, India), examined. 


\section{Remarks}

Although we have been unable to borrow the male holotype of Mashonarus davidi, our colleague John Caleb (Kolkata, West Bengal, India) has re-examined the type at our request and photographed the expanded palp of both the holotype and an additional male (Figs 504-506). The leg formula of both studied males of $M$. davidi (III,IV,I,II) corresponds to that of many aelurilline genera, including Stenaelurillus, and its body colour pattern (see figs 16-20 in Caleb et al. 2015) and cheliceral dentation
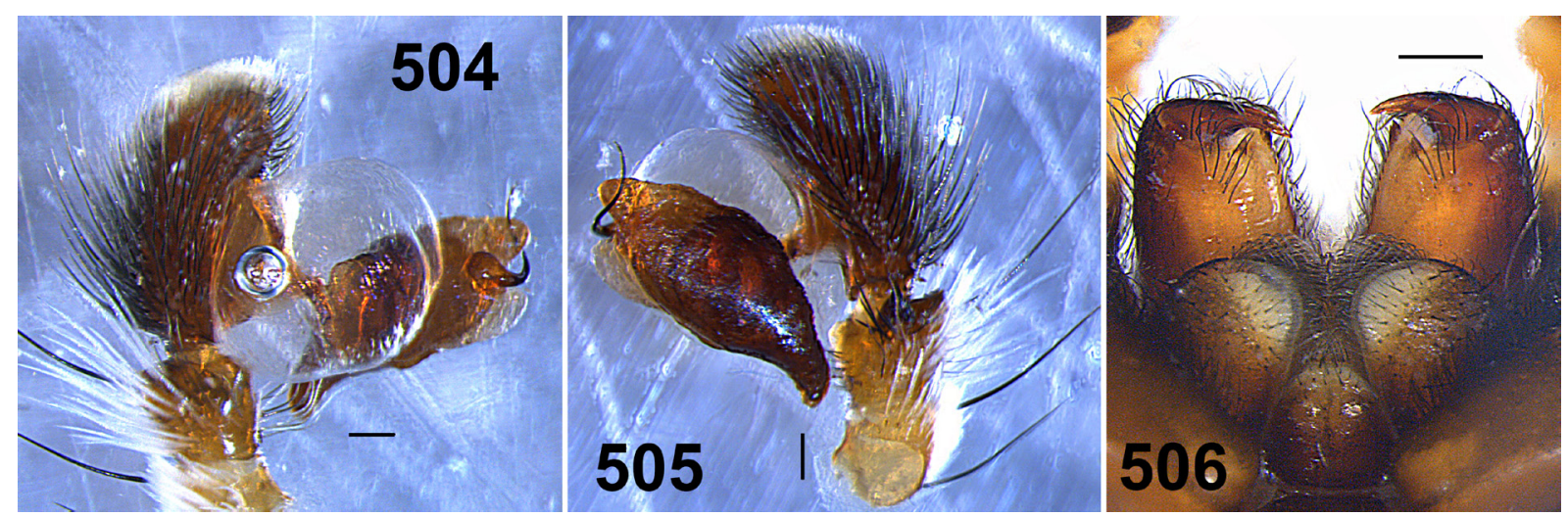

Figs 504-506. Phlegra davidi (Caleb, Mungkung \& Mathai, 2015) comb. nov., $\widehat{\jmath}$ from India (Tamil Nadu). 504. Expanded palp, median view. 505. Ditto, retrolateral view. 506. Chelicerae, endites and labium, ventral view. Scale bars: $0.1 \mathrm{~mm}$.

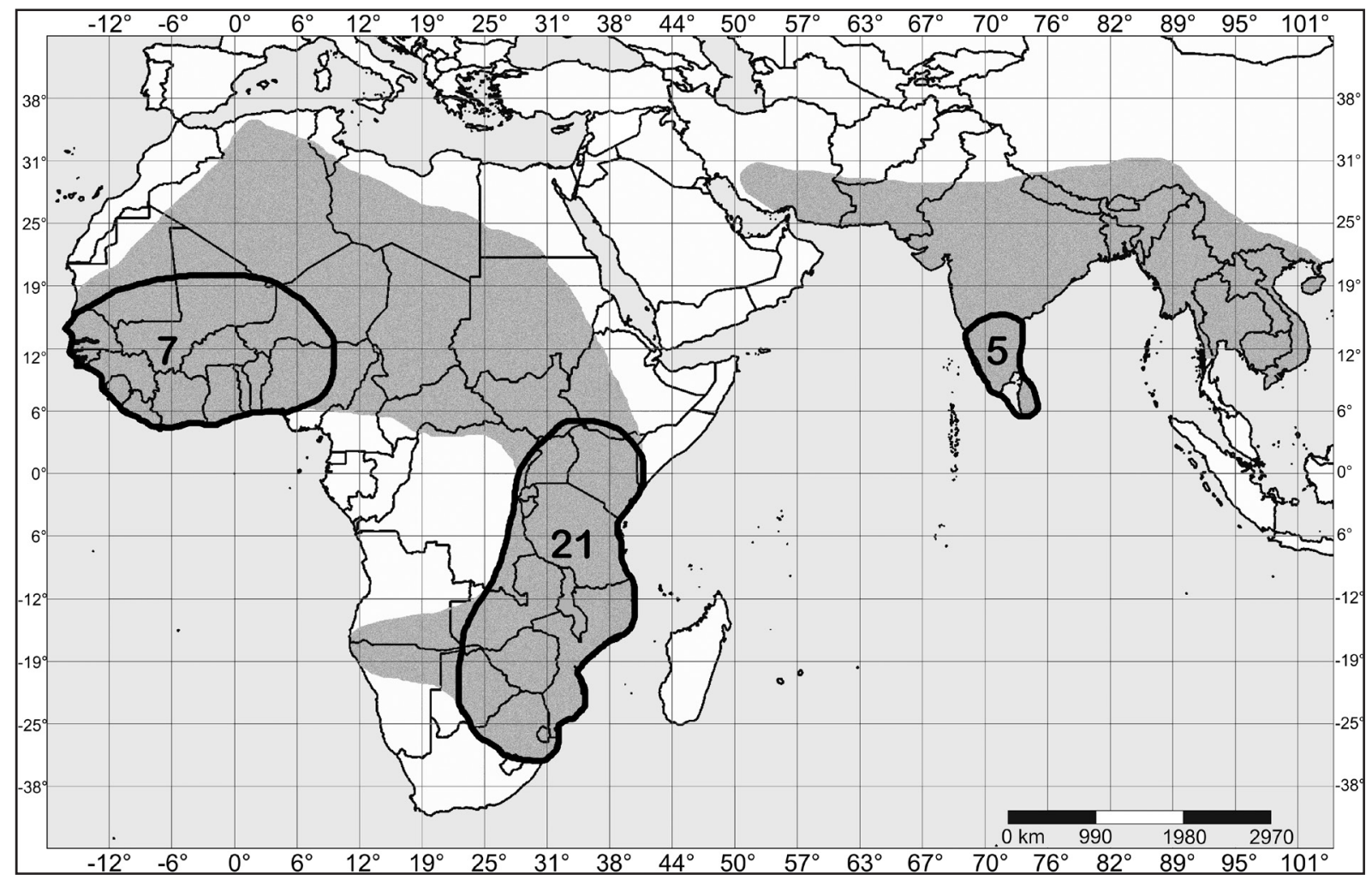

Fig. 507. General distribution and modern centres of species diversity of Stenaelurillus Simon, 1886. 
(Fig. 506) are also similar to those of many species of Stenaelurillus. However, the conformation of the copulatory organs in both males is typical of Phlegra Simon, 1876: viz., the narrow, elongated bulbus flattened in a dorso-ventral direction, two tibial apophyses, the presence of a cymbial lateral projection (= tutaculum), the spiralled embolus that is similar to that of representatives of the bresnieri species group, and the thickened first pair of legs. Besides, the true tegulum (see above, p. 9) is not seen in the expanded palp of M. davidi (Figs 504-505), as compared to true species of Stenaelurillus (Figs 33, 39, 90, etc.). Therefore, it is safe to conclude that this species is better transferred to the genus Phlegra.

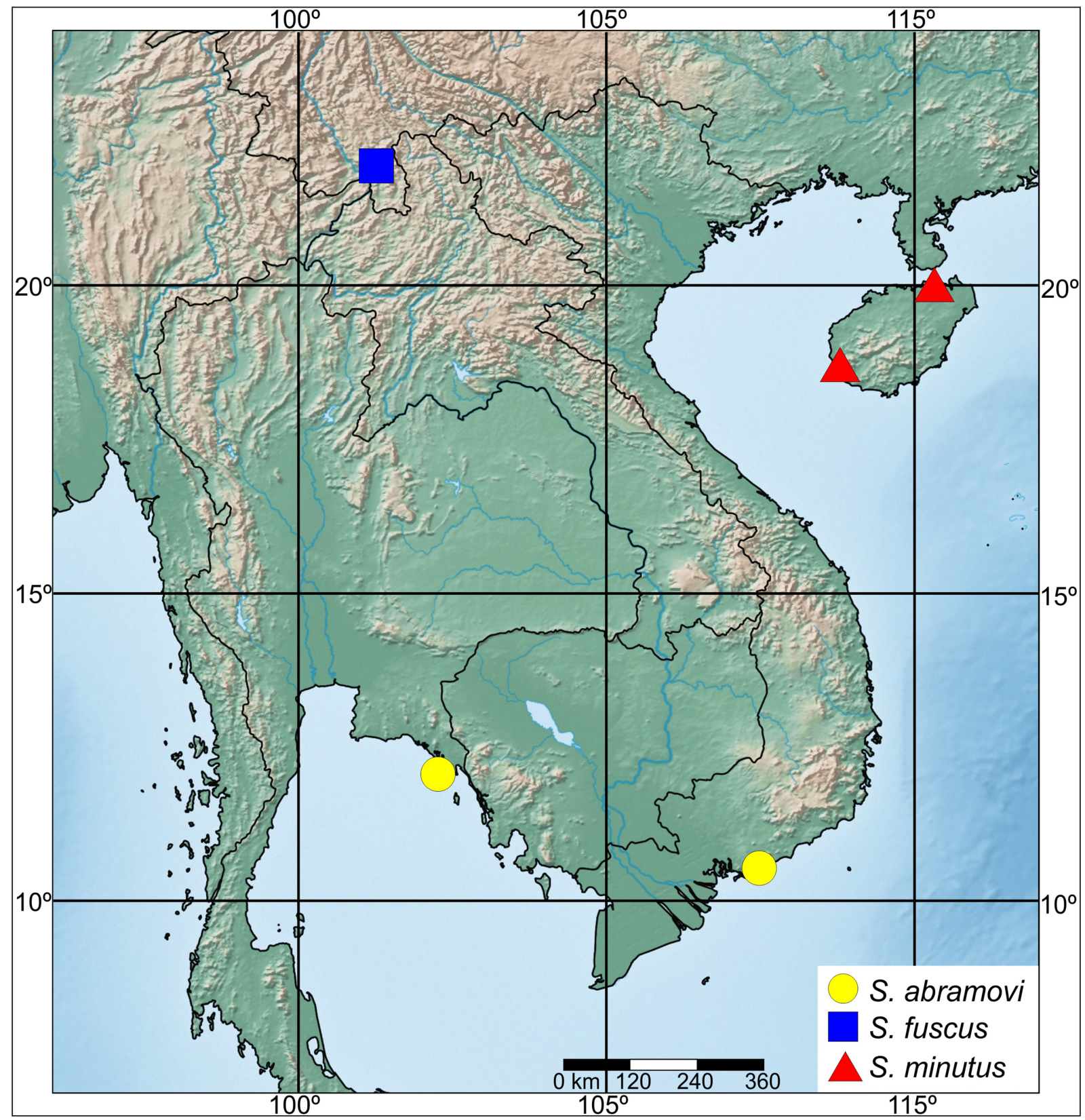

Fig. 508. Collecting localities of three Oriental species of Stenaelurillus Simon, 1885. 


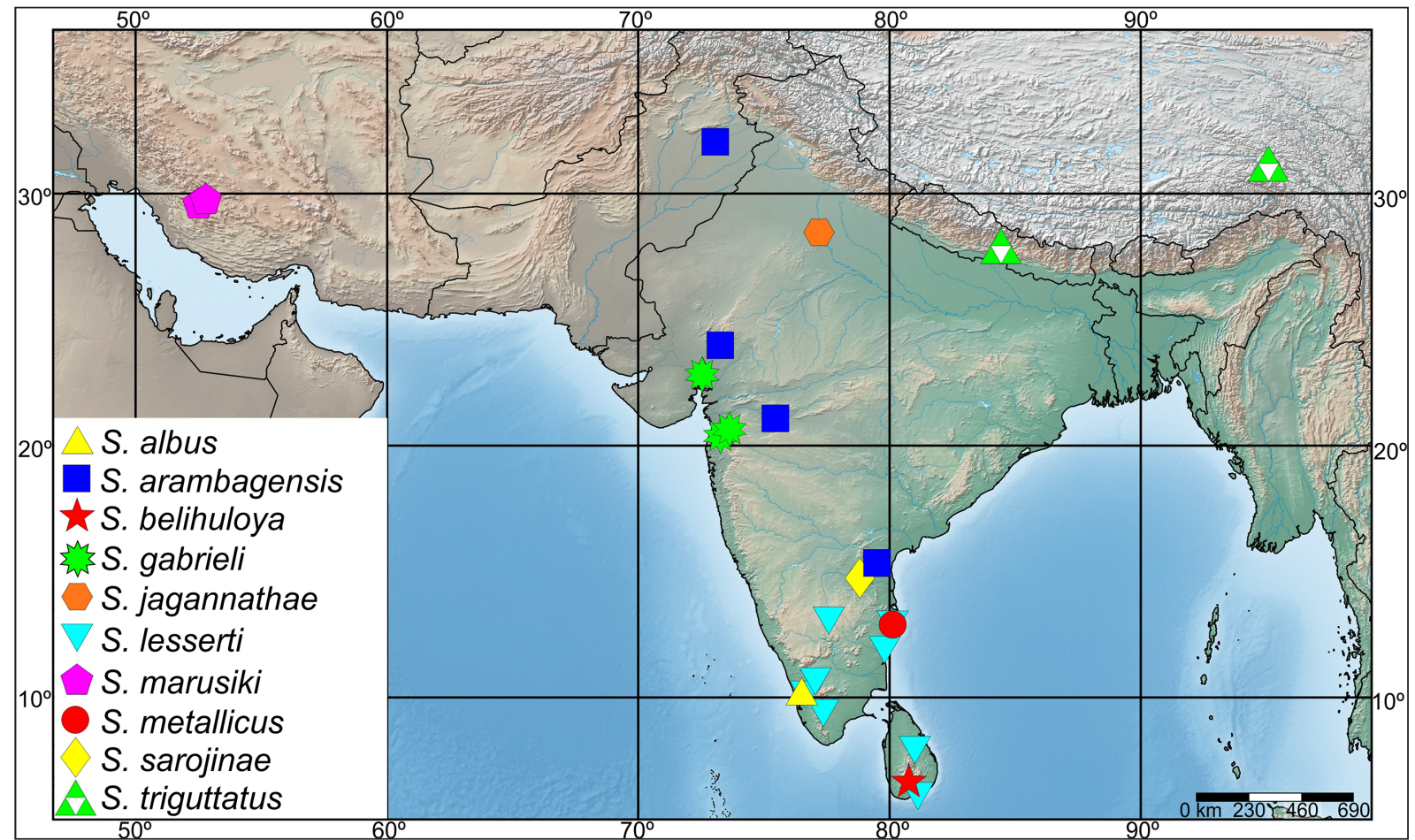

Fig. 509. Collecting localities of ten Asian species of Stenaelurillus Simon, 1885.

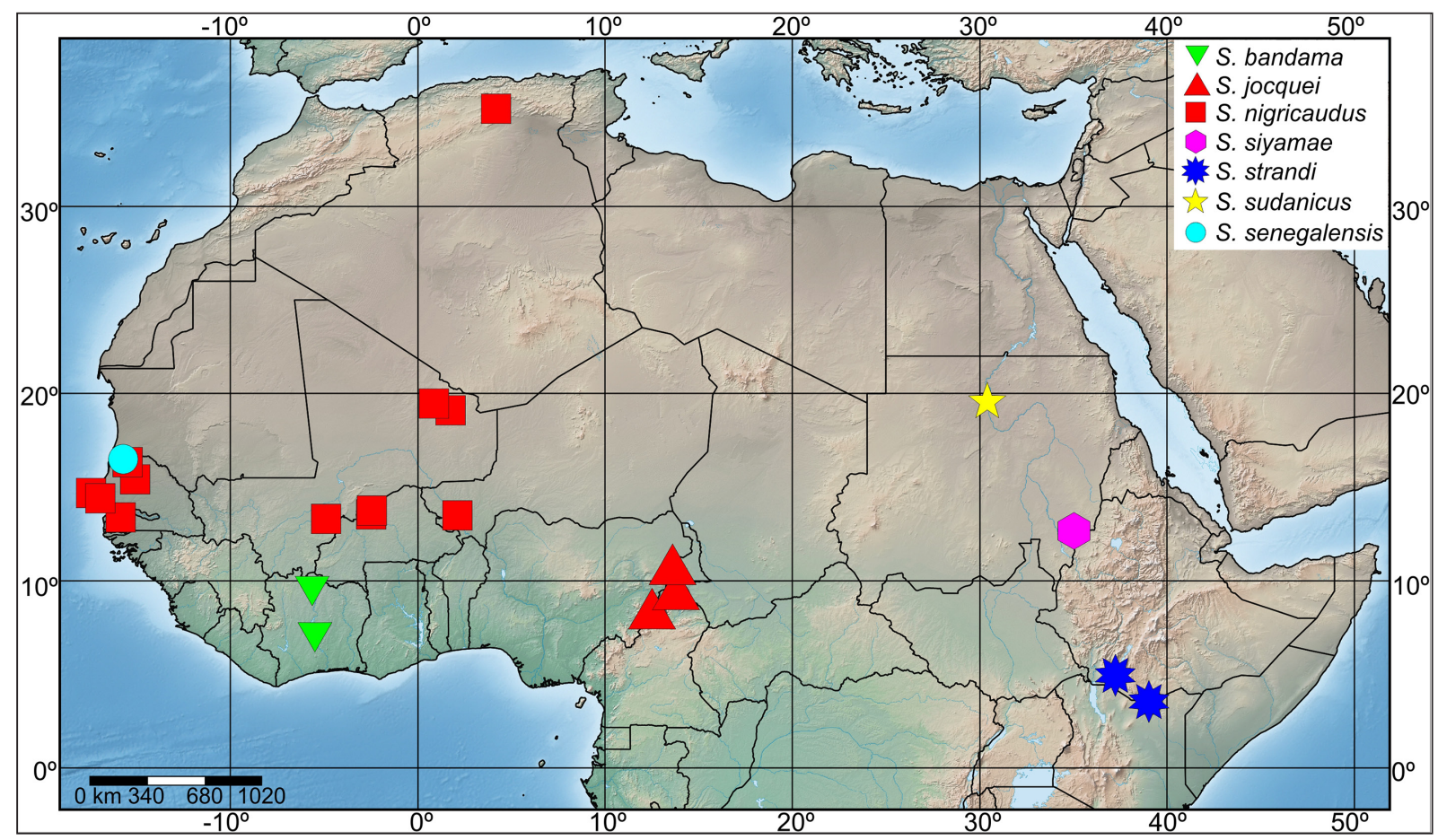

Fig. 510. Collecting localities of seven African species of Stenaelurillus Simon, 1885. 


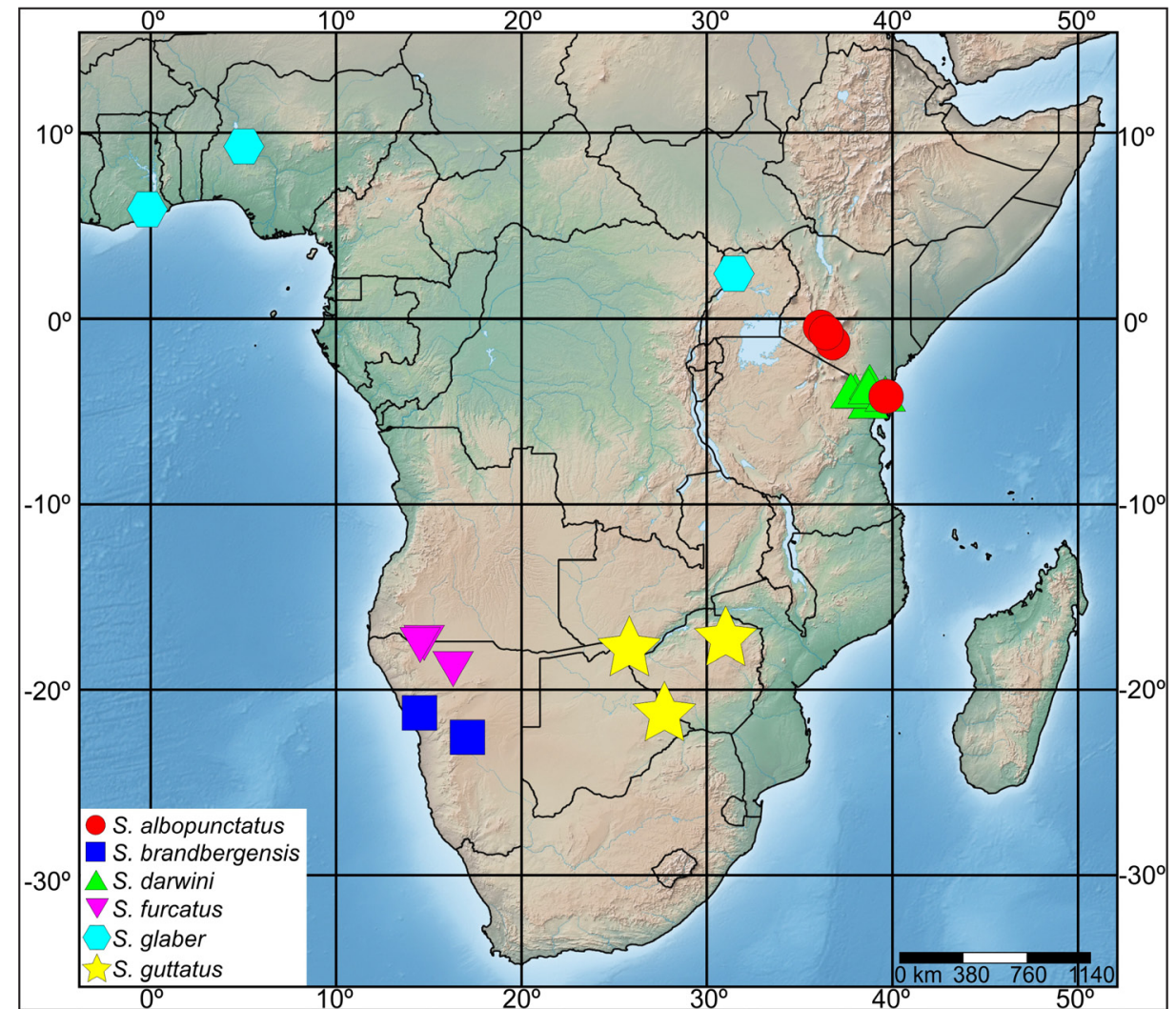

Fig. 511. Collecting localities of six African species of Stenaelurillus Simon, 1885.

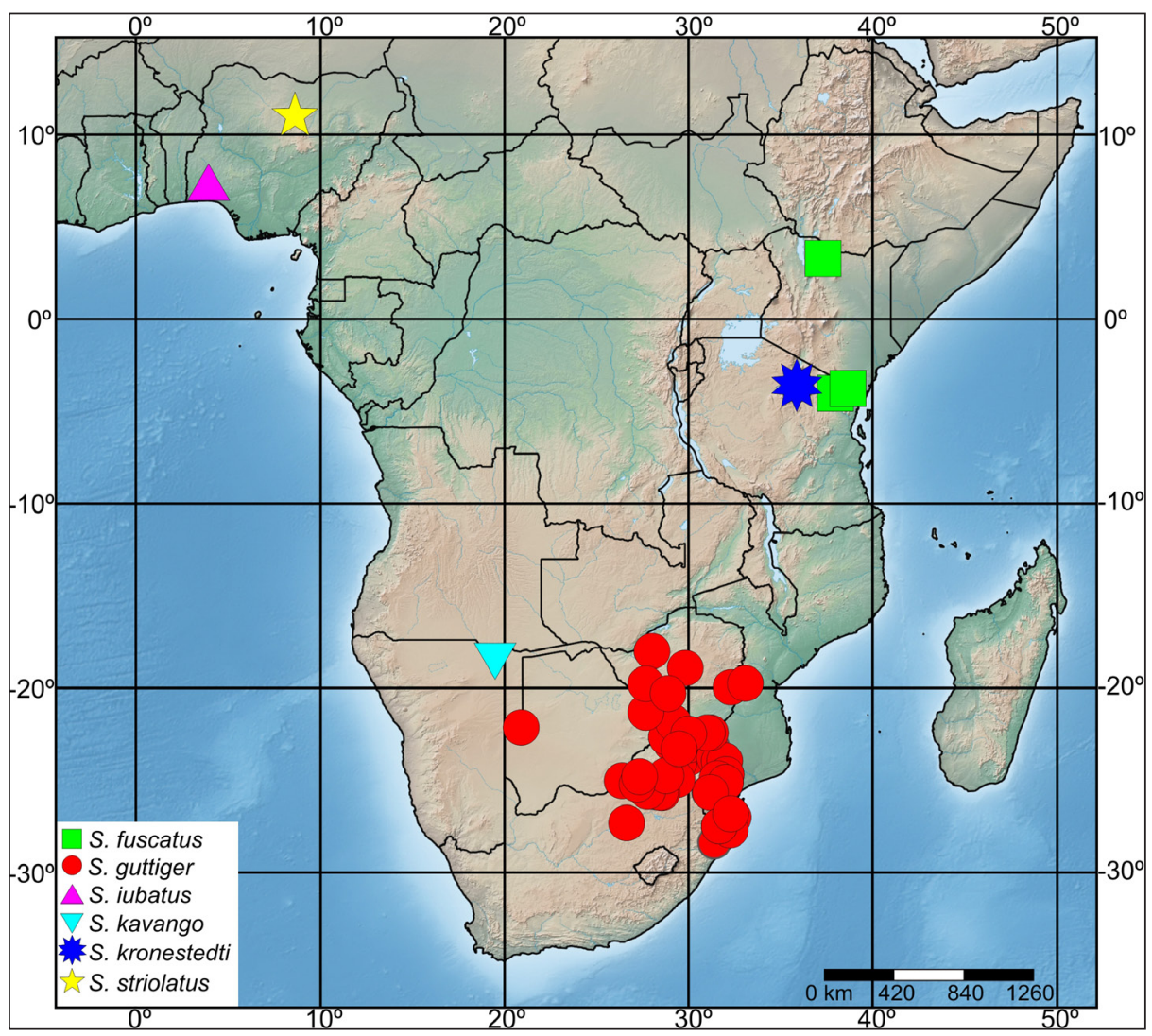

Fig. 512. Collecting localities of six African species of Stenaelurillus Simon, 1885. 


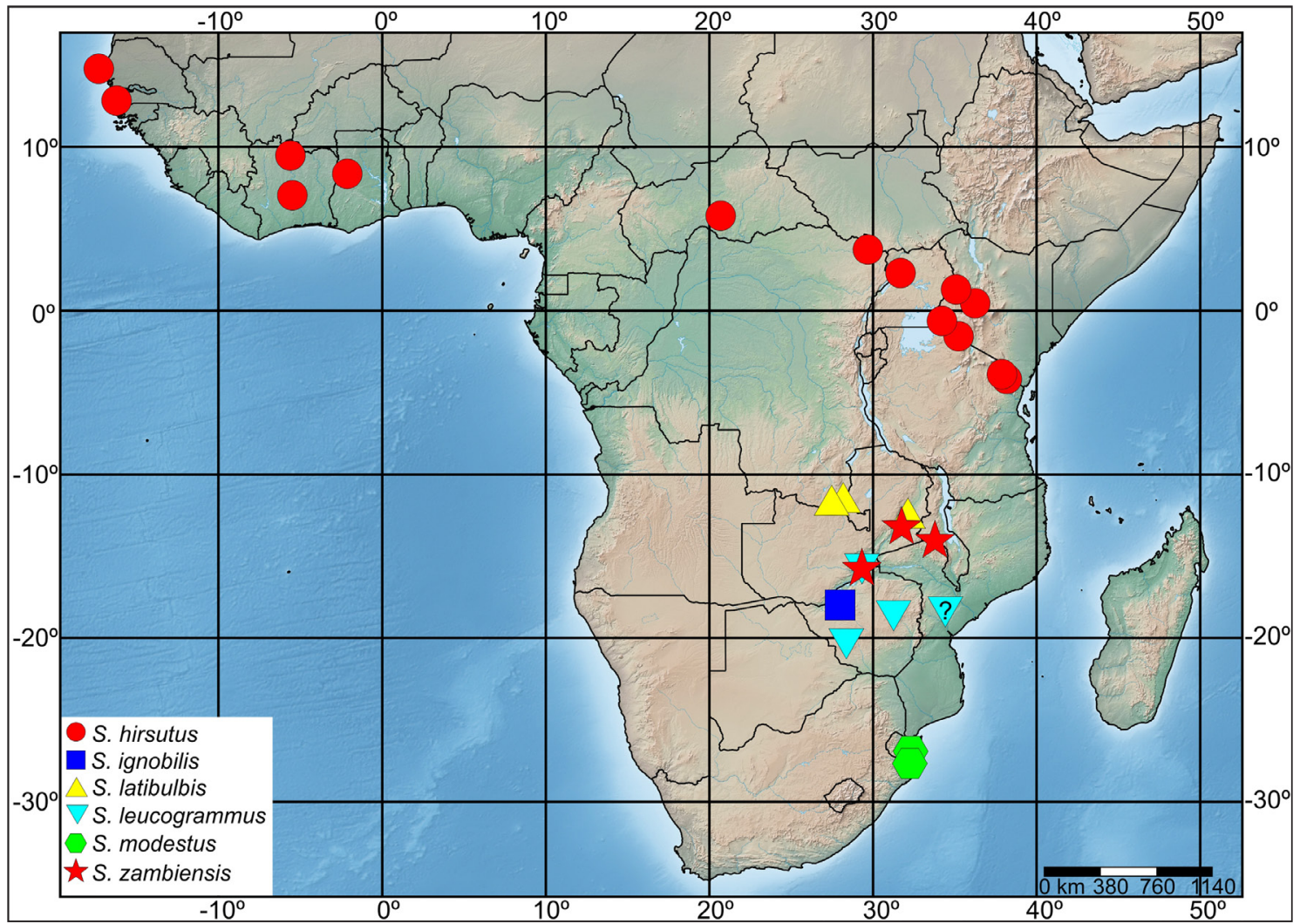

Fig. 513. Collecting localities of six African species of Stenaelurillus Simon, 1885.

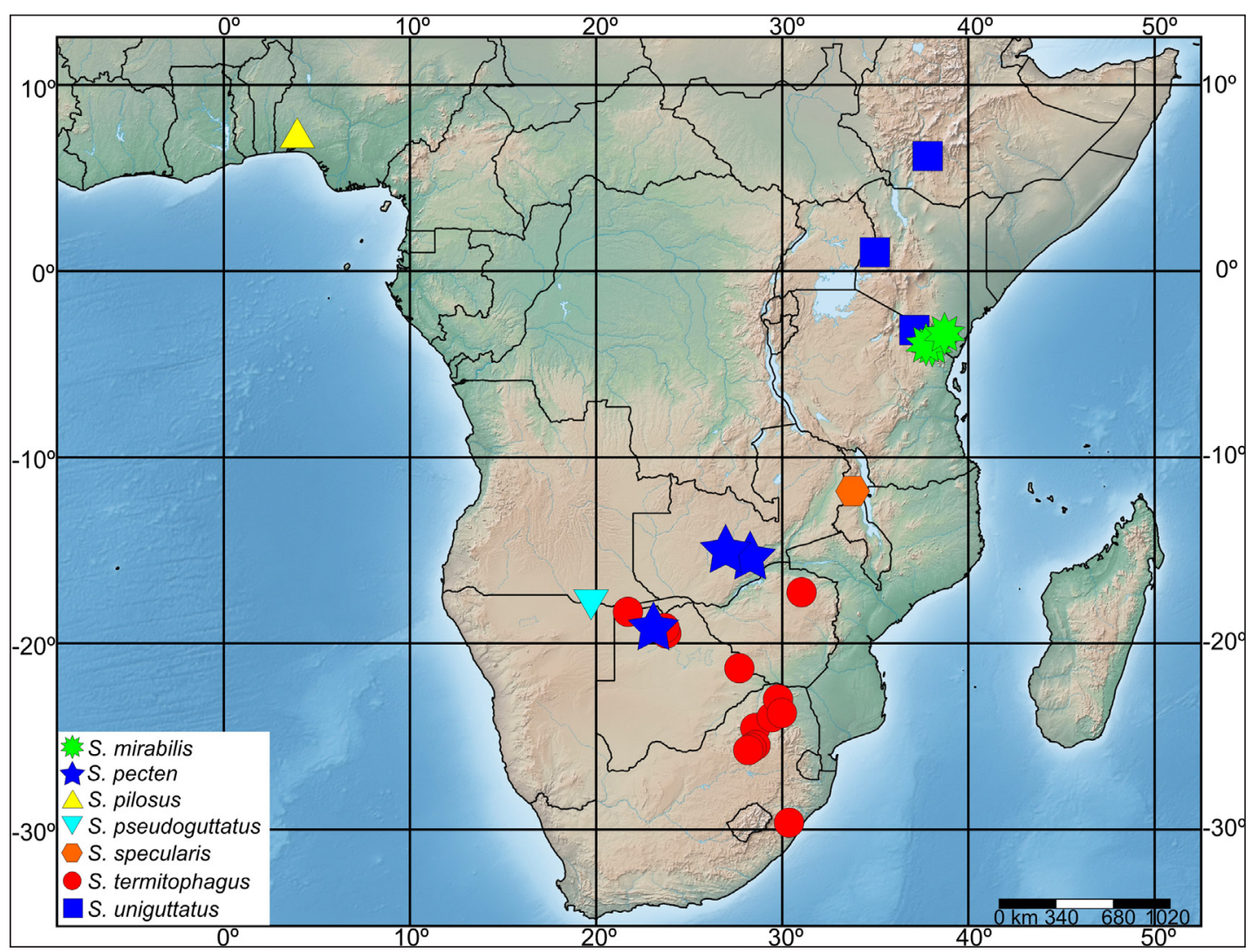

Fig. 514. Collecting localities of seven African species of Stenaelurillus Simon, 1885. 


\section{Discussion}

Stenaelurillus belongs to a compact group of salticid genera that are united by a putative synapomorphy, viz., the presence of the cymbial pocket in the males (sensu Logunov 1996), in which the embolic division is hidden. At present, 281 recognized species in nine genera are included in the group (Table 2) which to date has been treated as the subfamily Aelurillinae (e.g., Metzner 1999), the subtribe Aelurillina (Maddison 2015), or even just as the group of genera Aelurillines (Prószyński 2017); the latest proposal is a clear reminiscence of the original group Aelurilleae of Simon (1903).

Despite a comparatively large number of aelurilline species described to date (281 in total), our knowledge both of the taxonomic composition of the group and the distribution of its species still remains rather fragmentary. Of the described aelurilline species (Table 2), 108 (38\%) are known from their type

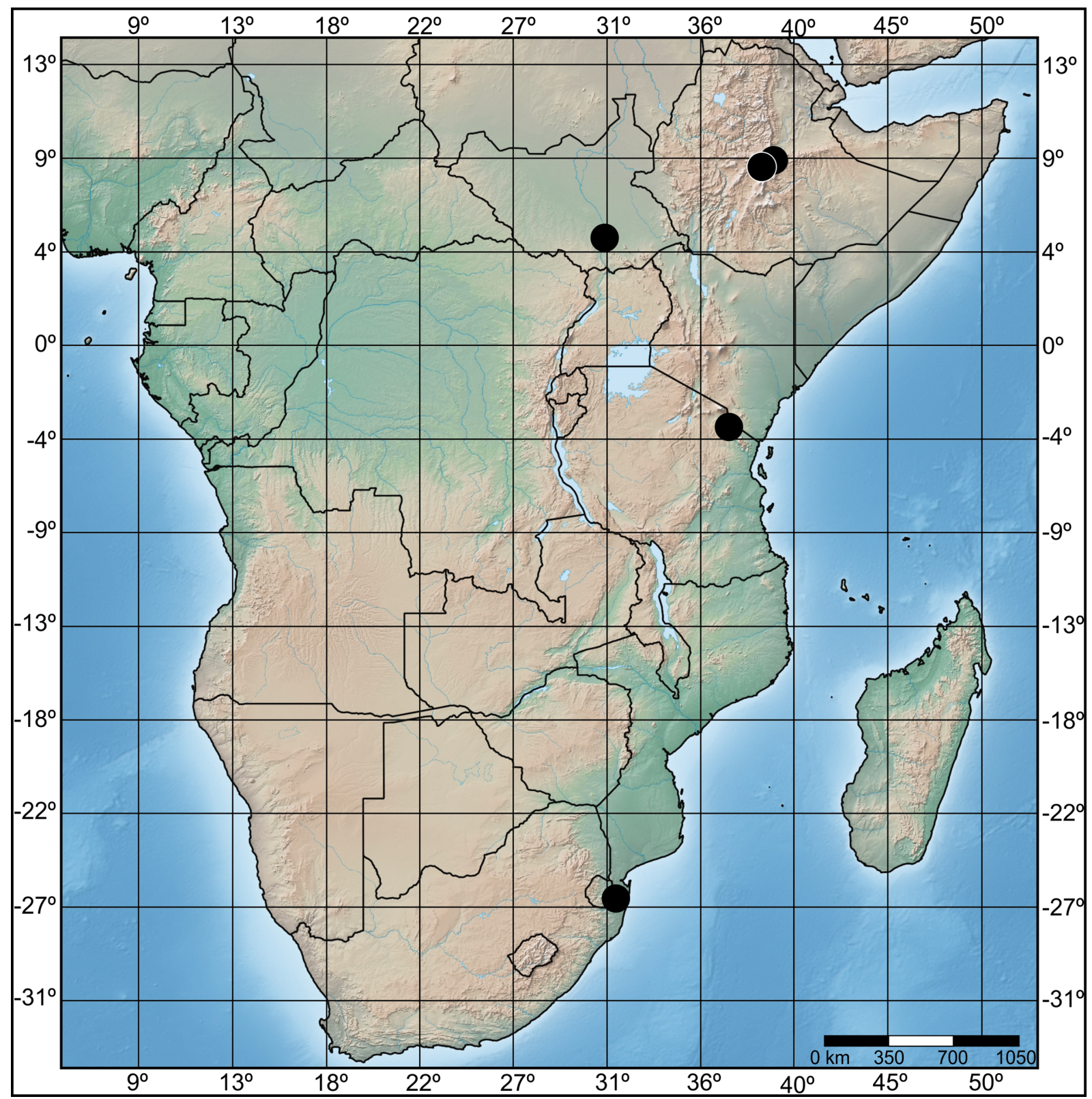

Fig. 515. Collecting localities of Evarcha werneri (Simon, 1906) comb. nov. 
Table 2. Number of described species in the nine genera of Aelurillina.

* = one species of Langona, viz. L. maindroni (Simon, 1886) from Senegal, was described from an immature specimen and is not counted here.

\begin{tabular}{|c|c|c|c|c|c|}
\hline \multirow{2}{*}{ Genera } & \multicolumn{3}{|c|}{ Species with described sexes } & \multirow{2}{*}{ Total } & \multirow{2}{*}{$\begin{array}{c}\text { Known only } \\
\text { from type } \\
\text { localities }\end{array}$} \\
\hline & $\widehat{\partial}$ 우 & o & q & & \\
\hline Aelurillus & 49 & 11 & 12 & 72 & 23 \\
\hline Asianellus & 4 & & 1 & 5 & \\
\hline Langellurillus & 8 & 5 & 7 & 20 & 13 \\
\hline Langona & 14 & 12 & 15 & $41^{*}$ & 22 \\
\hline Phanuelus & 1 & & & 1 & 1 \\
\hline Phlegra & 32 & 18 & 30 & 80 & 31 \\
\hline Proszynskiana & 4 & 1 & & 5 & 5 \\
\hline Rafalus & 5 & 6 & 1 & 12 & 5 \\
\hline Stenaelurillus & 33 & 8 & 4 & 45 & 8 \\
\hline Total & 151 & 61 & 70 & 281 & 108 \\
\hline
\end{tabular}

localities only, and $55(20 \%)$ of them remain unrevised and/or of an uncertain taxonomic status. The best studied aelurilline genera are those that have either been revised (Aelurillus and Stenaelurillus) or relatively recently described (Asianellus Logunov \& Heçiak, 1996; Phanuelus Caleb \& Mathai, 2015 and Proszynskiana Logunov, 1996). For instance, of the 72 species described in Aelurillus, only 23 $(32 \%)$ remain known from a single sex; in Stenaelurillus, of the 45 described species only 12 (27\%) are known from a single sex. In Asianellus and Proszynskiana this percentage is even smaller, 20\%. For comparison, in the genera Langellurillus Próchniewicz, 1994, Phlegra and Langona Simon, 1901, the percentage of such species is $60-65 \%$; all these genera are in urgent need of a taxonomic revision.

Although the current state of knowledge of the Aelurillina is not satisfactory and a serious analysis of a general distribution of its genera is not yet possible, it is worth providing some comparative data on a number of described/recorded species from various zoogeographic regions (see Table 3 ).

As becomes evident from Table 3, there are no aelurilline species recorded from the Neotropical Region. On the whole, the Aelurillina is predominantly an Old-World group, with $99 \%$ of its described species being restricted to the Afrotropical, Palaearctic or Oriental Regions. Only two genera contain singletons known from other areas. The genus Phlegra has single representatives in the Nearctic and Australian Regions: P. hentzi (Marx, 1890), a widespread species in the USA and Canada (Logunov \& Koponen 2002), and P. proszynskii Żabka, 2012 described and known from the holotype female from Lord Howe Island (Australia) (Żabka 2012). The genus Aelurillus contains a single species described from Madagascar: A. madagascariensis Azarkina, 2009 (see Azarkina 2009). None of the aelurilline genera contains widespread species that could be shared by two or more zoogeographic regions. The only currently known exception is Stenaelurillus nigricaudus, which has been recorded from northern regions of the Afrotropical Region and the SW part of the Palaearctic (see Table 1; Fig. 510); yet, the number of such species will certainly increase in the future, when distributional patterns of other aelurilline species, particularly those occurring in intermediate zones between different zoogeographic regions, are better understood.

Of the 281 valid species of the Aelurillina (Table 2), 112 species (40\%) are restricted to the Afrotropical Region, 142 species (51\%) to the Palaearctic Region and 27 species $(10 \%)$ to the Oriental Region (Table 3). Thus, the majority of aelurilline species (91\%) are confined to the Afrotropical and Palaearctic Regions, which seem to constitute modern chorological centers of the Aelurillina and contain about sub- 
Table 3. Species numbers of nine genera of the Aelurillina in six zoogeographic regions.

As there are no aelurilline species recorded from the Neotropical Region, it is excluded from the table.

\begin{tabular}{|c|c|c|c|c|c|c|}
\hline \multirow{2}{*}{ Genera } & \multicolumn{6}{|c|}{ Zoogeographic Regions } \\
\hline & Afrotropical & Madagascar & Palaearctic & Nearctic & Oriental & Australian \\
\hline Aelurillus & 9 & 1 & 61 & & 1 & \\
\hline Asianellus & & & 5 & & & \\
\hline Langellurillus & 18 & & & & 2 & \\
\hline Langona & 25 & & 12 & & 6 & \\
\hline Phanuelus & & & & & 1 & \\
\hline Phlegra & 28 & & 44 & 1 & 7 & 1 \\
\hline Proszynskiana & & & 5 & & & \\
\hline Rafalus & 2 & & 10 & & & \\
\hline Stenaelurillus & 30 & & 5 & & 10 & \\
\hline Total** & 112 & 1 & 142 & 1 & 27 & 1 \\
\hline
\end{tabular}

${ }^{* *}$ The total is 282 species (vs 281 described species, Table 2), because one species, Stenaelurillus nigricaudus Simon, 1886, is known from two zoogeographic regions.

equal numbers of described/recorded species and genera (112 vs 142 species and six vs seven genera, correspondingly). Yet, the species diversity of these regions is formed by different genera.

The Palaearctic fauna of Aelurillina is composed of seven genera, predominantly by Aelurillus (61 species; 43\%), Phlegra (44; 32\%), Langona (12, 9\%) and Rafalus (10, 7\%), constituting 91\% of the total regional species diversity. Two Palaearctic genera are endemics: Asianellus (5 species) and Proszynskiana (5 species) (Logunov 1996; Logunov \& Heçiak 1996). The Afrotropical fauna is composed of six genera, of which four are particulary important: Stenaelurillus is the most speciose (30 species; 27\%), followed by Phlegra $(28 ; 25 \%)$, Langona $(25 ; 23 \%)$ and Langelurillus $(18 ; 16 \%)$; these four genera also constitute $91 \%$ of the total regional species diversity. Surprisingly, there are no Afrotropical endemic genera, but at least four new genera from southern Africa are yet to be described (Azarkina, unpubl. data). Besides, the two species of Langelurillus recently described from W India (Sanap et al. 2017) are likely to be mis-classified and actually belong to Phanuelus; if so, the genus Langelurillus could be considered a true endemic genus of the Afrotropical Region. The matter requires special attention in the future, after the type series of the Indian species of Langelurillus have been re-examined. The Oriental fauna of Aelurillina consists of six genera, but with a much smaller total number of species (27; Table 3 ). This fauna looks like a slightly depleted variant of the Afrotropical and Palaearctic faunas, which seems to be indicative of a generally poorer knowledge of the Aelurillina in SE Asia. Yet, there is a monotypic genus, Phanuelus, described and known from India only (Caleb et al. 2015).

Two aelurilline genera - Aelurillus and Stenaelurillus - have recently been revised and therefore their distribution, regional diversity and composition can be assessed and compared with relative confidence (Table 3). The genus Aelurillus currently contains 72 valid species, of which the majority (61 species; $85 \%$ ) are confined to the Palaearctics; only nine species (13\%) are currently known from Africa. In contrast, Stenaelurillus demonstrates the highest species diversity in the Afrotropical Region, from which 30 species (67\%) have been described; only five species (11\%) are known from southern areas of the Palaearctics. Both genera have a small number of species described from SE Asia: one (1\%) in Aelurillus and ten (22\%) in Stenaelurillus. Thus, the genera demonstrate a clear palaeotropical distributional pattern, but seem to substitute each other in the Afrotropical and Palaearctic Regions. Of these genera, Aelurillus includes one Malagasy species (see above) and therefore seems to have originated earlier than Stenaelurillus, likely before Madagascar separated from Africa (183-158 Ma; see Vences et al. 2009). See also the remarks above under Distribution for Stenaelurillus (p. 11). 


\section{Acknowledgements}

We wish to express our warmest thanks to all the curators listed above under 'Material and methods' for allowing us to study the material of Stenaelurillus from their museums. Yuri Marusik (Magadan, Russia) is sincerely thanked for making digital images of some specimens of Stenaelurillus (Figs 8489) and SEM images of leg claws for Aelurillus, Phlegra and Langona (Figs 24-29). Our sincere thanks also go to Gergin Blagoev of the CBGO (Canada) for making digital photos of S. arambagensis available to us (Figs 60-62) and to John Caleb (Kolkata, West Bengal, India) for photographing and taking leg measurements from two specimens of Mashonarus davidi (Figs 504-506). Yuri Marusik and Sergei Zonstein (Tel-Aviv, Israel) helped with examples of the palaeotropical distribution in spiders. We also want to cordially thank Stefan Foord (Louis Trichardt, RSA), Charles Haddad and Burgert Muller (Bloemfontein, RSA), Ansie Dippenaar-Schoeman, Petro Marais, Robyn Lyle and Vida van der Walt (Pretoria/Tshwane, RSA), as well as Norman and Dawn Larsen (Cape Town, RSA) for their kind help to GA during her stay in South Africa. Darren Mann (Oxford, UK) and Varpu Vahtera (Turku, Finland) are greatly appreciated for allowing one of us (DL) to use the digital equipment of the Oxford University Natural History Museum and the Zoological Museum of Turku University, respectively. Finally, we wish to thank Wanda Wesołowska (Wrocław, Poland) and an anonymous referee for their critical comments on the submitted ms that helped to improve it. For GA this work was supported in part by the Federal Fundamental Scientific Research Program for 2013-2020 (AAAA-A16-116121410121-7) and NRF grant (CPRR) for 2015 (\#95569).

\section{References}

Azarkina G.N. 2009. Two new species of the genus Aelurillus Simon, 1885 (Araneae, Salticidae) from Africa. Journal of Afrotropical Zoology 5: 171-177.

Benjamin S.P. 2011. Phylogenetics and comparative morphology of crab spiders (Araneae: Dionycha, Thomisidae). Zootaxa 3080: 1-108.

Berland L. \& Millot J. 1941. Les araignées de l'Afrique Occidentale Française I. - Les salticides. Mémoires du Muséum national d'Histoire naturelle de Paris (N.S.) 12: 297-423.

Caleb J.T.D. \& Mathai M.T. 2014. Description of some interesting jumping spiders (Araneae: Salticidae) from South India. Journal of Entomology and Zoology Studies 2 (5): 63-71.

Caleb J.T.D. \& Mathai M.T. 2016. A new jumping spider of the genus Stenaelurillus Simon, 1886 from India (Araneae: Salticidae: Aelurillinae). Zootaxa 4103 (2): 185-188.

https://doi.org/10.11646/zootaxa.4103.2.10

Caleb J.T.D. \& Sanap R.V. 2016. Lessert's rainbow spider, Stenaelurillus lesserti Reimoser (Araneae: Salticidae: Aelurillina), from new localities in South India. Acta Arachnologica 62 (2): 83-87. https://doi.org/10.2476/asjaa.65.83

Caleb J.T.D., Mungkung S. \& Mathai M.T. 2015. Four new species of jumping spider (Araneae: Salticidae: Aelurillinae) with the description of a new genus from South India. Peckhamia 124.1: 1-18. Available from http://peckhamia.com/peckhamia/PECKHAMIA_124.1.pdf [accessed 4 Apr. 2017].

Caleb J.T.D., Prajapati D.A., Maheshwari N.R. \& Sanap R.V. 2017. Redescription and synonymy of Stenaelurillus arambagensis (Biswas \& Biswas, 1992) comb. nov. (Araneae: Salticidae). Arthropoda Selecta 26 (2): 119-123.

Cao Q., Li S. \& Żabka M. 2016. The jumping spiders from Xishuangbanna, Yunnan, China (Araneae, Salticidae). ZooKeys 630: 43-104. https://doi.org/10.3897/zookeys.630.8466

Caporiacco L. di 1939. Arachnida. In: Zavattari E. (ed.) Missione biologica nel Paese dei Borana. Raccolte zoologiche 3: 303-385. Reale Accademia d'Italia, Roma 
Caporiacco L. di 1940. Aracnidi raccolte nella Reg. dei Laghi Etiopici della Fossa Galla. Atti della Reale Accademia d'Italia 11: 767-873.

Caporiacco L. di 1949. Aracnidi della colonia del Kenya raccolti da Toschi e Meneghetti negli anni 1944-1946. Commentationes Pontificia Academia Scientiarum 13: 309-492.

Dankittipakul P., Jocqué R. \& Singtripop T. 2012a. Systematics and biogeography of the spider genus Mallinella Strand, 1906, with descriptions of new species and new genera from southeast Asia (Araneae, Zodariidae). Zootaxa 3369: 1-327.

Dankittipakul P., Jocqué R. \& Singtripop T. 2012b. Systematics and biogeography of the spider genus Mallinella Strand, 1906, with descriptions of new species and new genera from southeast Asia (Araneae, Zodariidae) - Erratum. Zootaxa 3395: 46.

Davies A.L.V., Scholtz C.H. \& Philips T.K. 2002. Historical biogeography of scarabaeine dung beetles. Journal of Biogeography 29: 1217-1256. https://doi.org/10.1046/j.1365-2699.2002.00776.x

Dawidowicz A. \& Wesołowska W. 2016. Jumping spiders (Araneae: Salticidae) of Kenya collected by Åke Holm. Annales Zoologici 66 (3): 437-466. https://doi.org/10.3161/00034541ANZ2016.66.3.010

Denis J. 1966. Les araignées du Fezzân. Bulletin de la Société d'Histoire Naturelle d'Afrique du Nord 55: $103-144$.

Fourie R., Haddad C.R. \& Jocqué R. 2011. A revision of the purse-web spider genus Calommata Lucas, 1837 (Araneae, Atypidae) in the Afrotropical region. ZooKeys 95: 1-28. https://doi.org/10.3897/zookeys.95.745

Haddad C.R. \& Wesołowska W. 2006. Notes on taxonomy and biology of two Stenaelurillus species from southern Africa (Araneae: Salticidae). Annales Zoologici 56: 575-586.

Hilgen F.J., Lourens L.J. \& van Dam J.A. 2012. The Neogene Period (Chapter 29). In: Gradstein F.M., Ogg J.G., Schmitz M. \& Ogg G. (eds) The Geologic Time Scale: 923-978. Elsevier B.V. https://doi.org/10.1016/B978-0-444-59425-9.00029-9

Jocqué R. \& Dippenaar-Schoeman A.S. 2006. Spider Families of the World. Royal Museum for Central Africa, Tervuren.

Kryzhanovsky O.L. 2002. Composition and Distribution of Entomofaunas of the Globe. KMK Scientific Press Ltd, Moscow. [In Russian.]

Lessert R. de 1925. Araignées du Kilimandjaro et du Merou (suite). 5. Salticidae. Revue Suisse de Zoologie 31: 429-528. https://doi.org/10.5962/bhl.part.117792

Lessert R. de 1927. Araignées du Congo (Première partie). Revue Suisse de Zoologie 34: 405-475. https://doi.org/10.5962/bhl.part.117612

Lin Y.C., Ballarin F. \& Li S.Q. 2016. A survey of the spider family Nesticidae (Arachnida, Araneae) in Asia and Madagascar, with the description of forty-three new species. ZooKeys 627: 1-168. https://doi.org/10.3897/zookeys.627.8629

Logunov D.V. 1996. Salticidae of Middle Asia. 3. A new genus, Proszynskiana gen. n., in the subfamily Aelurillinae (Araneae, Salticidae). Bulletin of the British Arachnological Society 10 (5): 171-177.

Logunov D.V. 1998. Pseudeuophrys is a valid genus of the jumping spiders (Araneae, Salticidae). Revue Arachnologique 12 (11): 109-128.

Logunov D.V. 1999. Redefinition of the genus Habrocestoides Prószyński, 1992, with establishment of a new genus, Chinattus gen. n. (Araneae: Salticidae). Bulletin of the British Arachnological Society 11 (4): 139-149. 
Logunov D.V. 2001a. A redefinition of the genera Bianor Peckham \& Peckham, 1885 and Harmochirus Simon, 1885, with the establishment of a new genus Sibianor gen. n. (Aranei: Salticidae). Arthropoda Selecta 9 (4): 221-286.

Available from http://arthropodaselecta.britishspiders.org.uk/articles/9_4_221_286_logunov.pdf [accessed 15 Feb. 2018].

Logunov D.V. 2001b. New and poorly known species of the jumping spiders (Aranei: Salticidae) from Afghanistan, Iran and Crete. Arthropoda Selecta 10 (1): 59-66.

Available from http://arthropodaselecta.britishspiders.org.uk/articles/10_1_59_66_logunov.pdf [accessed 15 Feb. 2018].

Logunov D.V. 2008. A new species of the genus Stenaelurillus Simon, 1885 (Araneae: Salticidae) from Vietnam. Acta Arachnologica 57 (1): 43-45. https://doi.org/10.2476/asjaa.57.43

Logunov D.V. \& Cutler B. 1999. Revision of the genus Paramarpissa F.O.P.-Cambridge, 1901 (Araneae, Salticidae). Journal of Natural History 33 (8): 1217-1236. https://doi.org/10.1080/002229399299996

Logunov D.V. \& Heçiak S. 1996. Asianellus, a new genus of the subfamily Aelurillinae (Araneae, Salticidae). Entomologica Scandinavica 26: 103-117.

Logunov D.V. \& Jäger P. 2015. Spiders from Vietnam (Arachnida: Aranei): new species and records. Russian Entomological Journal 24 (4): 343-363. Available from

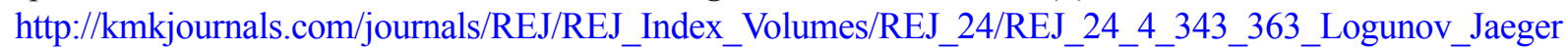
[accessed 4 Apr. 2017].

Logunov D.V. \& Koponen S. 2002. Redescription and distribution of Phlegra hentzi (Marx, 1890) comb. n. (Araneae, Salticidae). Bulletin of the British Arachnological Society 12: 264-267.

Logunov D.V. \& Marusik Yu.M. 2003. A Revision of the Genus Yllenus Simon, 1868 (Arachnida, Araneae, Salticidae). KMK Scientific Press, Moscow.

Available from http://szmn.sbras.ru/persons/logunov/logunov2003.pdf [accessed 15 Feb. 2018].

Maddison W.P. 1996. Pelegrina Franganillo and other jumping spiders formerly placed in the genus Metaphidippus. Bulletin of the Museum of Comparative Zoology 154 (4): 215-368. Available from http://www.biodiversitylibrary.org/page/10047302\#page/237/mode/1up [accessed 4 Apr. 2017].

Maddison W.P. 2015. A phylogenetic classification of jumping spiders (Araneae: Salticidae). Journal of Arachnology 43 (3): 231-292. https://doi.org/10.1636/arac-43-03-231-292

Merrett P. 1963. The palpus of male spiders of the family Linyphiidae. Proceedings of the Zoological Society of London 140 (3): 347-467. https://doi.org/10.1111/j.1469-7998.1963.tb01867.x

Metzner H. 1999. Die Springspinnen (Araneae, Salticidae) Griechenlands. Andrias 14: 1-279.

Nartschuk E.P. 1994. On the zoogeographic relationships of the world fauna of chloropid flies (Diptera, Chloropidae). I. Entomological Review 73 (1): 80-94. [In Russian.]

Ono H. 1988. A Revisional Study of the Spider Family Thomisidae (Arachnida, Araneae) of Japan. National Science Museum, Tokyo.

Ovtsharenko V.I., Levy G. \& Platnick N.I. 1994. A review of the ground spider genus Synaphosus (Araneae, Gnaphosidae). American Museum Novitates 3095: 1-27.

Peng X.J. 1995. Two new species of jumping spiders from China (Araneae: Salticidae). Acta Zootaxonomica Sinica 20: 35-38.

Prajapati D.A., Murthappa P.S., Sankaran P.M. \& Sebastian P.A. 2016. Two new species of Stenaelurillus Simon, 1886 from India (Araneae: Salticidae: Aelurillina). Zootaxa 4171 (2): 321-334. https://doi.org/10.11646/zootaxa.4171.2.5 
Pravdin F.N. \& Mishchenko L.L. 1980. Formation and Evolution of Ecological Insect Faunas in Middle Asia. Nauka, Moscow. [In Russian.]

Próchniewicz M. \& Hęciak S. 1994. The jumping spiders of the Ethiopian Region. Part II. New species of Aelurillus, Langona, Phlegra, Stenaelurillus (Araneae, Salticidae) from Kenya and Tanzania. Annales Zoologici, Warszawa 45: 33-41.

Prószyński J. 1984. Atlas Rysunków Diagnostycznych Mniej Znanych Salticidae (Araneae). Wyższa Szkola Rolniczo-Pedagogiczna, Siedlcach.

Prószyński J. 2017. Pragmatic classification of the World's Salticidae (Araneae). Ecologica Montenegrina 12: $1-133$.

Ramírez M.J. 2014. The morphology and phylogeny of dionychan spiders (Araneae: Araneomorphae). Bulletin of the American Museum of Natural History 390: 1-374. https://doi.org/10.1206/821.1

Reimoser E. 1934. Araneae aus Süd-Indien. Revue Suisse de Zoologie 41: 465-511.

https://doi.org/10.5962/bhl.part.155628

Rodrigues E.N.L. \& Buckup E.H. 2007. O gênero Nesticella Lehtinen \& Saaristo (Araneae, Nesticidae) no Brasil. Revista Brasileira de Zoologia 24: 673-676.

Saaristo M. 1977. Secondary genital organs in the taxonomy of Lepthyphantes (Araneae, Linyphiidae). Reports from the Department of Zoology, University of Turku 5: 1-16.

Sanap R.V., Joglekar A., Prajapati D.A. \& Caleb J.T.D. 2017. Two new species of Langelurillus Próchniewicz, 1994 from India (Araneae: Salticidae: Aelurillina). Zootaxa 4318 (1): 135-146. https://doi.org/10.11646/zootaxa.4318.1.6

Sebastian P.A., Sankaran P.M., Malamel J.J. \& Joseph M.M. 2015. Description of new species of Stenaelurillus Simon, 1886 from the Western Ghats of India with the redescription of Stenaelurillus lesserti Reimoser, 1934 and notes on mating plug in the genus (Arachnida, Araneae, Salticidae). ZooKeys 491: 63-78. https://doi.org/10.3897/zookeys.491.8218

Shorthouse D.P. 2010. SimpleMappr, an online tool to produce publication-quality point maps. Available from http://www.simplemappr.net [accessed 18 May 2017].

Sierwald P. 1990. Morphology and homologous features in the male palpal organ in Pisauridae and other spider families, with notes on the taxonomy of Pisauridae (Arachnida: Araneae). Nemouria 35: 1-59.

Simon E. 1886. Etudes arachnologiques. 18 ${ }^{\mathrm{e}}$ Mémoire. XXVI. Matériaux pour servir à la faune des Arachnides du Sénégal. (Suivi d'une appendice intitulé: Descriptions de plusieurs espèces africaines nouvelles). Annales de la Société entomologique de France (6) 5: 345-396.

Simon E. 1901. Etudes arachnologiques. $31^{\mathrm{e}}$ Mémoire. L. Descriptions d'espèces nouvelles de la famille des Salticidae (suite). Annales de la Société entomologique de France 70: 66-76.

Simon E. 1902. Description d'arachnides nouveaux de la famille des Salticidae (Attidae) (suite). Annales de la Société Entomologique de Belgique 46: 24-56, 363-406.

Simon E. 1903. Histoire naturelle des araignées 2: 669-1080. Roret, Paris. https://doi.org/10.5962/bhl.title.51973

Simon E. 1906. Ergebnisse der mit Subvention aus der Erbschaft Treitl unternommenen zoologischen Forschungsreise Dr F. Werner's nach dem ägyptischen Sudan und Nord-Uganda. VII. Araneida. Sitzungsberichte der Kaiserlichen Akademie der Wissenschaften, Mathematisch-naturwissenschaftliche Klasse, Wien 115: 1159-1176. 
Song D.X. \& Chai J.Y. 1991. New species and new records of the family Salticidae from Hainan, China (Arachnida: Araneae). In: Qian Y.W. et al. (eds) Animal Science Research: 13-30. China Forestry Publishing House, Beijing.

Szüts T. \& Scharff N. 2005. Redescriptions of little known jumping spider genera (Araneae: Salticidae) from West Africa. Acta Zoologica Academiae Scientiarum Hungaricae 51: 357-378.

Vences M., Wollenberg K.C., Vieites D.R. \& Lees D.C. 2009. Madagascar as a model region of species diversification. Trends in Ecology and Evolution 24 (8): 456-465.

https://doi.org/10.1016/j.tree.2009.03.011

Vidhel B.P., Malik S., Sabata B.C. \& Das S.K. 2015. A new spider species of the genus Stenaelurillus Simon, 1886 (Araneae: Salticidae: Aelurillinae) from India. International Journal of Science and Research 4 (7): 2332-2336.

Wesołowska W. 2006. Jumping spiders from the Brandberg massif in Namibia (Araneae: Salticidae). African Entomology 14: 225-256.

Wesołowska W. 2014a. A review of the Asian species of the spider genus Stenaelurillus (Araneae: Salticidae). Oriental Insects 47 (4): 246-254. https://doi.org/10.1080/00305316.2013.871823

Wesołowska W. 2014b. Further notes on the genus Stenaelurillus Simon, 1885 (Araneae, Salticidae) in Africa with descriptions of eight new species. Zoosystema 36 (3): 595-622.

https://doi.org/10.5252/z2014n3a3

Wesołowska W. \& Cumming M.S. 1999. The first termitivorous jumping spider (Araneae: Salticidae). Bulletin of the British Arachnological Society 11: 204-208.

Wesołowska W. \& Cumming M.S. 2002. Mashonarus guttatus, gen. and sp. n., the second termitivorous jumping spider from Africa (Araneae: Salticidae). Bulletin of the British Arachnological Society 12: $165-170$.

Wesołowska W. \& Cumming M.S. 2011. New species and records of jumping spiders (Araneae, Salticidae) from Sengwa Wildlife Research Area in Zimbabwe. Journal of Afrotropical Zoology 7: 75104.

Wesołowska W. \& Haddad C.R. 2009. Jumping spiders (Araneae: Salticidae) of the Ndumo Game Reserve, Maputaland, South Africa. African Invertebrates 50: 13-103.

https://doi.org/10.5733/afin.050.0102

Wesołowska W. \& Russell-Smith A. 2000. Jumping spiders from Mkomazi Game Reserve in Tanzania (Araneae Salticidae). Tropical Zoology 13: 11-127. https://doi.org/10.1080/03946975.2000.10531126

Wesołowska W. \& Russell-Smith A. 2011. Jumping spiders (Araneae: Salticidae) from southern Nigeria. Annales Zoologici, Warszawa 61: 553-619.

Wesołowska W. \& Tomasiewicz B. 2008. New species and records of Ethiopian jumping spiders (Araneae, Salticidae). Journal of Afrotropical Zoology 4: 3-59.

WSC. 2017. World Spider Catalog, version 18.0. Natural History Museum, Bern. Available from http://wsc.nmbe.ch [accessed 9 Jun. 2017].

Żabka M. 2012. Phlegra Simon, 1876, Phintella Strand, 1906 and Yamangalea Maddison, 2009 (Arachnida: Araneae: Salticidae) - new species and new generic records for Australia. Zootaxa 3176: $61-68$.

Zonstein S. \& Marusik Yu.M. 2013. On Levymanus, a remarkable new spider genus from Israel, with notes on the Chediminae (Araneae, Palpimanidae). ZooKeys 326: 27-45.

https://doi.org/10.3897/zookeys.326.5344 
Manuscript received: 13 June 2017

Manuscript accepted: 26 September 2017

Published on: 2 May 2018

Topic editor: Rudy Jocqué

Desk editor: Kristiaan Hoedemakers

Printed versions of all papers are also deposited in the libraries of the institutes that are members of the EJT consortium: Muséum national d'Histoire naturelle, Paris, France; Botanic Garden Meise, Belgium; Royal Museum for Central Africa, Tervuren, Belgium; Natural History Museum, London, United Kingdom; Royal Belgian Institute of Natural Sciences, Brussels, Belgium; Natural History Museum of Denmark, Copenhagen, Denmark; Naturalis Biodiversity Center, Leiden, the Netherlands; Museo Nacional de Ciencias Naturales-CSIC, Madrid, Spain; Real Jardín Botánico de Madrid CSIC, Spain. 